\title{
Understanding medical students' motivation and preferences to select medical studies and work in rural areas in North India
}

Citation for published version (APA):

Goel, S. (2020). Understanding medical students' motivation and preferences to select medical studies and work in rural areas in North India. [Doctoral Thesis, Maastricht University]. Gildeprint Drukkerijen. https://doi.org/10.26481/dis.20201013sg

Document status and date:

Published: 01/01/2020

DOI:

10.26481/dis.20201013sg

Document Version:

Publisher's PDF, also known as Version of record

\section{Please check the document version of this publication:}

- A submitted manuscript is the version of the article upon submission and before peer-review. There can be important differences between the submitted version and the official published version of record. People interested in the research are advised to contact the author for the final version of the publication, or visit the DOI to the publisher's website.

- The final author version and the galley proof are versions of the publication after peer review.

- The final published version features the final layout of the paper including the volume, issue and page numbers.

Link to publication

\footnotetext{
General rights rights.

- You may freely distribute the URL identifying the publication in the public portal. please follow below link for the End User Agreement:

www.umlib.nl/taverne-license

Take down policy

If you believe that this document breaches copyright please contact us at:

repository@maastrichtuniversity.nl

providing details and we will investigate your claim.
}

Copyright and moral rights for the publications made accessible in the public portal are retained by the authors and/or other copyright owners and it is a condition of accessing publications that users recognise and abide by the legal requirements associated with these

- Users may download and print one copy of any publication from the public portal for the purpose of private study or research.

- You may not further distribute the material or use it for any profit-making activity or commercial gain

If the publication is distributed under the terms of Article $25 \mathrm{fa}$ of the Dutch Copyright Act, indicated by the "Taverne" license above, 


\section{Understanding Medical Students' \\ Motivation and Preferences to Select \\ Medical Studies and Work in Rural \\ Areas in North India}

Sonu Goel 


\section{Colophon}

The research presented in this dissertation was conducted at the Department of Community Medicine and School of Public Health, Post Graduate Institute of Medical Education and Research (PGIMER), Chandigarh, India. PGIMER is an institute of National importance in India. In 2015, the British Medical Journal has adjudged it for having the best medicine experts in South Asia.

The research presented in this thesis was conducted at CAPHRI Care and Public Health Research Institute, Department of Health Services Research, of Maastricht University. CAPHRI participates in the Netherlands School of Public Health and Care Research (CaRe).

The research described in this dissertation was funded by the Indian Council of Medical Research (ICMR).

All the rights are reserved. No part of the book can be reproduced or transmitted in any form or by any means, without the written permission from the author.

\section{Des Masstrictt university $(2)$ Maastricht UMC+

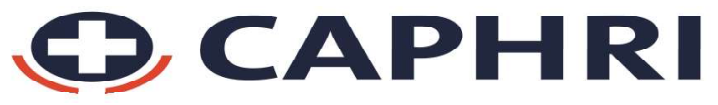

Copyright (C) Sonu Goel, Maastricht 2020

Cover design and Layout: Sonu Goel and Divya Sharma

Printing: Glideprint, Enschede

ISBN: 9789464021707 


\section{Understanding Medical Students' Motivation and Preferences to Select Medical Studies and Work in Rural Areas in North India}

\section{DISSERTATION}

To obtain the degree of Doctor at Maastricht University, on authority of the Rector Magnificus Prof. dr. Rianne M. Letschert in accordance with the decision of the Board of Deans,

to be defended in public on Tuesday $31^{\text {st }}$ March, 2020 at 12:45 hours

by

Sonu Goel 


\section{Promoters}

Prof. Dr. D. Ruwaard

Prof. Dr. F. Angeli (University of York)

Assessment committee:

Prof. Dr. J.J.E. Rethans (chairman)

Prof. Dr. J.S.M. Krumeich

Prof. Dr. S.V. Ramani

Prof. Dr. N.S. Klazinga, Amsterdam UMC

Dr. B. Kroon, Tilburg University 


\section{TABLE OF CONTENTS}

CHAPTER 1 General Introduction 1

CHAPTER 2 What motivates medical students to select medical 17 studies: A systematic literature review.BMC Medical Education 2018; 18 (1):16

CHAPTER 3 Development and Validation of the Motivations for Selection of Medical Study (MSMS) Questionnaire in India. PLoS One 2016; 11(12):e0164581.

CHAPTER 4 Retaining health workforce in rural and underserved areas of India: What works and what doesn't? A critical interpretative synthesis. National Medical Journal of India 2016;29(4):212-18

CHAPTER 5 Measuring the reasons that discourage medical students from working in rural areas: development and validation of a new instrument. Medicine 2018; 97(2): e9448

CHAPTER 6 Factors affecting medical student's interests in working in rural areas in India. PloS One 2019;14(1): e0210251

CHAPTER 7 General Discussion

Summary

Valorization

Acknowledgement

About the Author

Appendices 



\section{Chapter 1}

\section{General Introduction}

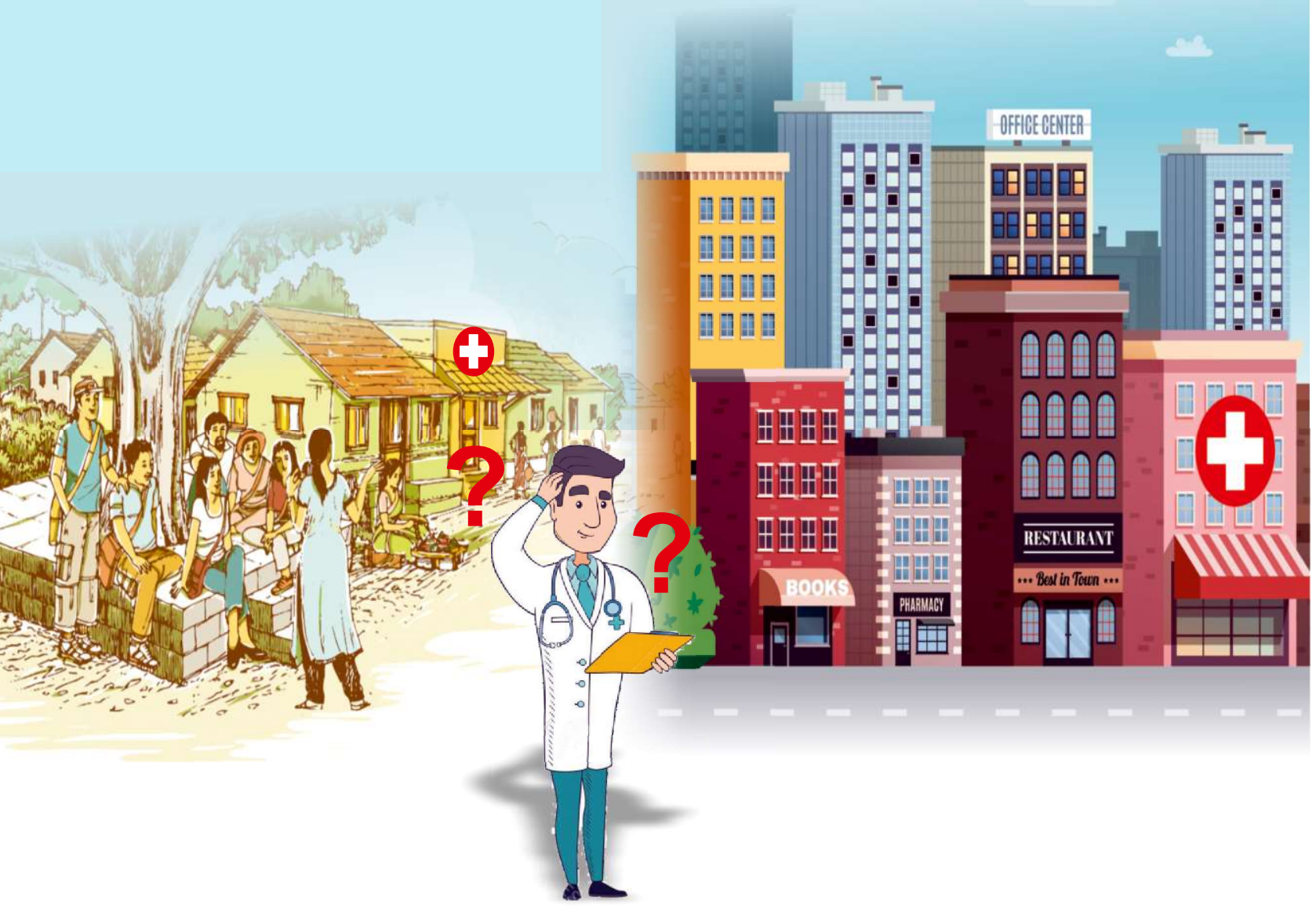




\section{General Introduction}

Within many health care systems worldwide, increased attention is being focused on human resources management (HRM). Specifically, human resources are one of three principle health system inputs, with the other two major inputs being physical capital and consumables [1]. Healthcare, more than any other sector depends on people to carry out its mission. Human resource for health is critical in quality health care delivery. The number of healthcare workers available in a country is a key indicator of that country's capacity to cadre health services [2]. Healthcare workforce is defined as the 'people engaged in actions with primary intent to enhance health' [3]. The importance of the healthcare workforce can be gauged from the fact that health care is a human resource-intensive industry and production of health workers is expensive and time-consuming [3]. There is consensus that despite their importance human resources have been a neglected component of health-system development in low income countries [4]. Many countries are struggling with enormous health policy challenges, such as how to address shortages or surpluses and how to improve the skills, geographic distribution and performance of health workers. Thus, effective human resources management strategies are greatly needed to achieve better outcomes from and access to health care around the world. Improving the health workforce situation remains an important pillar of the World Bank's health systems strengthening agenda [5].

\section{Shortage and unequal distribution of the health care workforce}

In 2006, the World Health Report drew attention to the global healthcare workforce crisis and its dramatic impact in 57 priority countries. It estimated a need for an additional 4.3 million healthcare workers in these countries to fulfill the Millennium Development Goals [3]. In addition to this, 83 countries (44.6\%) do not currently meet the 2006 World Health Report threshold of 22.8 skilled health professionals per 10,000 population. This issue of disparity in healthcare workforce has been escalated in recent years especially pertaining to Sustainable Development Goals (SDGs) across the countries. According to the WHO Health Workforce Report 2016-2017, global health workforce was over 43 million with the potential shortfall of 18 million healthcare workers by 2030. Over one third of health investments required for the SDGs will be 
needed for the healthcare workforce. The largest deficit of health workers in 2013 was in South-East Asia (6.9 million) followed by Africa (4.2 million) [6]. Worldwide, the health workforce per 1000 population ranges from as low as 2.2 and 3.3 in Africa and Southeast Asia, respectively, to as high as 24.8 in the USA [3].

Under the healthcare workforce, the doctors are playing a significant role in delivering health care services to the population. They are the most powerful professional group in health care. They are engaged with policy making, healthcare planning and management and act as frontline care providers within primary care teams. According to WHO, the estimated physician demand was 10.8 million in 2015, with a shortage of around 2.6 million [7]. The available statistics show that over $44 \%$ of WHO Member States have less than recommended scale of 1 physician per 1000 population [8]. Thus, there is an urgent need to increase the healthcare workforce for achieving essential health services in both low income and upper middle income countries.

The shortage of health workforce is compounded with an unbalanced distribution of health personnel between but also within countries. All countries, rich and poor, report a higher proportion of health personnel in urban and wealthier areas. Approximately half of the global population lives in rural areas, but these areas are served by only $38 \%$ of the total nursing workforce and by less than a quarter of the total physician workforce [9]. A comparison of two large health labor markets, India and China, showed that India has a lower workforce population ratio and greater inequality compared to China [9]. According to a report published in June 2016, using the Census 2001 data of India, nearly 2.01 health workers and of them 0.8 allopathic doctors exist per 1000 population [10].

The shortage and imbalance in the distribution of human resources for health care eventually lead to inequities in health services delivery and poor health outcomes of a country. In 2009, a high-level taskforce on International Financing for Health Systems identified health workforce as a priority area, requiring critical attention and additional investments. Poor coverage of primary healthcare interventions, e.g. measles immunization and antenatal care was observed in countries with less than 2.3 skilled workers (physicians, nurses and midwives) per 1000 population. It suggested to 
governments that all people, including rural and remote populations, have access to safe, high-quality and essential healthcare services. [11]

\section{Shortage and unequal distribution of the healthcare workforce in India}

India, with a population of over one billion, is placed in the lowest category of human resource for health (HRH) indicators [12]. The National Commission of Macroeconomics of Health (NCMH) reported in 2005 that India had a physician to population ratio of 0.5 per 1000 persons in comparison to 0.3 in Thailand, 0.4 in Sri Lanka, 1.6 in China, 5.4 in the United Kingdom, 5.5 in the United States of America and 5.9 in Cuba [13]. The 'High Level Expert Group for Universal Health Coverage' constituted by the Planning Commission in Nov. 2011, has set the minimum physicianto-population ratio to 1:1000 [14]. Currently, India counts only 1 physician for over 1700 people, indicating that more qualified medical professionals are needed [15]. This deficiency coupled with state wise and urban-rural disparities means that a large number of Indians mostly rural dwellers or the urban poor receive care from unqualified or under qualified providers. Despites physicians, there are significant disparities in overall distribution of all health workers across Indian states (Figure-1) [16]. As a rule the large, poorer states of north-central India have a lower density of health workers compared to the states in southern India. The total number of all health workers per 1000 population varies from 1 in Bihar to over 4 in Goa. The states that have the highest capacity to produce doctors and nurses tend to be those with the

highest density of these cadres. The states with low health workforce density (1-1.6 workers per 1000 population) include Rajasthan, Uttar Pradesh, Madhya Pradesh, Bihar, Jharkhand, Chhattisgarh, Assam and Meghalaya. The states of Jammu \& Kashmir, Haryana, Uttaranchal, Orissa, Andhra Pradesh, Karnataka, Manipur and Tripura have an average of 1.6-2.2 workers per 1000 population. Higher workforce densities (more than 2.2 workers per 1000 population) are found in Punjab, Himachal Pradesh, Maharashtra, Goa, Kerala, Tamil Nadu, West Bengal, Mizoram, Nagaland, Sikkim and Arunachal Pradesh, with Goa, Kerala, Mizoram and Sikkim having more than 3.7 workers per 1000 population [16]. 


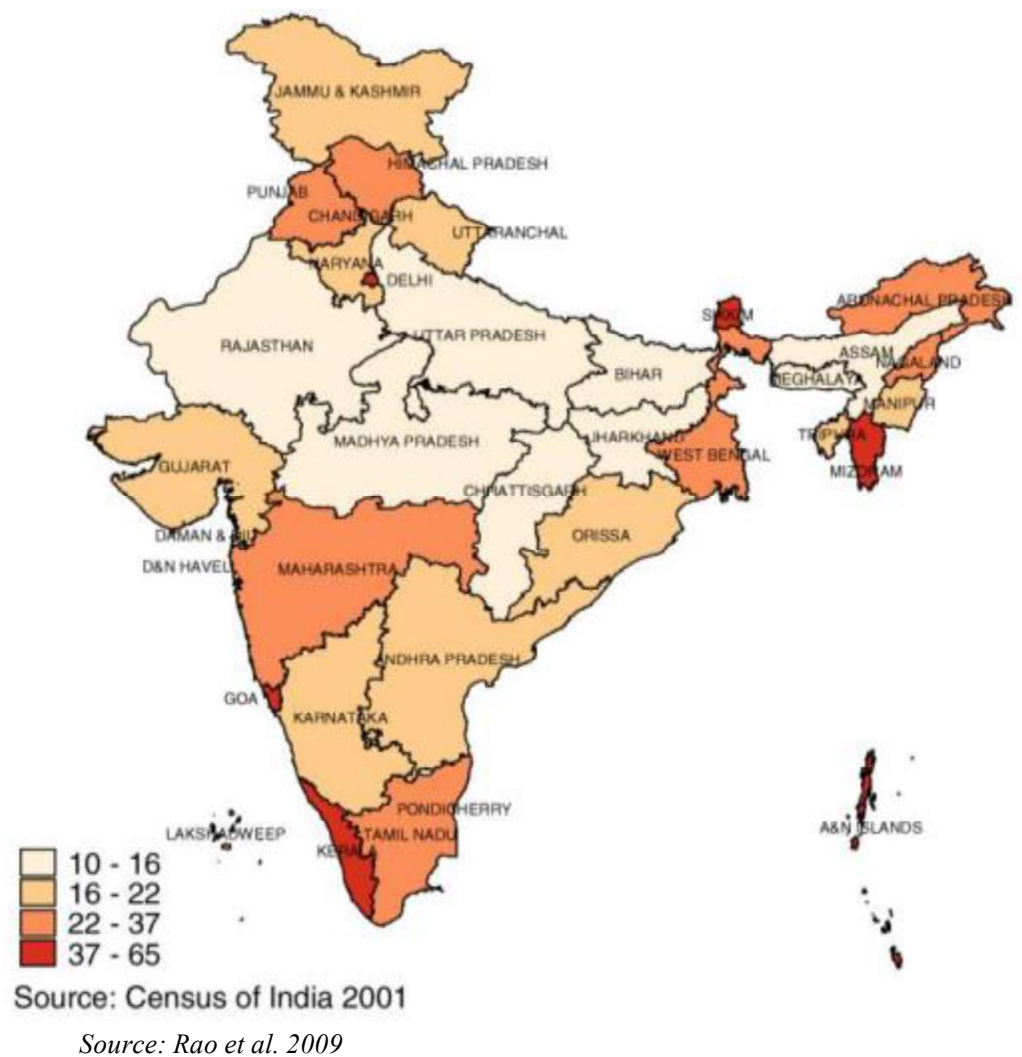

Figure 1- Health worker density across Indian states per 1000 population

Further, states with low doctor density (0.3-0.6 per 1000 population) include Gujarat, Rajasthan, Uttar Pradesh, Madhya Pradesh, Bihar, Jharkhand, Chhattisgarh, Orissa and Assam. Low doctor density states also include Himachal Pradesh, Kerala and Tamil Nadu. The states of Jammu \& Kashmir, Punjab, Haryana, Uttaranchal, Maharashtra, Goa, Karnataka and Andhra Pradesh have more than 0.6 doctors per 1000 population with Goa reporting a maximum of 1.3 allopathic physicians per 1000 population (Figure-2) [16]. 


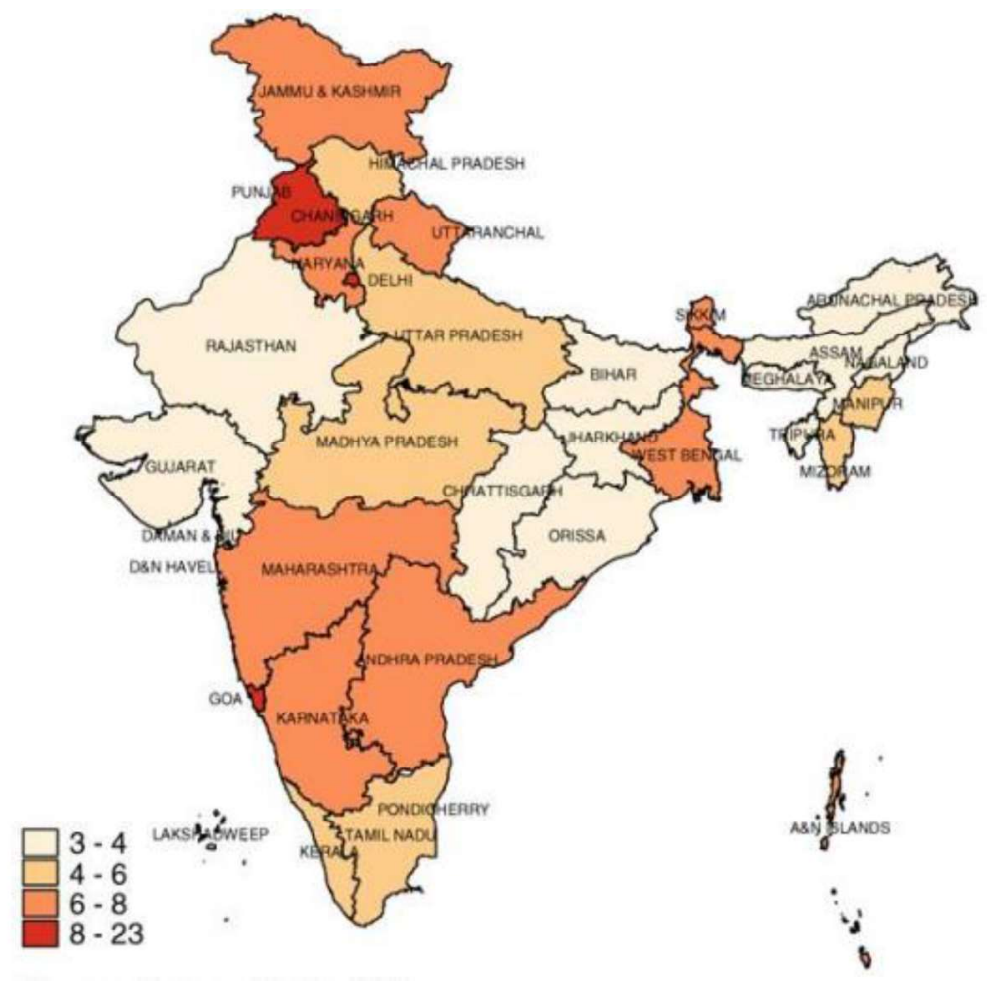

Source: Rao et al. 2009

Figure 2- Doctor density across Indian states per 1000 population

For $70 \%$ of the Indian rural population, the physician-population ratio is extremely low and amounts to a mere 1 physician for over 2,564 inhabitations. Estimates show that almost $60 \%$ of health workers live in urban areas, which account for $26 \%$ of the country's population. Health worker density in urban areas at 4.2 per 1000 is about 3.5 times higher than rural areas which have only 1.18 workers for a similar size of population, which is geographically more spread out given much lower population densities in rural India (Figure-3). This skew is consistent across cadres. Doctors, both allopathic and AYUSH (Ayurvedic, Yoga, Unani, Sidha and Homeopathic) as well as nurses have a density in urban areas that is three to four times higher than in rural areas [16]. Rural health statistics 2016 reports a shortfall of $11.6 \%$ medical officers at primary health care level and $81.2 \%$ medical specialists at community health centers 
[17]. The gap between the numbers of doctors working in urban compared to rural areas is widening, which is endangering the functioning and sustainability of the Indian health care system [18-19].

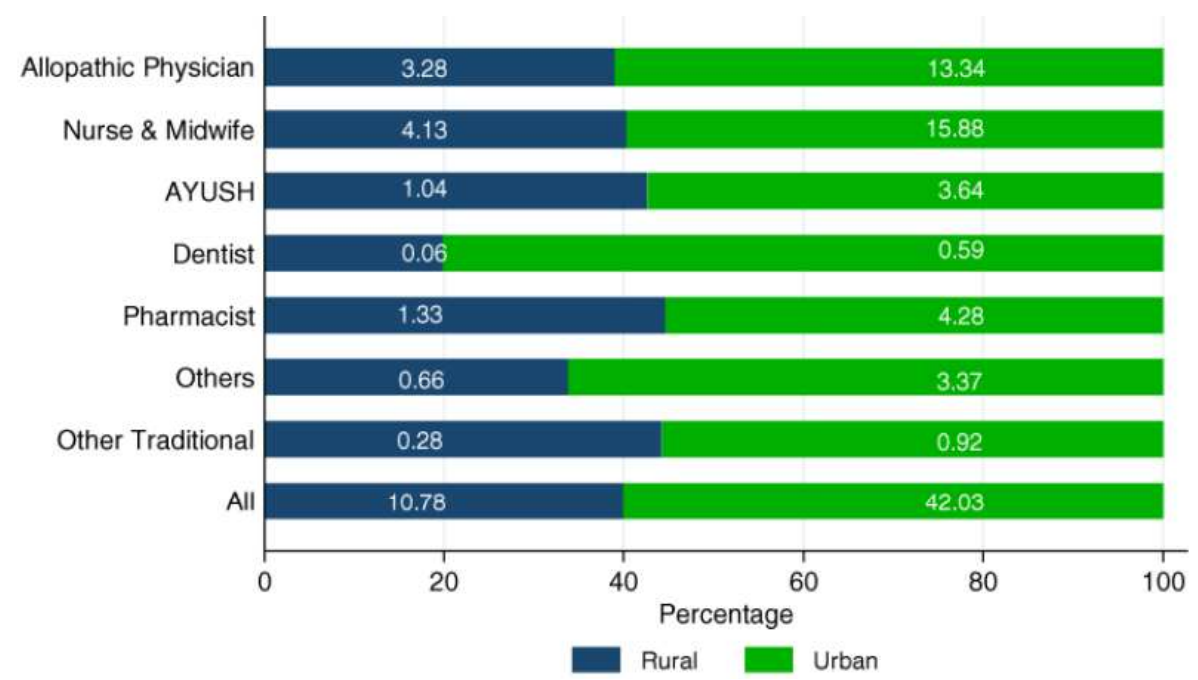

Source: Rao et al. 2009

Figure 3- Distribution of health workers across urban and rural India

Note: Number on the Bars indicate Density (per 10,000 Population)

This significant contrast in the distribution of health workers across urban and rural areas of India is reflected in health indicators as shown in Table 1. On average, urban populations in modern-day periods live longer than do rural populations [20].

Table 1: Comparison of Vital rates among urban and rural India

\begin{tabular}{|l|l|l|}
\hline Vital Rates, 2010 & Rural & Urban \\
\hline Crude Birth Rate & 23.7 & 18.0 \\
\hline Crude Death Rate & 7.7 & 5.8 \\
\hline Infant Mortality Rate & 54.7 & 33.7 \\
\hline Under Five Mortality & 66.0 & 38.0 \\
\hline Percent of deaths where medical attention received before death & 29.7 & 48.9 \\
\hline
\end{tabular}




\section{Role of medical students}

The National Health Policy in India affirms that the effective delivery of health care services would depend very largely on the nature of education, training and appropriate orientation towards community health of all categories of medical and health personnel [21]. Hippocrates had said "Medicine is an art" [22]. In medical school, the focus of education is primarily on grooming the clinical aspect of a doctor skilled only in diagnosis and management of diseases, with reduced emphasis on social and structural determinants of health. This narrowed vision makes a doctor short sighted and leave them without an understanding of issues of social relevance in health care [23]. The foremost deficiency in the Indian medical education system is limited exposure of medical students only up to tertiary level hospitals and not been trained at secondary and primary levels of care. Lack of training in virtues like dedication, compassion, and ethics in the medical education system seems to be the additional cause [21]. The "science" of medicine is thus well taught in medical schools but the "art" of medicine is given relentless treatment in the medical curriculum [23].

According to the World Health Organization (WHO), social justice begins by recognizing that (1) health is a fundamental human right, and (2) gross inequalities in health care are politically, socially, and economically unacceptable. To address health disparities effectively, medical education must go beyond skills, knowledge, and attitudes to foster critical awareness or consciousness of oneself and others. Educational interventions to recognize social determinants of health (SDH) in clinical practices are needed in medical and pre-medical curricula tailored to students' interests and cultivate socially conscious health professionals inclined towards interdisciplinary collaborations [24]. Thus it is of utmost importance to influence their opinions, perceptions and issues related to the delivery of the health services in a way that can bridge inequalities.

\section{Review of literature to explore the perceptions and issues of medical students towards rural postings}

In this context, few studies have been conducted in developed countries such as the UK, Australia, New Zealand and Hungary which have assessed the perception and 
attitudes of medical students towards rural settings.[24-27] They observed that social isolation, poor housing support, poor equipment supply, need for career development and inadequate incentives are primary deterrents from working in rural areas [24-27]. In developing regions like Bangladesh, India, Malawi, Ghana also various studies showed similar results with factors including accommodation, infrastructure, poor resources and financial motives as perceived deterrents by medical students to work in rural areas [28-30]. Although the Medical Council of India (MCI) reports educating 52,105 doctors each year [31], almost one third of them leave India for residency training and/or practice abroad [32].

Most of the global literature has either considered a very limited spectrum of potential deterrents to serve in rural areas or have deployed qualitative methods of enquiry such as semi-structured questionnaires. Also, these tools are developed for students studying in Western countries and therefore difficult to apply in developing countries such as India because of differences in culture and health systems. Thus, relatively little research has been done in India to understand the perceptions of medical students about the factors that can promote rural practice. Additionally, to our knowledge none of the research has comprehensively studied and validated the reasons associated with the non-selection of rural posting after Bachelor of Medicine and Bachelor of Surgery (MBBS) in India.

\section{Strategies, policies and government initiatives}

WHO Health System Framework enlists health workforce in sufficient number and skill-mix as one of the six building blocks of health system strengthening in order to improve coverage and quality of health services [33]. The international initiatives like Sustainable Development Goals also advocate for increase in recruitment, development, training and retention of healthcare workforce of a country in order to universal access to health care services [34]. Based on the available literature, various strategies have been implemented by governments in low- and high-income countries in the healthcare sector to recruit and retain healthcare professionals in rural and remote

areas. These measures covers financial incentives but also non-financial incentives like 
living conditions, education opportunities for employees' children, and future career prospects [35].

In India, the National Health Mission focuses on increasing human resources in order to up bring the health care services in the country [36]. Numerous efforts were also made by the Government of India to promote postings in rural areas, such as preferential admission in post-graduation after working for a fixed time period in rural areas, compulsory rural field experience during medical studies and rural service after medical graduation and rural allowances [37-38]. However, these strategies have tasted sporadic success. In countries like India, where the cost of medical training for the majority of its medical students is borne by government funds, reliable methods of retaining their healthcare professionals in rural areas is of prime concern. Therefore, understanding the perceptions of medical students about challenges in relation to rural areas could predict their subsequent practice location and help stimulate their choice to work or stay in rural areas. Understanding these perceptions of medical students could be the cornerstone to deploy strategies that can be effectively scaled up in India to attract medical students in rural set-up.

\section{Existing knowledge and gaps}

All across the globe, medical profession is one of the most reputed and highly paid professions. In the Indian context, medical professionals are highly respected and are associated with high social status. This cultural trait affects the students in the selection of the medical profession after post matriculation examination. Each individual has a different reason for choosing the medical field, although factors such as interest in the medical field, good job opportunities, desire to serve others, medical background of the parents and many more are commonly reported motivators [39]. In India the reasons for selecting the medical profession vary across people but also across geographic locations. Motivation of students to enter medical study is an important issue because it affects the number of physicians graduating each year from medical schools and therefore the services they can ultimately provide within the national healthcare system. Understanding the main motivational items that influence students to opt for medical studies is hence complex. Therefore there was a need to group and review all the 
studies that can summarize the literature related to motivation of medical students towards selection of medical study.

Although several studies have been conducted worldwide to determine the factors underpinning students' motivation to opt for medical study, very few of them have been performed in India [40-42]. In literature, no review has been conducted in the last ten years about motivating factors of students to select medical studies. The existing reviews have either been conducted before ten years or with different objectives [4344]. One review by Puertas et al. [43] (2013) was conducted to review the factors influencing medical students' choice in primary care while another one by Brissette and Howes [44] published in 2010 was conducted on the articles available till 2008. These studies have focused on very limited items of motivation. Understanding the motivating factors underpinning the choice for medical study in the Indian context is crucial to frame appropriate policies and organizational strategies to counteract the acute shortage of medical personnel and its sharply uneven distribution across urban and rural areas.

An array of questionnaires has been developed to identify the main reasons why medical students selected a medical study [45-48]. However, these tools have been constructed and validated in other countries, such as strength of motivation for medical school (SMMS) questionnaire by Kusurkar R. et al. [47] in the Netherlands, Academic Motivation Scale (AMS) by Vallerand et al. [45-46] in Canada, and Maslach Burnout Inventory-Student Survey (MBI-SS) in a cross-national study [48].

\section{Aim of the thesis}

To the best of our knowledge, studies in India have either used scales validated in western settings or used non-validated instruments to measure medical students' motivation to select medical studies [45-48]. Applying these instruments in culturally different contexts, such as India, could lead to bias and unreliable findings. None of the studies has comprehensively studied the factors in Indian settings. This hinders the valid and robust measurement of students' motivation to select medical studies in India. Hence, there is a need to have a valid and reliable tool to measure reasons that motivated medical students to choose medical study suited for use in India and perhaps 
other developing countries. The aim of this $\mathrm{PhD}$ research is to comprehensively understand the motivational and demotivational factors of students to select medical studies and also their choice towards working in rural areas in India in order to be helpful in formulating strategies. This leads to the following objectives:

(i) To review the motivational factors which underpin medical students' selection of medical studies.

(ii) To develop a valid and reliable instrument for measuring the choice of medical students to study Bachelor of Medicine, Bachelor of Surgery (MBBS) in Indian settings.

(iii) To undertake a narrative review of factors that lead to healthcare workforce shortage in India and the strategies deployed globally which could be replicated and scaled up in developing countries such as India.

(iv) To develop and validate an instrument measuring the factors deterring final year students of Bachelor of Medicine and Bachelor of Surgery (MBBS) from working in rural areas.

(v) To determine the discouraging and encouraging factors affecting medical students' interests in working in rural areas.

\section{Outline of thesis}

This study used an explanatory sequential mixed method approach to ascertain the factors for shortage of healthcare workforce resource in India as structured in various chapters. Chapter 2 delineates the literature related to the motivation of medical students to pursue a career in the medical field. Chapter 3 describes the development and validation of a reliable instrument for measuring the choice of medical students to study Bachelor of Medicine, Bachelor of Surgery (MBBS) in Indian settings using extensive literature review followed by Delphi technique. Chapter 4 represents the critical interpretative synthesis of the existing literature to capture various aspects that lead to human resource shortage in India and the strategies deployed globally which could be replicated and scaled up in developing countries such as India. Chapter 5 
outlines the development and validation of a scale identifying barriers for medical students for accepting rural postings in Indian settings using extensive literature review followed by Delphi technique. Exploratory factor analysis (EFA) followed by confirmatory factor analysis (CFA) was performed to identify the primary deterrents. The findings of the quantitative and qualitative study were mixed at the interpretation level to enhance, validate and provide explanation of the quantitative findings by using a mixed method approach. Chapter 6 represents a cross-sectional, descriptive qualitative study in which focus group discussions were made to display medical students' views about working in rural settings in India, in order to highlight the discouraging and encouraging factors. Lastly, Chapter 7 presents the general discussion, addressing the theoretical and methodological reflection on the main findings as presented in the previous chapters. It also provides recommendations for policy and practice as well as directions for future research. 


\section{References}

1. Stefane M Kabene, Carole Orchard, John M Howard, Mark A Soriano and Raymond Leduc. The importance of human resources management in health care: a global context.Human Resources for Health 2006;4:20

2. WHO. The World Health Report 2003: Shaping the future. Geneva: WHO; 2003. Available at www.who.int/whr/2003/en/whr03_en.pdf (accessed on 15 Sep 2015).

3. WHO. The World Health Report, 2006 - Working together for health. Geneva: World Health Organization, 2006. Available at www.who.int/whr/2006/en/index. html(accessed on 18 Sep 2013).

4. Gupta N, Dal Poz MR. Assessment of human resources for health using cross-national comparison of facility surveys in six countries. Human Resources for Health. 2009;7:22.

5. Human Resources for Health - World Bank Group available at www.worldbank.org/en/topic /health/brief/human-resources-health

6. Framing the health workforce agenda for the Sustainable Development Goals Biennium report 20162017, WHO health workforce

7. WHO. Bulletin of the World Health Organization 2015: Forecasting the global shortage of physicians: an economic- and needs-based approach. Accessed on $24^{\text {th }}$ August 2017.

8. Bull World Health Organ .Global Health observatory data. Accessed on $24^{\text {th }}$ August 2017.

9. Anand S. Measuring health workforce inequalities: Methods and application to China and India. Human Resources for Health Observer, Issue No. 5. Geneva:WHO; 2010. Available at http://whqlibdoc.who.int/publications/2010/9789241500227_eng.pdf(accessed on 25 Sep 2013).

10. Anand S, Fan V. The Health Workforce in India. Human Resources for Health Observer Series. No 16. World Health Organization 2016. Available at www.who.int(accessed on 13 Nov 2016).

11. McCoy D, Brikci N. Taskforce on innovative international financing for health systems: What next? Bull World Health Organ 2010;88:478-80.

12. Chen L, Evans T, Anand S, Boufford JI, Brown H, Chowdhury M, et al. Human resources for health: Overcoming the crisis. The Lancet 2004;364:1984-90.

13. High Level Expert Group Report on Universal Health Coverage for India Planning Commission of India New Delhi, November, 2011. http://planningcommission.nic.in/reports/genrep/rep_uhc0812.pdf. Accessed 7th April 2015.

14. Deo MG. "Doctor population ratio for India - The reality." The Indian Journal of Medical Research. 2013;137(4):632-635.

15. Kuriakose S, Revankar SKB, Viveka S, Shetty B, Rao CP. Why become a Doctor? Evaluation of Motivational factors for selecting medical profession as career. Journal of Evidence based Medicine and Healthcare.2015; 2: 206 \pm 211 .

16. Rao K, Bhatnagar A, Berman P. India's health workforce: size, composition, and distribution. Indian Heal Beat 2009;1. 
17. Government of India. Rural Health Statistics 2014-2015.Ministry of health and family welfare, Statistics Division. Available from: http://wcd.nic.in/sites/default/files/RHS_1.pdf, Accessed on April $18^{\text {th }} 2017$.

18. Katrak, H. (2008), Measuring the shortage of medical practitioners in rural and urban areas in developing countries: a simple framework and simulation exercises with data from India. Int. J. Health Plann. Mgmt., 23: 93-105. doi:10.1002/hpm.87

19. Garg S. Singh R, Grover M.India's health workforce: Current status and the way forward. National Med J of India. 2012;25 (2):111-113

20. Chillimuntha AK, Thakor KR, Mulpuri JS. Disadvantaged rural health - issues and challenges: a review. Natl J Med Res. 2013; 3(1): 80-82

21. Kumar R. Medical education in India: An Introspection. Indian Journal Of Public Administration, 2014; LX(1):146-154

22. Gupta P. Humanity in Medicine. Journal of Medical Ethics and History of Medicine. 2011;4:3.

23. Ambrose AJH, Andaya JM, Yamada S, Maskarinec GG. Social Justice in Medical Education: Strengths and Challenges of a Student-Driven Social Justice Curriculum. Hawai'i Journal of Medicine \& Public Health. 2014;73(8):244-250.

24. World Health Organization. Increasing access to health workers in remote and rural areas through improved retention.[accessed on 2016 September 30]. Available from: http://www.who.int/hrh/migration/background_paper.pdf.

25. Polasek O, Kolcic I, Dzakula A, Bagat M: Internship workplace preferences of final-year medical students at Zagreb University Medical School, Croatia: all roads lead to Zagreb. Human Resources for Health 2006; 4:7.

26. Hungarian Central Statistical Office: Yearbook of Health Statistics 2006 Budapest: Hungarian Central Statistical Office; 2007.

27. Peach HG, Bath NE. Comparison of rural and non-rural students undertaking a voluntary rural placement in the early years of a medical course. Med Educ2000, 34 (3):231-33.

28. Khan MM, R Hotchkiss D, Dmytraczenko $T$ et al. Use of a Balanced Scorecard in strengthening health systems in developing countries: an analysis based on nationally representative Bangladesh Health Facility Survey. IntJHealth PlannManage. 2013;28(2):202-215.

29. Rao M, Rao KD, Kumar AKS et al. India: Towards Universal Health Coverage 5 Human resources for health in India. Lancet 2011;377:587-98.

30. Muula A, Mfutso-Bengo J, Makoza J et al. Is it ethical for industrialist nations to recruit nurses from a developing country? The case of Malawi. Blantyr: Department of Community Health, University of Malawi College of Medicine and Nurses and Midwives Council of Malawi, 2002.

31. Medical Council of India. http://www.mciindia.org. Accessed 7th April 2015.

32. Aggarwal S, Rai A, Bath KS, Singh H, Sharma V. Migratory Trends of Medical Graduates in India.Journal of Pioneering Medical Sciences.2014; 4:155-158.

33. Anand S, Bärnighausen T. Health workers at the core of the health system: Framework and research issues. Health Policy (2011), doi:10.1016/j.healthpol.2011.10.012 
34. The Sustainable Development Goals Report. Department of Economic andSocial Affairs (DESA). New York: United Nations Publications; 2017.

35. Curran V, Rourke J: The role of medical education in the recruitment and retention of rural physicians. Med Teach 2004; 26(3):265-72.

36. Lakshminarayanan S. Role of government in public health: Current scenario in India and future scope. Journal of Family and Community Medicine. 2011;18(1):26-30. doi:10.4103/1319-1683.78635

37. Rao M, Rao KD, Kumar AKS et al. India: Towards Universal Health Coverage 5 Human resources for health in India. Lancet 2011;377:587-98.

38. Saini NK, Sharma R, Roy R et al. What impedes working in rural areas? A study of aspiring doctors in the National Capital Region, India. Rural Remote Health 2012. 12:1967. Epub 2012 Mar 15

39. Agyei-Baffour P, Kotha SR, Johnson JC, Gyakobo M, Asabir K, Kwansah J et al. Willingness to work inrural areas and the role of intrinsic versus extrinsic professional motivations- a survey of medical students in Ghana. BMC Medical Education.2011; 11:56 \pm 64 . doi: 10.1186/1472-6920-11-56 PMID:21827698

40. Lal P, Malhotra C, Nath A, Malhotra R, Ingle GK. Career aspirations and apprehensions regarding medical education among first year medical students in Delhi. Indian J Community Med. 2007; 32: $217 \pm 218$

41. Shah S. Why students want to join MBBS? Www.medicalacademy.com. accessed 9thApril 2015.

42. Diwan V, Minj C, Chhari N, De Costa A. Indian medical students in public and private sector medical schools: are motivations and career aspirations different? \pm studies from Madhya Pradesh, India. BMC Medical Education; 2013 13:127.

43. Puertas EB, Arósquipa C, Gutiérrez D. Factors that influence a career choice in primary care among medical students from high-, middle-, and low-income countries: a systematic review. Rev PanamSaludPublica. 2013;34(5):351-8.

44. Brissette A, Howes D. Motivation In Medical Education: A Systematic Review. WebmedCentral Medical Education 2010;1(12):WMC001261

45. Vallerand RJ, Blais MR, Brie're NM, Pelletier LG. Construction et validation de l'E0 chelle de Motivationen Education (EME). Revue canadienne des sciences du comportement. 1989; 21: 323-349.

46. Vallerand RJ, Pelletier LG, Blais MR, Briere NM, Senecal C, Vallieres EF. The Academic Motivation Scale: A measure of intrinsic, extrinsic and motivation in education. Educational and Psychological Measurement. 1992; 52: 1003-1017.

47. Kusurkar R, Croiset G, Kruitwagen C, ten Cate O. Validity evidence for the measurement of the strength of motivation for medical school. Adv in Health Sci Educ. 2011; 16:183 \pm 195 .

48. Schaufeli WB, Martinez IM, Pinto AM, Salanova M, Bakker AB. Burnout and engagement in university students: A cross-national study. Journal of Cross-Cultural Psychology. 2002; 33(5): $464 \pm 481$ 


\section{Chapter 2}

What motivates medical students to select medical studies: A systematic literature review.

Sonu Goel, Federica Angeli, Nonita Dhirar, Neetu Singla and Dirk Ruwaard BMC Medical Education 2018; 18 (1):16

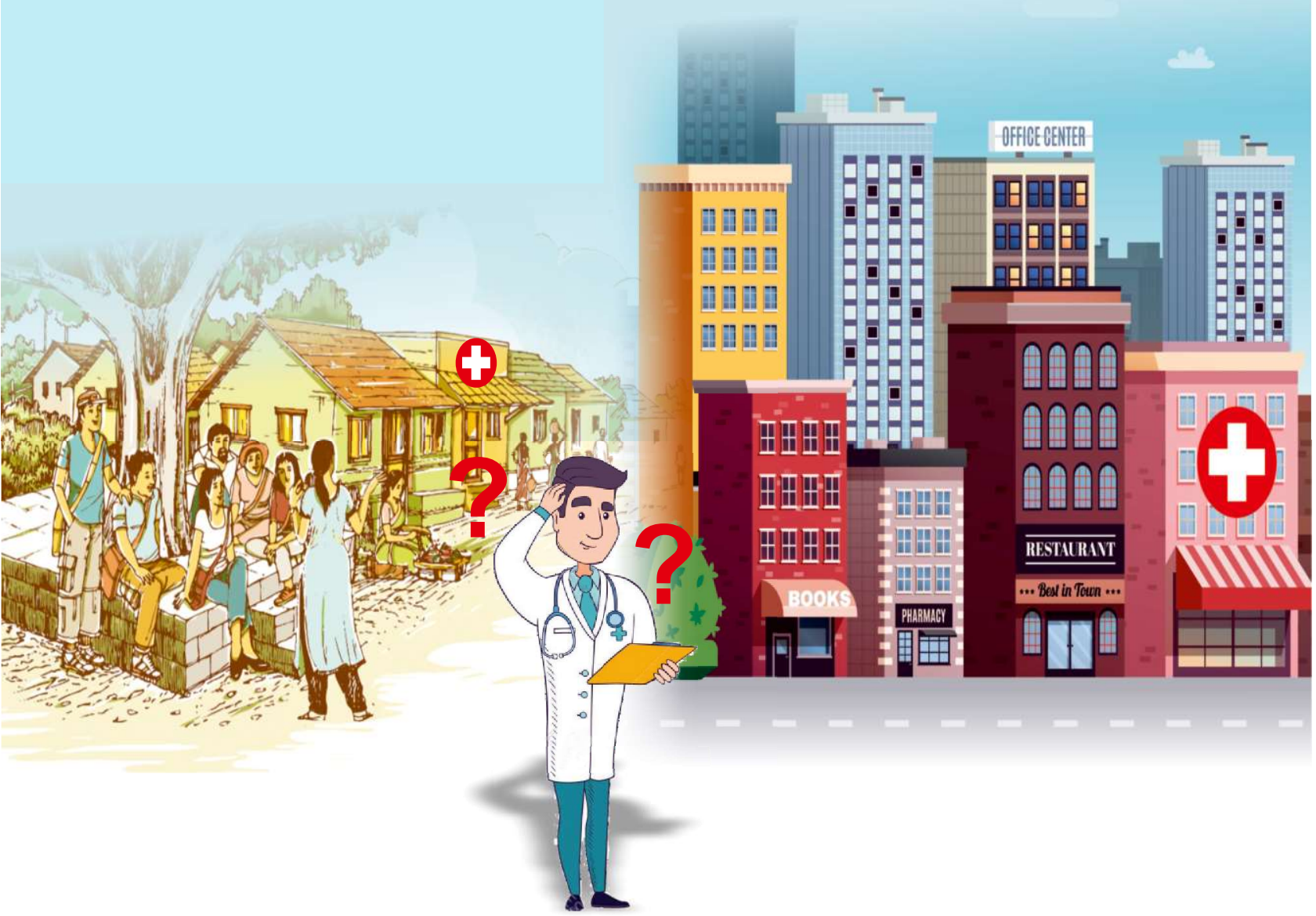




\begin{abstract}
Background: There is a significant shortage of health workers across and within countries. It is of utmost importance to determine the factors that motivate students to opt for medical studies. The objective of this study is to group and review all the studies that investigated the motivational factors that underpin students' selection of medical study in recent years. Methods: The literature search was carried out by two researchers independently in PubMed, Google Scholar, Wiley and IndMED databases for articles published from year 2006 till 2016. A total of 38 combinations of MeSH words were used for search purpose. Studies related to medical students and interns have been included. The application of inclusion and exclusion criteria and PRISMA guidelines for reporting systematic review led to the final selection of 24 articles.
\end{abstract}

Results: The majority of the studies $(n=16 ; 66.6 \%)$ were from high-income countries followed by an equal number from upper-middle and lower-middle income countries ( $\mathrm{n}$ $=4,16.7 \%$ ). None of the studies were from low-income countries. All of the studies were cross-sectional in nature. The main motivating factors that emerged were scientific (interest in science / medicine, social interest and academia, flexible work hours and work independence), societal (prestige, job security, financial security) and humanitarian (serving the poor and under privileged) in high-, upper-middle and lower-middle income countries, respectively. The findings were comparable to Maslow's hierarchy of needs theory of motivation.

Conclusion: This systematic review identifies the motivational factors influencing students to join medical studies in different parts of the globe. These factors vary per country depending on the level of income. This study offers cues to policy makers and educators to formulate policy in order to tackle the shortage of health workers, i.e. medical doctors. However, more research is needed to translate health policy into concrete and effective measures. 


\section{Background}

The world is currently facing a dual problem of shortage and inequitable distribution of health workers, especially in middle- and low-income countries [1]. The World Health Organization (WHO) estimated a need for an additional 4.3 million health workers in 57 countries to fulfill the Millennium Development Goals [2]. In addition, 83 countries (44.6\%) do not currently meet the 2006 World Health Report threshold of 22.8 skilled health professionals per 10,000 population [3]. Among many, the main reasons cited for shortage of health workers in rural areas include poor working conditions, lack of accommodation, lack of transport, poor pay structure, overburden with additional administrative responsibility and political interference [4]. In middle- and low-income countries, the situation is more critical because of migration of doctors to high-income (developed) countries whereas inequitable distribution of health workers between urban and rural areas is primarily due to poor motivation of health workers to work in rural areas. [5]

The choice of medical study depends upon various factors such as interest in the medical field, good job opportunities, a desire to serve others, medical background of the parents and many more $[6,7]$. In literature, no review has been conducted in the last ten years about motivation factors of students to select medical studies. The existing reviews have either been conducted before ten years or with different objectives [8,9]. One review by Puertas et al. [8] published in 2013 was conducted to review the factors influencing medical student's choice in primary care while another one by Brissette and Howes [9] published in 2010 was conducted on the articles available till 2008. Brisstte and Howes identified that motivation to take up medical studies lies in addressing learner's needs for competence, autonomy, and relatedness. Providing optimal challenge and positive performance feedback, choice and opportunity for self-direction, and a sense of belongingness and connection to the medical profession can all be focused on to address the above mentioned motivators [9]. The review has given points for educators to act upon. The lacunae left by the previous review studies need to be addressed in a finer manner in context with the current challenge of the global workforce. 
In last few years, human resources for health have attracted substantial scholarly attention. Over the last decade, there has been advancement in different fields of medical sciences, from prevention, patient care to laboratory workup and management of severe diseases and palliation. With the growing population and improving health care owing to better technologies, it is gravely important to improve the medical workforce, mostly doctors.

Globally, several health-related goals and programs are giving priority to human resource development in the health sector. The major health related initiatives like Sustainable Development Goals [10] and WHO's six building blocks [11] focus on human resource development for achieving universal health coverage. The National health programs, like the National Health Mission in India, focuses on increasing human resources to upbring the health care services in the country.

The prospective medical students form a significant pool of health care workers that can help overcome the shortage globally. Therefore, understanding the current common motivational factors is essential and a summary of the factors through a review of these studies would derive a clearer picture. A strong predictor for any student to take up a career in any field is the motivation or drive from within. Motivation is defined as the process that initiates, guides, and maintains goal-oriented behaviours. It involves the biological, emotional, social, and cognitive forces that activate behaviour. Fulfilment of needs results in some type of behaviour, which can be either intrinsic or extrinsic [7]. Understanding motivation is very important in the medical sector because a motivated individual is willing to exert and maintain an effort to provide good- quality health services.

The objective of this study is to group and review all the studies that investigated the motivational factors that underpin students' selection of medical study in recent years. 


\section{Methods}

\section{Search strategy}

The literature search was carried out with the purpose to identify the perceptions of medical students to enter medical studies. The search was carried out by two researchers (NS and ND) independently in PubMed, Google Scholar, Wiley and IndMED databases for original studies conducted from 2006 to 2016. This time frame was chosen as many studies were done during this period to identify the motivational factors. MeSH and freetext terms "(Moti- vat*) AND (select* OR choice OR choose) AND (medical student* OR medical school* OR interns) have been used. Internship in the period of practical application of theoretical (mostly) knowledge of the previous medical school years, hence interns were also made a part of the search strategy. Search terms and keywords were altered as per specification of individual databases. A total of 38 combinations were used for search purpose.

An initial search identified thousands of related records from the Google scholar, PubMed, IndMed and Wiley online library databases. The articles which were not related to motivation were excluded at the first step. Then search results were imported to Microsoft Excel and duplications were removed by sorting the titles of articles. The selected studies were then screened by reading the title and abstract resulting in shortlisting 91 articles. Of these, 62 articles were excluded based on eligibility criteria. The remaining 29 full-text articles were further assessed, and five were excluded because the articles were in Korean, Spanish and Chinese. A total of 24 studies were selected. Any differences of opinion were debated and consensus was reached. Further differences were resolved by the third researcher (SG). PRISMA guidelines were strictly followed during the study. Figure 1 represents the flow chart leading to sample selection.

\section{Selection criteria and sample}

All studies carried out and published from year 2006 till 2016 were included in the review. Inclusion criteria were studies describing motivation to study medicine, conducted among medical students and interns and available in English language. Exclusion 
criteria were those studies done before 2006, published in languages other than English, and those not related to motivation or medical students and interns.

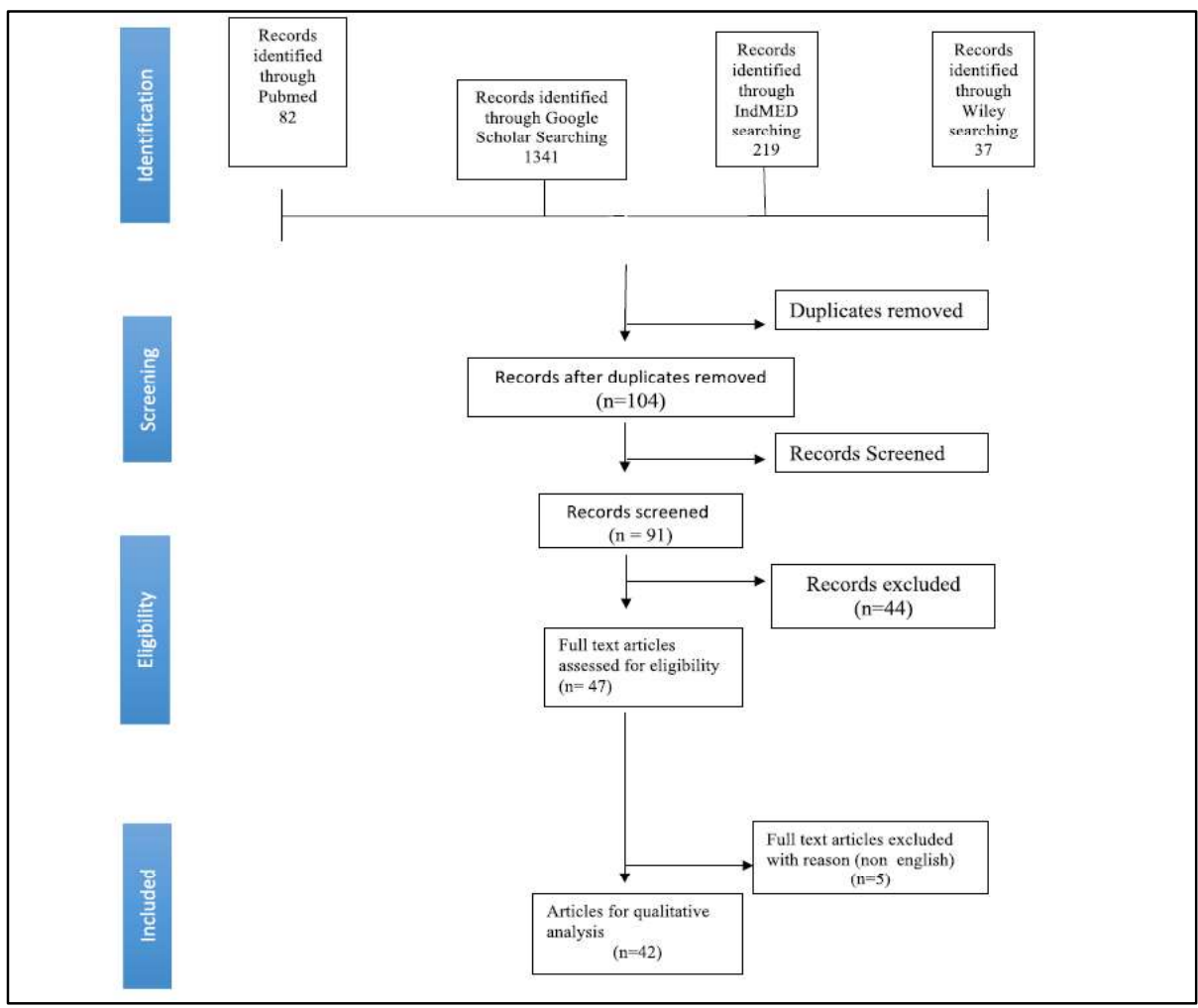

Figure 1- Flow chart of selection and exclusion of studies for the systematic review

\section{Data analysis}

A thematic analysis of selected papers was performed, wherein two research assistants coded the papers independently and reached consensus on relevant themes [12]. They also extracted details of the final articles using a standardized abstraction form that collected information on: the author, the journal, the year of publication, location, study objectives, study design, findings, limitations, and observations. In this paper, we systematically review the literature related to medical education with the goal of identifying the motivating factors influencing the medical students to join medical studies.

The results of the studies' review were categorized under different heads viz. scientific 
factors, social factors and humanitarian factors based upon criteria devised by Goel S et al. in their study on development and validation of the motivations for selection of medical study in India [13]. In this study a Motivation of Selection of Medical Study (MSMS)' tool was developed using extensive literature review followed by Delphi technique. The three domains and the issues that emerged are shown in Table 1.

Table 1: Domains and issues that emerge as main motivational factors

\begin{tabular}{ll}
\hline Domains & Issues \\
\hline Scientific & - Ability to use new cutting edge technologies \\
& - Interest in medicine as a subject matter \\
& - Opportunities to travel and work internationally \\
& - Research opportunities \\
Societal & - Joss of a loved one \\
& - Social status/prestige \\
& - High income \\
Humanitarian & - Proposed by parents \\
& - Desire to help others \\
& \\
&
\end{tabular}

\section{Ethical considerations}

The study was granted ethical approval from the Institute's Ethical Committee, PGIMER, Chandigarh (PGI/ IEC/2012/810-1 P-154). Since the study is a systematic review of studies and individual level data is neither obtained nor presented, the consent.

\section{Results}

The characteristics of the studies included in the systematic review are shown in Table 2. The assessment of factors of motivations for medical students to select medical studies was based on the World Bank categorization of low-, middle- and high-income countries. [14]The low- income, lower middle-income, upper middle-income and high-income economies are defined as those with a Gross National Income (GNI) per capita of $\$ 1005$ 
or less, between $\$ 1006$ and $\$ 3955$, between $\$ 3956$ and $\$ 12,235$ and $\$ 12,236$ or more, respectively in the year 2016. The majority of the studies $(n=16,66.6 \%)$ were from high-income countries followed by an equal number from upper middle and lower middle income countries $(n=4,16.7 \%)$. None of the studies were from low-income countries. All of the studies were cross sectional in nature $(n=24)$. Figure 2 shows the geographic distribution of the different studies.

Table 2: Characteristics of the studies included in the systematic review $(n=24)$

\begin{tabular}{ll}
\hline Characteristic & Number (\%) \\
\hline Income Group & \\
- high-income countries & $16(66.6)$ \\
- upper-middle income countries & $4(16.7)$ \\
- low-income countries & $4(16.7)$ \\
- Study design & \\
- cross sectional studies & $24(100 \%)$ \\
Study type & \\
- quantitative & $21(87.5)$ \\
- qualitative & $1(4.2)$ \\
- mixed methods & $2(8.3)$ \\
\hline
\end{tabular}

\section{Predominance of motivating factors according to income group}

Results reported for motivation to select medicine by medical students' changes in the context of place (see Figure 3 and Table 3). The choice of medical study among students differs between students in high-income countries, and those in upper-middle and lowermiddle-income countries. The individual motivation factors that emerged are presented in Table 4.

\section{High-income countries}

In most of the high-income counties, scientific and humanitarian factors were described as the main motivators to select medicine by medical students [15-29]. Most of the high income countries including Spain, Croatia, Poland, UK, Hungary, Germany and South Korea reported similar type of motivators to motivate the medical students for choosing 
medicine: interest in science/medicine, social interest, flexible work hours and work independence. Results reported by Kim et al. (2016) [16], Becker et al. (2015) [29], Wouters (2014) [19] emphasized on the scientific factors. Societal factors were also reported in most of these studies but fell lower in hierarchy.

\section{Upper middle income countries}

The main motivators to select medicine by medical students of upper-middle income countries include the societal and scientific factors [30-33]. A study by Kavousipour et al. (2015) [30] conducted in Iran explains that the factors which were most significant to motivate the students were family attitudes, getting good jobs in future, respect for themselves, the ability to learn, believing their role in victory and defeat and the tendency toward optimism about themselves. Pagnin et al. (2013) [32] also concluded similar findings. Social and professional status of the job, healthcare-people factor, others' recommendation and advices, personal interest and nature of occupation, occupational experience and personal life had been identified as main factors of motivation. The findings reported by Korkmaz et al. (2013) [31] also found societal and scientific factors to be more significant motivators

\section{Lower-middle -income}

In low-middle income countries, students have mixed responses for the choice of medical studies [34-37]. Humanitarian and societal factors had been reported as main influences to join medicine.

Few studies conducted in various parts of India had reported almost similar results. A study conducted in Madhya Pradesh, India by Diwan et al. (2013) [35] concluded that reasons for entering medical education included personal ambition, parental desire, prestigious profession, altruistic reasons and pecuniary incentives. Similar to these findings were those reported by Kuria- kose (2015) [34], Seetharaman et al. (2012) [36] and Lal et al. in 2007 [37]. The main reasons that motivate the medical students were to serve the sick and society and having a high status in society. 


\section{Discussion}

To our knowledge, this is the first systematic review of motivational factors for choosing medical studies by medical students globally. Earlier reviews were related to factors influencing student rating in undergraduate medical education course evaluations and factors that influence a career choice in primary care among medical students from high, middle- and low-income countries [8]. The present systematic review, which has analyzed 24 studies in detail, is important as it identifies the motivational factors influencing the medical students to join medical studies in different parts of the globe along with the variations among the factors in lower-middle, upper- middle and highincome countries. As such, it provides essential insights into how students could be motivated, and how this varies across countries. No study was found from low-income countries. The limited research on this topic in low-income countries could be related to the lack of interest in this particular area, or to an overall deficit in research in developing nations, or both. These countries could identify the issues and intervene according to the research done in lower-middle and upper-middle income countries.

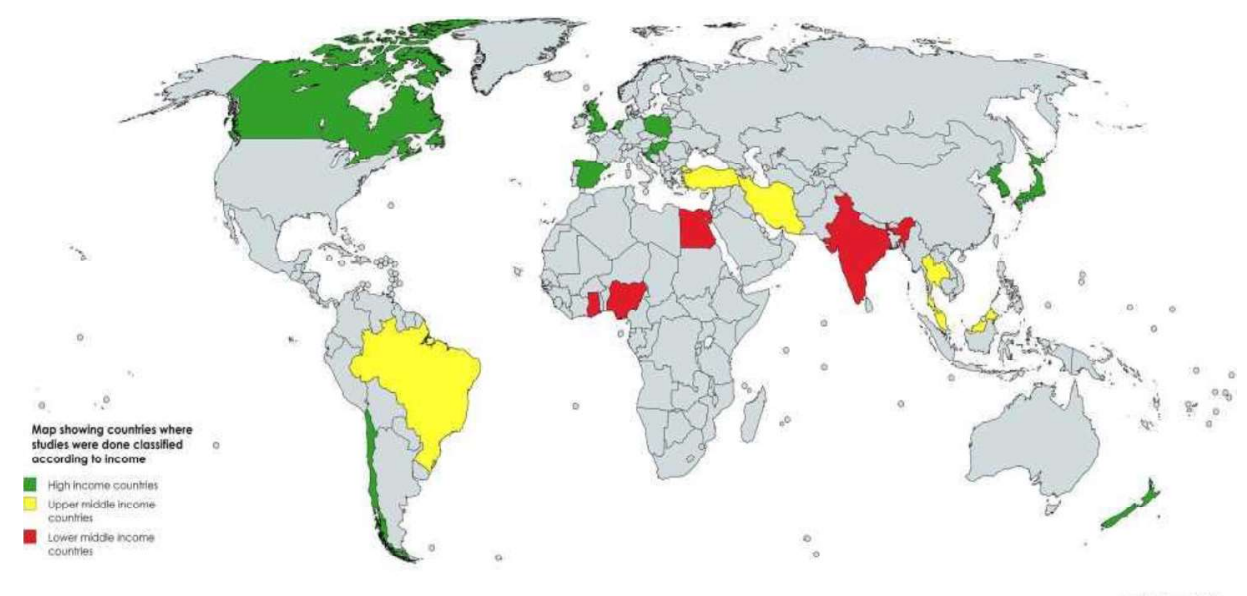

Figure 2- Geographical distribution of the different studies across the globe (used a web page https://mapchart.net which is free of cost and specifically designed for making customized maps)

Several theories of motivation have been described in relation to career choice among student including intrinsic and extrinsic factors as described by Brissette and Howe [9] and by Maslow [38], Taylor, McClelland and Herzberg [39]. However, Maslow's theory 
remains to be the most detailed and frequently used theory [38]. The Maslow's hierarchy of needs describes motivational factors under five broad segments: the physiological needs, the needs for safety and security, the needs for love and belonging, the needs for esteem, and the need to actualize the self, in that order [38].

Physiological needs are the basic needs required by an individual, such as food, water, sleep, etc. Once these needs are met, the second segment of needs comes into picture making safety, stability, protection the prime concerns. Following these factors the third segment consists of desires to marry, have a family, become a part of their community etc. The fourth segment of esteem has two versions as described by Maslow. The need for respect, prestige, prominence, magnificence, appreciation, attention, status, selfesteem, and dominance forms the lower version while the higher form involves the need for self-respect which includes feelings as self-confidence, capability, accomplishment, mastery, and freedom. The last segment is the phase of self-actualization which is a desire for self-fulfilment [38].

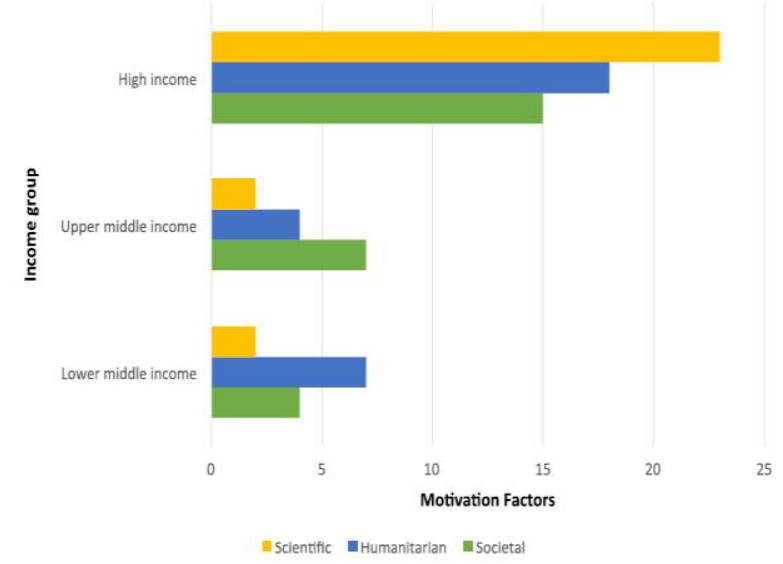

Figure 3-Categorization of motivation factors across different income country groups

In low-middle income countries, students are still striving to fulfill primary basic needs and safety and security of employment, family, health. They fall under the first two segments of the pyramid comprising of basic needs, safety stability and protection and hence the predominant motivational factors are humanitarian in this group. In some areas 


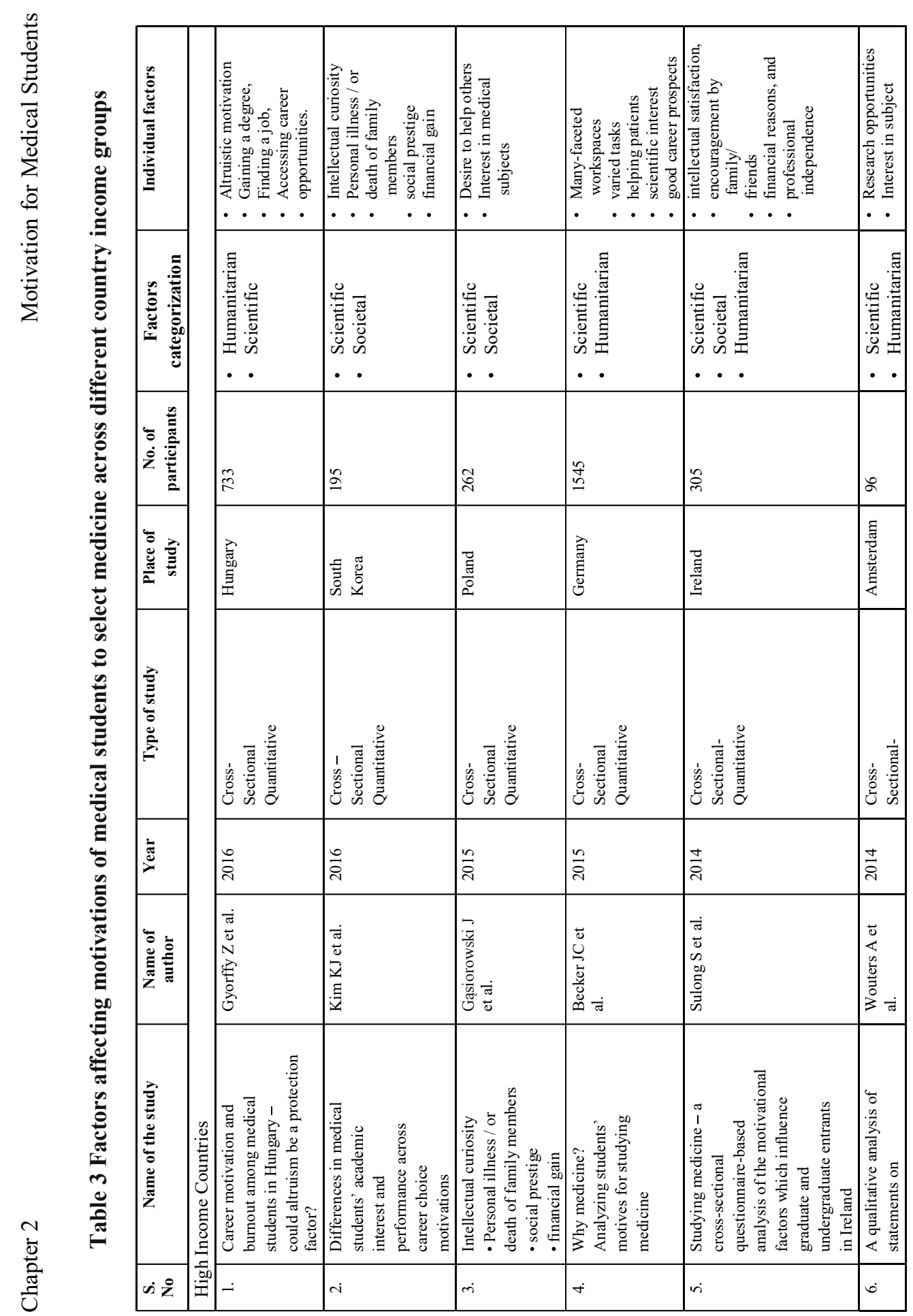




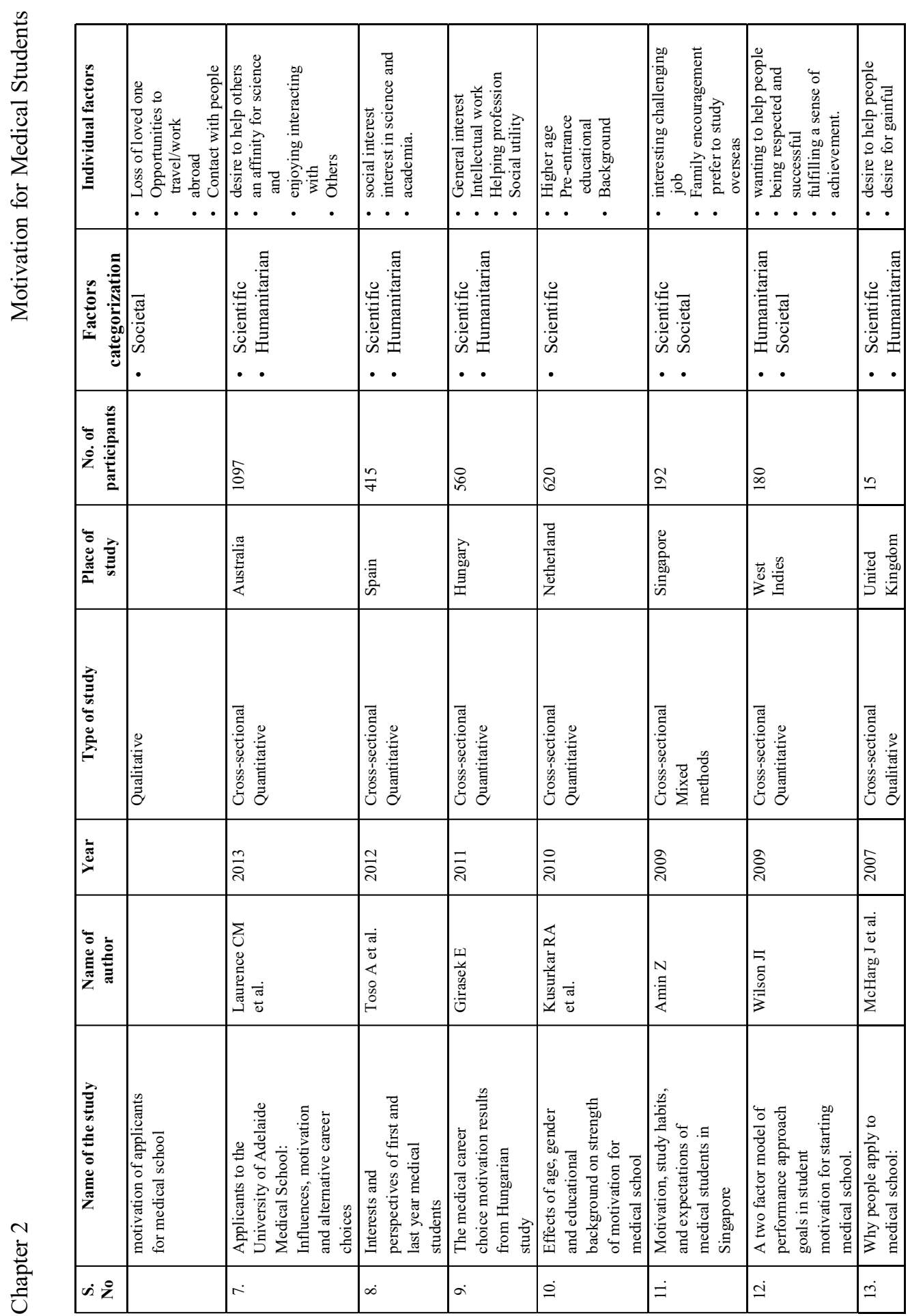

จิ 


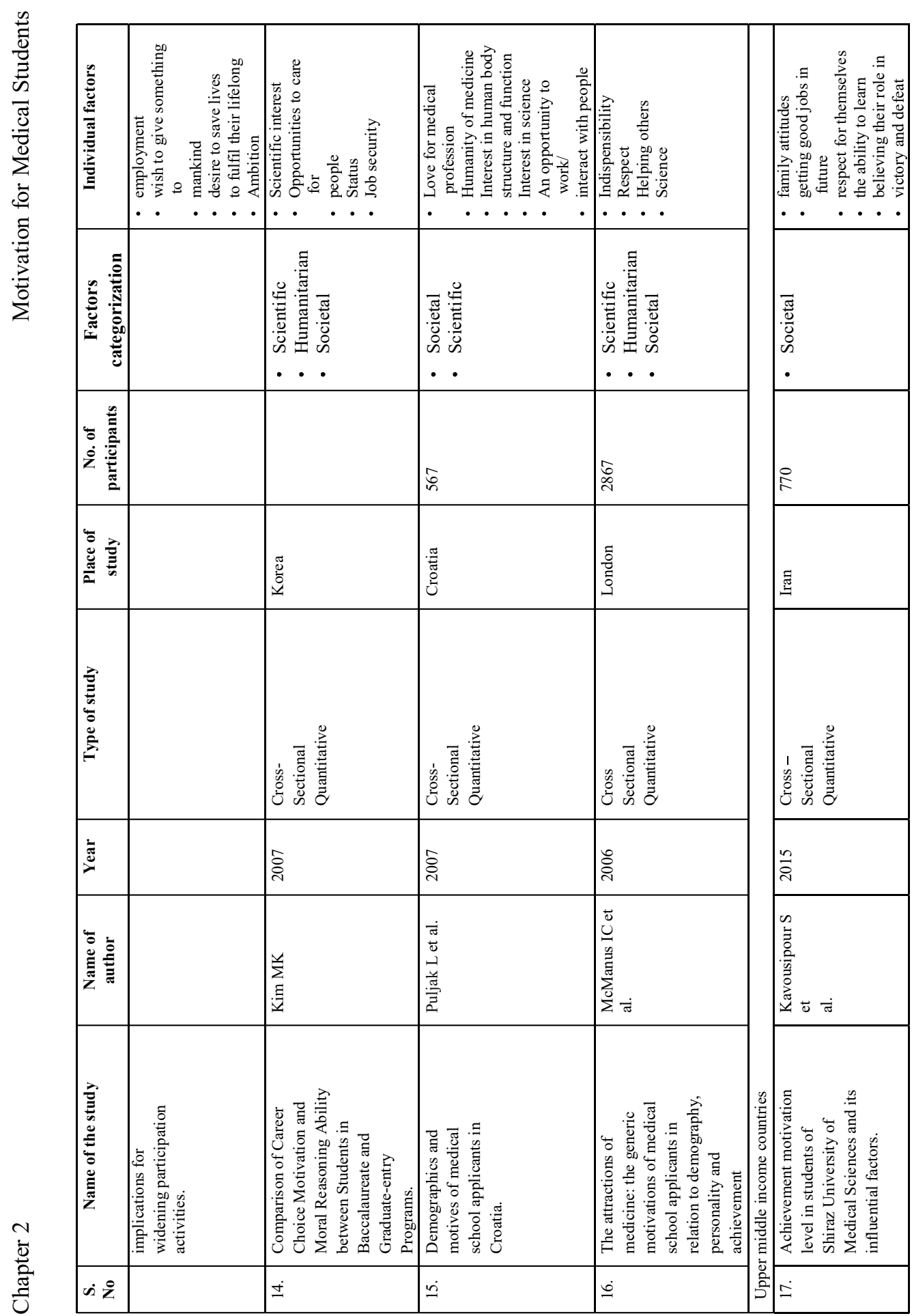

요 


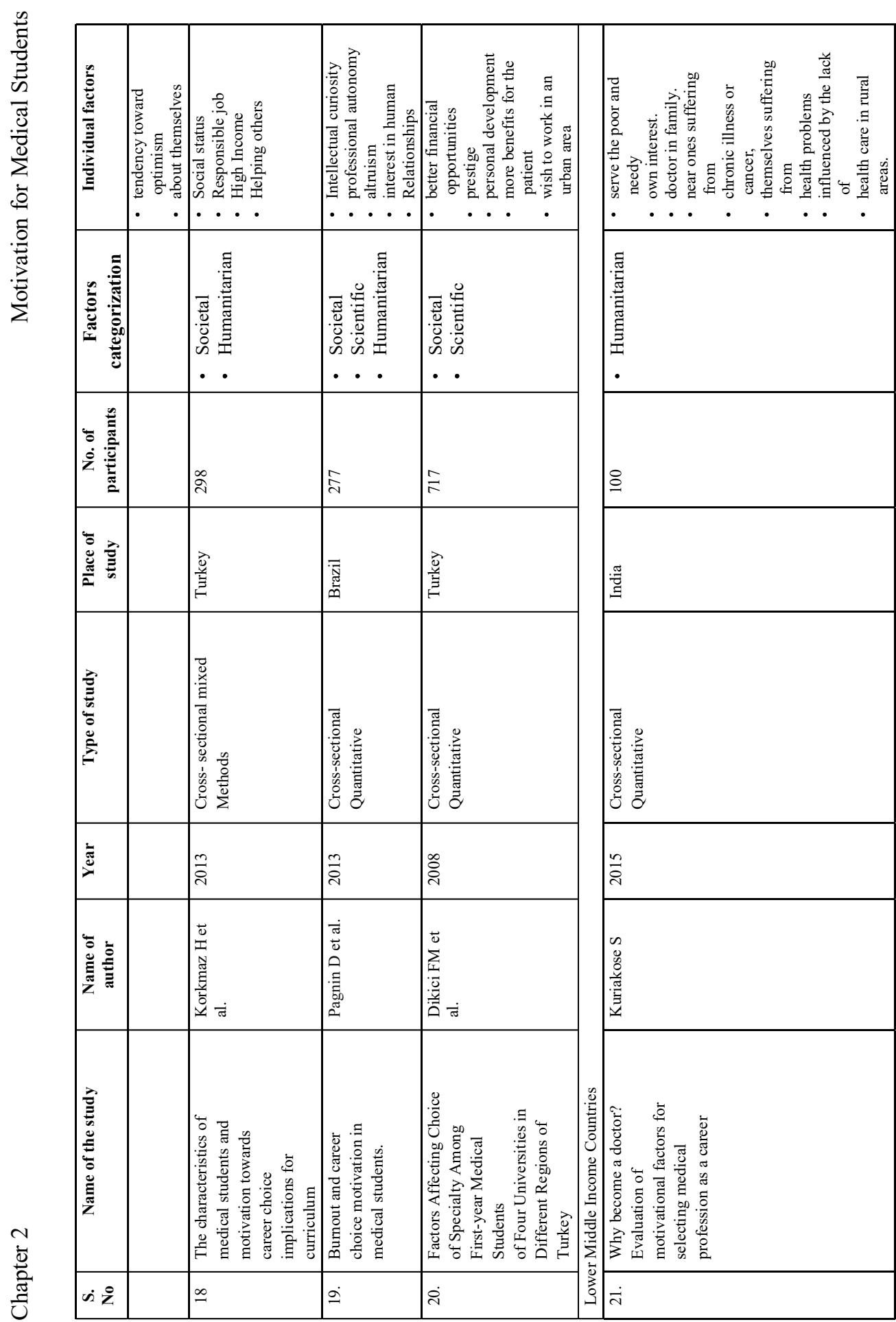

m 


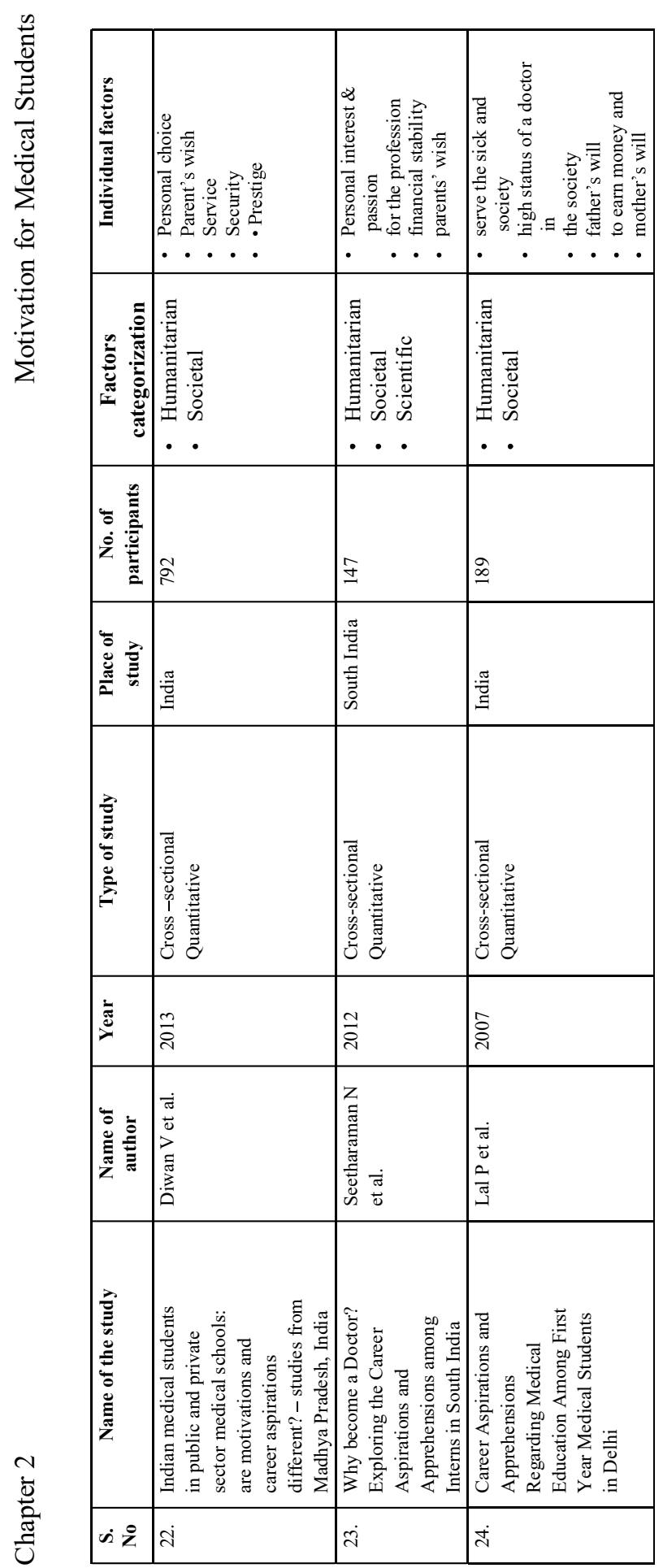

กี 
where these needs are fulfilled, the higher segment of self-esteem also come into picture, hence societal factors are also seen in lower-middle income countries. The prime reasons for selecting medical studies among students in low-income countries were parental desire, respected profession and economic incentives, respect in society, high societal status and to serve the sick. The desire to serve the poor is deeply ingrained in this society.

Table 4: Most commonly cited motivational factors among all the studies analyzed $(\mathrm{N}=\mathbf{2 4})$

\begin{tabular}{|c|c|c|}
\hline $\begin{array}{c}\text { Motivational } \\
\text { factors }\end{array}$ & $\begin{array}{l}\text { Number of } \\
\text { Studies }\end{array}$ & $\begin{array}{c}\text { Percentage of } \\
\text { studies }\end{array}$ \\
\hline \multicolumn{3}{|l|}{ Scientific factors } \\
\hline 1. Interest in Medicine & 16 & 66.7 \\
\hline $\begin{array}{ll}\text { 2. Professional } \\
\text { growth/challenging career }\end{array}$ & 6 & 25 \\
\hline 3. Work independence & 3 & 12.5 \\
\hline 4. Work abroad/urban areas & 3 & 12.5 \\
\hline \multicolumn{3}{|l|}{ Humanitarian factors } \\
\hline $\begin{array}{l}\text { 5. Work for people/help } \\
\text { underprivileged }\end{array}$ & 18 & 75 \\
\hline 6. Family experience of a disease/death & 3 & 12.5 \\
\hline \multicolumn{3}{|l|}{ Societal factors } \\
\hline 7. Social status/Prestige & 8 & 33.3 \\
\hline 8. Financial security & 6 & 25 \\
\hline 9. Job Security & 5 & 20.8 \\
\hline 10. Parental wish & 5 & 20.8 \\
\hline 11. Family Tradition & 2 & 8.3 \\
\hline
\end{tabular}

Most of the students belong to lower or middle socioeconomic groups and understand the miseries of poor well and these factors lead them to serve the humanity and poor people. Here medical students are more sensitive to the social needs of population. The very reasons identified to take up medical career in these countries can be used to encourage students to take up medical studies. Mainly, the respect and feeling of altruism, followed by the monetary and social benefits are a driving force that can be used to attract the students into medical profession, hence improving the workforce. As 
the motivational factors are mostly innate, their further interest in medical studies and serving the nation will remain significant.

In the upper-middle income countries the factors as described by the middle zone in the Maslow's hierarchy of needs pyramid were identified. The majority of studies identified societal factors as better predictors as compared to humanitarian and scientific factors. The main motivators to select medicine by medical students of upper-middle income countries are job security, social status, and parental wish. The reason behind this is that, to become a doctor is one of the highest ambition of many school-going students and their parents in middle- and low-income countries, along with the fact that the medical profession is preferred by the students due to its high prospect of financial security and high social status. Being a respected profession with high social status and higher salaries has been found to be motivating factor for students. The students in these countries have mostly met their basic needs and are more attracted towards a better lifestyle and income. Security in all fronts is a strong predictor for picking medical studies, and this can help enroll more students into this career. Excelling in their medical education may act as a strong target as their competition decides their future prospects.

The motivational factors commonly reported by most of the studies in high-income countries were the third and fourth segments of the Maslow's hierarchy of needs pyramid. The scientific factors were the main motivators to select medicine by students. This may be due to the fact that the students in high-income countries chose medicine or science, who have prime interest in these subjects. The interest in science is usually developed during their school times to become medical school academics in a well- developed education system and with advanced technologies (modern laboratory facilities). The availability of good technologies and advanced education helps in developing specialized skills through the medical school years and beyond. In addition, the ability to earn well, pay their debts and live comfortably are strong motivators as well. There are various strengths of the study. Firstly, the review was done on a sizeable number of 24 studies across the globe, hence generating stronger evidence. Secondly, the study relates the motivational factors across different countries with the Maslow's hierarchy of needs theory [38]. This helps to understand the motivational factors of medical students to work 
in rural areas with respect to the innate motivational factors of a human being.

This review has a few limitations. Despite our efforts to identify all relevant studies by searching four different databases and using a fairly large number of search terms, we might have missed relevant studies. Additionally, unpublished studies from low- and middle-income countries were not represented (publication bias). The exclusion of articles published before 2006 may have omitted literature that could have provided valuable information. However, our review supplement two existing reviews published earlier $[8,9]$.

\section{Conclusion}

In conclusion, this systematic review investigated the reasons that affect students' decisions to join medical profession. The motivational factors are being classified in scientific factors (e.g. 'interest in medicine'), societal factors (e.g. 'respect/prestige') and humanitarian factors (e.g. 'desire to help others'). The predominance of factors varied among students in high-, upper-middle and lower-middle income countries. Hence, this study offers cues to policy makers and educators in different countries to understand the motivational factors as a first step to formulate policy in order to tackle the shortage of health workers to improve the status of human resources across nations. However, more research on the subject would assist in promoting as well as translating health policy into concrete and effective measures at the local, national, regional and global levels in lowand middle- income countries. 


\section{References}

1. World Health Organization. The world health report 2006: working together for health. Geneva: WHO; 2006 [Internet]. 2015. Available from: http://www.who.int/whr/2006/en/. Accessed 12 Oct 2015.

2. Smith MK, Henderson Andrade N. Facing the health worker crisis in developing countries: a call for global solidarity. Bull World Heal Organ. 84(6):425-504.

3. Campbell J, Dussault G, Buchan J, Pozo-Martin F, Guerra Arias M, Leone C, Siyam A, Cometto G. A universal truth: no health without a workforce. Forum Report, Third Global Forum on Human Resources for Health, Recife, Brazil. Geneva: Global Health Workforce Alliance and World Health Organization; 2013.

4. Rao K, Bhatnagar A, Berman P. India's health workforce: size, composition and distribution. In: La Forgia KR J, editor. India health beat. New Delhi: World Bank;New Delhi and Public Health Foundation of India; 2009.

5. Hurst SA. Eroding students' rural motivation: first do no harm? Swiss Med Wkly. 2014;144

6. Lambrou P, Kontodimopoulos ND. Motivation and job satisfaction among medical; and nursing staff in a Cyprus public general hospital. Hum Res Health. 2010; 8:26.

7. Kusurkar RA, Ten Cate TJ, Van Asperen M, Croiset G. Motivation as an independent and a dependent variable in medical education: a review of the literature. Med Teach. 2011;33(5):e242-62.

8. Puertas EB, Arosquipa C. Factors that influence a career choice in primary care among medical students from high-, middle-, and low-income countries: a systematic review. Rev PanamSalud Publica. 2013;34(5):351-8.

9. Brissette A, Howes D. Motivation in medical education: a systematic review. Web Med Central Med Educ. 2010;1(12):WMC001261.

10. The Sustainable Development Goals Report. Department of Economic and Social Affairs (DESA). New York: United Nations Publications; 2017.

11. Monitoring the building blocks of health systems: a handbook of indicators and their measurement strategies. Geneva: World Health Organization; 2010.

12. Egger M, Smith DG, Altman DG, ediors. Systematic reviews in health care: meta-analysis in context. 2nd ed. UK: BMJ Publishing Group;2008.

13. Goel S, Angeli F, Singla N, Ruwaard D. Development and validation of the motivations for selection of medical study (MSMS) questionnaire in India. PLoS One. 2016;11(12):e0164581.

14. Bank TW. The World bank. World bank country and lending groups [internet]. [cited 16 Jan 2017]. Available from: https://datahelpdesk.worldbank.org/knowledgebase/articles/906519-world-bankcountry-and-lending-groups.

15. Gyorffy Z, Birkas E, Sandor I. Career motivation and burnout among medical students in Hungary-could altruism be a protection factor? BMC Med Educ. 2016;16(1):182.

16. Kim KJ, Hwang JY, Kwon BS. Differences in medical students' academic interest and performance across career choice motivations. Int J Med Educ. 2016;7:52.

17. Gqsiorowski J, Rudowicz E, Safranow K. Motivation towards medical career choice and future career plans of polish medical students. Adv Heal Sci Educ. 2015;20(3):709-25.

18. Sulong S, McGrath D, Finucane P, Horgan M, O'Flynn S, O'Tuathaigh C. Studying medicine-a crosssectional questionnaire-based analysis of the motivational factors which influence graduate and undergraduate entrants in Ireland. JRSM open. 2014;5(4):2042533313510157. 
19. Wouters A, Bakker AH, van Wijk IJ, Croiset G, Kusurkar RA. A qualitative analysis of statements on motivation of applicants for medical school. BMC Med Educ. 2014;14(1):200.

20. Laurence CM, Zajac IT, Turnbull DA, Sumner KE, Fleming J. Applicants to the University of Adelaide medical school: influences, motivation and alternative career choices. Focus Heal Prof Educ A Multidisciplinary J. 2013;14(2):81.

21. Toso A, Ayala MJ, Brunner V, Rodriguez J, Hernandez MI, Urquidi C, et al. Interests and perspectives of first and last year medical students. Rev Med Chil. 2012;140(5):609-15.

22. Girasek E, Molnar R, Eke E, Szocska M. The medical career choice motivations-results from a Hungarian study. Open Med. 2011;6(4):502-9.

23. Kusurkar R, Kruitwagen C, ten Cate O, Croiset G. Effects of age, gender and educational background on strength of motivation for medical school. Adv Heal Sci Educ. 2010;15(3):303-13.

24. Amin Z, Tani M, Hoon Eng K, Samarasekara DD, Huak CY. Motivation, study habits, and expectations of medical students in Singapore. Med Teach. 2009;31(12):e560-9.

25. Wilson JI. A two factor model of performance approach goals in student motivation for starting medical school. Issues Educ Res. 2009;19(3):271-81.

26. Kim MK, Kang JO. Comparison of career choice motivation and moral reasoning ability between students in baccalaureate and graduate-entry programs. Korean J Med Educ. 2007;19(2):91-9.

27. Puljak L, Kraljevic JB, Latas VB, Sapunar D. Demographics and motives of medical school applicants in Croatia. Med Teach. 2007;29(8):e227-34.

28. McManus IC, Livingston G, Katona C. The attractions of medicine: the generic motivations of medical school applicants in relation to demography, personality and achievement. BMC Med Educ. 2006;6(1):11.

29. Becker JC, Burghaus D, Kappe K, Heue M, Liebelt A, Kindler Rohrborn BP A. No title. Dtsch Med Wochenschr. 2015;140(21):e207-16.

30. Kavousipour S, Noorafshan A, Pourahmad S, Dehghani-Nazhvani A. Achievement motivation level in students of Shiraz University of Medical Sciences and its influential factors. J Adv Med Educ Prof. 2015;3(1):26.

31. Korkmaz H, \$enol YY. The characteristics of medical students and motivation towards career choice: implications for curriculum. Hacettepe Universitesi Egitim Fakultesi Derg. 2013;28:28-1.

32. Pagnin D, De Queiroz V, De Oliveira Filho MA, Gonzalez NVA, Salgado AET, Oliveira BCE, et al. Burnout and career choice motivation in medical students. Med Teach. 2013;35(5):388-94.

33. Fevzi Dikici M, Yaris F, Topsever P, Muge Filiz T, Serdar Gurel F, Cubukcu M, et al. Factors affecting choice of specialty among first-year medical students of four universities in different regions ofTurkey. Croat Med J. 2008;49(3):415-20.

34. Kuriakose S, Revankar SKB, Viveka S, Shetty B, Rao CP. Why become a doctor? Evaluation of motivational factors for selecting medical profession as career. Engineer. 2015;16(14):30.

35. Diwan V, MinjC, Chhari N, De Costa A. Indian medical students in public and private sector medical schools: are motivations and career aspirations different?-studies from Madhya Pradesh, India. BMC Med Educ. 2013;13(1):127.

36. Seetharaman N, LogarajM. Why become a doctor? Exploring the career aspirations and apprehensions among interns in South India. Natl J Res Community Med. 2012;1(4):188-95.

37. Lal $\mathrm{P}$, Malhotra $\mathrm{C}$, Nath $\mathrm{A}$, Malhotra $\mathrm{R}$, Ingle GK. Career aspirations and apprehensions regarding medical education among first year medical students in Delhi. Indian J Community Med. 2007;32(3):217.

38. Maslow AH. Maslow's hierarchy of needs. Psychol Rev. 1943;50:370-96. 
39. Asperoni G. Motivation, teamwork and agile development. Agile Times.2004. Available at https://www.researchgate.net/publication/229037802_Motivation_teamwork_and_agile_development. Accessed 12 Jan 2018 


\section{Chapter 3

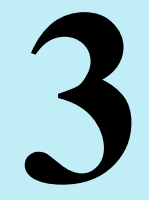

Development and Validation of the Motivations for Selection of Medical

Study (MSMS) Questionnaire in India.

Sonu Goel, Federica Angeli, Neetu Singla, Dirk Ruwaard

PLoS One 2016; 11(12):e0164581.

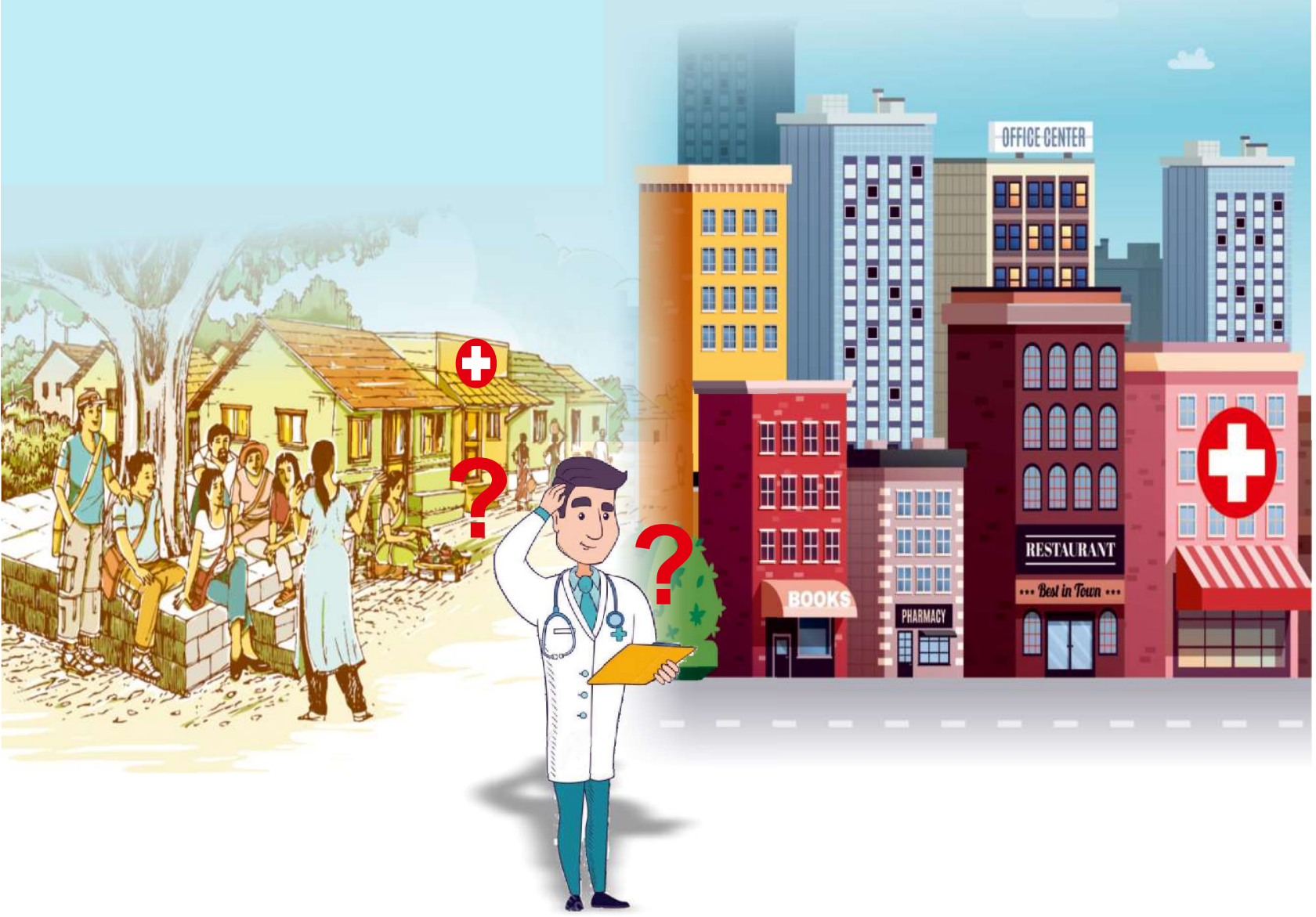




\begin{abstract}
Background and Objective: Understanding medical students' motivation to select medical studies is particularly salient to inform practice and policymaking in countries such as India where shortage of medical personnel poses crucial and chronicle challenges to healthcare systems. This study aims to develop and validate a questionnaire to assess the motivation of medical students to select medical studies.
\end{abstract}

Methods: A Motivation for Selection of Medical Study (MSMS) questionnaire was developed using extensive literature review followed by Delphi technique. The scale consisted of 12 items, 5measuring intrinsic dimensions of motivations and 7 measuring extrinsic dimensions. Exploratory factor analysis (EFA), confirmatory factor analysis (CFA), validity, reliability and data quality checks were conducted on a sample of 636 medical students from six medical colleges of three North Indian states.

Results: The MSMS questionnaire consisted of 3 factors (subscales) and 8 items. The three principal factors that emerged after EFA were the scientific factor (e.g. research opportunities and the ability to use new cutting edge technologies), the societal factor (e.g. job security) and the humanitarian factor (e.g. desire to help others). The CFA conducted showed goodness of-fit indices supporting the 3-factor model.

Conclusion: The three extracted factors cut across the traditional dichotomy between intrinsic and extrinsic motivation and uncover a novel three-faceted motivation construct based on scientific factors, societal expectations and humanitarian needs. This validated instrument can be used to evaluate the motivational factors of medical students to choose medical study in India and similar settings and constitutes a powerful tool for policymakers to design measureable to increase selection of medical curricula. 


\section{Introduction}

India is facing an acute shortage of medical practitioners in rural and regional areas, especially in North India [1,2]. The shortage has become more critical over the last two decades. The migration of physicians from developing to developed countries and intracountry disparities between urban and rural regions are argued as the main reasons [37].There have been considerable efforts from the Government of India to address these shortages through a wide range of programs and policies targeting medical students [8]. The 'High Level Expert Group for Universal Health Coverage' constituted by the Planning Commission has set the minimum doctor-to-population ratio to 1:1,000 [9]. Currently, India counts only 57 physicians for 100,000 people or 1 physician for over 1,700 people, indicating that more qualified medical professionals are needed [10]. For $70 \%$ of the Indian rural population, the patient-physician ratio is extremely low and amounts to a mere 1 physician for over 2,564 inhabitations [2]. The proposed ratio of 1:1,000 can be achieved only if more students will opt for medical study and remain in India to practice the profession. Although the Medical Council of India (MCI) reports educating 52,105 doctors each year [11], almost one third of them leave India for residency training and/or practice abroad [12].

Globally, the medical profession is one of the most reputed and highly paid professions. In the Indian context, medical professionals are highly respected and are associated with high social status. This cultural trait affects the students in the selection of the medical profession after post matriculation examination. Each individual has a different reason for choosing the medical field, although factors such as interest in the medical field, good job opportunities, desire to serve others, medical background of the parents and many more are commonly reported motivators [13]. In India the reasons for selecting the medical profession vary across people but also across geographic locations. Understanding the main motivational items that influence students to opt for medical studies is therefore complex. Motivation of students to enter medical study is an important issue because it affects the number of physicians graduating each year from medical schools and therefore the services they can ultimately provide within the national healthcare system.

Several studies have been conducted worldwide to determine the factors underpinning 
students' motivation to opt for medical study [14-32]. However, only very few of them have been performed in India [10,33,34,35]. These studies have focused on very limited items of motivation and in different Indian states. Understanding the motivating factors underpinning the choice for medical study in the Indian context is crucial to frame appropriate policies and organizational strategies to counteract the acute shortage of medical personnel and its sharply uneven distribution across urban and rural areas.

An array of questionnaires has been developed to identify the main reasons why medical students selected a medical study [36-41]. However, these tools have been constructed and validated in other countries, such as strength of motivation for medical school (SMMS) questionnaire by Kusurkar R. et al. [41] in the Netherlands; a scale to measure intrinsic and extrinsic motivators to study medicine by Agyei-Baffour et al. [13] in Ghana, Academic Motivation Scale (AMS) by Vallerand et al. [36,37,38] in Canada, and Maslach Burnout Inventory-Student Survey (MBI-SS) [39]. Applying these instruments in culturally different contexts, such as India, could lead to bias and unreliable findings $[13,36-41]$.

To the best of our knowledge, studies in India have either used scales validated in western settings or used non-validated instruments to measure medical student's motivation to select medical studies [13,36-41]. None of the studies has comprehensively studied the factors in Indian settings. This hinders the valid and robust measurement of students' motivations to select medical studies in India. There is hence a need for a valid and reliable tool to measure reasons that motivated medical students to choose medical study suited for use in India and perhaps other developing countries. To tackle this important gap, we decided to develop a valid and reliable instrument for measuring the choice of medical students to study Bachelor of Medicine, Bachelor of Surgery (MBBS) in Indian settings.

\section{Methods}

The study was ethically approved from the Institute's Ethical Committee, Post Graduate Institute of Medical Education and Research (PGIMER), Chandigarh (PGI/IEC/2012/810-1 P154). The permission from the Principals of all medical colleges 
was obtained prior to the study. The students provided written informed consent to participate in the study. All the students voluntarily participated in the study after being informed about the objectives of the study and assured about anonymity of the responses.

\section{Item generation}

Literature review- Because the socio-cultural peculiarities of the Indian context and the socio-cultural heterogeneity between Indian states could undermine the validity of prevalidated measurement tools, a structured questionnaire was developed for the purpose of this study (S1 File). The questionnaire was based on extensive literature search that was carried out with the purpose to identify the perceptions of medical students to enter in medical study. The search was carried out by two researchers independently in PubMed, IndMED, Directory of Open Access journals and Google scholar. Medical Subject Headings (MeSH) and free-text terms "motivation, motivator, motivate" AND "selection, choose" AND "medical students, interns, medical school, medical study" have been used. Search terms and keywords were altered as per specification of individual databases. In addition, a manual search of articles in journals held in the library of the PGIMER was done. Accordingly, thousands of articles were identified from various search engines. After removing duplication and screening of titles, abstracts and full text, 43 relevant articles on the subject were selected.

Questionnaire development- Delphi technique was used in the process. A Delphi technique is a practical approach to achieve a consensus among a group of experts. It is based on the assumption that group opinion has a greater validity than an individual opinion [42].

Two rounds of Delphi were conducted. In the first round, the initial versions of the questionnaire was presented to technical experts $(n=7)$, teachers of medical colleges $(n=10)$ and doctors $(\mathrm{n}=5)$ of clinical departments in health care facilities of Chandigarh city. Discussions were held on various dimensions of motivations to select a medical study. The first author then built consensus on the items to be included in motivations for selection of the medical study by students. The second round was held two weeks later. 
The first author shared the responses of various experts among themselves with the purpose of clarity of responses and for the finalization of questionnaire.

Pilot testing of questionnaire- The questionnaire was pretested on 20 students of a government medical college (not participating in the study). To examine whether field investigators correctly administered the questionnaire, five interviews were audio recorded. The principal investigator found no problem in administration of the instrument and found that questions were correctly interpreted by students. No item was deleted or modified. The structure of the questionnaire remained the same after this stage (i.e.12 items).

\section{Item reduction}

Data collection. Study site: Three North Indian states, namely Himachal Pradesh, Punjab and Haryana, were selected as study site. Two government medical colleges from each state were considered for data collection. The students in medical colleges were selected for admission by a common state medical entrance test. In India, medical education consists of 5 years of medical study followed by one year of clinical training (known as (internship') in a rural or urban hospital attached to medical college. The Medical Council of India (MCI) is the statutory regulatory and registration authority for medical education and practitioners in India.

The MCI has the authority to cancel the registration and recognition of any medical college in the country if the college does not comply with its guidelines.

Study population: The data collection was conducted during the period from November 2014 to January 2016 in six Government medical colleges (two from each state). The data was collected by two researchers who were trained in administering the questionnaire by the first author, which helped to standardize the administration of the instrument. All final year medical (MBBS) students of the college were invited to participate in the study, resulting in 636 participants. The sample size is appropriate for the study as most studies of questionnaire's validation in social sciences use 5 to 10 respondents per questionnaire item for factor analysis $[43,44]$. Students were asked to 
rate the items on a 5-point Likert scale where 1 represents "very unlikely to select", 2 represents "unlikely to select", 3 represents "not Sure", 4 represents "likely to select" and 5 represents "very likely to select". The questionnaire was handed out and collected after completion. To preserve the anonymity and confidentiality of participants, the participants were asked to place the filled questionnaire in a sealed box.

Content validity. A content validity index, as proposed by Lynn [45], was defined by an independent group of experts (different from the original panel included in the Delphi study). The expert group was asked to assess the content of each item generated on a five-point Likert scale. The assessment was based on the appropriateness, comprehensibility and clarity of phrasing of each item.

Data quality. Data quality was assessed by checking the percentage of missing data, extent of ceiling and floor effects and corrected item-to-total correlation. The ceiling and floor effects usually happen when the score for an item in the scale are rated very high and low by respondents respectively. Corrected item-to- is the correlation between each item and the total score from the questionnaire and all the items should correlate with the total for a reliable scale.

Items were eliminated if: the missing response rate of an item was more than $10 \%$; the floor and ceiling effect of an item was between $1 \%$ and $15 \%$; and items had a correlation of less than 30 with the total scale score (corrected item-to-total correlation) [46].

Validation and reliability. The main outcome of interest was the validation of MSMS scale and extraction of relevant motivation factors for MBBS students to select medical study. Students were identified as having strong intrinsic motivation if two or more of their motivational items (out of 5) were strongly intrinsic (i.e. they responded as 4 or 5 on 5 point Likert scale) and having strong extrinsic motivation if two or more of their motivational items (out of 7) were strongly extrinsic [13]. Summary statistics for sociodemographic variables as well as for the list of twelve items were calculated.

In the context of construct validity, exploratory factor analysis (EFA) with varimax rotation was applied on the MSMS list of items to group items with similar characteristics 
together (extraction of factor structure), which further gives a small list of factors/ subscales capable of explaining most of the variance. Kaiser-Meyer-Olkin (KMO) test was used to check sampling adequacy which should be greater than 0.5 for a satisfactory factor analysis to proceed [47]. Bartlett's test was applied to check the strength of the relationship among items. The criterion of eigen value or characteristic root (Eigenvalue) $>1$ was used for defining the number of the factors that were kept [48-50]. Scree plot, a graphic representation of eigen values, suggests the number of the essential factors to be retained. After the rotation each item was loaded in one or another factor. Items with factor loading greater than 0.4 were retained [50]. Cronbach's alpha for internal consistency was determined for establishing the reliability of the subscales. Convergent and discriminant validity was checked using Spearman correlation. The value of a correlation coefficient of greater than 0.40 between an item and its own scale is regarded as an adequate evidence of convergent validity. Discriminant validity is supported whenever a correlation between an item and its hypothesized scale is higher than its correlation with the other scales. A scaling success is counted if the item to own-scale correlation is significantly higher than the correlations of the item to other scale [51].

EFA was followed by Confirmatory factor analysis (CFA) for validating the underlying structure of MSMS scale on prior empirical and theoretical grounds. CFA is a particular case of structural equation modeling (SEM) which consists of collecting data in order to confirm that a factor is defined according to the theoretical approach the researcher uses as a starting point. Then, the model will serve to represent, in a reasonably good way, how the observed variables are interconnected [52]. We calculated goodness of fit of CFA model using widely accepted indices: root mean square error of approximation (RMSEA), comparative fit index (CFI) and GFI (Goodness-of-fit index). The cut off values of acceptable model fit cited by Leach et al. [53] are CFI and GFI values greater than .93 and RMSEA below .08. Data was entered and analyzed using Statistical Package for Social Sciences version- 16 (SPSS IBM, New York, NY, USA). To ensure accuracy of data, double data entry was done. SPSS/Amos 22 software was used for CFA. 
The steps for the development and validation of the questionnaire are shown in Fig 1.

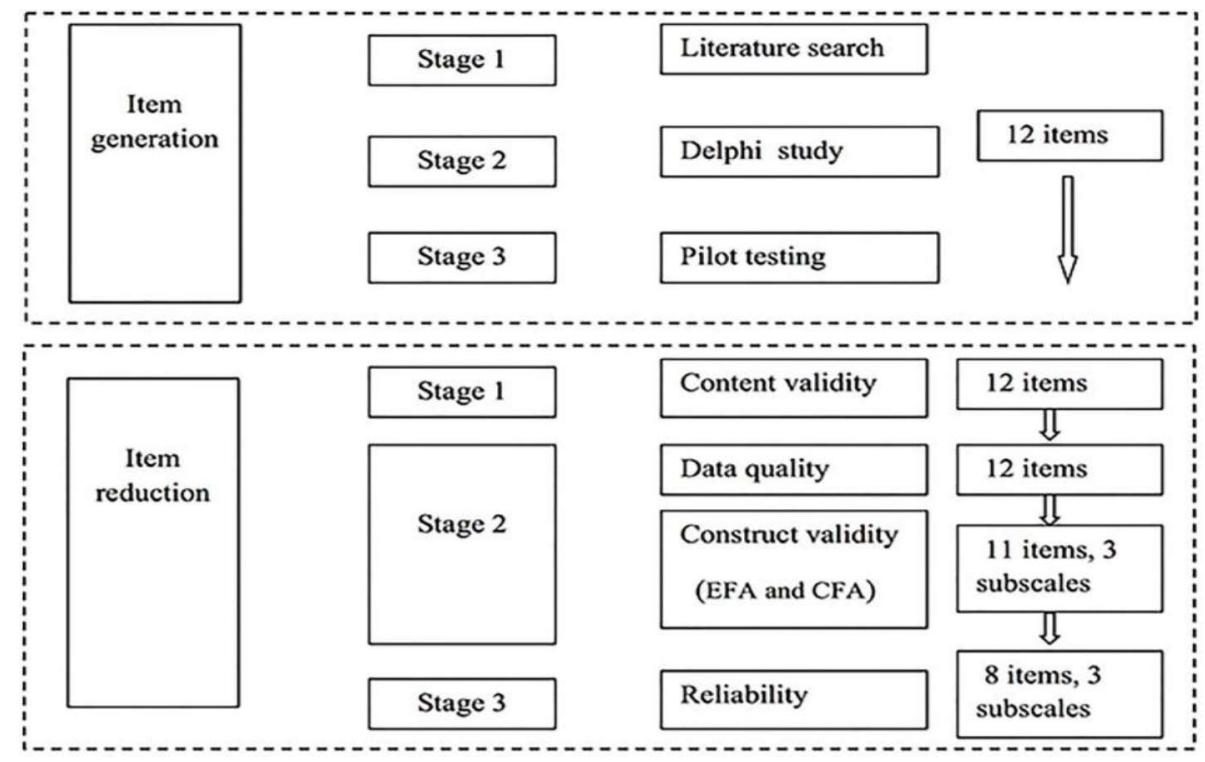

Figure 1- Steps for development and validation of MSMS.

\section{Results}

\section{Item generation}

Based on the literature review, a framework on various dimensions of motivation to select medical study by medical students was developed, resulting in a 12-item scale named the Motivations for Selection of Medical Study (MSMS) scale. During the two rounds of Delphi, the experts revisited their responses along with responses of other experts involved in the process, refined wording and content of questions to reach a consensus.

In pilot testing, no potential problems were found in the administration of the instrument by the field investigators. The structure of the questionnaire remained the same after this stage (i.e. twelve items). The questionnaire was divided into two parts: Part 1 was meant to assess the socio-demographic profile of the medical students while Part 2 investigated the items/reasons why they choose a medical study. Part 2 included a total of twelve items: five intrinsic items (desire to help others, desire to give back to your community 
or country, interest in medicine as a subject matter, inspiration by a role model and loss of loved ones) and seven extrinsic items (income of physician, job security and lifestyle, social status/prestige, proposed by parents, opportunities to travel and work internationally, ability to use new cutting edge technologies and research opportunities) for selection of a medical study.

\section{Item reduction}

Results on study settings. Demographics: The total sample consisted of $636 \mathrm{MBBS}$ final year students (response rate $=100 \%$ ) of both genders. Out of 636, a total of 297 (44.7\%) were male with mean age 22.4 years (SD 2.03) and 339 (53.3\%) were females with mean age 22.1 years (SD 1.53). A total of 405 (63.7\%) students were born in rural areas and the majority of the students $(80.8 \%)$ studied in urban areas before MBBS. The socio-demographic characteristics are presented in Table 1.

Table 1: Demographic characteristics of medical students

\begin{tabular}{|l|l|l|}
\hline Characteristics & & Frequency (\%) \\
\hline \multirow{4}{*}{ Age-group } & $19-24$ & $521(81.9)$ \\
\cline { 2 - 3 } & $24-29$ & $111(17.5)$ \\
\cline { 2 - 3 } & $>29$ & $4(0.6)$ \\
\hline \multirow{4}{*}{ Caste } & Male & $297(46.7)$ \\
\cline { 2 - 3 } & Female & $339(53.3)$ \\
\hline \multirow{5}{*}{ Religion } & General & $467(73.4)$ \\
\cline { 2 - 3 } & Others (SC/ST/OBC/ others) & $169(26.6)$ \\
\hline \multirow{5}{*}{ Marital status } & Hindu & $518(81.4)$ \\
\cline { 2 - 3 } & Others(Christian, Sikh, & $118(18.6)$ \\
& Muslim, Jain and Buddhism) & \\
\hline \multirow{3}{*}{ Residential status } & Married & $12(1.9)$ \\
\cline { 2 - 3 } & Unmarried & $622(97.8)$ \\
\cline { 2 - 3 } & Others & $2(0.3)$ \\
\hline Birth location & Living alone & $389(61.2)$ \\
\cline { 2 - 3 } & Living with family & $247(38.8)$ \\
\hline \multirow{3}{*}{ Family background } & Urban & $405(63.7)$ \\
\cline { 2 - 3 } & Rural & $231(36.3)$ \\
\hline \multirow{2}{*}{\begin{tabular}{l} 
Location of premedical \\
\hline
\end{tabular}} & Urban & $377(59.3)$ \\
\cline { 2 - 3 } & Rural & $259(40.7)$ \\
\cline { 2 - 3 } & Urban & $121(19.0)$ \\
\hline
\end{tabular}


Content validity and data quality. No item was deleted after the expert group review (Delphi technique). The content validity index of the item scale (12 items and 3 factors) was 0.75 which was acceptable according to conventional criteria [46]. As the researchers were available during the process of filling out the questionnaire missing data was very negligible. No floor or ceiling effects were observed.

Construct validity and reliability. Exploratory factor analysis (EFA) was carried out with varimax rotation. KMO measure scores 0.690, which indicates that the sample is adequate for factor analysis [54]. Bartlett's test of sphericity rejected null hypothesis at 0.05 level of significance (Bartlett's test significance $<0.05$ ) and ensures the relevance of factor analysis. Three factors (subscales) reporting eigenvalue _ 1 emerged, which together explained $51.53 \%$ of the total variance in the MSMS scale. Table 2 depicts the three factors with corresponding loadings of items.

Table 2: Loadings of items from the MSMS questionnaire on the three main factors

\begin{tabular}{|l|c|r|r|}
\hline & Factor 1 & Factor 2 & Factor 3 \\
\hline $\begin{array}{l}\text { Ability to use new cutting edge } \\
\text { technologies }\end{array}$ & $\mathbf{. 8 4 5}$ & .112 & .147 \\
\hline $\begin{array}{l}\text { Opportunities to travel and work } \\
\text { internationally }\end{array}$ & $\mathbf{. 7 6 5}$ & .237 & .033 \\
\hline Research opportunities & $\mathbf{. 7 6 4}$ & -.073 & .211 \\
\hline Loss of loved one & $\mathbf{. 4 3 0}$ & .050 & -.168 \\
\hline Inspiration by a role model & .311 & .164 & .224 \\
\hline Job security & -.015 & $\mathbf{. 8 1 7}$ & .010 \\
\hline Social status & -.050 & $\mathbf{. 7 5 7}$ & .202 \\
\hline High income & .298 & $\mathbf{. 6 6 6}$ & -.201 \\
\hline Proposed by parents & .205 & $\mathbf{. 4 5 2}$ & .039 \\
\hline Desire to help others & -.062 & .025 & $\mathbf{. 8 2 9}$ \\
\hline Desire to give back to community & .066 & .056 & $\mathbf{. 7 5 9}$ \\
\hline Interest in medicine as a subject & .144 & -.007 & $\mathbf{. 6 0 8}$ \\
\hline
\end{tabular}

The three factors emerged out in our study were labeled as:

1. Scientific factor of motivation (Factor 1) 


\section{Societal factor of motivation (Factor 2)}

\section{Humanitarian factor of motivation (Factor 3)}

Factors explanation: Factor 1: Scientific factor of motivation. This factor measures the scientific reasons that motivate medical students to select medical study. It explains $23.73 \%$ of the total variance in the MSMS scale. Ability to use new cutting edge technologies, opportunities to travel and work internationally, research opportunities and loss of a loved one are four items substantially loading on this factor. Internal consistency of this subscale was checked by Cron-bach's alpha (Table 3) which was 0.699 , but increases to .783 by dropping item loss of a loved one. So this item was eliminated and the final sub-scale is formed by three items.

Table 3: Cronbach's alpha coefficient, convergent and discriminant validity for three subscales

\begin{tabular}{|l|c|c|c|c|c|c|c|}
\hline Factor & $\begin{array}{c}\text { No of } \\
\text { Items }\end{array}$ & $\begin{array}{l}\text { Mean } \pm \\
\text { SD }\end{array}$ & Alpha & \multicolumn{2}{|c|}{ Convergent validity } & \multicolumn{2}{|c|}{ Discriminant validity } \\
\hline & & & & $\begin{array}{c}\text { Range of } \\
\text { correlation }\end{array}$ & $\begin{array}{c}\text { Scaling } \\
\text { success }\end{array}$ & $\begin{array}{c}\text { Range of } \\
\text { correlation }\end{array}$ & $\begin{array}{c}\text { Scaling } \\
\text { success }\end{array}$ \\
\hline Scientific & 3 & $\begin{array}{c}3.223 \pm \\
1.366\end{array}$ & 0.783 & $0.563-0.735$ & $03-M a r$ & $0.072-0.280$ & $06-J u n$ \\
\hline Societal & 3 & $\begin{array}{c}3.653 \pm \\
1.232\end{array}$ & 0.66 & $0.436-0.555$ & $03-\mathrm{Mar}$ & $0.054-0.294$ & $06-\mathrm{Jun}$ \\
\hline Humanitarian & 2 & $\begin{array}{c}4.062 \pm \\
0.859\end{array}$ & 0.699 & 0.542 & $02-\mathrm{Feb}$ & $0.054-0.294$ & $04-\mathrm{Apr}$ \\
\hline
\end{tabular}

Factor 2: Societal factor of motivation. This factor explains the social variables that motivate medical students to select medical study. It explained $14.96 \%$ of the total variance in the MSMS scale. Four items job security, social status/prestige, high income and proposed by parents has been loaded on factor 2. Internal consistency of this factor 2 was checked (Cronbach's alpha $=0.613$ increases to 0.660 by dropping item proposed by parents). This item was eliminated so the final sub-scale contains three items.

Factor 3: Humanitarian factor of motivation. Desire to help others, desire to give back to their home community or country and interest in medicine as a subject matter has been loaded onfactor 3. Internal consistency of this factor 3 was checked (Table 3). By dropping item interest in medicine as a subject matter, Cronbach's alpha increased from 
0.599 to 0.699 . Because this item was eliminated, the final sub-scale contains two items. Factor 3 is named as "humanitarian factor of motivation" and explained $13.04 \%$ of the total variance.

No item cross-loaded on more than one subscale with loading greater than .40. The Cronbach's alpha coefficient, convergent and discriminant validity for three subscales are shown in Table 3. The frequencies of responses for various items had been reported in Table 4.

Table 4: Category frequencies for each item under three subscales.

\begin{tabular}{|l|c|c|c|c|c|}
\hline Factors & \multicolumn{5}{|c|}{ Category frequency } \\
\hline & $\mathbf{1}$ & $\mathbf{2}$ & $\mathbf{3}$ & $\mathbf{4}$ & $\mathbf{5}$ \\
\hline Scientific & & & & & \\
\hline Opportunities to travel and work internationally & 148 & 82 & 144 & 137 & 125 \\
\hline Ability to use new cutting-edge technologies & 98 & 76 & 149 & 189 & 124 \\
\hline Research opportunities & 87 & 68 & 129 & 211 & 141 \\
\hline Societal & & & & & \\
\hline Job security & 49 & 38 & 79 & 313 & 157 \\
\hline Social status & 31 & 31 & 50 & 290 & 234 \\
\hline High income & 113 & 96 & 111 & 220 & 96 \\
\hline Humanitarian & & & & & \\
\hline Desire to help others & 14 & 7 & 52 & 350 & 213 \\
\hline Desire to give back to community & 17 & 26 & 95 & 326 & 172 \\
\hline
\end{tabular}

CFA was conducted on the factors (subscales) obtained in EFA. The CFA measurement model is presented in Figure 2. Per conventional path diagram notation, the latent variables are depicted by circles and indicators by squares or rectangles. CFA goodness of fit indices obtained are $\mathrm{CFI}=.925, \mathrm{GFI}=.959$, and $\mathrm{RMSEA}=.081$ which suggested an acceptable model fit. 


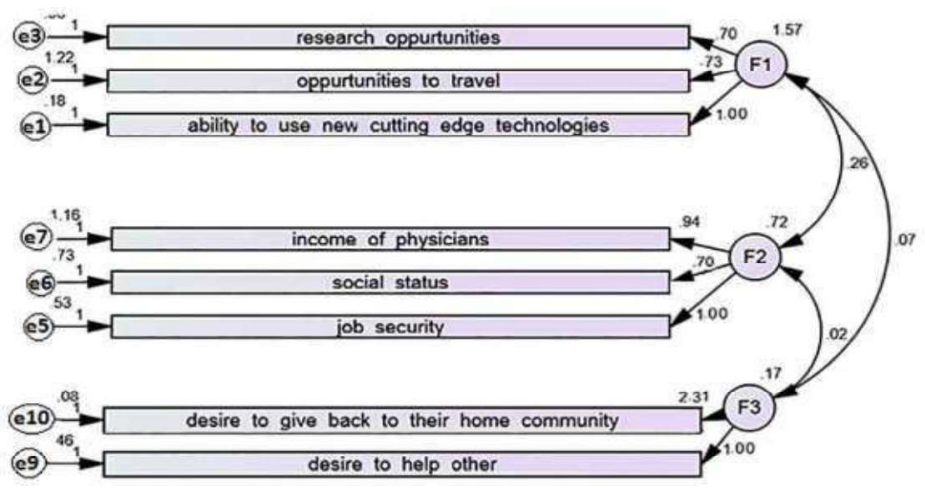

Figure 2- Measurement model obtained in Confirmatory factor analysis for MSMS scale

\section{Discussion}

In the current study, we developed a MSMS questionnaire for measuring reasons of motivation to select medical study by medical students in North India. Scientific factor, which consider the interest in medicine as a scientific field; societal factors, which points towards the societal expectations and pressures; and humanitarian factors, which takes into account the intrinsic need to serve the poor and the needy emerged out as three major dimensions to measure the motives behind student's choice of medicine. These dimensions, however, cut across the traditional dichotomy between intrinsic and extrinsic motivation and highlight instead a novel distinction. These dimensions have never been consolidated into a single comprehensive tool in earlier studies. These three subscales with an 8 item scale is a valid and reliable tool and therefore could be used to study the intentions of medical students to join medicine in India and other similar settings.

Various countries or regions have developed a variety of instruments to measure reasons of motivation to select medical study, however, they either were not standardized or focused on different goals and populations. For example, Agyei-Baffour [13] used a questionnaire on medical students of Ghana to assess the role of intrinsic and extrinsic motivation on their willingness to work in rural areas, rather than measuring motivational factors to join medical study. Further, the scale was not validated and categorization into broad heads of scientific, societal and humanitarian factors was not done. Some other tools such as the Academic Motivation Scale (AMS) by Vallerand et al. [36,37,38], Maslach Burnout Inventory-Student Survey (MBI-SS) containing Exhaustion scale [39] 
and Strength of Motivation for Medical School (SMMS) questionnaire [40,41] for evaluation of strength of motivation of students for medical study exist in literature but all of them have been validated in western countries and due to cultural differences these are difficult to apply in developing countries like India.

There is very limited literature on the factors underpinning medical students' choice for medical study. The self-determination theory postulates that the factors for motivation are dichotomized into intrinsic and extrinsic, which can interchange depending on various factors. With regards to intrinsic motivation, some studies [10,13,31,33,54] report that 'serving their country' and 'serving humanity' are amongst the strongest reasons for choosing medical study. In contrast, a study conducted in Ahmedabad, India reported that only $8 \%$ of students wanted to serve the poor and the main intrinsic motivator to select medical study that emerged out in this study was interest in medicine [34]. With regard to extrinsic motivation, few studies [55-59] reported that prestige, money, and personal development are important factors in career decision-making among medical students. A study by Shahab et al. [31] in Pakistan reported that medical students choose medicine because their parents wanted them to be doctors and because of their interest in medicine. A study conducted by Greenhalgh et al. [60] in UK highlighted that students belonging to higher socioeconomic status had more intrinsic motivation for seeking admission to medical college. In contrast, the students from lower socioeconomic class focused more on extrinsic rewards and higher expected income on becoming a doctor. In the present study, the three factors of motivation viz. scientific factors, societal expectations and humanitarian needs were extracted, thus offering a new perspective that goes beyond the traditional distinction between intrinsic and extrinsic motivators.

\section{Limitations}

The conclusion of this study should be seen in light of a few design limitations. Our sample consists of students from medical colleges of three states of the country of India which may not necessarily represent the entire medical student population of the country. Moreover most of the students are Hindu, unmarried and younger (lying in range 20 to 23 years), thus representing the outcomes for this particular group. But these results can 
be generalized because in India, the majority of the population belongs to the Hindu community. Further, all the motivation items were equally weighted and some might have not been included in the questionnaire, despite best efforts of the researchers through extensive literature review and adopting group consensus methods.

While generalizing the results of this study, it should be taken into account that our study does not provide in-depth understanding for low motivation of MBBS students. Hence, it is recommended that further exploratory, mixed method studies, with focus group discussions or interviews, should be done to collect in-depth information for exploring the reasons of varying levels of motivation among medical students.

Considering huge shortage of doctors especially in rural areas, a further research is also needed to be carried out amongst high school students to extract the factors that motivate or de-motivate them to choose medical study. Further, it needs to be explored that out of those who completed their medical study, what proportion of them wish to stay in India and to work in rural areas. The need for such study is especially important in current scenario where there is dearth of students opting medical study resulting in shortage of physicians in India.

\section{Conclusions}

To the best of our knowledge, this is the first instrument for measuring the motivation to choose medicine by medical students that has been developed and validated in India. The study also proposes a more salient motivational taxonomy that cuts across traditional distinction between intrinsic and extrinsic factors, and that takes into account the scientific appeal of medical study, the social pressures and expectations of family and friends, and the humanitarian drive, specifically to give back to their own community. The relevant recommendations can be made for practical guidance to policy-makers on how to design, implement and evaluate policy to motivate students to choose medical study. This will in turn strengthens the existing capacity of health care systems. We propose that this instrument should be applied in other populations of developing countries with shortages of medical doctors in rural areas to undertake context specific policy measures. 


\section{References}

1. Hazarika I. Health workforce in India: assessment of availability, production and distribution. WHO South East Asia Journal of Public Health. 2013; 2:106-112.

2. Rao M, Rao KD, Kumar AK, Chatterjee M, Sundararaman T. Human resources for health in India. Lancet. 2011; 377: 587-598. doi:10.1016/S0140-6736(10)61888-0PMID:21227499

3. Astor A, Akhtar T, Matallana MA, Muthuswamy V, Olowu FA, Tallo V et al. Physician migration: Views from professionals in Colombia, Nigeria, India, Pakistan and the Philippines. Social Science \& Medicine. 2005; 61:2492-2500.

4. Syed NA, Khimani F, Andrades M, Ali SK, Paul R. Reasons for migration among medical students from Karachi. Medical Education. 2008; 42: 61-68. doi:10.1111/j.1365-2923.2007.02904.xPMID:18042189

5. Gadit AAM. Migration of Doctors: Should we apply the Index of Happiness? J Pak Med Assoc. 2008;58: 342-344. PMID:18988399

6. Vujicic M, Zurn P, Diallo K, Adams O, Dal Poz MR. The role of wages in the migration of health care professionals from developing countries. Human Resources for Health. 2004; 2: 3. doi:10.1186/14784491-2-3PMID:15115549

7. Jenkins R, Kydd R, Mullen P, Thomson K, Sculley J, Kuper S, et al. (2010) International Migration of Doctors, and Its Impact on Availability of Psychiatrists in Low and Middle Income Countries. PLoS ONE 5(2): e9049. doi:10.1371/journal.pone.0009049PMID:20140216

8. Talati JJ, Pappas G. Migration, Medical Education, and HealthCare: A View from Pakistan. Academic Medicine. 2006; 81 Suppl 12:55-62.

9. High Level Expert Group Report on Universal Health Coverage for India Planning Commission of India New Delhi, November, 2011.http://planningcommission.nic.in/reports/genrep/rep uhc0812.pdf. Accessed 7th April 2015.

10. Kuriakose S, Revankar SKB, Viveka S, Shetty B, Rao CP. Why become a Doctor? Evaluation of Motivational factors for selecting medical profession as career. Journal of Evidence based Medicine and Healthcare. 2015; 2: 206-211.

11. Medical Council of India.http://www.mciindia.org. Accessed 7th April 2015.

12. Aggarwal S, Rai A, Bath KS, Singh H, Sharma V. Migratory Trends of Medical Graduates in India.Journal of Pioneering Medical Sciences.2014; 4:155-158.

13. Agyei-Baffour P, Kotha SR, Johnson JC, Gyakobo M, Asabir K, Kwansah J et al. Willingness to work in rural areas and the role of intrinsic versus extrinsic professional motivations- a survey of medicalstudents in Ghana. BMC Medical Education.2011; 11:56-64. doi:10.1186/1472-6920-11-56PMID: 21827698

14. McManus IC, Livingstone G, Katona C. The attractions of medicine: The generic motivations of medical school applicants in relation to demography, personality and achievement. BMC Medical Education.2006; 6: 11. doi:10.1186/1472-6920-6-11PMID:16504048

15. Millan LR, Azevedo SR, Rossi E, de Marco OL, Millan MP, de Arruda PC. What is behind a student's choice for becoming a doctor? Clinics. 2005; 60:143-150. doi: /S1807-59322005000200011PMID: 15880251 
16. Baboolal NS, Hutchinson GA. Factors affecting future choice of specialty among first-year medical students of the University of the West Indies, Trinidad. Medical Education.2007; 41:50-56. doi:10.1111/j.1365-2929.2006.02646.XPMID:17209892

17. Draper C, Louw G. What is medicine and what is a doctor? Medical students' perceptions and expectations of their academic and professional career. Medical Teacher. 2007; 29:100-107.

18. Vahid DM, Mahdian M, Vahid DE, Namdari M. Study motives and career choices of iranian medical and dental students. ActaMedica Iranica.2012; 50: 417-424.

19. de Vries E, Irlam J, Couper I, Kornik S. Career plans of final year medical students in South Africa.South African Medical Journal. 2010; 100: 227-228. PMID:20459968

20. Aasland OG, R0vik JO, Wiers-Jenssen J. Motives for choice of specialty during and after medical school. Tidsskrift for den Norske Laegeforening. 2008; 128:1833-1837. PMID:18787594

21. Avgerinos ED, Msaouel P, Koussidis GA, Keramaris NC, Bessas Z, Gourgoulianis K. Greek medical students' career choices indicate strong tendency towards specialization and training abroad. Health Policy. 2006; 79:101-106. doi:10.1016/j.healthpol.2005.12.007PMID:16413630

22. Amin Z, Tani M, Eng KH, Samarasekara D, Huak CY. Motivation, study habits and expectations of medical students in Singapore. Medical Teacher. 2009; 31: 560-569.

23. Crossley ML, Mubarik A. A comparative investigation of dental and medical students towards career choice. British Dental Journal. 2002; 193: 471-473. PMID:12516673

24. Diderichsen S, Andersson J, Johansson E, Verdonk P, Lagro-Janssen A, Hamberg K. Swedish medical students' expectations of their future life. International Journal of Medical Education. 2011; 2:140-146.

25. Drinkwater J, Tully MP, Dornan T. The effect of gender on medical students' aspirations: A qualitative study. Medical Education. 2008; 42: 420-426. doi:10.1111/j.1365-2923.2008.03031.xPMID: 18338995

26. Puljak L, Kraljevic JB, Latas VB, Sapunar D. Demographics and motives of medical school applicants in Croatia. Medical Teacher. 2007; 29: 227-234.

27. Al-Fouzan R, Al-Ajlan S, Marwan Y, Al-Saleh M. Factors affecting future specialty choice among medical students in Kuwait. Medical Education Online.2012; 17:1-7.

28. Ferrinho P, Sidat M, Fresta MJ, Rodrigues A, Fronteira I, da Silva F, et al. The training and professional expectations of medical students in Angola, Guinea-Bissau and Mozambique. Human Resources for Health. 2011; 9: 9. doi:10.1186/1478-4491-9-9PMID:21473778

29. Heiligers PJM. Gender differences in medical students' motives and career choice. BMC Medical Education.2012; 12: 82. doi:10.1186/1472-6920-12-82PMID:22913471

30. Mandeville KL, Bartley T, Mipando M. Future career plans of Malavian medical students: A cross-sectional study. Human Resources for Health. 2012; 10: 29. doi:10.1186/1478-4491-10-29PMID: 22971119

31. Shahab F, Hussain H, Inayat A and Shahab A. Attitudes of medical students towards their career perspective from Khyber-Pukhtunkhwa. J. Pak. Med. Ass. 2011; 61: 832-836.

32. Bodger O, Byrne A, Evans PA, Rees S, Jones G, Cowell C, et al. (2011) Graduate Entry Medicine: Selection Criteria and Student Performance. PLoS ONE 6(11): e27161. doi:10.1371/journal.pone. 0027161PMID:22132089 
33. Lal P, Malhotra C, Nath A, Malhotra R, Ingle GK. Career aspirations and apprehensions regarding medical education among first year medical students in Delhi. Indian J Community Med. 2007; 32:217-218.

34. Shah S. Why students want to join MBBS? www.medicalacademy.com. accessed 9thApril 2015.

35. Diwan V, Minj C, Chhari N, De Costa A. Indian medical students in public and private sector medical schools: are motivations and career aspirations different?-studies from Madhya Pradesh, India. BMC Medical Education; 2013 13:127. doi:10.1186/1472-6920-13-127PMID:24034988

36. Vallerand RJ, Blais MR, Brie 're NM, Pelletier LG. Construction et validation de l' $\mathrm{E}^{0}$ chelle de Motivation en Education (EME). Revue canadienne des sciences du comportement. 1989; 21:323-349.

37. Vallerand RJ, Pelletier LG, Blais MR, Briere NM, Senecal C, Vallieres EF. The Academic Motivation Scale: A measure of intrinsic, extrinsic and amotivation in education. Educational and Psychological Measurement. 1992; 52: 1003 \pm 1017 .

38. Vallerand RJ, Pelletier LG, Blais MR, Briere NM, Senecal C, Vallieres EF. On the assessment of intrinsic, extrinsic and amotivation in education: Evidence of concurrent and construct validity of the Academic Motivation Scale. Educational and Psychological Measurement. 1993; 53, $159 \pm 172$.

39. Schaufeli WB, Martinez IM, Pinto AM, Salanova M, Bakker AB. Burnout and engagement in university students: A cross-national study. Journal of Cross-Cultural Psychology. 2002; 33(5): 464 \pm 481 .

40. Nieuwhof MGH, Ten Cate TJ, Oosterveld P, Soethout MBM. Measuring strength of motivation for medical school. Medical Education Online. 2004; 9: 16.

41. Kusurkar R, Croiset G, Kruitwagen C, ten Cate O. Validity evidence for the measurement of the strength of motivation for medical school. Adv in Health Sci Educ. 2011; 16:183 \pm 195 .

42. The Delphi technique: making sense of consensus. http://pareonline.net/pdf/v12n10.pdf. accessed 25thApril 2015.

43. MacCallum RC, Widaman KF, Zhang S, Hong S. Sample size in factor analysis. Psychological Methods.1999; 4(1): 84 \pm 99

44. Heritage B, Pollock C and Roberts L. Validation of the Organizastional Culture Assessment Instrument. PLoS ONE 2014; 3: e92879.

45. Lynn MR. Determination and quantification of content validity. Nurs Res 1986; 35: 382 \pm 385 . PMID:3640358

46. Terwee CB, Bot SD, de Boer MR, van der Windt DA, Knol DL, Dekker J et al.Quality criteria were proposed for measurement properties of health status questionnaires. J ClinEpidemiol 2007; 60: $34 \pm 42$.

47. Kaiser HF. An index of factorial simplicity. Psychometrika.1974; 39: 31 \pm 36 .

48. Kaiser HF. The application of electronic computers to factors analysis. Educational and Psychological Measurement.1960; 20: 141 \pm 151 .

49. Sharma S. Applied Multivariate Techniques. USA: John Willey \& Sons, Inc.1996.

50. Hair J, Anderson R, Tatham R, Black W. Multivariate Data Analysis with Readings, USA: Prentice-Hall International, Inc.1995. pp.373.

51. Fayers PM, Machin D: Quality of life: The assessment, analysis and interpretation of patient-reported outcomes. 2nd edition. Chichester: John Wiley; 2007. 
52. Schumacker RE, Lomax RG. A beginner's guide to structural equation modeling. New Jersey: Lawrence Erlbaum Associates. 1996.

53. Leach C., van Zomeren M., Zebel S., Vliek M., Pennekamp S., Doosje B., Ouwerkerk J., Spears R. (2008). Self-definition and self-investment: A multi component model of in-group identification. Journal of Personality and Social Psychology, 95, 144 \pm 165 . doi: 10.1037/0022-3514.95.1.144 PMID:18605857

54. Kusurkar RA, Ten Cate TJ, van Asperen M, Croiset G. Motivation as an independent and a dependent variable in medical education: a review of the literature. Med Teach. 2011; 33:242 \pm 262 .

55. Baharvand M, Moghaddam EJ, Pouretemad H, Alavi K. Attitudes of Iranian dental students toward their future careers: an exploratory study. J Dent Educ. 2011; 75: 1489 1495. PMID: 22058399

56. Dikici MF, Yaris F, Topsever P, Filiz TM, Gurel FS, Cubukcu M, Gorpelioglu S. Factors Affecting Choice of Specialty Among First-year Medical Students of Four Universities in Different Regions of

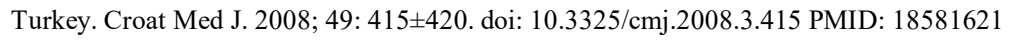

57. Razali SM. Medical school entrance and career plans of Malaysian medical students. Med Educ. 1996;30: 418 \pm 423 . PMID: 9217903

58. Harth SC, Biggs JS, Thong YH. Mature-age entrants to medical school: A controlled study of socio demographic characteristics, career choice and job satisfaction. Med Educ. 1990; 24: 488 \pm 498 . PMID: 2266885

59. Perara KM, Dharamarajan AM, Chandrika P. Career decisions and motivational influences among medical students: A view from Sri Lanka. Indian J Med Educ. 1981; 20:68 73 .

60. Greenhalgh T, Seyan K, Boynton P. Not a university type: focus group study of social class, ethics and

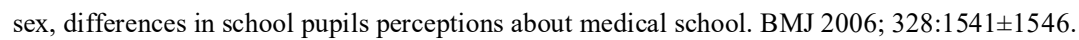




\section{Chapter 4}

Retaining health workforce in rural and underserved areas of India: What works and what doesn't? A critical interpretative synthesis.

Sonu Goel, Federica Angeli, Nidhi Bhatnagar, Neetu Singla, Manoj Grover, Hans Maarse

National Medical Journal of India 2016; 29(4):212-18

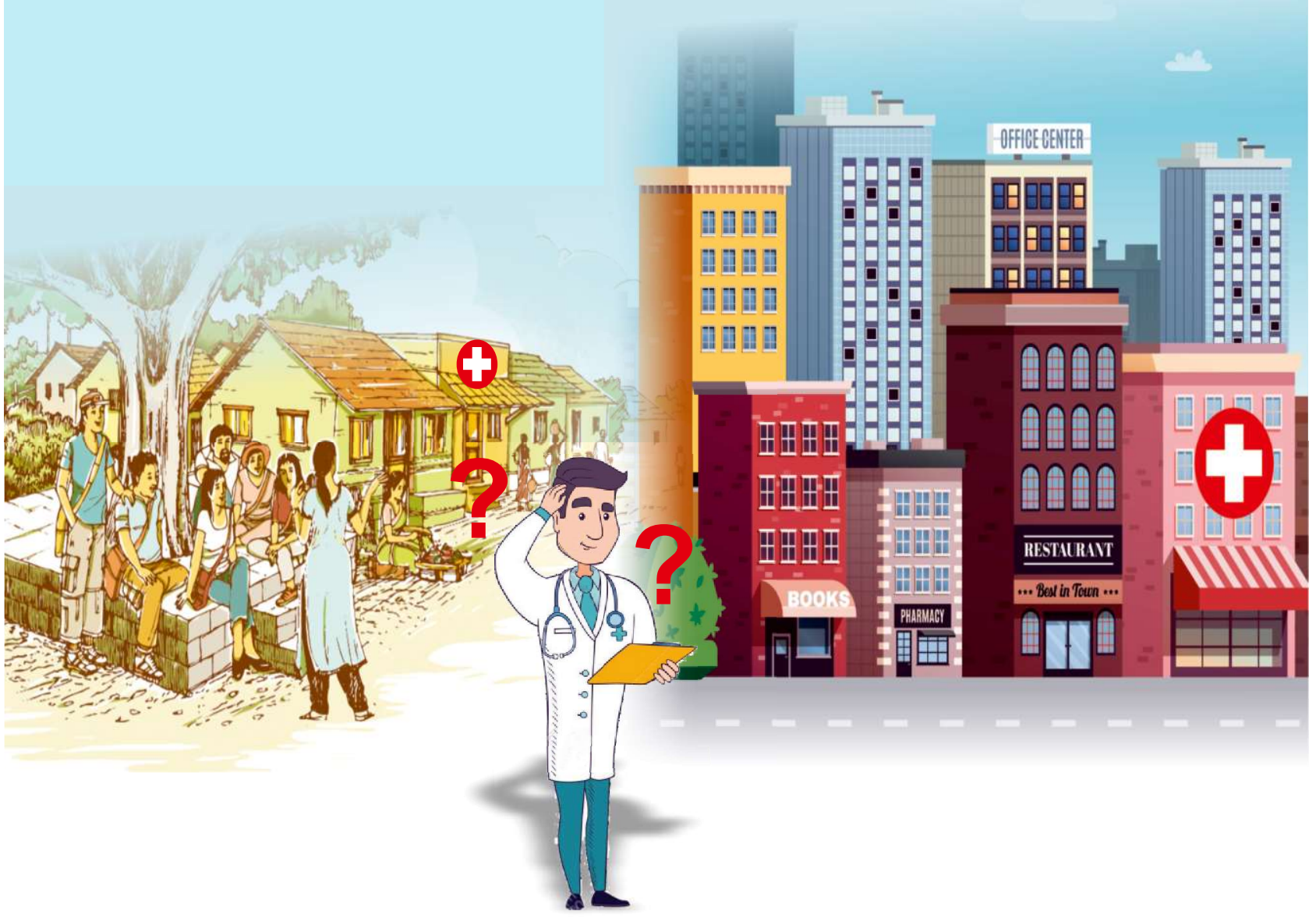




\section{Abstract}

Background: Human resource for health is critical in quality healthcare delivery. India, with a large rural population $(68.8 \%)$, needs to urgently bridge the gaps in health workforce deployment between urban and rural areas.

Methods: We did a critical interpretative synthesis of the existing literature by using a predefined selection criterion to assess relevant manuscripts to identify the reasons for retaining the health workforce in rural and underserved areas. We discuss different strategies for retention of health workforce in rural areas on the basis of four major retention interventions, viz. education, regulation, financial incentives, and personal and professional support recommended by WHO in 2010. This review focuses on the English-language material published during 2005-14 on human resources in health across low and middle-income countries.

Results: Healthcare in India is delivered through a diverse set of providers. Inequity exists in health manpower distribution across states, area (urban-rural), gender and category of health personnel. India is deficient in health system development and financing where health workforce education and training occupy a low priority. Poor governance, insufficient salary and allowances, along with inability of employers to provide safe, satisfying and rewarding work conditions-are causing health worker attrition in rural India. The review suggests that the retention of health workers in rural areas can be ensured by multiplicity of interventions such as medical schools in rural areas, rural orientation of medical education, introducing compulsory rural service in lieu of incentives providing better pay packages and special allowances, and providing better living and working conditions in rural areas.

Conclusions: A complex interplay of factors that impact on attraction and retention of health workforce necessitates bundling of interventions. In low-income countries, evidence based strategies are needed to ensure context-specific, field tested and costeffective solutions to various existing problems. To ensure retention these strategies must be integrated with effective human resource management policies and rural orientation of the medical education system. 


\section{Introduction}

Health workforce is defined as the "people engaged in actions with primary intent to enhance health' [1]. The number of health workers available in a country is a key indicator of that country's capacity to provide delivery of interventions [2]. The importance of the health workforce can be gauged from the fact that healthcare is a human resourceintensive industry and production of health workers is expensive and time-consuming. The Joint Learning Initiative (2004) for Human Resources for Health estimates a requirement of 2.5 workers per 1000 population for achieving $80 \%$ coverage of the population [3]. In 2006, the World Health Report drew attention to the global health workforce crisis and its dramatic impact in 57 priority countries. It estimated a need for additional 4.3 million health workers in these countries to fulfil the Millennium Development Goals [1]. These countries are affected by severe shortages, inequitable distribution, poor motivation and uneven performance of healthcare workers [1].

In 2009, a high-level taskforce on International Financing for Health Systems identified health workforce as a priority area, requiring critical attention and additional investments. Poor coverage of primary healthcare interventions, e.g. measles immunization and antenatal care was observed in countries with less than 23 skilled workers (physicians, nurses and midwives) per 10000 population. It suggested to governments that all people, including rural and remote populations, have access to safe, high-quality and essential healthcare services [4].

Globally, the health workforce per 1000 population ranges from as low as 2.3 and 4.3 in Africa and Southeast Asia respectively, to as high as 24.8 in the USA [1]. The situation is critical in 57 countries where a billion people have no access to essential healthcare services due to shortage of trained health workers [1]. Worldwide, there is also unbalanced distribution of health personnel between and within countries. All countries, rich and poor, report a higher proportion of health personnel in urban and wealthier areas. Approximately half of the global population lives in rural areas, but these areas are served by only $38 \%$ of the total nursing workforce and by less than a quarter of the total physician workforce. A comparison of two large health labour markets, India and China, showed that India has a lesser workforce population ratio and greater inequality 
compared to China [5]. According to a report published in June 2016, using the Census 2001 data of India, nearly 2.01 health workers and of them 0.8 allopathic doctors exist per thousand population [6]. With these projections there will be a shortage of around 12.9 million healthcare workers globally by $2035 ; 80 \%$ of them in poor nations [1].

India, with a population of over one billion, is placed in the lowest category of human resource for health (HRH) indicators [7]. This deficiency is worsened by the unfavourable distribution of $\mathrm{HRH}$ in rural areas, where a majority of the population resides. There are only 100 skilled health workers per 100000 population against the international norm of 228 per 100000 population [8]. Despite several attempts, the government has failed to tackle the problem effectively. We reviewed the literature to capture various aspects that lead to human resource shortage in India and the strategies deployed globally which could be replicated and scaled up in developing countries such as India.

\section{Methods}

We did a critical interpretative synthesis (CIS) of a diverse body of evidence on HRH to generate a theory with considerable explanatory powers. The predefined selection criterion used to assess relevant manuscripts in this literature review was to identify "the reasons for retaining health workforce in rural and underserved areas'. The tasks of searching, sampling, critiquing and analysing were done as dynamic and mutually informative processes [9]. Search engines such as PubMed, Google Scholar and IndMed were used to identify relevant articles. The keywords 'health workers or nurses or doctors or mid-level workers' AND 'retention or recruitment or shortage' AND 'rural area or underserved area in India' were used in 24 combinations for the search (Figure 1). We also used a snow-balling approach to identify further literature from the reference lists of relevant journal articles. The search was limited to articles in English published from 2005 to 2014.

The article search followed an iterative strategy aimed at theoretical saturation. From a total of 170 articles identified, 90 were shortlisted. We rejected 80 articles because of duplication in different search engines and after screening their abstracts. Of the 90 
articles, those dealing with subject-based training, new medical education techniques, methods of quality assurance, quality improvement of healthcare staff, continuous medical education and cross-country migration were excluded from review as they did not meet the predefined criteria of the study. Further, these articles considered short-term effect of pre- and post-test knowledge scores, rather than long-term impact of job satisfaction or motivation. Finally, 56 articles were included in the review on the basis of a screening of the full text of each article (Figure 1).

On the basis of our search, we attempt to explain the existing HRH in India along with the distribution in rural and remote areas. We also discuss the reasons for shortage of HRH in various countries along with successful initiatives undertaken by some countries. These strategies are discussed in terms of their merits and demerits in the Indian context. The results are summarized according to the framework given in Figure 2.

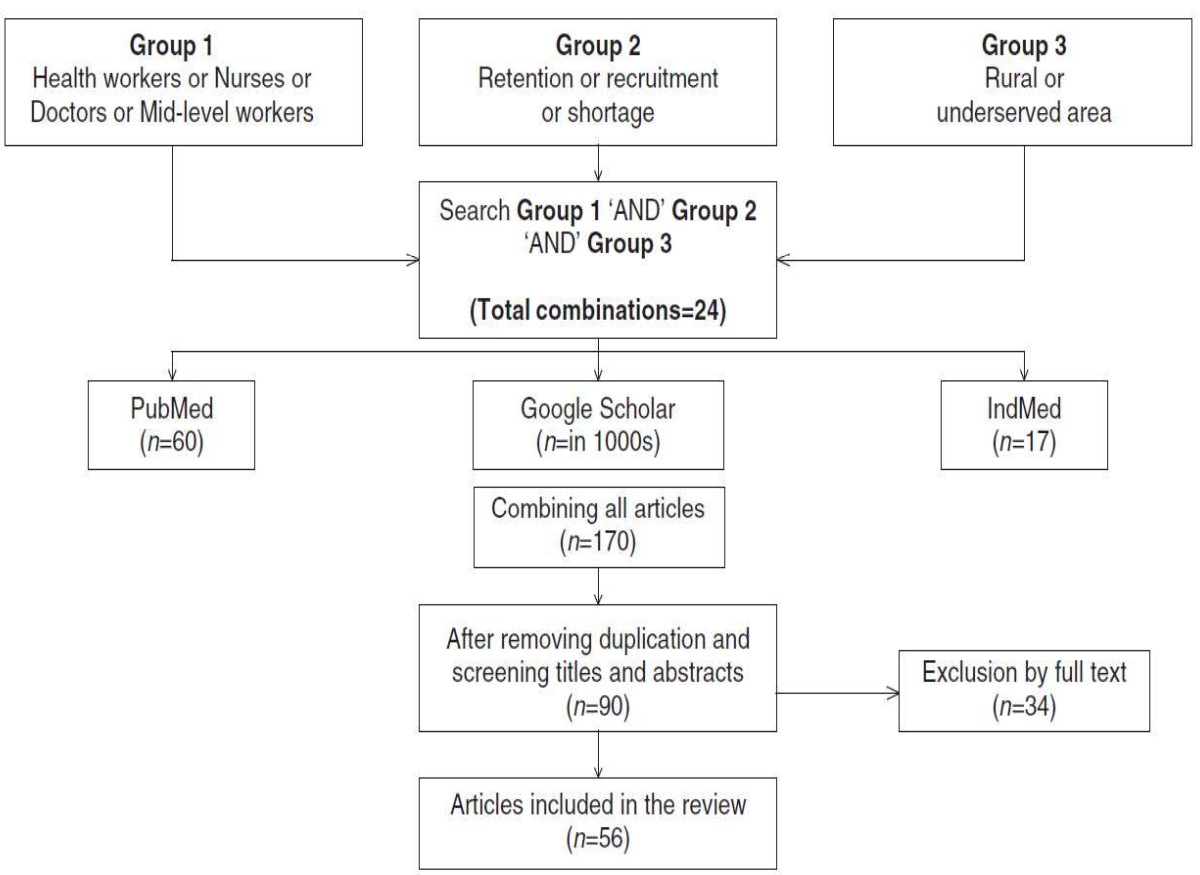

Figure 1-Scheme used in the study for literature search 


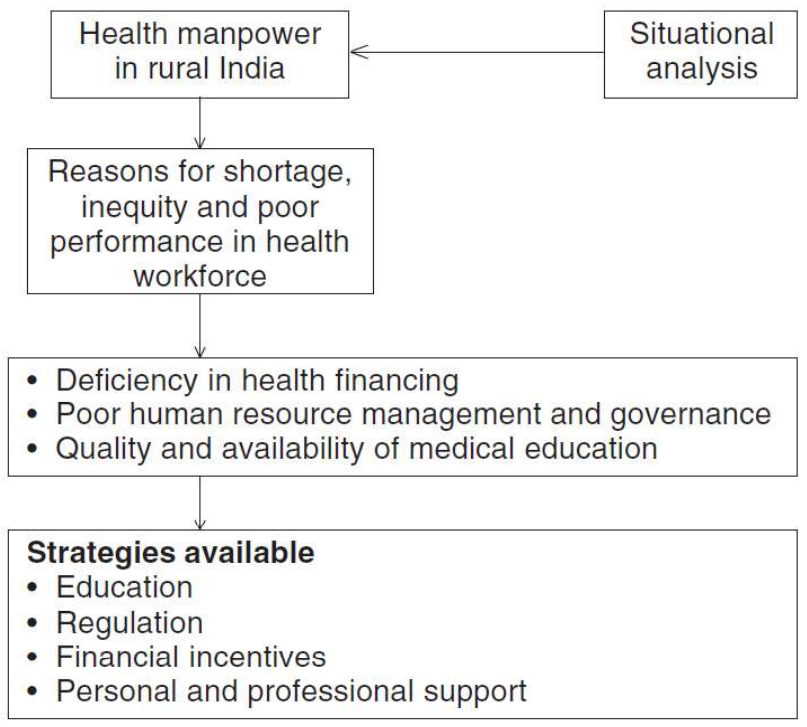

Figure 2- Framework for analysis

\section{History of HRH Policies in India}

Before Independence in 1947, there were two classes of allopathic physicians in the Indian health workforce; namely, doctors who underwent a five-and-a-half-year course and Licentiate Medical Practitioners (LMPs) who underwent a three-to-four-year course. Nearly two-thirds of qualified medical practitioners practising in rural areas were LMPs. The abolition of the licentiate system post Independence resulted in an immediate and massive crunch of health manpower in rural areas [10]. The situation remained grim until the health sector reforms in the early 1990s provided marginal relief to the HRH problem. Many private medical colleges were opened to augment the existing manpower [11]. In 2004, the World Health Assembly passed a resolution to address the migration of health workers from rural and underserved areas [12]. In 2005, the National Rural Health Mission (NRHM) — now the National Health Mission (NHM)-provided for the recruitment of contractual staff to fill in the HRH gap in rural areas in India.

\section{Current Status of Health Workforce in India}

The wide range of HRH in India includes formal and informal medical practitioners. According to the Rural Health Statistics Report 2015, India had almost 2.2 million health 
personnel including about 677000 allopathic doctors and 200000 AYUSH (Ayurveda, Yoga and naturopathy, Unani, Siddha and Homoeopathy) practitioners [13]. India had roughly 20 health workers per 10000 population, which consists of allopathic doctors (31\%), nurses and midwives (30\%), pharmacists (11\%), practitioners of AYUSH (9\%), and others $(9 \%)$. The National Sample Survey Organization estimates an adjusted population of healthcare workers (adjusted for educational qualifications) as 8 per 10000 people (3.8 allopathic doctors and 2.4 nurses and nurse-midwives). The combined density of allopathic doctors, nurses and midwives (11.9/10 000) is about half the WHO benchmark (25.4/10 000 population), which declines further when adjusted for qualification [13].

Recent data from the Rural Health Statistics Report 2015 indicate that 8.1\% of primary health centres (PHCs) were without a doctor, 38.1\% were without a laboratory technician and $21.9 \%$ were without a pharmacist. The situation of community health centres (CHCs) with respect to human resources is even poorer in terms of the sanctioned posts: $74.6 \%$ of surgeons, $65.4 \%$ of obstetricians and gynaecologists, $68.1 \%$ of physicians and $62.8 \%$ of pediatricians were vacant. Overall, $67.6 \%$ of the sanctioned posts of specialists at CHCs were vacant [14]. The Workforce Indicators and Staffing Need (WISN) approach which calculates the expected demand a package of services should generate, found a considerable gap in the supply of health workers across all categories in Ganjam district of Odisha and estimated a need for an additional 43 physicians, 15 nurses and 80 nurse midwives [15].

There is an uneven distribution of health workers across India, which ranges from 23.2 per 10000 population in Chandigarh to 2.5 per 10000 population in Meghalaya. The states of Goa and Kerala have a very high number of allopathic doctors (41.6 per 10000 and 38.4 per 10000 , respectively) compared with states such as Odisha (19.7 per 10000 ) and Chhattisgarh (15.8 per 10000$)$ and other north-central states. The inequity in distribution is also observed in terms of male-female ratio of health workers. Almost twothirds of all health workers are men. The number of women doctors across different states of India ranges from 7.5 in Chandigarh to 0.26 in Bihar per 10000 population. There are 6.5 women allopathic doctors per 10000 population in urban areas compared to 0.5 per 
10000 in rural areas [13].

A gross imbalance in health workers between urban and rural areas is seen as there are 42 health workers in urban areas as compared to 11.8 in rural areas per 10000 population. This imbalance is even more (three times) when we consider allopathic doctors (13.3 in urban v. 3.9 in rural areas), nurses and midwives (15.9 in urban v. 4.1 in rural areas) and AYUSH practitioners (3.6 in urban v. 1.0 in rural areas) per 10000 population. Further, a majority $(70 \%)$ of the existing health workforce works in the private sector [13]. This imbalanced distribution of health workers in terms of men or women, urban or rural, public or private impedes the universal access to healthcare goals.

\section{Explaining Health Workforce Shortage in Rural and Underserved Areas of India}

A multitude of interconnected causes result in health manpower deficit in rural and underserved areas of India. Different factors operate in different states. Various case studies of Indian states published by the Central Bureau of Health Intelligence (CBHI), India revealed an absence of a formal mechanism to undertake manpower planning and forecasting on a regular basis. The planning exercise focused mostly on the creation of new infrastructure rather than recruiting specialized manpower. Other reasons cited were non-existence of specialized human resource department, poor recruitment, and transfer and promotion system [16]. Moreover, socio-demographic and economic factors of the region have a considerable role in the distribution of their health workforce [17]. Shortages of health workers can also be caused by conditions in other countries, wherein one country's domestic and foreign policies can affect health worker shortages in other countries [18].

India is deficient in health system development and financing because health workforce education, training and continuing field education is given a low priority. India has moved from 19 medical schools post-Independence to more than 380 at present. Private medical institutions have contributed to this rapid rise as $57 \%$ schools are privately operated nowadays compared to 33\% in 1990 [19]. However; regional imbalances exist in medical education with less number of colleges in areas where they are required most. 
Since southern India has about $63 \%$ of the total medical colleges, northern India has to enhance its medical education infrastructure to correct the imbalance. Even with appropriate number and mix of trained health workers, the availability of jobs is a concern which depends on money to pay for salaries and other benefits. This is attributed to poor governance and insufficient budget allocation to healthcare. The Government of India is committed to increase the public healthcare budget under the 12th Five-year Plan (2012-17) as a part of its flagship NRHM, which is expected to lessen manpower woes [20]. Evaluation of the NRHM (2005-10) has shown an additional appointment of 8624 MBBS doctors, 2640 specialists and 26793 staff nurses [21]. Inability of employers to provide safe, satisfying and rewarding work conditions is another important factor for healthcare worker attrition in rural India. Compulsory postings and financial incentives in rural areas are stop-gap measures for securing a postgraduate seat or job in an urban area. Although contractual appointments done under the NRHM have resulted in some immediate gain in health outcomes, they have done little to address dissatisfaction and attrition of health manpower in the long run.

Due to poor working and living conditions, lack of monetary and non-monetary incentives, health workers prefer to migrate within and across countries. Other reasons include lack of employment opportunities, appropriate work environment and wages, growing demand in high-income countries due to demographic transition, and favourable country policies for financial remittances by migrant workers. Thus, the migration of health workers to urban areas leads to a heavy workload for health workers in rural areas. This leads to a domino effect; i.e. those in dire situations look for areas where they may be able to find more satisfactory and less demanding working conditions.

\section{Strategies for Retention in Rural and Underserved Areas}

Development of appropriate strategies requires an understanding of the factors that influence decisions to accept and/or stay in a remote area. Several theoretical models categorize factors impacting workforce mobility. The Neoclassic Wage Theory suggests that the choice is driven largely by financial motives and probability of finding employment. Behavioural theories show a complex decision-making process emphasizing on job satisfaction. The recent literature on health workforce mobility has 
classified influencing factors into 'pull' and 'push' categories. 'Pull' factors include improved employment opportunities and/ or career prospects, higher income, better living conditions and more stimulating environment. 'Push' factors act to repel the individual from a location and include poor administrative policies, nepotism, poor job satisfaction, poor growth opportunities, lack of incentives, etc [22].

WHO has identified four key strategies that influence recruitment and retention of the health workforce in rural and remote areas. These strategies are education, regulation, financial incentives, and personal and professional support [23]. WHO has also suggested that interventions should respond to factors that health workers value in their work [24]. Therefore, policy should design the interventions in the local context. Many countries have implemented these interventions in their local context to attract and retain health workers in remote and rural areas [25]. However, a Cochrane review on HRH suggested the need for well-designed studies on HRH to support interventions [26].

There is limited evidence of successful attraction and retention strategies in developing countries such as India. We provide a review of different strategies for retention of health workforce in rural areas on the basis of four major retention interventions recommended by WHO in 2010 .

\section{Educational Interventions}

Studies done in the developed world indicate that retention of the health workforce in rural areas can be ensured by having medical schools in rural areas and recruiting staff with a rural background. A review of studies on undergraduate medical education suggests placement of medical students in rural settings to be a positive influencer for placement in a rural area, wherein they displayed better performance, greater clinical exposure, more satisfaction and considerable improvement in clinical skills compared to their urban counterparts [27]. A retrospective study from Japan found that rural medical school graduates were 4-times more likely to work in rural areas than others [28]. Rural training experience in medical schools of Australia elicited increased interest in rural medicine among students [29]. Barriers for recruitment identified by a rural clinical 
school were quality of teaching and education at school, location, transport, ability to get preferred internship and family concerns [30]. Studies in Norway and the USA have also concluded that students from rural background achieve similar level of success in nursing education as their urban counterparts [31,32].

No studies on rural orientation of medical education have been done in India, as the majority of medical colleges are located in urban areas. In a study done in medical schools of Bengaluru, India, 44\% medical interns preferred to serve in rural areas immediately after under graduation, but $<10 \%$ wanted to settle permanently [33]. Another study in two medical colleges of central India with nearly $80 \%$ students from a rural background rated the status of rural health services in India as highly unsatisfactory $(88.6 \%)$ and indicated (54.7\%) an interest in working in rural areas after graduation [34]. Few states have introduced state-specific cadre of health workers focusing on recruiting students from rural background, e.g. Chhattisgarh deployed rural medical assistants (RMAs) and women RMAs in peripheral health centres. Similarly, Assam introduced a new cadre of health workers to fill up vacant positions in remote, far-flung and rural areas [35]. The 'Bachelor in Rural Health' was envisioned to train science students from rural schools in public healthcare institutions to practise under supervision in a population $<50$ 000. However, these courses were fraught with challenges in structure of training, type of service delivery and quality of healthcare [36]. It would also be difficult to stop those employed in rural areas from migrating to urban areas for lucrative practice opportunities [37]. Factors such as infrastructure and salary were perceived as potential barriers for a career in rural health [38].

\section{Regulatory Interventions}

Regulatory interventions with regard to recruitment and retention in rural areas seek to expand the scope of practice of rural health workers, produce different types of health workers, and influence compulsory service requirements and bonding schemes. In Thailand, students recruited by the Ministry of Public Health receive heavily subsidized tuition and free clothing, room and boarding, and learning materials during their studies 
in return for doing compulsory public health service-usually in remote areas-after graduation $[39,40]$. Many Latin American countries have made use of compulsory rural service, particularly for medical doctors, to help them stay in rural areas [41].

In India, states such as Assam, Chhattisgarh, Kerala, Himachal Pradesh, Haryana, Punjab, Andhra Pradesh and Tamil Nadu reserve postgraduate seats for in-service doctors who complete a fixed quota of rural service. The states of Kerala, Mizoram and Uttarakhand provide additional marks to candidates who serve in rural areas for 2-3 years; these marks are added to their marks obtained in entrance examination. Compulsory rural bonds for those receiving medical education from government colleges have been used in many states such as Kerala, Tamil Nadu, Meghalaya and Nagaland to fill vacancies in rural areas. The state of Nagaland has introduced the Diplomate of National Board in Family Medicine for in-service candidates. Effectiveness of most of these initiatives has not been evaluated. However, an initiative of Andhra Pradesh of a post-graduation incentive scheme was evaluated and has shown to be effective in reducing the vacancies of medical officers and specialists in the public health system [42]. The experiences from Tamil Nadu and Karnataka have also shown a beneficial effect on worker morale by providing rotational posting in difficult areas followed by a posting in the area of their choice [43]. Many other states have made rural service mandatory for admission into postgraduate programmes [44]. Since most medical graduates are eager to pursue post-graduation, rural postings have been shown to be acceptable if they are made a mandatory component of postgraduate rather than undergraduate degrees [45].

\section{Financial Interventions}

Financial measures are adopted in policies over professional and personal support measures as they are proven better for influencing choices and preferences for work in underserved areas [25]. Financial incentives encompass all additional benefits given to health workers to entice them to work in a remote or rural area. They include monetary bonuses and in-kind benefits (a free house or vehicle). 
In Thailand, financial incentives started with special allowances for physicians working in remote district hospitals [40]. In the Philippines, a special financial package, the Magna Carta, was created for public health workers which included increased salaries and benefits, particularly for physicians [46]. In Indonesia, graduates who work in very remote areas receive a higher salary and a guarantee of a civil service career after completion of the 3-year compulsory contract [47]. Zambia has introduced a package of measures to attract doctors to and retain them in remote rural areas [48]. The package includes a rural allowance equivalent to about $30 \%$ of their salary, accommodation, contribution to school fees, vehicle and/or housing loans and some support for further education.

Financial incentives are one of the most commonly used strategies in India to attract and retain doctors in rural areas. Eighteen states have monetary incentive schemes to compensate doctors for service in underserved areas [8]. These schemes, which are focused mainly on allopathic doctors, are more effective when combined with incentives such as better living environment, housing and schooling. However, such incentives need to be substantial in order to retain health workers in rural areas, especially for doctors as compared to nurses and other staff. Effectiveness of monetary incentives has not been widely evaluated in India. An 2013 that, for every salary level, a considerably higher proportion of nursing students and nurses were willing to accept a rural job compared to medical students and doctors [49].

\section{Personal and Professional Interventions}

Personal and professional interventions relate mainly to living and working conditions in rural areas. Personal preferences that rank high among health workers include good infrastructure, opportunities for social interaction, schooling for children and employment for spouses. Professional preferences include opportunities for career advancement as well as for networking with peers. Limited evidence exists of strategies aimed at improving working conditions and job satisfaction, although a number of studies discuss the benefits of introducing participatory management and flexibility in US institutions [51,52]. Case studies in countries such as Papua New Guinea and the 
Philippines found that supportive supervision improved not only work satisfaction but also performance and quality of care in remote settings [53,54]. These results are supported by a six-country study which showed that the quality of care improved by focusing on supporting performance of staff [55].

Thailand invested heavily in general rural infrastructure (roads, phones, water supplies and radio communication) and staff housing at rural district hospitals, which led to improved retention of health workers [39]. The Zambian Health Worker Retention Scheme included refurbishment of government housing and school fees to allow staff to send their children away for better education [48]. However, little is known about the long-term impact of the retention scheme.

States such as West Bengal and Chhattisgarh have introduced group housing schemes for health workers living in remote areas. In a qualitative research study in Chhattisgarh, the prime reasons for staying in rural areas included availability of schools, geographical and ethnic affinities, co-location with spouses and professional interest. Effective management policies and provision of improved infrastructure for health personnel in Tamil Nadu, Karnataka and Nagaland have had a major impact on worker morale [56]. Access to training, healthcare and education for children, career opportunities, the availability of electricity, water and housing are the main reasons for favouring urban jobs $[57,58]$.

\section{Bundling of Interventions}

Considering the complexity of attraction and retention of health workforce in rural and underserved areas, the emphasis globally is on bundling of different interventions. In Indonesia, a 'bundle' of interventions, such as compulsory service, training and financial

incentives, is employed for increasing the density of health workforce in remote areas [47]. The Ministry of Health of South Africa introduced compulsory service as well as financial incentives to influence the staffing of rural hospitals [56]. Zambia introduced a 'package' of measures, such as rural allowances, vehicle and house loans, contribution to school fee of children and support for further education, to retain doctors in remote 
rural areas.[48]

Few studies in India have also reported that the interplay between factors, such as career growth, organizational setup, bureaucracy, the work and living environment, influences the choices health workers make regarding job location, thus requiring bundling of interventions [34,58-60]. Bundling of financial and educational incentives across states of India has resulted in attracting doctors and nurses to rural postings [61]. Many states of India have adopted a bundle of interventions, however, their impact has largely not been evaluated. These interventions need to be field-tested and adapted in different states, with a view to improve efficiency and effectiveness of the healthcare services.

\section{Conclusion}

Healthcare delivery is labour-intensive where quality, efficiency and effectiveness are dependent on successful planning of the health workforce. Over the past two decades, various strategies for attraction and retention of the health workforce were successfully and un-successfully implemented by the Indian government. The diversity of India with each state having its own challenges and assets makes it obligatory for designing tailor-

made, field-tested, cost-effective interventions and strategies. A complex interplay of factors that impact the attraction and retention of health workforce necessitates a bundling of interventions. 


\section{References}

1. WHO. The World Health Report, 2006 - Working together for health. Geneva: World Health Organization, 2006. Available at www.who.int/whr/2006/en/index.hlml(accessed on 15 Sep 2013).

2. WHO. The World Health Report 2003: Shaping the future. Geneva:WHO; 2003. Available at www.who.int/whr/2003/en/whr03_en.pdf (accessed on 18 Sep 2015).

3. Human Resources for Health: Overcoming the crisis: Joint Learning Initiative. Boston:Rockfeller Foundation, Harvard University Press; 2004. Available at www.issuelb.org/organizations/profile /rockfeller_Joundation (accessed on 18 Sep 2015).

4. McCoy D, Brikci N. Taskforce on innovative international financing for health systems: What next? Bull World Health Organ 2010;88:478-80.

5. Anand S. Measuring health workforce inequalities: Methods and application to China and India. Human Resources for Health Observer, Issue No. 5. Geneva:WHO; 2010. Available at http://whqlibdoc.who.int/publications/2010/9789241500227_eng.pdf(accessed on 25 Sep 2013).

6. Anand S, Fan V. The Health Workforce in India. Human Resources for Health Observer Series. No 16. World Health Organization 2016. Available at www.who.int(accessed on 13 Nov 2016).

7. Chen L, Evans T, Anand S, Boufford JI, Brown H, Chowdhury M, et al. Human resources for health: Overcoming the crisis. The Lancet 2004;364:1984-90.

8. Sundararaman T, Gupta G. Indian approaches to retaining skilled health workers in rural areas. Bull World Health Organ 2011;89:73-7.

9. Dixon-Woods M, Cavers D, Agarwal S, Annandale E, Arthur A, Harvey J, et al. Conducting a critical interpretive synthesis of the literature on access to healthcare by vulnerable groups. BMC Med Res Methodol 2006;6:1.

10. Rao MS. The history of medicine in India and Burma. Med Hist 1968;12:52-61.

11. Jan Swasthya Abhiyan. Health system in India: Crisis and alternatives. Delhi: National Coordination Committee, Jan Swasthya Abhiyan; 2006 Available at www.communityhealth.in / commun26/wiki/images/8/85/JSA Health_system_in_India.pdf (accessed on 25 Sep 2013).

12. World Health Organization. International migration of health personnel: A challenge for health systems in developing countries. Resolution WHA57. Geneva: WHO; 2004:19. Available at http://apps.who.int/gb/ebwha/pdfJiles/WHA57/A57_R19- en.pdf (accessed on 25 Sep 2013).

13. Rao KD, Bhatnagar A, Berman P, Saran I, Raha S. India's health workforce: Size, composition and distribution. India Health Beat. New Delhi: World Bank and Public Health Foundation of India; 2009.

14. Health Management Information System. Rural Health Statistics 2015, Health Management Information System, A digital initiative under the National Health Mission. New Delhi: Ministry of Health and Family Welfare, Government of India. Available at https://nrhmmis.nic.in/Pages/RHS2015.aspx?RootFolder=\%2FRURAL\%20HEALTH\%20STATISTICS\%2F(A)RH S\%20-\%202015\&FolderCTID=\&View=\%7BC50BC181-07BB-4F78-BE6F-FCE916B64253 \%7D (accessed on 18 Sep 2015).

15. Hagopian A, Mohanty MK, Das A, House PJ. Applying WHO's 'workforce indicators of staffing need' 
(WISN) method to calculate the health worker requirements for India's maternal and child health service guarantees in Orissa State. Health Policy Plan 2012;27:11-18.

16. Managing CB. Human resources for health in India—a case study of MP and Gujarat. New Delhi:DGHS, Ministry of Health and Family Welfare; 2007.

17. De Costa A, Al-Muniri A, Diwan VK, Eriksson B. Where are healthcare providers? Exploring relationships between context and human resources for health Madhya Pradesh province, India. Health Policy 2009;93:41-7.

18. O'Brien P, Gostin LO. Health worker shortages and global justice. Millbank Memorial Fund, 2011; U of Melbourne Legal Studies Research Paper No. 569. Australia:Melbourne Law School; 2011. Available at SSRN: https://ssrn.com/ abstract=1965786 (accessed on 18 Sep 2015).

19. Medical Council of India. Annual Report 2013-14. Available at www.mciindia.org/ pdf/Annual\%20Report.pdf (accessed on 18 Sep 2015).

20. Richards T. Medical education in India—in poor health. Br Med J (Clin Res Ed) 1985;290:1132-5.

21. Ministry of Health and Family Welfare. Four years of NRHM-2005-09. Making a difference everywhere. New Delhi:Ministry of Health and Family Welfare, Government of India; 2009.

22. Todaro M. Internal migration in developing countries: A survey. In: Easterlin RA (ed). Population and economic change in developing countries. Chicago:National Bureau of Economic Research, University of Chicago Press; 1976.

23. World Health Organization. Increasing access to health workers in remote and rural areas through improved retention. Geneva: WHO; 2010. Available at www.searo.who.int $/$ nepal/mediacentre /2010_increasing_access_to_health_workers_in_remote_and_rural_areas.pdf (accessed on $18 \mathrm{Sep}$ 2015).

24. World Health Organization. Policies and practices of countries that are experiencing a crisis in human resources for health: Tracking survey. Geneva:WHO; 2010. Available at http://whqlibdoc.who.int/publications/2010/9789241500821_eng.pdf(accessed on 18 Sep 2015).

25. Dolea C, Stormont L, Braichet JM. Evaluated strategies to increase attraction and retention of health workers in remote and rural areas. Bull World Health Organ 2010;88:379-85.

26. Grobler L, Marais BJ, Mabunda SA, Marindi PN, Reuter H, Volmink J. Interventions for increasing the proportion of health professionals practising in rural and other underserved areas. Cochrane Database Syst Rev 2009;1:CD005314.

27. Barrett FA, Lipsky MS, Lutfiyya MN. The impact of rural training experiences on medical students: A critical review. Acad Med 2011;86:259-63.

28. Matsumoto M, Inoue K, Kajii E. Characteristics of medical students with rural origin: Implications for selective admission policies. Health Policy 2008;87:194-202.

29. Eley D, Baker P. Does recruitment lead to retention? Rural clinical school training experiences and subsequent intern choices. Rural Remote Health 2006;6:511.

30. Jones GI, DeWitt DE, Cross M. Medical students' perceptions of barriers to training at a rural clinical school. Rural Remote Health 2007;7:685.

31. Norbye B, Skaalvik MW. Decentralized nursing education in Northern Norway: Towards a sustainable 
recruitment and retention model in rural Arctic healthcare services. Int $\mathrm{J}$ Circumpolar Health 2013;72:22793.

32. Bigbee J, Mixon D. Recruitment and retention of rural nursing students: A retrospective study. Rural Remote Health 2013;13:2486.

33. Gaikwad V, Sudeepa D, Madhukumar S. A study on career preferences and attitude towards the rural health services among the graduating interns of a medical college in Bangalore rural. Int J Biol Med Res 2012;3:1577-80

34. Saini NK, Sharma R, Roy R, Verma R. What impedes working in rural areas? A study of aspiring doctors in the National Capital Region, India. Rural Remote Health 2012;12 (1967):1-7.

35. Rao KD, Khanna S, Kumar N, Kokho P, Bhatnagar A, Gupta G, et al. Which doctor for primary health care? An assessment of primary health care providers in Chhattisgarh, India. New Delhi:Public Health Foundation of India and National Rural Health Mission; 2010. Available at http://cghealth.nic.in/ehealth/studyreports/Which\%20Doctor\%20For\%20Primary\%20Health\%20Care.p df (accessed on 15 Sep 2013).

36. Taneja DK. Rural doctors course: Need and challenges. Indian J Public Health 2010;54:1-2.

37. Garg S, Singh R, Grover M. Bachelor of rural health care: Do we need another cadre of health practitioners for rural areas? Natl Med J India 2011;24:35-7.

38. Ranmuthugala G, Humphreys J, Solarsh B, Walters L, Worley P, Wakerman J, et al. Where is the evidence that rural exposure increases uptake of rural medical practice? Aust J Rural Health 2007;15:2858.

39. Nitayarumphong S, Srivanichakom S, Pongsupap Y. Strategies to respond to health manpower needs in rural Thailand. In: Ferrinho P, Van Lerberghe W (eds). Providing health care under adverse conditions: Health personnel performance and individual coping strategies. Antwerp: ITG Press; 2000:157-62.

40. Wibulpolprasert S, Pengpaibon P. Integrated strategies to tackle the inequitable distribution of doctors in Thailand: Four decades of experience. Hum Resour Health 2003;1:12.

41. Cavender A, Alban M. Compulsory medical service in Ecuador: The physician's perspective. Soc Sci Med 1998;47:1937^-6.

42. Shroff ZC, Murthy S, Rao KD. Attracting doctors to rural areas: A case study of the post-graduate seat reservation scheme in Andhra Pradesh. Indian J Commun Med 2013;38:27-32.

43. Bruno Mascarenhas JM. Overcoming shortage of doctors in rural areas: Lessons from Tamil Nadu. Natl Med J India 2012;25:109-11.

44. Matsumoto M, Kajii E. Medical education program with obligatory rural service: Analysis of factors associated with obligation compliance. Health Policy 2009;90: 125-32.

45. Garg S, Singh R, Grover M. India's health workforce: Current status and the way forward. Natl Med J India 2012;25:111-13.

46. Wibulpolprasert S. Inequitable distribution of doctors: Can it be solved? Thailand: Ministry of Public Health; 1999.

47. Chomitz K, Setiadi G, Azwar A. What do doctors want? In developing strategies for doctors to serve in Indonesia's rural and remote areas. World Bank Policy Research Working Paper no. 1888. Washington, 
DC: The World Bank Development Research Group; 1998.

48. Koot J, Martineau T. Mid-term review: Zambian Health workers retention scheme (ZHWRS) 2003-2004. Final Report, 2005.

49. Rao KD, Ryan M, Shroff Z, Vujicic M, Ramani S, Berman P. Rural clinician scarcity and job preferences of doctors and nurses in India: A discrete choice experiment. PLoS ONE 2013;8:e82984.

50. Buchan J, Calman L. The global shortage of registered nurses: An overview of issues and actions. Geneva: International Council of Nurses; 2004.

51. MacPhee M, Scott J. The role of social support networks for rural hospital nurses: Supporting and sustaining the rural nursing work force. J Nurs Adm 2002;32: 264-72.

52. Wells N, Roberts L, Medlin LC. Issues related to staff retention and turnover. Semin Nurse Manag 2002; 10: $171-9$.

53. Douglas M. Supervision of rural health centres in Papua New Guinea: Consolidation of the delivery of health services. PNG Med J 1991;34:144-8.

54. Loevinsohn BP, Guerrero ET, Gregorio SP. Improving primary health care through systematic supervision: A controlled field trial. Health Policy Plan 1995;10:144-53.

55. Marquez L, Keane L. Making supervision supportive and sustainable: New approaches to old problems. In: Health MS, Marquez L, Kean L (eds). Management and leadership program, produced for the maximizing access and quality initiative (MAQ), Management Sciences for Health [MSH], Supplement to Population Reports 2002;30, No. 4.

56. Reid S. Community service for health professionals. In: Ijumba P (ed). South African Health Review 2002. Durban: Health Systems Trust; 2003.

57. Dussault G, Franceschini MC. Not enough there, too many here: Understanding geographical imbalances in the distribution of the health workforce. Hum Resour Health 2006;4:12.

58. Lindelow M, Serneels P. The performance of health workers in Ethiopia: Results from qualitative research. Soc Sci Med 2006;62:2225-35.

59. Schofield D, Fletcher S, Fuller J, Birden H, Page S. Where do students in the health professions want to work? Hum Resour Health 2009;7:74.

60. Stephen E. Attracting generation next to the rural health sector. Natl Med J India 2007;20:46.

61. Ramani S, Rao KD, Ryan M, Vujicic M, Berman P. For more than love or money: Attitudes of student and in-service health workers towards rural service in India. Hum Resour Health 2013;11:58. 



\section{Chapter}

Measuring the reasons that discourage medical students from working in rural areas: development and validation of a new instrument

Sonu Goel, Federica Angeli, Neetu Singla, Dirk Ruwaard

Medicine 2018; 97(2): e9448

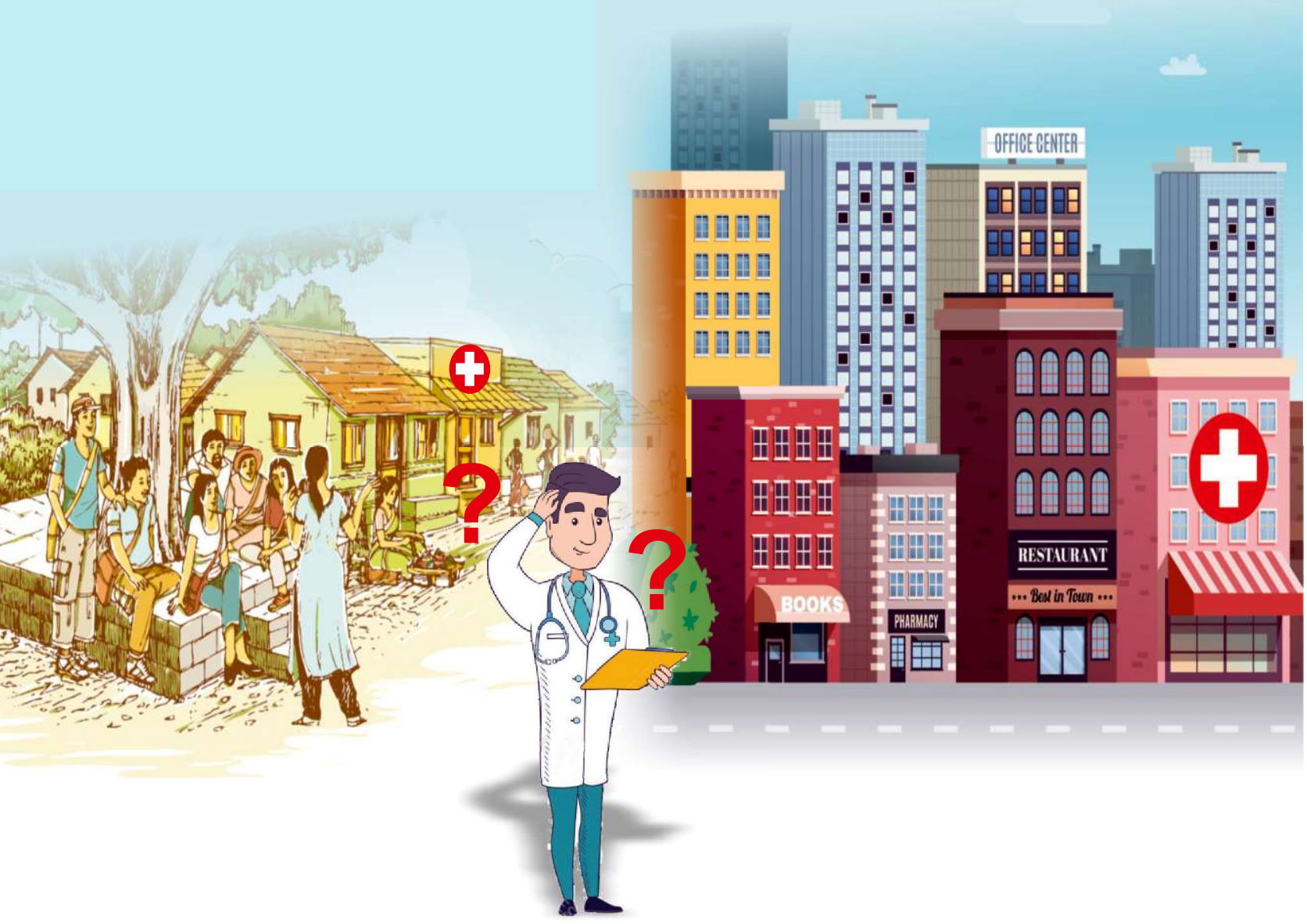


Chapter $5 \quad$ Reasons discouraging medical students from working in rural areas

\begin{abstract}
The sharply uneven distribution of human resources for health care across urban and rural areas has been a long-standing concern globally. The present study aims to develop and validate an instrument measuring the factors deterring final year students of Bachelor of Medicine and Bachelor of Surgery (MBBS) in 3 northern states of India, from working in rural areas. The medical student's de-motivation to work in rural India (MSDRI) scale was developed using extensive literature review followed by Delphi technique. The psychometric properties of the questionnaire were assessed in terms of content validity, construct validity, data quality and reliability. Exploratory factor analysis (EFA) followed by confirmatory factor analysis (CFA) was performed to identify the primary deterrents. Thirty-three items were generated from literature search followed by Delphi exercise. After assessing psychometric properties, the final instrument included 29 items whereas the EFA and CFA highlighted 5 main factors, namely lack of professional challenge, social segregation, socio-cultural gap, hostile professional environment, and lack of financial incentives as underpinning students' demotivation towards working in rural areas. The MSDRI instrument is the first valid and reliable measure for identifying deterring factors for MBBS students to work in rural areas of India. The use of it may be very helpful for policymakers as well as healthcare organizations in formulating effective measures to encourage medical students to work in rural areas, which suffer from a chronic shortage of medical personnel.
\end{abstract}




\section{Introduction}

Human resources are vital to an effective health care system [1]. The World Health Organization (WHO) estimates that 57 countries worldwide are facing critical shortages of health workers [2]. Adding to this, many countries are also facing rural- urban inequity in the distribution of health workers, wherein health workers are disproportionately located in urban areas. The shortage and imbalance in the distribution of human resources for health eventually lead to inequities in health services delivery and poor health outcomes of a country [3].

Globally, many reasons of disparities exist between urban and rural regions. Lack of financial rewards, limited training opportunities, limited professional interaction with peers, heavy workload, social isolation, poor social services, poor living and working conditions, lack of education opportunities for children, and limited opportunities for income-generation through a second job or private practice are often cited as the main factors [4-7]. If the expectations of health workers are not met then they tend to migrate within countries (to urban areas) or to developed countries [8-11]. Governments in lowand high-income countries alike are struggling to attract and retain health workers in underserved areas by offering a package of incentives that covers an array of salary and non-salary related factors. Few studies have been conducted worldwide to report factors which deter medical students from working in rural areas. A study by Gadi [4] in 2012 conducted in Sri Lanka and another study by Shankar and Thapa [12] in Nepal reported that poor working and living conditions, fewer opportunities for postgraduate education, language differences, insecurity, lack of financial incentives were barriers identified by medical students to work in rural area.

India is also facing acute shortage of health personnel, especially in rural areas $[13,14]$. The estimated density of health workers (allopathic physicians, nurses, and midwifes) in 2005 is 13.4, which is about half of the WHO benchmark of 25.4 workers of these categories per 10,000 population. Doctor-population ratio in rural areas in India is $3 / 10,000$ population while it is $13 / 10,000$ for urban areas [15]. A study from the National Capital Region of India concluded that lack of infrastructural facilities, less salary, and low standard of living impedes medical students from working in rural areas [16]. Another study from Bihar, central-east part of India, showed that poor living conditions, 
lack of professional future, priority for post-graduation, and tough working conditions were found to be the main factors for their reluctance to work in rural area [17].

Most of the global literature has either considered a very limited spectrum of potential deterrents to serve in rural areas or have deployed qualitative methods of enquiry such as semi structured questionnaires. Also, all of them have been developed for students studying in Western countries and, therefore, difficult to apply in developing countries such as India because of differences in culture and health systems.

To our knowledge, no research has comprehensively studied and validated the reasons associated with the non-selection of rural posting after Bachelor of Medicine and Bachelor of Surgery (MBBS) in India. As a consequence, validated scales for data collections are still missing as well as rigorous evidence of the factors underpinning India's sharply unequal distribution of health workforce between rural and urban areas. Analyzing the inclination of current medical students towards working in rural health care is an important exercise as they will compose the health workforce of the near future. This evidence will assist in identifying strategies to increase the quality and quantity of healthcare human resources available to underserved regions of the nation. Hence, the need for a valid and reliable scale to assess the factors deterring medical students from working in rural areas is compelling. With this background, this study aims to develop and validate a scale identifying barriers for medical students for accepting rural postings in Indian settings. If a standardized tool will be used by the researchers, the findings would become easy to compare and draw a conclusion from. This will help in mitigating the problem of human resources for health crisis.

\section{Methods}

\section{Conceptual map}

A thorough literature review was carried out which was eventually narrowed down to 20 relevant studies. The final articles were used to develop a conceptual framework of the questionnaire. Delphi technique followed the literature review in which consensus on the items in the questionnaire among a group of experts was achieved. The questionnaire was pre-tested on 20 students to assess its correct interpretation by the respondents. Data were collected from 636 final year MBBS students and a content validity index was identified and exploratory factor analysis (EFA) and confirmatory factor analysis (CFA) were performed (Figure 1). 


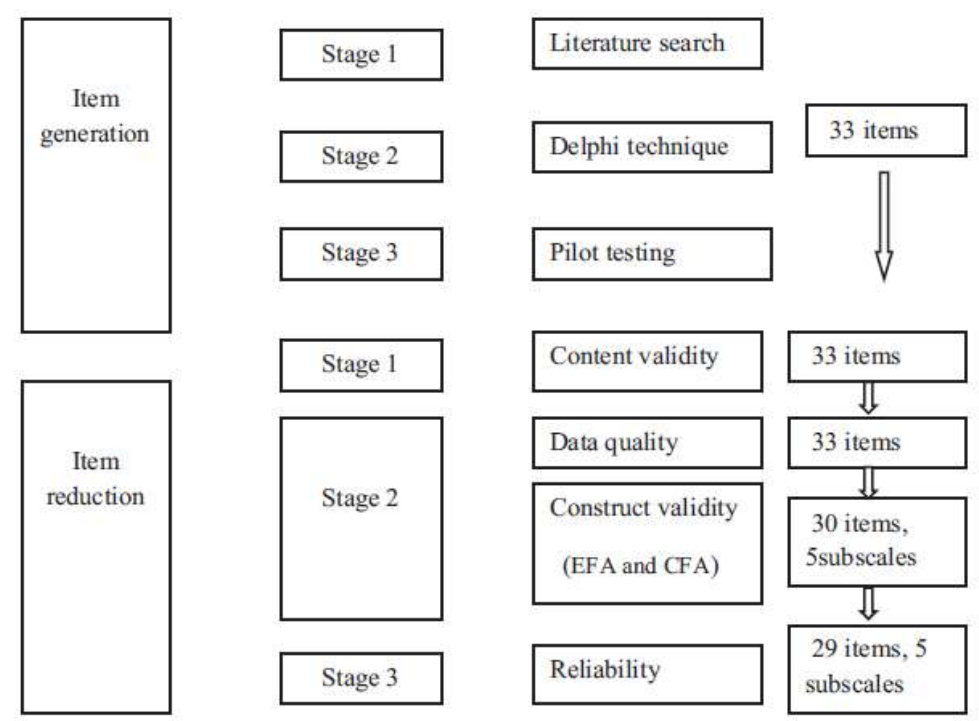

Figure 1- Conceptual framework for development and validation of a questionnaire measuring demotivation of medical students to work in rural areas.

\section{Item generation}

Literature review. Since the diversity of each state in terms of socio-cultural differences could undermine the validity of pre validated measurement tools existed in literature, we developed a structured questionnaire after extensive literature search using PubMed, Directory of Open Access journals, IndMED, and Google Scholar. In addition to that, a manual search of articles in Journals in the library of the Post Graduate Institute of Medical Education and Research, Chandigarh was conducted. The key words for search in various combinations included "de-motivation, medical students and interns, work in rural areas, barriers." The search strategy had resulted in a few thousand articles, after which screening of studies was done on the basis of title and abstract followed by full article review which resulted in 20 relevant studies. The final articles were used to develop a conceptual framework of the questionnaire.

Questionnaire development. Delphi technique followed the literature review in which consensus on the items in the questionnaire among a group of experts was achieved.[18] Two rounds of Delphi were conducted. In the first round, the conceptual framework questionnaire was presented to technical experts $(n=7)$, public health consultants $(n=$ 
10), and public health managers $(\mathrm{n}=5)$ which was followed by extensive discussions on various dimensions of the questionnaire. The first author then built consensus on the items to be included. In the second round held 2 weeks later, the experts revisited the questions, and refined wording and content of the questionnaire.

Pilot testing of the instrument. The questionnaire was pretested on 20 students of a nonparticipant government medical college to assess its correct interpretation by the respondents and to identify potential problems with the methods, logistics, and the questionnaire.

\section{Item reduction}

Study settings and data collection. The main study was conducted among 636 final year Bachelor of Medicine and Bachelor of Surgery (MBBS) students of 6 Government medical colleges of 3 states viz. Himachal Pradesh (HP), Punjab, and Haryana located in Northern India ( 2 medical colleges from each state). Final year students of MBBS were selected as they are near to complete their medical education and have to take decision about their posting in rural and urban areas. The sample size is appropriate for the study as most studies of questionnaire's validation in social sciences use 5 to 10 respondents per questionnaire item for factor analysis [19]. In India, medical education consists of 5 years of medical studies followed by year of clinical training (known as "internship") in a rural or urban hospital attached to medical college. The Medical Council of India (MCI) being the statutory regulatory and registration authority for medical education and practitioners in India, has the authority to recognize a medical college or cancel its registration if the college does not comply with its guidelines.

Two trained researchers collected the data, who also had prior experience of survey research. Students were asked to rate the items that discouraged them to choose medical studies on a 5 point Likert scale where 1 represents "weakly deterrent," 2 represents "slightly deterrent," 3 represents "deterrent," 4 represents "highly deterrent," and 5 represents "strongly deterrent." The questionnaire was handed out and collected after completion confidentially. 
Content validation and data quality. A content validity index was identified by an independent group of subject experts from state health services (different from the original panel included in the Delphi exercise) using method proposed by Lynn [20]. The expert group was asked to assess the content of each item generated on a 5-point Likert scale in terms of appropriateness, comprehensibility, and clarity of phrasing of each item.

Data quality was ascertained by the completeness of responses. The percentage of missing data, extent of ceiling and floor effects, and corrected item-to-total correlation for each item in the scale were calculated. Ceiling effect in an item occurs when most of the respondents assign maximum score to that item and floor effect is in which most data points fall in the very low range of possible values. Corrected item-to-total correlations are the correlation between each item and the total score from the questionnaire and all the items should correlate with the total for a reliable scale. Items were eliminated if the missing response rate of an item was $>10 \%$, the floor and ceiling effect of an item was between $1 \%$ and $15 \%$, and correlation of items of questionnaire $<0.30$ with total scale score (corrected item-to-total correlation) [21].

Construct validity and reliability. Exploratory factor analysis (EFA) with varimax rotation was used to measure construct validity. It was applied on the list of selected items to group the items with similar characteristics together into factors/ subscales. Multi-collinearity and singularity was checked and the items that showed high correlation $(\mathrm{r}= \pm 0.90)$ and low correlation $(\mathrm{r}= \pm 0.30)$ with other items were dropped out from further analysis [22]. Kaiser-Meyer-Olkin (KMO) test was used to check sampling adequacy which should be $>0.5$ for a satisfactory factor analysis to proceed.[23] Bartlett test was applied to check the strength of the relationship among items. The criterion of Eigenvalue $>1$ was used for defining the number of the factors that were kept [24-26]. Screen plot, a graphic representation of Eigenvalues, suggested the number of the essential factors to be retained. Items were loaded into various factors on the basis of 2 criteria: each item to be included in a factor should have a factor loading $>0.5$ and $<0.4$ to the rest of the factors [27].

The internal consistency of each factor was checked by calculating Cronbach a [28]. 
Chapter 5 Reasons discouraging medical students from working in rural areas

Nunnally and Bernstein [29] has indicated 0.7 to be an acceptable reliability coefficient. Convergent and discriminant validity were checked using Spearman correlation coefficient. Convergent validity is a type of construct validity which measures that the same constructs are related to each other. Conversely, discriminant validity measures that the 2 constructs are unrelated to each other. Fabrigar et al [30] mention that if the correlation between an item and its factor is $>0.40$, it means that convergent validity exists, whereas discriminant validity exists if the correlation between an item and its factor is higher than its correlation with other factors.

Confirmatory factor analysis (CFA) was performed on EFA factors to confirm that the factor is defined according to the theoretical approach the researchers used as a starting point and to assess validity and reliability of the latent constructs. In contrast to EFA, which identifies the dimensionality of items, to drop the items having low factor loading as well as redundant items from the questionnaire; CFA is a particular case of structural equation modeling (SEM) which represents how the observed variables are interconnected [31]. So, we selected the items with higher factor loadings by EFA and then performed a CFA (cross loadings are not permitted in CFA model). SEM is quite popular among the behavioral and health researchers for its ability to assess psychometric properties of measures and estimate of relationship among the constructs [32]. Moreover, it can be extended to repeated measurement data, missing data, and violations of assumption of normality [33].

For testing for statistical assumptions for the SEM, skewness and kurtosis values for each of the variable for assumption of normality was obtained and inspected. Multivariate outliers detection analysis was carried out using Mahalanobis distance (MD) measure with robust estimates at 97.5 th quantile $(\mathrm{Q})$ of chi-square distribution. All the samples with $\mathrm{MD}>\mathrm{Q}$ are declared as outliers. Multicollinearity diagnostic was also carried out using variance inflation factor (VIF). Comparative fit index (CFI), Goodness-of-fit Index (GFI), Root Mean Square Error of Approximation (RMSEA), and Tucker-Lewis index (TLI) are calculated in order to measure the goodness of fit of the model. A value of about 0.06 or less for RMSEA and 0.95 or greater for CFI and TLI, 0.90 or greater for GFI, and greater than 0.80 for AGFI would indicate an acceptable model fit [34]. 
Data were analyzed using Statistical Package for Social Sciences version-16 (SPSS IBM, New York, NY). SPSS/Amos22 has been used for CFA.

\section{Ethical considerations}

The study was granted ethical approval from the Institute's Ethical Committee, PGIMER, Chandigarh (PGI/IEC/2012/810-1 P-154). The approvals from Principal of selected medical college and consent of students participating in the study were obtained. To preserve the anonymity and confidentiality of participants, the respondents were asked to place the filled questionnaire in a sealed box.

\section{Results}

\section{Item generation}

The extensive literature review led to the development of a 33- item scale, which was named the medical student's demotivation to work in rural India (MSDRI) questionnaire to identify the reasons behind the unwillingness of medical students to work in rural areas. During the Delphi method, the wording of 2 questions was reframed, however, the number of items remained same. In pilot testing, the questionnaire was found comprehensible, correctly interpreted by students and no potential problems were found in its administration by the field investigator. No item was deleted or modified. So, the structure of the questionnaire remained the same after this stage (i.e., 33 items).

\section{Item reduction}

Results on study settings and data collection.

Study demographics. The sample comprised 636 medical students (297 boys, 339 girls) aged 19 to 40 (mean age $=22.24 \pm 1.78$ years). A total of $405(63.7 \%$ ) students were born in rural areas and the majority of the students $(80.8 \%)$ studied in urban areas before MBBS.

Content validation and data quality. After extensive literature review, 33 items questionnaire was developed. Based on the expert group debate, the agreement was made 
that all items are contextually relevant. It was suggested that no item should be deleted from this list. Rewording of a few items was done by the experts. Data quality checks have been applied by screening of the responses of all 33 items. As the researchers were available during the process of filling out the questionnaire missing data were very negligible. No floor and ceiling effects were observed.

Construct validity and reliability. Exploratory factor analysis was carried out with varimax rotation. KMO measure was found to be 0.930 , which indicates that sample is adequate for factor analysis. Bartlett test of sphericity rejected null hypothesis at 0.05 level of significance (Bartlett test significance $<0.05$ ) and ensures the relevance of factor analysis Five factors (subscales) having 29 items been retained, explaining $60 \%$ of the variance, namely lack of professional challenge, social segregation, socio-cultural gap, lack of infrastructure and social support, and lack of financial incentives. Table 1 reports the results of EFA.

Table 1: Five subscales with the corresponding loadings of items from the MSDRI questionnaire.

\begin{tabular}{|l|c|c|c|c|c|}
\hline Items & $\begin{array}{l}\text { Lack of } \\
\text { professional } \\
\text { challenge }\end{array}$ & $\begin{array}{c}\text { Social } \\
\text { segregation }\end{array}$ & $\begin{array}{l}\text { Socio- } \\
\text { cultural } \\
\text { gap }\end{array}$ & $\begin{array}{l}\text { Hostile } \\
\text { professional } \\
\text { environment }\end{array}$ & $\begin{array}{l}\text { Lack of } \\
\text { financial } \\
\text { incentives }\end{array}$ \\
\hline $\begin{array}{l}\text { Lesser challenging } \\
\text { work }\end{array}$ & 0.743 & 0.169 & 0.115 & 0.05 & 0.209 \\
\hline Lesser job variety & 0.681 & 0.132 & 0.177 & 0.179 & 0.292 \\
\hline $\begin{array}{l}\text { Less chances to } \\
\text { upgrade your skills }\end{array}$ & 0.674 & 0.26 & 0.148 & 0.292 & -0.005 \\
\hline $\begin{array}{l}\text { Limited access to } \\
\text { medicines }\end{array}$ & 0.642 & 0.28 & 0.071 & 0.434 & 0.031 \\
\hline $\begin{array}{l}\text { Limited clinical } \\
\text { experience }\end{array}$ & 0.64 & 0.195 & 0.143 & 0.135 & 0.004 \\
\hline $\begin{array}{l}\text { Poor infrastructure } \\
\text { of health facilities }\end{array}$ & 0.627 & 0.243 & 0.09 & 0.344 & 0.054 \\
\hline $\begin{array}{l}\text { Lesser career } \\
\text { prospects }\end{array}$ & 0.582 & 0.29 & 0.106 & 0.262 & 0.269 \\
\hline $\begin{array}{l}\text { Limited access to } \\
\text { good technology }\end{array}$ & 0.553 & 0.283 & 0.083 & 0.519 & -0.081 \\
\hline Lower job security & 0.537 & -0.069 & 0.09 & -0.230 & 0.283 \\
\hline $\begin{array}{l}\text { Less entertainment } \\
\text { sources }\end{array}$ & 0.168 & 0.736 & 0.102 & 0.096 & 0.267 \\
\hline $\begin{array}{l}\text { Have to live away } \\
\text { from family }\end{array}$ & 0.173 & 0.732 & 0.175 & 0.103 & 0.048 \\
\hline Social isolation & 0.142 & 0.717 & 0.2 & 0.074 & 0.145 \\
\hline
\end{tabular}




\begin{tabular}{|c|c|c|c|c|c|}
\hline $\begin{array}{l}\text { Poor living } \\
\text { conditions }\end{array}$ & 0.164 & 0.668 & 0.149 & 0.059 & 0.217 \\
\hline $\begin{array}{l}\text { No opportunity for } \\
\text { spouse job nearby } \\
\text { place }\end{array}$ & 0.183 & 0.663 & 0.051 & 0.209 & 0.126 \\
\hline $\begin{array}{l}\text { Lack of educational } \\
\text { opportunity for } \\
\text { children }\end{array}$ & 0.232 & 0.558 & 0.104 & 0.368 & 0.025 \\
\hline $\begin{array}{l}\text { Possible effects on } \\
\text { health due to social } \\
\text { isolation }\end{array}$ & 0.191 & 0.511 & 0.241 & 0.113 & 0.328 \\
\hline Cultural gap & 0.136 & 0.157 & 0.848 & 0.065 & 0.173 \\
\hline Language barrier & 0.147 & 0.175 & 0.835 & 0.064 & 0.145 \\
\hline Lack of safety & 0.102 & 0.149 & 0.749 & 0.195 & 0.14 \\
\hline $\begin{array}{l}\text { Poor community } \\
\text { support }\end{array}$ & 0.191 & 0.148 & 0.74 & 0.091 & 0.201 \\
\hline $\begin{array}{l}\text { More interference } \\
\text { by local } \\
\text { administrative and } \\
\text { political leaders }\end{array}$ & 0.127 & 0.132 & 0.618 & 0.421 & 0.058 \\
\hline $\begin{array}{l}\text { Lack of supportive } \\
\text { supervision }\end{array}$ & 0.313 & 0.045 & 0.098 & 0.679 & 0.283 \\
\hline $\begin{array}{l}\text { Lack of motivation } \\
\text { to study for Post- } \\
\text { Graduation }\end{array}$ & 0.405 & 0.064 & 0.12 & 0.589 & 0.284 \\
\hline $\begin{array}{l}\text { Interference of } \\
\text { traditional helpers in } \\
\text { practice }\end{array}$ & 0.099 & 0.242 & 0.339 & 0.584 & 0.139 \\
\hline $\begin{array}{l}\text { Limited access to } \\
\text { updates in medical } \\
\text { field }\end{array}$ & 0.519 & 0.145 & 0.074 & 0.557 & 0.073 \\
\hline $\begin{array}{l}\text { Poor transportation } \\
\text { services }\end{array}$ & 0.08 & 0.309 & 0.279 & 0.528 & 0.283 \\
\hline More conflicts & 0.306 & 0.113 & 0.109 & 0.512 & 0.353 \\
\hline Poor communication & 0.039 & 0.242 & 0.4 & 0.467 & 0.258 \\
\hline $\begin{array}{l}\text { Lesser chance to } \\
\text { earn money through } \\
\text { other sources }\end{array}$ & 0.15 & 0.2 & 0.144 & 0.09 & 0.811 \\
\hline No extra rewards & 0.095 & 0.162 & 0.164 & 0.12 & 0.782 \\
\hline $\begin{array}{l}\text { Insignificant } \\
\text { allowances }\end{array}$ & 0.146 & 0.275 & 0.147 & 0.209 & 0.61 \\
\hline $\begin{array}{l}\text { Low professional } \\
\text { status }\end{array}$ & 0.231 & 0.133 & 0.223 & 0.29 & 0.455 \\
\hline Heavy workload & 0.017 & 0.187 & 0.207 & 0.308 & 0.452 \\
\hline
\end{tabular}

Confirmatory factor analysis (CFA) was the next step performed after exploratory factor analysis to determine the factor structure of the dataset. CFA in Amos 22 produces a path diagram. Final path diagram has been shown below in Figure 2. 


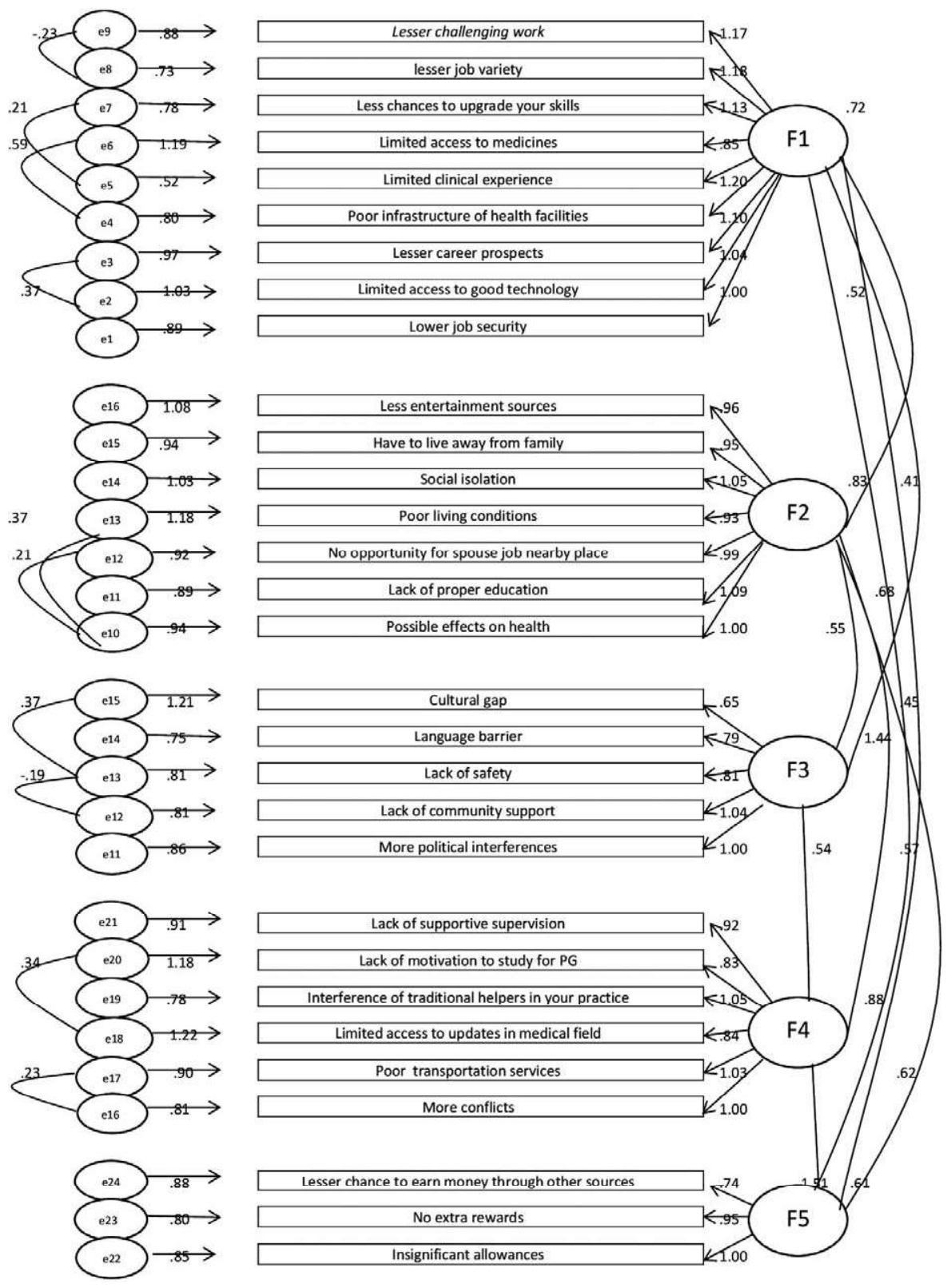

Figure 2- Measurement model obtained in CFA. CFA=confirmatory factor analysis

The values pertaining to CFA model are goodness-of-fit index $(\mathrm{GFI})=0.880$, adjusted goodness-of-fit index $(\mathrm{AGFI})=0.854$, Tucker-Lewis Index $(\mathrm{TLI})=0.905$, Comparative Fit Index $(\mathrm{CFI})=0.917$, and RMSEA $=0.062$, which indicates an acceptable model fit. 
The majority of the skewness and kurtosis values for variables lie between -2 and +2 , thus it is safe to assume about normality of data in a large sample size. Multivariate outliers detection analysis using Mahalanobis distance measure and Multicolli-nearity diagnostic using variance inflation factor (VIF) does not show any anomaly. Most of the Mahalanobis values were $<3$ whereas all the VIF values were $<10$.

The 5 factors highlighted by EFA and confirmed by CFA are the following.

\section{Subscale 1: lack of professional challenge}

It refers to the situation in which one's abilities and available resources in the professional environment may not be fully utilized, and where learning opportunities are limited, which hinders medical students to work in rural areas. Nine items viz. lesser challenging work, lesser job variety, lesser chances to upgrade skills, limited access to medicines, limited clinical experience, poor infrastructure of health facilities, lesser career prospects, limited access to good technology, and low job security were substantially loaded on this subscale. Internal consistency of this subscale was checked by Cronbach which was 0.858 but increases to 0.897 by dropping the item low job security. Thus, this subscale consisted of 8 items.

\section{Subscale 2: social segregation}

The social segregation factor considers reasons which relate to the specific interrelation between the environment, family, and social life that occurs in rural settings. In particular, it points to the fact that living in rural areas is often perceived as decreasing quality of care and reducing the opportunities for nurturing private life, in terms of family bonds, friendships, and hobbies. Less entertainment sources, have to live away from family, social isolation, poor living conditions, no opportunity for spouse job at nearby place, lack of educational opportunity for children, and possible effects on health due to social isolation were 7 items substantially loaded on this subscale. Internal consistency of this subscale was checked by Cronbach $a$ which was 0.859 . 
Chapter $5 \quad$ Reasons discouraging medical students from working in rural areas

\section{Subscale 3: socio-cultural gap}

The socio-cultural gap considers the gap between the socio-cultural background of medical students and the perceived rural socio-cultural environment. Gap in cultural practices, language barrier, lack of safety, poor community support and more interference by local administrative and political leaders were loaded on the socio-cultural factors (subscale) impeding medical students to work in rural areas. Cronbach $a$ measure found was 0.884 .

\section{Subscale 4: hostile professional environment}

This subscale considers the lack of congenial professional environment in rural settings. This perception is determined by a number of different aspects, including lack of stimulating supervision, interference by local traditional health practitioners or healers, poor technological infrastructure which impairs access to medical updates and poor transportation services which compromise fast service provision and professional trips. Lack of supportive supervision, lack of motivation to study for post-graduation, interference of traditional helpers in practice, limited access to updates in medical field, poor transportation services, and more conflicts were items loaded on this subscale. Internal consistency measured by Cronbach $a$ found for this subscale was 0.842 .

\section{Subscale 5: lack of financial incentives}

The financial factor takes into account the financial considerations related to working in rural areas. The attributes lesser chances to earn money through other sources, no extra rewards and insignificant allowances have been named as the financial factors for reluctance. Internal consistency of this subscale was checked by Cronbach $a$ which was 0.853. Table 1 presents the 5 subscales and the loadings on these subscales in EFA.

\section{Discussion}

The current study is the first one conducted in developing countries that developed and validated a scale describing the barriers faced by medical students for working in rural areas in Indian settings. The earlier few studies have either considered a limited spectrum 
of items in the questionnaire or were conducted in developed nations $[4,12,16,17,35,36]$. After rigorous literature review and expert Delphi consultations, a questionnaire consisting of 33 items was developed which was named the MSDRI questionnaire. Interestingly, our analyses highlight 5 factors/ subscales for the items listed in the questionnaire. Five main subscales, namely lack of professional challenge, social segregation, socio-cultural gap, hostile professional environment, and lack of financial incentives emerged to deter medical students from working in rural areas, and describe a complex nexus of reasons that undermines the presence of medical professionals in rural areas. Internal consistency using Cronbach $a$ was found good for all subscales.

The studies conducted globally have reported the items of demotivation that fall under these new emerged subscales in the current study. Gadi, [4] Kotzee and Couper, [5] Manongi et al, [6] Shankar and Thapa, [12] Henderson and Tulloch, [37] Lori et al,[35] Kaye et al, [38] and Steinhaeuser et al. [39] have mentioned items related to professional challenge as the barriers for medical students to serve in rural areas. Few studies in the context of the social segregation subscale are Gadi, [4] Saini et al, [16] Sinha, [17] Shankar and Thapa, [12] Lori et al,[35] and Kaye et al.[38] who concluded that low standard of living impedes medical students for working in rural areas. A study by Henderson and Tulloch [37] has reported that items related to hostile professional environment were responsible barriers for health workers for accepting rural postings. The health personnel value adequate water, sanitation, and up-to-date lighting and communication technologies and the lack of it hinder medical students to work in rural settings. A study by Manongi et al [6] stated that forcing health workers to perform tasks beyond their scope and lack of supervision from supervisors lead to frustration and demotivation. Another study by Kaye et al [38] reported that heavy workload, inadequate opportunities for continuing graduate training are the factors that make medical students not to work in rural areas. Other references in this context are Kotzee and Couper[5] and Saini et al. [16] A study by Gadi in 2012 [4] stated that language differences, insecurity, and fear of an unpleasant social response, which fall under the socio-cultural gap subscale, are demotivators to medical students for working in the North East Sri Lanka. 
In many studies, lack of financial incentives have been identified as a major reason for job dissatisfaction and/or migration among health workers [40-44]. A study by Kaye et al [38] reported insufficient salary and another study [39]conducted in Germany found that low salaries and high stress levels were prime contributors to physicians migration to urban areas.

Gadi, [4] Saini et al, [16] Shankar and Thapa [12] also indicate lack of financial factors as barriers to work in rural and remote areas.

The current study had the merit of a $100 \%$ response rate and ability to capture an entire population of young medical students of 6 medical colleges of North India. Nevertheless, there are a few limitations. Our sample consists of students from medical colleges of North India which may not necessarily represent the entire medical student population of the country, because profiles of medical students and socio-environmental factors are likely to differ between different settings. Notwithstanding, the prime objective of current study was to develop and validate a contextually relevant instrument, and not underpinning various deterrents of medical students to join medical studies. However, the rural areas in most states of India are almost similar. Further, all the discouraging factors were equally weighted and some may have been disregarded, even after thorough review of literature and adopting group consensus.

In addition, there is a slightly increased risk of misguided conclusions from SEM. Acceptable fit statistics might be caused by the estimation of correlations among measurement errors and omitting relevant variables from the model. This may lead to deviation from the model applying to the true population and may also bias the parameter estimates. However, in absence of a well-defined theoretical framework which guides variable selection, we have adopted the data-driven empirical approach by correlating errors. This model may be tested by researchers in range of settings $[45,46]$.

The need for developing and validating the current instrument is especially important given an ever increasing dearth of students opting for medical studies and not choosing to work in rural areas. An increasing shortage of physicians working in rural areas and hence a decrease in population health and health inequalities will be the result. Having a 
Chapter $5 \quad$ Reasons discouraging medical students from working in rural areas

newly-developed and validated instrument, like the MSDRI, to measure the reasons that discourage medical students from working in rural areas may be very helpful for policy makers. They can make new policies or strategies and set priorities so that medical students become willing to accept the rural postings. One can think of formulating effective measures such as mandatory postings in rural areas during the internship period, improved living and working conditions and providing extra incentives. Government should also make efforts in the direction of fulfilling the requirements as stated by medical students by implementing the MSDRI tool in different settings.

\section{Conclusions}

The newly-developed and validated instrument, the MSDRI, exploring the de-motivation factors of medical students for working in rural areas is a valid and reliable tool. Five broad domains emerged out in this tool are lack of professional challenge, social segregation, socio-cultural gap, hostile professional environment, and lack of financial incentives. This instrument can be implemented in other settings as well to explore the deterring factors so that strategies can be made to attract medical students to work in rural areas. However, a cautious approach should be adopted while undertaking error correlations in structural equation modelling, which may underscore the findings of study. 
Chapter $5 \quad$ Reasons discouraging medical students from working in rural areas

\section{References}

1. Vujicic M, Zurn P. The dynamics of the health labour market. Int J Health Plann Manage 2006;21:10115.

2. Nations U. Towards global equity in longevity. United Nations; 2012.Available at:www.un.org/esa/population/publications/popfacts/popfacts 2012-2.pdf.

3. Eastwood JB, Conroy RE, Naicker S, et al. Loss of health professionals from sub-Saharan Africa: the pivotal role of the UK. Lancet 2005; 365:1893-900.

4. Gadi $\mathrm{AD}$, Higuchi M, Warnasuriya N, et al. Medical students' willingness to work in post-conflict areas: a qualitative study in Sri Lanka. Health 2012;4:824-31.

5. Kotzee TJ, Couper ID. What interventions do South African qualified doctors think will retain them in rural hospitals of the Limpopo province of South Africa? Rural Remote Health 2006;6:581.

6. Manongi RN, Marchant TC, Bygbjerg IC. Improving motivation among primary health care workers in Tanzania: a health worker perspective. Hum Resour Health 2006;4:6.

7. Willis-Shattuck M, Bidwell $\mathrm{P}$, Thomas $\mathrm{S}$, et al. Motivation and retention of health workers in developing countries: a systematic review. BMC Health Serv Res 2008;8:247.

8. Astor A, Akhtar T, Matallana MA, et al. Physician migration: views from professionals in Colombia, Nigeria, India, Pakistan and the Philippines. Soc Sci Med 2005;61:2492-500.

9. Syed NA, Khimani F, Andrades M, et al. Reasons for migration among medical students from Karachi. Med Educ 2008;42:61-8.

10. Muhammad Gadit AA. Migration of doctors: should we apply the index of happiness? J Pak Med Assoc 2008;58:342-4.

11. Vujicic M, Zurn P, Diallo K, et al. The role of wages in the migration of health care professionals from developing countries. Hum Resour Health 2004;2:3.

12. Shankar P, Thapa TP. Student perception about working in rural Nepal after graduation: a study among first- and second-year medical students. Hum Resour Health 2012;10:27.

13. Hazarika I. Health workforce in India: assessment of availability, production and distribution. WHO South-East Asia J Public Health 2013;2:106-12.

14. Rao M, Rao KD, Kumar AKS, et al. India: towards universal health coverage 5 human resources for health in India. Lancet 2011;377:587-98.

15. Rao K, Bhatnagar A, Berman P. India's health work force: size, composition, and distribution. Indian Heal Beat 2009;1:4.

16. Saini NK, Sharma R, Roy R, et al. What impedes working in rural areas? A study of aspiring doctors in the National Capital Region, India. Rural Remote Health 2012;12:1967.

17. Sinha RK. Perception of young doctors towards service to rural population in Bihar. J Indian Med Assoc 2012;110:530-4.

18. Hsu C, Sandford B. The delphi technique: making sense of consensus. Pract Assess Res Eval 2007;12:18.

19. MacCallum RC, Widaman KF, Zhang S, et al. Sample size in factor analysis. Psychol Methods 
Chapter 5 Reasons discouraging medical students from working in rural areas

1999;4:84-99.

20. Lynn MR. Determination and quantification of content validity. Nurs Res 1986;35:382-5.

21. Terwee CB, Bot SD, de Boer MR, et al. Quality criteria were proposed for measurement properties of health status questionnaires. J Clin Epidemiol 2007;60:34-42.

22. Tabachnick BG, Fidell LS. Using Multivariate Statistics. 5th ed. Boston: Allyn \& Bacon; 2007.

23. Kaiser HF. An index of factorial simplicity. Psychometrika 1974;39:31-6.

24. Kaiser HF. The application of electronic computers to factors analysis. Educ Psychol Measur 1960;20:141-51.

25. Sharma S. Applied Multivariate Techniques. USA: John Willey \& Sons, Inc; 1996.

26. Hair J, Anderson R, Tatham R, et al. Multivariate Data Analysis with Readings. USA: Prentice-Hall International, Inc; 1995; 373.

27. Schene A, Wijngaarden B, Koeter M. Family caregiving in schizophrenia: domains, distress. Schizophr Bull 1998;24:609-18.

28. Cronbach LJ. Coefficient alpha and the internal structure of tests. Psychometrika 1951;16:297-334.

29. Nunnally JC, Bernstein IH. Psychometric Theory. New York: McGraw- Hill; 1996.

30. Fabrigar LR, Wegener DT, MacCallum RC, et al. Evaluating the use of exploratory factor analysis in psychological research. Psychol Methods 1999;4:272-99.

31. Schumacker RE, Lomax RG. A Beginner's Guide to Structural Equation Modeling. New Jersey: Lawrence Erlbaum Associates; 1996.

32. Bollen KA. Structural Equations With Latent Variables. 2nd ed. New York: Wiley Online Library. Copyright (C 1989 John Wiley \& Sons, Inc. DOI: 10.1002/9781118619179.

33. Tomarken AJ, Waller NG. Structural equation modeling: strengths, limitations, and misconceptions. Annu Rev Clin Psychol 2005;1:31-65.

34. $\mathrm{Hu} \mathrm{L}$, Bentler PM. Cutoff criteria for fit indexes in covariance structure analysis: conventional criteria versus new alternatives. Struct Equat Model 1999;6:1-55.

35. Lori JR, Rominski SD, Gyakobo M, et al. Perceived barriers and motivating factors influencing student midwives' acceptance of rural postings in Ghana. Hum Resour Health 2012;10:17.

36. Shankar PR, Dubey AK, Nandy A, et al. Student perception about working in rural United States/Canada after graduation: a study in an offshore Caribbean medical school. Version 2. F1000Res 2015;3:301.

37. Henderson LN, Tulloch J. Incentives for retaining and motivating health workers in Pacific and Asian countries. Hum Resour Health 2008;6:18

38. Kaye DK, Mwanika A, Sekimpi P, et al. Perceptions of newly admitted undergraduate medical students on experiential training on community placements and working in rural areas of Uganda. BMC Med Educ 2010;10:47.

39. Steinhaeuser J, Joos S, Szecsenyi J, et al. A comparison of the workload of rural and urban primary care physicians in Germany: analysis of a questionnaire survey. BMC Fam Pract 2011;12:112.

40. Stilwell B, Diallo K, Zurn P, et al. Migration of health-care workers from developing countries: strategic approaches to its management. Bull World Health Organ 2004;82:595-600.

41. Dieleman M, Cuong PV, Anh LV, et al. Identifying factors for job motivation of rural health workers in 
North Viet Nam. Hum Resour Health 2003;1:10.

42. Oum S, Keat P, Saphonn V, et al. Human Resources for Health and Child Survival in Cambodia. Bankok: Asia Pacific Action Alliance on Human Resources for Health, Country reviews; 2005.

43. Soeters R, Soeters R, Griffiths F, et al. Improving government health services through contract management: a case from Cambodia. Health Policy Plan 2003;18:74-83.

44. Wibulpolprasert S, Pengpaibon P. Integrated strategies to tackle the inequitable distribution of doctors in Thailand: four decades of experience. Hum Resour Health 2003;1:12.

45. Hermida R. The problem of allowing correlated errors in structural equation modeling: concerns and considerations. Comput Methods Soc Sci 2015;3:5-17.

46. Cortina J. "Big things have small beginnings; an assortment of minor methodological understandings". J Manag 2002;28:339-62. 


\section{Chapter 6}

Factors affecting medical students interests in working in rural areasin

India

Sonu Goel, Federica Angeli, Nonita Dhirar, Garima Sangwan, Kanchan Thakur, Dirk Ruwaard

PloS One 2019;14(1): e0210251

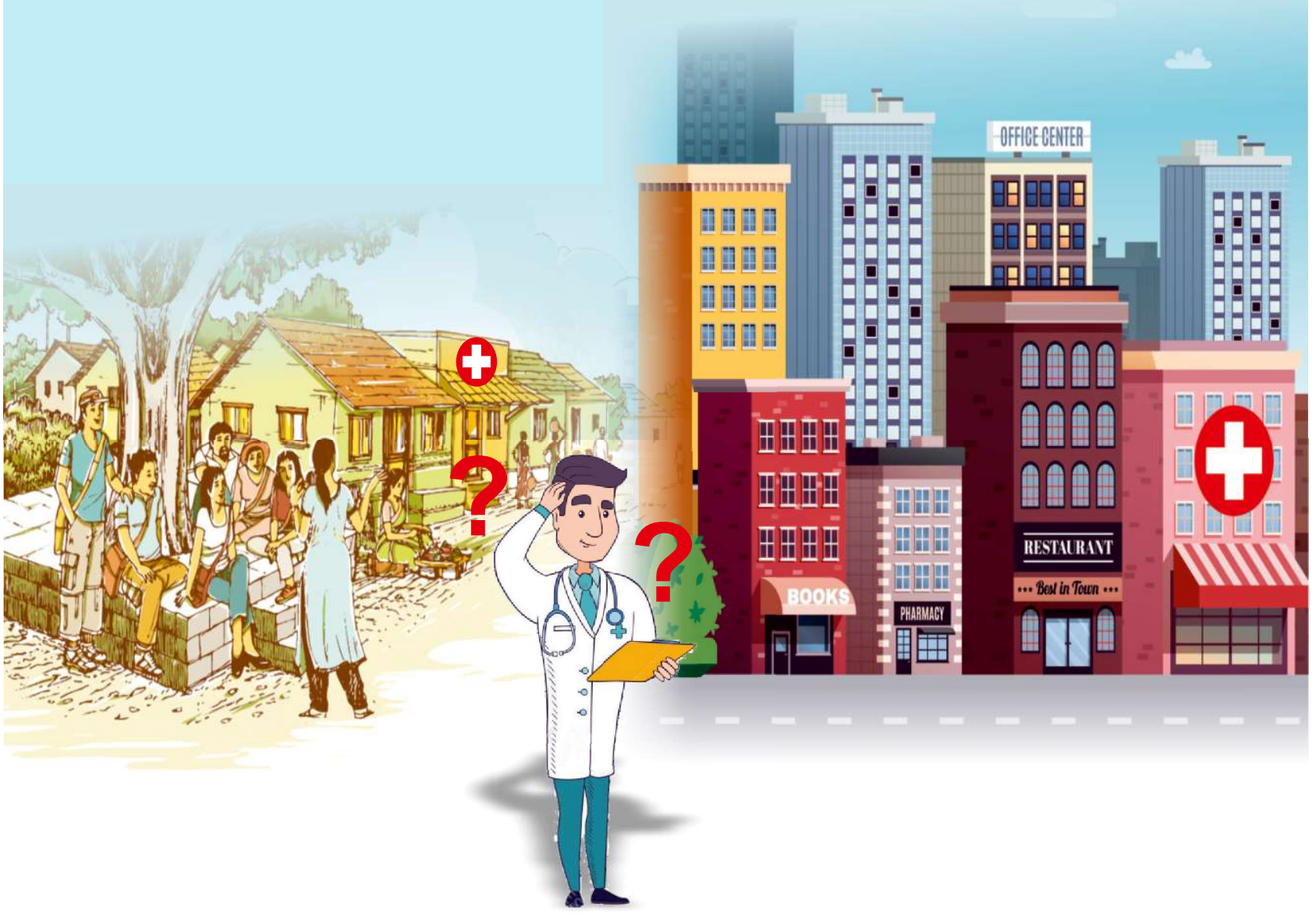




\section{Abstract}

Background and Objective: The shortage of doctors, especially in rural areas, is a major concern in India, which in turn affects the effective delivery of health care services. To overcome this issue, a study was conducted to determine the discouraging and encouraging factors affecting medical students' interests in working in rural areas.

Methods: This cross-sectional, descriptive qualitative study was conducted in three states of North India. It comprised six focus group discussions each comprising 10-20 medical students in six randomly selected government medical colleges. The verbatim and thematic codes were transcribed by using a 'categorical aggregation approach'. The discussions were thematically analyzed.

Results: Ninety medical students participated in the study (100\% response). The main factors identified were 'scientific and professional' (poor accommodation facilities and lack of necessary infrastructure; lack of drug and equipment supplies; inadequate human resource support, lesser travel and research opportunities) and 'societal'(less salary and incentives, social isolation, political interference, lack of security). The primary encouraging factors were 'humanitarian' (desire to serve poor, underprivileged and home community), 'scientific and professional' (preferential admission in post-graduation after working more than 2-3 years in rural areas) and 'societal' (achieving higher social status).

Conclusions: This first qualitative study in an Indian context highlights key factors for medical students to work in rural areas. A substantial similarity was noted between these factors emerging in the Indian context and the ones documented in other countries. These findings will help policymakers and medical educators design and implement a comprehensive human resource strategy targeting specific factors to encourage students and interns to choose job positions in rural areas. 


\section{Introduction}

There is a shortage of doctors globally, especially in rural and remote areas, which hinders the progress towards improving the health of people in these areas [1-2]. This global challenge has been accorded high priority by the World Health Organization (WHO) [3]. Against the optimal threshold of 4.45 skilled health professionals including one doctor per 1,000 population, the estimated shortage is 17.4 million experienced professionals and 2.6 million doctors globally, with the greatest shortage in the high disease burden countries of South East Asia and African regions [4]. There is a need to increase the health workforce for achieving essential health services in both low income and upper-middle-income countries [5]. Current data document that more than $44 \%$ of WHO member states have fallen short of the WHO standard of one physician per 1,000 populations [6].

India, with a population of over 1 billion, is placed in the lowest category of human resources for health (HRH) indicators. [7] A large number of trained doctors leave India for residency training and to work abroad, while the remaining works in urban areas. This pattern has resulted in an uneven distribution of doctors in India [8]. Rural health statistics-India 2016 reports a shortfall of $11.6 \%$ of medical officers at the primary health care level and $81.2 \%$ of medical specialists at community health centers [9]. The gap between the numbers of doctors working in urban areas as compared to rural areas is widening, which is endangering the functioning and sustainability of the Indian health care system [10-11].

A few studies conducted in developed countries, such as the UK, Australia, New Zealand, Croatia, and Hungary, had assessed the perception and attitudes of medical students towards rural settings. They observed that social isolation, poor housing support, poor equipment supply, need for career development and inadequate incentives were the primary deterrents for doctors towards working in rural areas [12-16]. The studies from developing countries like Bangladesh, India, Malawi, and Ghana had also shown similar

results citing factors like accommodation, infrastructure, poor resources and financial motives [17-21] as major deterrents by medical students to work in rural areas. A mixture 
of factors was cited by elements of other studies from both developed and developing countries [22-25].

Various strategies have been implemented in the health sector to recruit and retain health professionals in rural and remote areas [12,16,26]. These measures have attempted to address not only financial incentives, but also non-financial incentives like living conditions, education opportunities for employees' children, and future career prospects $[12,16,21]$. Numerous efforts were also made by the Government of India to promote postings in rural areas, such as preferential admission in post-graduation after working for a fixed time period in rural areas [18,19], compulsory rural field experience during medical studies and rural service after medical graduation [18], or rural allowances [1819]. However, they have tasted only sporadic success, primarily because of the implementation of isolated strategies rather than bundled interventions [8,10-11,18-19]. Moreover, relatively little research has been done in India, on understanding the perceptions of medical students about the factors that can promote rural practice [10-12].

Medical education in India consists of a five and a half years course of medical teaching in a tertiary health care institution which includes one year of compulsory internship. The medical study focuses on basic pre-clinical subjects for the first two and a half years and clinical subjects for the next two years. The students simultaneously obtain hands-ontraining in the wards and outpatient departments, where they interact with real patients. The four and half years of medical study are followed by one year of internship wherein the medical students (now called interns) undergo compulsory rotational postings in various clinical disciplines. Postings can be conducted in the medical college hospital or any approved hospital facility (also known as Teaching Hospital) in order to obtain practical experience under supervision of senior doctors. Apart from being posted in other clinical disciplines, the interns are compulsorily posted for three months in the community where they not only practice skills in patient care accumulated during earlier postings but also learn comprehensive care including preventive, promotive, curative and rehabilitative services. The interns do not have a full license to practice medicine 
unsupervised by the Medical Council of India and are being paid a meagre stipend to sustain their expenditures. After the period of internship, the interns are expected to acquire competencies to deal effectively with an individual and the community in the context of primary health care during their posting in government-funded primary or secondary care hospitals. The primary care units are essentially single-physician clinics usually with facilities for minor surgeries, whereas, secondary care centers are referral units with advanced specialized facilities like obstetric and new born care, major surgical facilities and blood storage capacities at all hours every day.

In countries like India, where government funds bear the cost of medical education for the majority of its medical students, reliable measures for retaining health professionals in rural areas is of prime concern. The existing research demonstrates that it is possible for medical schools to combat the dearth of doctors in rural areas by selecting medical students from a rural background and also providing medical education in a rural setting $[12,16,18]$. However, there is insufficient evidence from India in support of these ideas as fewer studies have been conducted $[18,19]$.

Therefore, understanding the perception of medical students about the challenges of rural areas could predict their subsequent practice location and help stimulate their choice to work or stay in rural areas. The present study aims at exploring medical students' interest in working in rural settings in India by examining the discouraging and encouraging factors.

\section{Material and methods}

\section{Study design}

This research used qualitative methods of inquiry in order to explore the discouraging and encouraging factors affecting medical students' interests in working in rural areas, along with understanding the context and mechanisms behind their interests. The entire process of conducting the FGD was based on standard literature on qualitative research [27]. 


\section{Study setting}

The study has been conducted in three northern states of India (Himachal Pradesh, Haryana, and Punjab) which have a combined population of around 60 million [28]. These three states have a total of six government medical colleges. The states are almost equal in area, size and have poor health indicators as compared to the southern part of India. Many areas in these northern states are predominantly 'rural' and categorized by low population density with poor facilities for doctors, hence face difficulty in recruiting and retaining them.

\section{Study population}

The current qualitative research is a part of broader mixed method study which included 636 medical students (including interns) of six government medical colleges of three states viz. Himachal Pradesh (HP), Punjab and Haryana located in Northern India. Of the 636 medical students, 297 (53.3\%) were males, and 339 (46.7\%) were females. The average age for males was 22.4 years $(\mathrm{SD}=2.03)$ and for females 22.10 years $(\mathrm{SD}=$ 1.53). Most (97.8\%) were unmarried, $81 \%$ of students had completed their premedical studies in urban areas, and $40.7 \%$ belonged to rural family background. Final year students of Bachelor of Medicine, Bachelor of Surgery (MBBS) and interns were selected as they are near to complete their medical education and have to decide their posting in rural or urban areas.

After obtaining quantitative data, focus group discussions (FGDs) were conducted among few of them. A variable number (between 10 and 20) of students from each medical college was enrolled in an FGD, thus totalling to 90 students from 6 FGDs. The students who were very vocal had experienced a clinical environment and were thought to provide the best information in the form of positive or negative comments ('information rich' cases) were purposively included in the FGD, to guarantee sample heterogeneity. The selection process ensured the homogeneity of participants in terms of year of medical study and at least one other characteristic among gender, medical school admission process or rural interest. These selection criteria were applied because they 
can contribute to the student's attitude towards rural practice [29,30]. Representativeness of the college population was ensured by including all the government medical colleges in the three states. Representativeness on other dimensions such as age, gender, ethical/religious background, and geographical origin was also assured [27,31]. When the researchers observed that no new themes emerged in the last FGDs, they deemed that saturation had been achieved and that no additional FGDs were necessary.

\section{Study tool}

Focus group guidelines with open-ended questions were developed based on the existing literature $[11,12,16,18,29]$. FGDs were conducted to explore information about the topic of interest using structured discussions. The trained facilitators used a pre-prepared topic list of questions on discouraging and encouraging factors related to working in rural areas. Further, students were asked to recommend possible interventions that may be effective to improve attraction and retention of doctors in rural areas. The questions used for the FGDs are shown in Table 1.

\section{Data collection}

A prior written informed consent was taken from the participants. The participants were ensured about their anonymity and confidentiality while reporting the results. The necessary permissions were also obtained from Principals of medical colleges in each state.

The research team consisted of two research assistants (Masters of Public Health with two years of research experience) and one research associate (Ph.D.), who were well versed with local languages and trained in qualitative research methods. The research assistants conducted the FGDs, one being the moderator and the other the facilitator. The FGDs were conducted in the native local language, at a suitable time and place convenient to the participants. The purpose of the study has been explained to the participants, to allow for an informed participation choice. After an 'icebreaker' question, 'discussion starter' questions were floated among the participants for generating interest 
in the topic, facilitating discussion and deterring 'group think'. After that, open-ended questions were asked to obtain the participants' perspective on the problem. Each person was asked to provide a final summary statement before concluding the session. After that, the research associate concluded the discussion by summarizing the key statements raised during the FGD to ensure participants' validation.

Table 1: Questions asked during focus group discussions to identify encouraging and discouraging factors for working in rural areas.

How many of you would like to serve in rural areas after graduation?

What, according to you are the motivational factors of working in a rural setup?

What, would you say, are the possible challenges faced while working in a rural setting?

What facilities have been provided by the government to retain doctors in rural areas?

What provisions should be made available by the government to encourage doctors to work in rural areas?

\section{Data analysis}

The two research assistants took notes of the focus group session and independently examined and coded the transcripts for reduction of bias and interpretative credibility. After that, categories were developed representing themes in the subject area by combining similar codes (inductive approach). The consensus was obtained by further discussion of the final data with the research associate, principal investigator and subject experts (academicians and researchers $(n=6)$, program managers $(n=3)$ and policymakers $(\mathrm{n}=3))$. They also examined the transcripts separately to determine whether any new issues or themes had emerged, ensuring the completeness of ideas and reliability of the data. The verbatim and thematic codes were transcribed by using a 'categorical aggregation approach' [32,33]. The results of both medical students, as well as interns, were grouped during analysis since both were in the phase of decision-making regarding choosing to work in rural areas. The findings were reported in accordance with the Qualitative Research reporting guidelines COREQ (Consolidated criteria for 
reporting qualitative research) [34].

This study has been approved by the Institute Ethical Committee (PGI/IEC/2012/810-I P154) of Post Graduate Institute of Medical Education and Research, Chandigarh, India.

\section{Results}

Ninety students participated in the study with males $(n=51,56.7 \%)$ outnumbering females $(n=39,43.3 \%)$. The age range was 20-27 years (mean age 22.4 years, SD 2.03) and all were unmarried. Nearly one-third of the study subjects were from the state of Himachal Pradesh $(\mathrm{n}=33 ; 36.7 \%)$, and quite similar numbers belonged to Punjab $(\mathrm{n}=$ $30 ; 33.3 \%)$ and Haryana $(n=27 ; 30 \%)$. There were almost equal numbers of final year medical students $(n=46,51.1 \%)$ and interns $(n=44,48.9 \%)$. Around one third $(n=32$, $36 \%)$ belonged to the rural background while one fifth $(\mathrm{n}=15,20 \%)$ underwent premedical studies (i.e., prerequisite educational track during secondary schooling for obtaining admission in medical school) from rural areas. (Table 2)

Table 2: Descriptive statistics of the sample $(n=90)$

\begin{tabular}{|c|c|c|c|c|c|c|}
\hline & $\begin{array}{l}\text { FGD } 1 \\
(n=20) *\end{array}$ & $\begin{array}{l}\text { FGD } 2 \\
(n=15)\end{array}$ & $\begin{array}{l}\text { FGD } 3 \\
(n=10)\end{array}$ & $\begin{array}{l}\text { FGD } 4 \\
(n=15)\end{array}$ & $\begin{array}{l}\text { FGD } 5(n \\
=10)\end{array}$ & $\begin{array}{l}\text { FGD } 6 \\
(n=20)\end{array}$ \\
\hline $\begin{array}{l}\text { Age group } \\
\text { (in years) }\end{array}$ & $22-27$ years & $22-27$ years & $22-27$ years & $\begin{array}{l}22-27 \\
\text { years }\end{array}$ & $22-27$ years & $22-27$ years \\
\hline Gender & $\begin{array}{c}\text { Males }=10 \\
\text { Females }=10\end{array}$ & $\begin{array}{c}\text { Males }=8 \\
\text { Females }=7\end{array}$ & $\begin{array}{l}\text { Males }=6 \\
\text { Females }=4\end{array}$ & $\begin{array}{l}\text { Males }=9 \\
\text { Females }=6\end{array}$ & $\begin{array}{l}\text { Males }=8 \\
\text { Females }= \\
2\end{array}$ & $\begin{array}{l}\text { Males }=10 \\
\text { Females } \\
10\end{array}$ \\
\hline $\begin{array}{l}\text { Final year } \\
\text { intern ratio }\end{array}$ & $7: 13$ & $8: 7$ & $4: 6$ & $8: 7$ & $6: 4$ & $13: 7$ \\
\hline $\begin{array}{l}\text { Geographical } \\
\text { origin wise } \\
\text { distribution }\end{array}$ & $\begin{array}{l}\text { Himachal } \\
\text { Pradesh }=15 \\
\text { Punjab }=2 \\
\text { Haryana }=3\end{array}$ & $\begin{array}{l}\text { Himachal } \\
\text { Pradesh =13 } \\
\text { Punjab = } 1 \\
\text { Haryana = } 1\end{array}$ & $\begin{array}{l}\text { Himachal } \\
\text { Pradesh = } 1 \\
\text { Punjab = } 8 \\
\text { Haryana=1 }\end{array}$ & $\begin{array}{l}\text { Himachal } \\
\text { Pradesh = } \\
2 \\
\text { Punjab=12 } \\
\text { Haryana= } \\
1\end{array}$ & $\begin{array}{l}\text { Himachal } \\
\text { Pradesh }=1 \\
\text { Punjab }=3 \\
\text { Haryana=6 }\end{array}$ & $\begin{array}{l}\text { Himachal } \\
\text { Pradesh = } 1 \\
\text { Punjab = } 4 \\
\text { Haryana = } \\
15\end{array}$ \\
\hline $\begin{array}{l}\text { Rural } \\
\text { background }\end{array}$ & 7 & 5 & 4 & 6 & 5 & 5 \\
\hline $\begin{array}{l}\text { Underwent } \\
\text { premedical } \\
\text { studies from } \\
\text { rural areas }\end{array}$ & 3 & 2 & 1 & 4 & 2 & 3 \\
\hline
\end{tabular}


The analysis revealed that the level of medical students' interest in rural areas could be structured broadly into discouraging and encouraging factors. The discouraging factors were further grouped under two themes- unchallenging professional environment and gap between financial rewards and social disadvantages; whereas encouraging factors were grouped under three themes- willingness to give back to disadvantaged communities, broader clinical exposure, and higher status and respect. All students mentioned both discouraging and encouraging factors but stressed more on discouraging factors as compared to encouraging factors.

\section{Discouraging factors}

Theme-1: Unchallenging professional environment. The students cited unavailability of cutting-edge technologies, inadequate human resource support, fewer opportunities to travel abroad and fewer research options as barriers to work in rural areas. Moreover, poor accommodation facilities along with lack of basic amenities (like inadequate hospital infrastructure, poor drug supply and lack of equipment) demotivate them to work in rural settings. The following quotes express the students' opinions:

- 'We can't cater to diagnostic and curative needs of all the patients due to lack of modern equipment.'

- 'There is no equipment, no medication, and no challenging work in rural areas.'

- 'There is no staff in Primary Health Centers (PHCs), no helpers to assist us. How can a doctor work without human resource?'

- 'The basic facilities, like electricity, proper infrastructure, accommodation, medicines, etc. are lacking. It is very difficult to work in such scenario. '

Some respondents expressed that they lacked the competence to serve in rural areas, as they were not adequately taught rural medicine and primary care during their medical education. They strongly felt a need to incorporate rural healthcare in the curriculum of medical education depicted by their statements:

- 'We are not confident to treat illnesses in a rural area as we are not taught rural medicine in our syllabus.' 
- 'There are atypical clinical cases in rural areas to which we have not been exposed. We lack knowledge for their effective management.'

The students believed that improved hospital infrastructure and supplies, provision of basic amenities in hospitals (for example, water supply, sanitation, electricity, accommodation),availability of communication facilities (roads, phones, internet) and preferential opportunity to go abroad for updating skills would incite them to work in rural areas. Some statements:

- 'We want state-of-art technology, access to the latest medicines and equipment in rural setups so that our skills are not wasted.'

- 'After five years of rural service, a doctor should be given an opportunity to visit abroad to learn about newer technologies.'

Theme-2: Gap between financial rewards and social disadvantages. The medical students felt that they would probably be isolated and left out in the remote and rural settings. Students have a general feeling that the salary package offered in rural areas does not fairly compensate for the benefits of working in urban areas. They wished that the salary package for doctors working in a rural area should be significantly more than the doctors serving in urban settings. They expressed their feelings as:

- 'The salary and other emoluments should be significantly more for rural areas as compared to urban.

- 'The students who will be graduating by paying hefty admission fees will tend to work in the private hospitals in urban areas to make more money to compensate for hefty fees.'

Isolation from families, loneliness, boredom, and lack of work opportunities for a spouse was other factors, which repel medical students from working in rural areas. Political interference in the form of frequent transfers of doctors from one place to another, the insensitive attitude of the community leaders towards them, incidents of violence and lack of security also discourage them towards working in the rural area. The students mentioned the problems as follows:

- 'We don't want to live away from our families.' 
- 'Work options for spouse and schooling for children in rural areas are not as good as in urban areas.'

- 'We have heard that few influential people threaten doctors to see their patients on priority, which compromises their security in an isolated rural setting.'

- 'There should be less political interference and more security for doctors working in rural areas.'

\section{Encouraging factors}

The most common encouraging factors for medical students' towards working in rural and remote areas after completing graduation could be categorized under three major themes, as described below.

Theme-1: Willingness to give back to disadvantaged communities. The students had a desire to serve the poor and underprivileged communities who cannot afford quality medical services. Further, they feel responsible and privileged towards their family and community who have supported them during their studies. The respondents were also aware of the real unmet needs in rural areas. Their words describing the desire to give back to their people are as follows:

- 'My parents have shown me the path and have supported me throughout my studies.'

- 'I want to pay the debt to the community where I was born and studied by serving them.'

Theme-2: Broader clinical exposure. The medical students mentioned that they would gain better clinical experience while practicing on the diverse group of patients in rural areas, which would be unusual in urbanized settings. Also, they had the edge over their counter parts in getting preference for admission to post-graduation courses after a few years of rural service.

The statements that summarize their perceptions are as below:

- 'We would get more exposure to various types of cases in the rural areas.'

- 'We want to get admission in post-graduation, so prefer to serve in rural areas.' 
Theme-3: Higher status and respect. The medical students also perceived that they would get more respect in society if they practice in the rural community. They also opined that the people in rural areas are humble and appreciative of the medical profession. The students quoted their feelings as follows:

- 'People in rural areas are more thankful unlike in urban areas.'

- 'Our motivation increases when the community shows respect and gratitude for our hard work.'

\section{Discussion}

This is the first qualitative study from the northern part of India, which explored the factors influencing medical students' interest to work in rural areas. The earlier studies have evaluated isolated governmental efforts to retain health workforce in rural areas, such as financial incentives, compulsory rural field experience, and preferential admission in post-graduation [10-12]. Little research on understanding the perceptions of medical students about the factors that can promote rural practice has been conducted, which could serve as good predictors for their subsequent practice location in rural areas. The themes generated out of the present exploratory qualitative study are in confirmation with the themes emanated from the quantitative development and validation study by Goel et al., hence strengthening the findings [35]. Further, the findings of the present study can be mirrored to the Maslow's Hierarchy of needs theory for the better understanding of the issue of motivation of medical students towards working in rural areas [36].

The five-stage "Maslow's Hierarchy of Needs" behavioral model of motivation places from below upwards; physiological, safety, belongingness, self-esteem; and selfactualization need (Figure 1). The theory states that the motivation of an individual undergoes a transition to higher segments (self-esteem, self-actualization) after fulfillment of needs in the lower segments (physiological, safety/security) of the pyramid. In the present study also, it was observed that the discouraging factors were the ones that lie in the lower segments of the pyramid and were stronger influencers of motivation as compared to encouraging factors. In low and middle income countries, the 
students fall in the lower segments of the Maslow's pyramid as they were still struggling to receive basic health care facilities and employment opportunities. Hence their major motivating factors were primarily humanitarian (like willingness to give back to disadvantaged communities), which is fulfilled, could lead to higher-level needs for motivation. Thus, Maslow's Hierarchy of needs theory helps us to understand the issue of motivation of medical students towards working in rural areas.

\section{DEMOTIVATING FACTORS}

\section{MOTIVATING FACTORS}

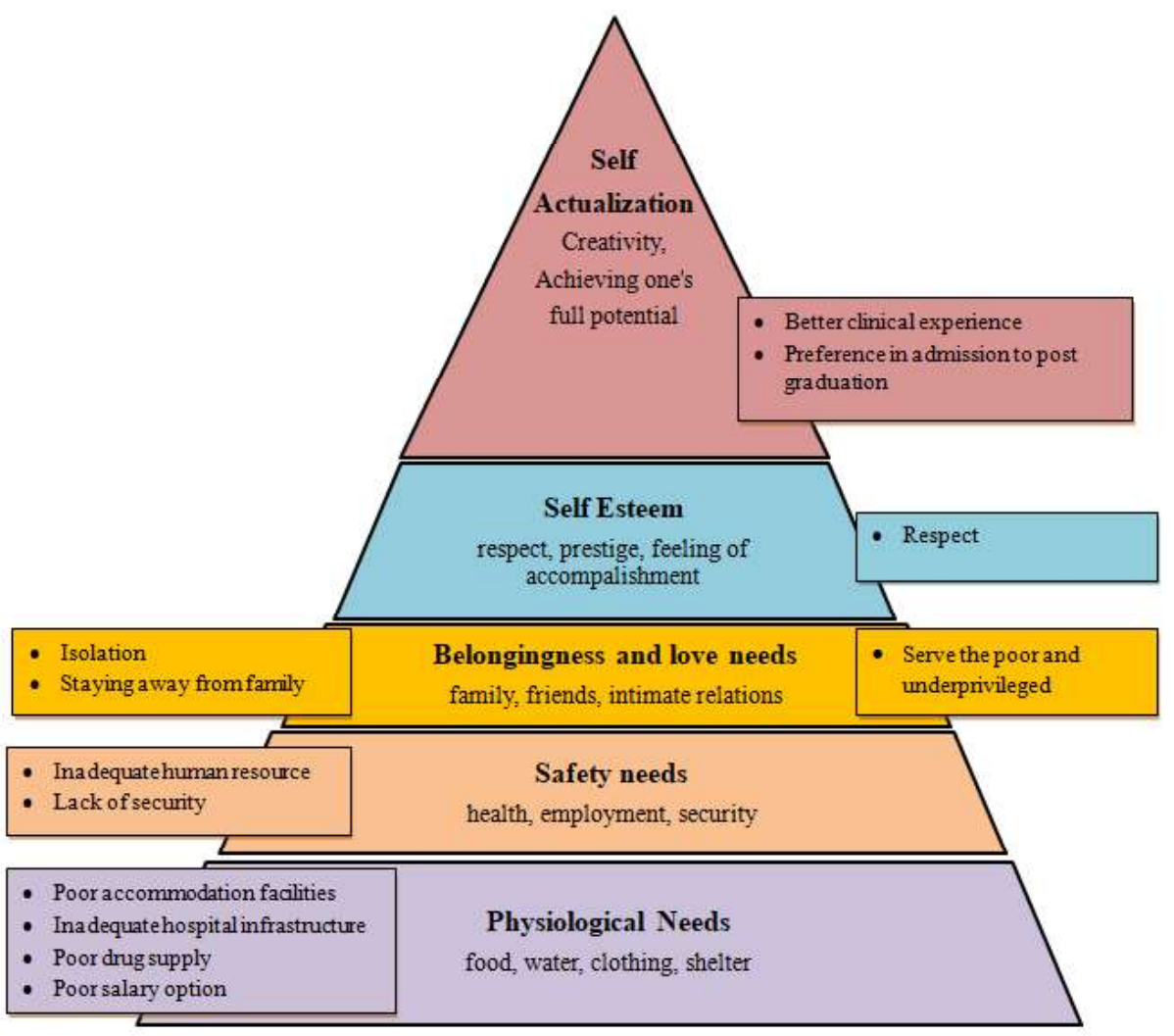

Figure 1- Factors motivating medical students to work in rural as depicted by Maslow's Hierarchy of needs pyramid.

The results of this research are in line with other studies that have identified unchallenging professional environment like hospital infrastructure [15,18,19,37,38,39], poor drug and equipment supply [15,19,38,39], lack of human resources [37-40], poor 
transport services $[37,38,40]$, inadequate housing/accommodation $[37-42]$ as the discouraging factors affecting the choice of medical students to work in rural settings. It is hardly surprising that doctors who were used to working with the best equipment in medical colleges lack the willingness to work in rural hospitals where these components are lacking. The medical graduates also consider it essential to treat patients to the best of their ability, which they perceived as less possible in rural hospitals. The students' perception about the unavailability of cutting edge technology as one of the key discouraging factors highlights the faulty medical education of India which overemphasizes specialized care over basic medical services in rural areas. Thus, a curriculum based on rural medicine, which would strengthen the skills of medical students in tackling rural illnesses, is needed for a country where the majority of the population resides in rural areas. Further, a human resource policy for medical doctors at the national and state levels is needed, which should ensure rational staffing along with adequate remuneration based upon the area of posting. Improving facilities and the availability of medical supplies may be resource intensive; however, it is a long-term investment that may yield positive results, especially when accompanied by additional professional support. The feeling of unavailability of resources among students also suggests their reluctance to face rural realities and a disjuncture between students and rural society.

The financial factors, such as low salary and insufficient incentives, under the theme ' $\mathrm{g} a p$ between financial rewards and social disadvantages' also emanated to be a deterrent for students 'willingness to work in rural areas. Similar findings were observed in other studies globally [15, 16, 37-39]. Rural practice may be encouraged through direct financial incentives.

However, its impact on retention of doctors from developing countries is not conclusive with the exceptions of few countries such as Mali, Zambia, and South Africa [43-49]. In developing nations, it is widely documented that the financial incentives must be supplemented by adequate living conditions like providing free housing and transport, communication sources (telephones, internet), jobs for spouses and recreational activities $[37,38,40,42,43]$. Thus in adequate financial incentives may not be the only important 
factor in the medical students' decision to work in remote or rural areas. Moreover, this type of intervention can be very costly, and may not be sustainable, with a risk of the spillover effect of raising salary in other service sectors as well.

The theme also encompasses the findings of medical students' concerns of being isolated from family, friends and other social support networks at rural posts, which are also supported by other studies [38,39,41]. Similar to the results of current study, other studies have also documented the unattractive rural lifestyle as a key factor that negatively affects the attitudes of medical students to work in rural settings [23-24, 50-51]. Organized events and informal opportunities to socialize with professional peers and local communities had a positive influence on perceptions of appreciation and recognition [42-46]. Similar to few countries that have undertaken special efforts to assist rural doctors' spouses in finding employment in the same area, and in facilitating admission of their children to high-quality schools with boarding arrangements, other countries can plan along the similar lines. [47-49]. Some governments have implemented rotation policies, in order to limit the time spent in a difficult area within the entire professional career [11-12,17].

Very few encouraging factors emerged from the study, which influenced students' interest to work in rural areas. They were mostly categorized under the theme-willingness to give back to disadvantaged communities, which contained factors like serving the poor community and desire to give back to the home community. These factors were also the dominant factors in the studies conducted globally [18-19, 21-22]. In India, the feeling of serving the poor and underprivileged is a value embedded in medical students for the inner satisfaction of their humanitarian motives [18-19].

The factors that are grouped under the theme of broader clinical exposure were 'gain of better clinical experience' and 'the ability to easily get into post-graduation courses after serving a few years in rural service'. Participants believed that the experience of working in a rural area would be valuable and would positively influence their future career. These findings were incoherence with the findings of many other studies [39,40,42]. The societal factors that provided a boost to their motivation and self-esteem were aggregated under the broader theme of higher status and respect. Other studies have also quoted 
'prestige' and 'respect' as the major facilitators for working in rural areas. [44-53]. It indicates that teaching students to build harmonious relationships with other individuals and groups in the villages can go a long way. It will also make communication easier and more effective.

There are various strengths of the study. Firstly, the current qualitative study has explored the discouraging and encouraging factors from three large states of India. Secondly, the themes generated out of the present exploratory study are in support with the themes emanated from the quantitative development and validation study conducted by authors, hence strengthening the findings [35]. Thirdly, COREQ guidelines for reporting the qualitative outcomes were strongly adhered to while reporting the results [34].

The study also has limitations. Firstly, it explained the opinion of medical students, which may not be truly reflecting their decision to work in rural settings. The establishment of any possible causal link between motivation and decision to work in rural settings was beyond the scope of present research. Secondly, the FGD may have led to socially desirable responses in the form of positive self-description rather than their honest opinions. Moreover, since the students have limited exposure and experience of working in rural areas, they were restricted in their ability to put together the discouraging and encouraging factors. Their judgments might also have been influenced by the hearsay from their senior counterparts. Also, improving the curriculum design of medical schools based on rural needs and requirements was beyond the scope of the study.

The findings of the present study encapsulate the important aspects that may be required to recruit and retain future doctors in rural areas. The outcome shall be helpful to policymakers and medical educators for making concerted efforts towards facilitating medical students' decision in favor of working in rural areas. This endeavor will, in turn, improve the workforce in rural settings and strengthen the health systems for achieving universal health coverage. We propose that further research is necessary for different cross-cultural settings, also among medical doctors practicing in rural areas, to validate the findings of the present study. 


\section{Conclusion}

This study throws light upon the significant topic of medical students' interest to work in rural settings and highlights discouraging and encouraging factors that deter or attract them to work in rural areas. The discouraging factors prevailed over encouraging factors which need to be identified and rectified to attract the medical students to work in rural areas. With the present state of affairs where recruitment and retention of students in rural areas appear to remain a continuous challenge for the governments across the globe, the present study offers important clues to policymakers for designing tailor-made, fieldtested and cost-effective measures for attracting and retaining a workforce in rural areas. Countries like India need to provide basic infrastructure of health services in rural areas to attract and retain doctors.

Furthermore, newer approaches like community-based medical education and a longer clinical apprenticeship in rural health facilities can increase students' exposure to the needs of rural communities leading to better community engagement. A medical curriculum review that prioritizes the health needs of the whole country is necessary, which includes early and long-term clinical exposure in rural areas during medical training, providing equitable provision of health services across urban cities and rural villages, and investing in infrastructure and basic facilities for doctors working in rural areas. The preferential selection of recruiting students from rural areas in medical studies followed by their placements in rural areas (preferentially in their native villages) might also be useful. They can in-turn become the advocates for further improvements in rural facilities. Further, reorganizing the workforce through delegation of specific tasks to less specialized health workers (task shifting) who are more willing to practice in rural area scan be a more efficient strategy towards retaining health workforce in rural areas. The program implementers and medical educators worldwide could benefit from the exchange of best practices, and learn from the design and implementation of similar strategies across various countries. 


\section{References}

1. Wilson NW, Couper ID, De Vries E, Reid S, Fish T, Marais BJ. A critical review of interventions to redress the inequitable distribution of healthcare professionals to rural and remote areas. Rural Remote Health [Internet]. [cited 2018 Mar 28]; 9(2):1060. Available from: http://www.ncbi.nlm.nih.gov/pubmed/ 19530891 PMID: 19530891

2. Strasser R. Rural health around the world: challenges and solutions. Fam Pract [Internet]. 2003 Aug [cited 2018 Mar 28]; 20(4):457-63. Available from: http://www.ncbi.nlm.nih.gov/pubmed/ 12876121 PMID: 12876121

3. WHO | The World Health Report 2006-working together for health. WHO [Internet]. World Health Organization; 2013 [cited 2018 Mar 28]; http://www.who.int/whr/2006/en/

4. WHO | Forecasting the global shortage of physicians: an economic- and needs-based approach. WHO. World Health Organization; 2011;

5. Ly C, Arcand J-L, Scheffler R, Liu J, Bruckner T. 5. Global health workforce alliance: working group. Economic, Demographic, and Epidemiological Transitions and the Future of Health Labor Markets. 2014 [cited 2018 Mar 28]; http://www.who.int/workforcealliance/media/news/2014/WG1_ SynthesisSept282014.pdf

6. WHO $\mid$ Global Health Observatory (GHO) data. WHO [Internet]. World Health Organization; 2018 [cited 2018 Mar 28]; http://www.who.int/gho/en/

7. Chen L, Evans T, Anand S, Boufford JI, Brown H, Chowdhury M, et al. Human resources for health: overcoming the crisis. Lancet [Internet]. 2004 Nov [cited 2018 Mar 28]; 364(9449):1984-90. Available from: http://www.ncbi.nlm.nih.gov/pubmed/15567015 https://doi.org/10.1016/S0140-6736(04)17482-5

8. Rao M, Rao KD, Kumar AS, Chatterjee M, Sundararaman T. Human resources for health in India. Lancet [Internet]. 2011 Feb 12 [cited 2018 Mar 28]; 377(9765):587-98. Available from: http://www.ncbi.nlm. nih.gov/pubmed/21227499 https://doi.org/10.1016/S0140-6736(10)61888-0

9. Partners A. Community Health Systems Catalog Country Profile: India—September 2016. 2016 [cited 2018 Mar 28]; https://www.advancingpartners.org/sites/default/files/ apc_india_chs_catalog_profile.pdf

10. Katrak H. Measuring the shortage of medical practitioners in rural and urban areas in developing countries: a simple framework and simulation exercises with data from India. Int J Health Plann Manage [Internet]. Wiley-Blackwell; 2008 Apr 1 [cited 2018 Mar 28]; 23(2):93-105. Available from: http://doi. wiley.com/10.1002/hpm.871

11. Garg S, Singh R, Grover M. India's health workforce: current status and the way forward. Natl Med J India [Internet]. [cited 2018 Mar 28]; 25(2):111-3. Available from: http://www.ncbi. nlm. nih.gov/pubmed/ 22816170 PMID: 22816170

12. Increasing access to health workers in remote and rural areas through improved retention. [cited 2018 Mar 28];http://www.searo.who.int/nepal/mediacentre/2010_ increasing_access_to_health_workers_in_remote_and_rural_areas.pdf

13. Polasek O, Kolcic I, Dzakula A, Bagat M. Internship workplace preferences of final-year medical students at Zagreb University Medical School, Croatia: all roads lead to Zagreb. Hum Resour Health [Internet]. BioMed Central; 2006 Apr 1 [cited 2018 Mar 28]; 4:7. Available from: http://www.ncbi.nlm.nih.gov/ pubmed/16579857 
14. Yearbook of Health Statistics 2006 Budapest: Hungarian Central Statistical Office [Internet]. [cited 2018 Mar 28]. https://www.ksh.hu/?lang=en

15. Comparison of rural and non-rural students undertaking a voluntary rural placement in the early years of a medical course. Med Educ [Internet]. Wiley/Blackwell (10.1111); 2000 Mar 1 [cited 2018 Mar 28]; 34 (3):231-3. Available from: http://doi.wiley.com/10.1046/j.1365-2923.2000.00515.x

16. Curran V, Rourke J. The role of medical education in the recruitment and retention of rural physicians. Med Teach [Internet]. 2004 May 3 [cited 2018 Mar 28]; 26(3):265-72. Available from:http://www.ncbi.nlm.nih.gov/pubmed/15203506 https://doi.org/10.1080 $/ 0142159042000192055$

17. Khan MM, Hotchkiss DR., Dmytraczenko T, Zunaid Ahsan K. Use of a Balanced Scorecard in strengthening health systems in developing countries: an analysis based on nationally representative Bangladesh Health Facility Survey. Int J Health Plann Manage [Internet]. 2013 Apr [cited 2018 Mar 28]; 28(2):202-15. Available from: http://www.ncbi.nlm.nih.gov/pubmed/22887590 https://doi.org/10.1002/hpm.2136

18. Singh Z. Universal health coverage for India by 2022: a utopia or reality? Indian J Community Med [Internet]. Wolters Kluwer-Medknow Publications; 2013 Apr [cited 2018 Mar 28]; 38(2):70-3 Available from: http://www.ncbi.nlm.nih.gov/pubmed/23878417

19. Saini N, Sharma R, Roy R, Verma R. What impedes working in rural areas? A study of aspiring doctors in the National Capital Region, India What impedes working in rural areas? A study of aspiring doctors in the National. Cap Reg India Rural Remote Heal [Internet]. 1967 [cited 2018 Mar 28]; 12. Available from: http://www.rrh.org.au

20. Human Resources for Health Country Profile Malawi. [cited 2018 Mar 28]; http://ecsahc.org/wpcontent/uploads/2017/05/malawi_country_profile-HumanResources.pdf

21. Kruk ME, Johnson JC, Gyakobo M, Agyei-Baffour P, Asabir K, Kotha SR, et al. Rural practice preferences among medical students in Ghana: a discrete choice experiment. Bull World Health Organ [Internet]. 2010 May 1 [cited 2018 Mar 28]; 88(5):333-41. Available from: http://www.ncbi.nlm.nih.gov/ pubmed/20458371 https://doi.org/10.2471/BLT.09.072892

22. Mohamed AM. Willingness and professional motivations of medical students to work in rural areas: a study in Alexandria, Egypt. Healthc Low-resource Settings [Internet]. 2013 Mar 20 [cited 2018 Mar $28] ; 1(1): 4$.

Available from:http://www.pagepressjournals.org/index.php/hls/article/view/hls.2013.e4

23. Henderson LN, Tulloch J. Incentives for retaining and motivating health workers in Pacific and Asian countries. Hum Resour Health [Internet]. BioMed Central; 2008 Dec 15 [cited 2018 Mar 28]; 6(1):18. Available from: http://human-resources-health.biomedcentral.com/articles/10.1186/1478-4491-6-18

24. Kaye DK, Mwanika A, Sekimpi P, Tugumisirize J, Sewankambo N. Perceptions of newly admitted undergraduate medical students on experiential training on community placements and working in rural areas of Uganda. BMC Med Educ [Internet]. BioMed Central; 2010 Dec 23 [cited 2018 Mar 28]; 10 (1):47. Available from: http://bmcmededuc.biomedcentral.com/articles/10.1186/1472-6920-10-47

25. Steinhaeuser J, Joos S, Szecsenyi J, Miksch A. A comparison of the workload of rural and urban primary care physicians in Germany: analysis of a questionnaire survey. BMC Fam Pract [Internet]. BioMed Central; 2011 Oct 11 [cited 2018 Mar 28]; 12:112. Available from: http://www.ncbi.nlm.nih.gov/ pubmed/21988900 


\section{Chapter 6}

Medical students' interests in working in rural areas

26. Willis-Shattuck M, Bidwell P, Thomas S, Wyness L, Blaauw D, Ditlopo P. Motivation and retention of health workers in developing countries: a systematic review. BMC Health Serv Res [Internet]. BioMed Central; 2008 Dec 4 [cited 2018 Mar 28]; 8(1):247. Available from: http://bmchealthservres. biomedcentral.com/articles/10.1186/1472-6963-8-247

27. Couper ID, Hugo JF, Conradie H, Mfenyana K. Influences on the choice of health professionals to practice in rural areas. S Afr Med J. 2007 Nov; 97(11):1082-628. PMID: 18250918

28. Focus Groups as Qualitative Research-PLANNING AND RESEARCH DESIGN FOR FOCUS GROUPS PLANNING AND RESEARCH DESIGN FOR FOCUS GROUPS. [cited 2018 Mar 28]; https:// pdfs.semanticscholar.org/6895/650998233a7bb52efcdaa39b0e42d2102f3c.pdf

29. Census of India Website: Office of the Registrar General \& Census Commissioner, India [Internet]. [cited 2018 Mar 28]. http://censusindia.gov.in/2011-Common/CensusData2011.html

30. Who wants to do rural social work? Student perceptions of rural social work practice [Internet]. [cited 2018 Mar 28]. https:/www.researchgate.net/publication/312466274_Who_wants_to_do_rural_social_ work_Student_perceptions_of_rural_social_work_practice

31. Qualitative data analysis: An expanded sourcebook. 2nd Sage; Thousand Oaks, CA: 1994. [cited 2018 Mar 28]; http://researchtalk.com/wp-content/uploads/2014/01/Miles-Huberman-Saldana- Drawing-andVerifying-Conclusions.pdf

32. Creswell JW. Qualitative inquiry and research design: Choosing among five traditions. Thousand Oaks, CA: Sage;1998 [Internet]. [cited 2018 Mar 28]. http://community.csusm.edu/pluginfile.php /21115/mod_resource/content/1/Creswell_J.W._2007_._Designing_a_Qualitative_Study_Qualitative_in quiry_and_research_design_Choosing_among_5_approaches_2nd_ed._Thousand_Oaks_CA-_ SAGE.pdf

33. Steven J. Taylor RB. Introduction to qualitative research methods: a guidebook and resource [Internet]. [cited 2018 Mar 28]. https://trove.nla.gov.au/work/23703751?selectedversion $=$ NBD13367381

34. Tong A, Sainsbury P, Craig J. Consolidated criteria for reporting qualitative research (COREQ): a 32 item checklist for interviews and focus groups. Int J Qual Heal Care [Internet]. Oxford University Press; 2007 Sep 16 [cited 2018 Mar 28]; 19(6):349-57. Available from: https://academic.oup.com/intqhc/ article-lookup/doi/10.1093/intqhc/mzm042

35. Goel S, Angeli F, Singla N, Ruwaard D. Development and Validation of the Motivations for Selection of Medical Study (MSMS) Questionnaire in India. Baradaran HR, editor. PLoS One[Internet]. Public Medical students' interests in working in rural areas PLOS ONE https://doi.org/10.1371/journal.pone.0210251 January 10, 201913 / 14Library of Science; 2016 Dec 20 [cited 2018 Mar 28]; 11(12):e0164581. Available from: http://dx.plos. org/10.1371/journal.pone.0164581

36. Classics in the History of Psychology-A. H. Maslow (1943) A Theory of Human Motivation [Internet]. [cited 2018 Mar 28]. http://psychclassics.yorku.ca/Maslow/motivation.htm

37. Rao KD, Bhatnagar A, Berman P. So many, yet few: Human resources for health in India. Hum Resour Health [Internet]. BioMed Central; 2012 Aug 13 [cited 2018 Mar 28]; 10:19. Available from: http://www. ncbi.nlm.nih.gov/pubmed/22888906

38. Gadi AD, Higuchi M, Warnasuriya N, Kawaguchi L, Aoyama A. Medical students' willingness to work in post-conflict areas: A qualitative study in Sri Lanka. Health (Irvine Calif) [Internet]. Scientific 
Research Publishing; 2012 Oct 31 [cited 2018 Mar 28]; 4(10):824-31. Available from: http://www.scirp.org/journal/doi.aspx?DOI=10.4236/health.2012.410127

39. Dieleman M, Cuong PV, Anh LV, Martineau T. Identifying factors for job motivation of rural health workers in North Viet Nam. Hum Resour Health [Internet]. BioMed Central; 2003 Dec 5 [cited 2018 Mar 28]; 1(1):10. Available from: http://human-resources-health.biomedcentral.com/articles/10.1186/1478 4491-1-10

40. Elam CL, Weaver AD, Whittler ET, Stratton TD, Asher LM, Scott KL, et al. Discerning applicants' interests in rural medicine: a textual analysis of admission essays. Med Educ Online [Internet]. Taylor \& Francis; 2015 [cited 2018 Mar 28]; 20:27081. Available from: http://www.ncbi.nlm.nih.gov/pubmed/25795383

41. Cooper RS, Kennelly JF, Orduñez-Garcia P. Health in Cuba. Int J Epidemiol [Internet]. 2006 Aug 1 [cited 2018 Mar 28]; 35(4):817-24. Available from: http://www.ncbi.nlm.nih.gov/pubmed/16931525 https://doi.org/10.1093/ije/dyl175

42. Panagariya A. The Challenges and innovative solutions to rural health dilemma. Ann Neurosci [Internet].Karger Publishers; 2014 Oct [cited 2018 Mar 28]; 21(4):125-7. Available from: http://www.ncbi.nlm.nih.gov/pubmed/25452670

43. Deakin University. Rural and remote health. [Internet]. Deakin University; 2001 [cited 2018 Mar 28]. https://www.rrh.org.au/journal/article/314

44. Laven G, Wilkinson D. Rural doctors and rural backgrounds: how strong is the evidence? A systematic review. Aust J Rural Health [Internet]. 2003 Dec [cited 2018 Mar 28]; 11(6):277-84. Available from:http://www.ncbi.nlm.nih.gov/pubmed/14678410 PMID: 14678410

45. Playford D, Larson A, Wheatland B. Going country: Rural student placement factors associated with future rural employment in nursing and allied health. Aust J Rural Health [Internet]. 2006 Feb [cited 2018 Mar 28]; 14(1):14-9. Available from: http://www.ncbi. nlm.nih.gov/pubmed/ 16426427https://doi.org/10.1111/j.1440-1584.2006.00745.x

46. Easterbrook M, Godwin M, Wilson R, Hodgetts G, Brown G, Pong R, et al. Rural background and clinical rural rotations during medical training: effect on practice location. CMAJ [Internet]. 1999 Apr 20 [cited 2018 Mar 28]; 160(8):1159-63. Available from: http://www.ncbi.nlm. nih.gov/pubmed/ 10234346 PMID: 10234346

47. Chaudhury N, Hammer JS. Ghost Doctors: Absenteeism in Rural Bangladeshi Health Facilities. World Bank Econ Rev [Internet]. Washington, DC: World Bank; 2004 Jan 1 [cited 2018 Mar 28]; 18(3):42341.Available from: https://academic.oup.com/wber/article-lookup/doi/10.1093/wber/lhh047

48. Dussault G, Franceschini MC. Not enough there, too many here: understanding geographical imbalances in the distribution of the health workforce. Hum Resour Health [Internet]. BioMed Central; 2006 May 27 [cited 2018 Mar 28]; 4:12. Available from: http://www.ncbi.nlm.nih.gov/ pubmed/16729892

49. Syed NA, Khimani F, Andrades M, Ali SK, Paul R. Reasons for migration among medical students from Karachi. Med Educ [Internet]. 2007 Nov 28 [cited 2018 Mar 28]; 42(1):61-8. Available from: http://www.ncbi.nlm.nih.gov/pubmed/18042189-https://doi.org/10.1111/j.1365-2923.2007.02904.x

50. Rabinowitz HK. Recruitment, Retention, and Follow-up of Graduates of a Program to Increase the Number of Family Physicians in Rural and Underserved Areas. N Engl J Med [Internet]. Massachusetts Medical Society; 1993 Apr 15 [cited 2018 Mar 28]; 328(13):934-9. Available from: http://www.nejm.org/doi/abs/10.1056/NEJM199304013281307 
51. Dovlo D. The Brain Drain and Retention of Health Professionals in Africa. [cited 2018Mar28];http://siteresources.worldbank.org/INTAFRREGTOPTEIA/Resources/dela_dovlo.pdf

52. Stilwell B, Diallo K, Zurn P, Vujicic M, Adams O, Dal Poz M. Migration of health-care workers from developing countries: strategic approaches to its management. Bull World Health Organ [Internet]. 2004 [cited 2018 Mar 28]; 82(8). Available from: http://www.who.int/workforcealliance/11.pdf

53. De Vries E, Reid S. Do South African medical students of rural origin return to rural practice? S Afr Med J [Internet]. 2003 Oct [cited 2018 Mar 28]; 93(10):789-93. Available from: http://www.ncbi.nlm.nih.gov/pubmed/14652974 PMID: 14652974 



\section{Chapter 7}

\section{General Discussion}

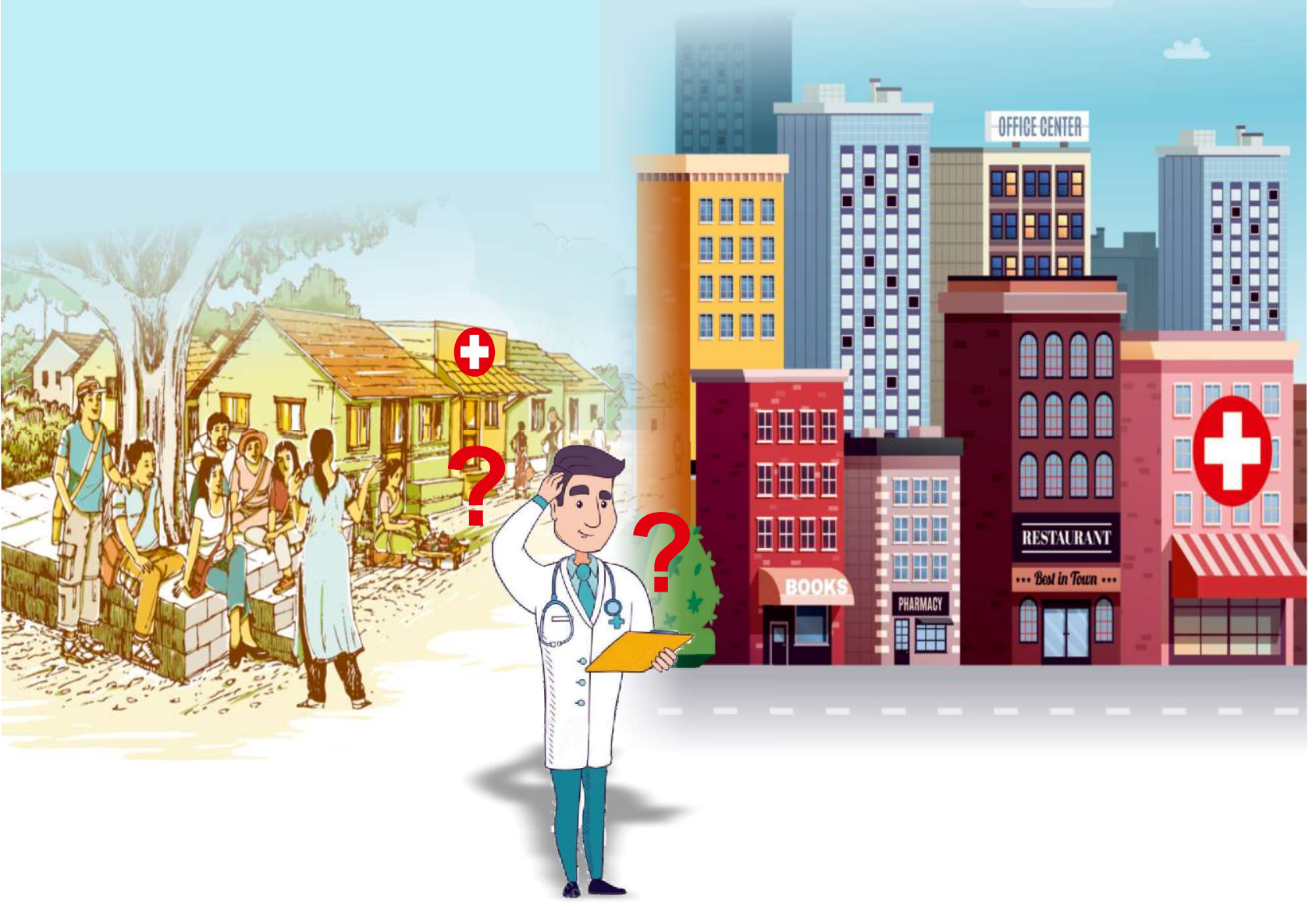




\section{Introduction}

India is facing an acute shortage of medical practitioners in rural and regional areas, especially in North India [1,2]. The shortage has become more critical over the last two decades. The 'High Level Expert Group for Universal Health Coverage' of India, constituted by the Planning Commission, has set the minimum doctor-to-population ratio to $1: 1,000$ [3]. Currently, India counts only 57 physicians for 100,000 people or 1 physician for over 1,750 people, indicating that more qualified medical professionals are needed [4]. For $70 \%$ of the Indian rural population, the doctor to population ratio is extremely low and amounts to a mere 1 physician for over 2,564 inhabitations [2]. In middle-and low-income countries, the situation is more critical because of migration of doctors to high-income (developed) countries and their in-equitable distribution between urban and rural areas, primarily due to poor motivation of healthcare workers to work in rural areas [5]. The proposed ratio of 1:1,000 can be achieved only if more students will opt for medical study and remain in India to practice the profession. Although the Medical Council of India (MCI)reports educating 52,105 physicians each year [6], almost one third of them leave India for residency training and/or practice abroad [7]. Thus along with overall shortage of healthcare workers, the gap between the numbers of doctors working in urban compared to rural areas is widening, which is endangering the functioning and sustainability of the Indian health care system [8,9]. Therefore, understanding the perception of medical students about challenges in relation to rural areas could predict their subsequent practice location and help stimulate their choice to work or stay in rural areas.

With this significant background, the sequential, explanatory mixed method approach adopted in the current thesis aims to comprehensively understand the motivation factors stimulating students to select medical studies and to work in rural areas. This objective was pursued through two theoretical and three empirical studies, which have been presented in this dissertation. The remainder of this chapter will commence by summarizing the main findings of the studies presented in this dissertation. It will subsequently describe several theoretical as well as methodological reflections. After 
sharing the limitations and offering various suggestions for future research, this chapter concludes by discussing the implications of this work for policymakers and practitioners.

\section{Main findings}

In the current thesis, all recent studies which focused on motivation factors of medical students were grouped and reviewed. The primary motivating factors that emerged out of the review were scientific (o.a. interest in academia, work independence), societal (prestige, job security, financial security) and humanitarian (serving the poor and underprivileged) in high, upper-middle and lower-middle income countries, respectively. These results revealed that motivating factors vary per country and depend on the level of income [10]. The review concluded that although medical students were conscious about their societal and humanitarian responsibilities while selecting medical studies, shortage and an unequal distribution of healthcare workers in remote and rural areas persists [11].

The review also highlighted dearth of literature in India. Hence, to close this gap and gain knowledge on motivating factors in the Indian context, an instrument was designed and validated, namely the Motivation for Selection of Medical Study (MSMS) questionnaire, for measuring the choice of medical students to study Bachelor of Medicine, Bachelor of Surgery (MBBS) in Indian settings. This novel scale offers a three-faceted motivation construct, composed by scientific factors(e.g. research opportunities and the ability to use new cutting edge technologies), the societal expectations (e.g. job security) and the humanitarian needs (e.g. desire to help others), in line with the factors found in various international studies [12].

Further, in order to capture various aspects that lead to human resource shortage in India, especially inequity in health workforce deployment between urban and rural areas, a critical interpretative synthesis was executed.The main deterrents causing healthcare worker's attrition in rural areas of India which emerged in the study are poor governance, insufficient salary and allowances, and the inability of employers to provide safe, satisfying and rewarding work conditions. The review further suggests that the retention of health workers in rural areas can be ensured by a multiplicity of interventions such as 
medical schools in rural areas, rural orientation of medical education, introducing compulsory rural service in lieu of incentives providing better pay packages and special allowances, and providing better living and working conditions in rural areas. But most of the global literature has either considered a very limited spectrum of potential deterrents to serve in rural areas or has deployed qualitative methods of enquiry such as semi-structured questionnaires. Also, all of them have been developed for students studying in Western countries.

This encouraged us to design and validate another tool named Medical Student's Demotivation to work in Rural India (MSDRI) scale in which thirty-three items were generated based on the results of the critical interpretative synthesis followed by Delphi exercise. This highlighted five main factors, namely lack of professional challenge, social segregation, socio-cultural gap, hostile professional environment, and lack of financial incentives underpinning students' demotivation towards working in rural areas. This scale described a complex nexus of reasons and constitutes a powerful tool for policymakers as well as healthcare organizations.

Lastly, a qualitative study was conducted to explore encouraging and discouraging factors among medical students for their choice to work in rural and remote areas, which supported the items developed in the MSMS and MSDRI questionnaires. The encouraging factors which emerged aggregated under three major themes, namely willingness to give back to disadvantaged communities (desire to serve poor, underprivileged and home community), broader clinical exposure (preferential admission in post-graduation after working more than 2-3 years in rural areas) and higher status and respect (achieving higher social status), which were in line with items of the MSMS scale. The discouraging factors to work in rural and remote areas were categorized under two broad themes, namely an unchallenging professional environment (poor accommodation facilities and lack of necessary infrastructure; lack of drug and equipment supplies; inadequate human resource support; lesser travel and research opportunities) and the gap between financial rewards and social disadvantages (less salary and incentives, social isolation, political interference, lack of security). These findings support the results of MSDRI tool. 


\section{Understanding motives of medical students to select medical studies}

The prospective medical students form a significant pool of healthcare workers. Therefore, it is important to understand the current motivation factors that underpin students' selection of medical study in the context of different settings. With this intention, a systematic literature review based on the World Bank categorization of low, middle- and high-income countries [13] was conducted as part of this thesis. Disappointedly, the literature search could identify merely 24 studies globally, which assessed the reasons for selecting the medical profession among medical students. The majority of the studies ( $\mathrm{n}=16 ; 66.6 \%)$ came from high-income countries followed by an equal number from upper-middle $(n=4 ; 16.7 \%)$ and lower-middle income countries $(\mathrm{n}=4 ; 16.7 \%)$ and none from low-income countries. In particular, the scientific factors, societal factors, and humanitarian factors were the primary reasons to select medicine by students of high-income [14-16], upper-middle income [17,18] and low income countries $[4,19,20]$ respectively. The limited research on this topic in low-income countries could be related to the lack of interest in this particular area, or to an overall deficit in research in developing nations, or both.

To enrich the existing evidence from India, a study was conducted as part of the current thesis, which studied motivation factors among medical students to select medical studies. Similar to the findings of the systematic literature review, the current study uncovered a novel three-faceted motivation construct based on scientific factors, societal expectations and humanitarian needs. Under the scientific, societal and humanitarian factors, the primary reasons which motivated them to select medical studies were ability to use new cutting edge technologies, opportunities to travel and work internationally and research opportunities; job security, social status/prestige, high income and proposed by parents; and desire to help others, desire to give back to their home community or country, respectively. So it appears that not only humanitarian factors but also scientific and societal factors are important motivation factors among medical students to select medical studies.

In addition to filling the gap in existing literature, the current study highlighted the varied levels of motivation regarding selection of medical studies due to socio-cultural peculiarities and heterogeneity between Indian states. Based on the current study findings, it was argued that separating motivation into intrinsic and extrinsic may be 
over-simplistic as they are not dichotomous [21], rather they are context dependent, not easily distinguishable, and interrelate with one another in complex ways [22]. Thus the current study cut-across the traditional dichotomy between intrinsic and extrinsic motivation (as proposed in self-determination theory) [23] and highlights instead a novel distinction by consolidating these dimensions into a single comprehensive tool.

\section{Understanding motives of medical students to work in rural areas}

The shortage of doctors, especially in rural areas, is a major concern in India, which inturn affects the effective delivery of health care services [24]. The literature search revealed that little research has been done in India, on understanding the perceptions of medical students about the factors that can promote rural practice. In order to fill the gap in current literature, a critical interpretative synthesis of the existing literature was conducted as part of the current thesis in order to assess relevant strategies adopted in India for improving deployment and retention of healthcare workforce in rural and remote areas. After following an iterative strategy followed by theoretical saturation, a total of 56 studies were included in the review. The current study has summarised the findings based upon the key four-point strategy proposed by WHO [25]. Herein the interventions influencing healthcare workers distribution were grouped into four categories, namely education, regulation, financial incentives, and personal and professional support. The review revealed that unfortunately, no studies on rural orientation of medical education had been conducted in India, as most of medical colleges are located in urban areas. Another study from central India exposed that the students rated the status of rural health services in India as highly unsatisfactory (88.6\%) [26]. Few states have introduced state-specific cadre of health workers focusing on recruiting students from a rural background. Most of the states including Assam, Chhattisgarh, Kerala, Himachal Pradesh, Haryana, Punjab, Andhra Pradesh and Tamil Nadu reserve postgraduate seats for in-service doctors who complete a fixed quota of rural service [27]. Similarly, eighteen states have monetary incentive schemes to compensate doctors for service in underserved areas. Limited evidence exists of strategies aimed at improving working conditions and job satisfaction among medical students.

Considering the complexity of factors playing behind attraction and retention of the healthcare workforce in rural areas, the emphasis globally is on bundling different 
interventions. In Indonesia, a 'bundle' of interventions, such as compulsory service, training and financial incentives is employed for increasing the density of the healthcare workforce in remote areas [28]. Similarly, bundling of financial and educational incentives across states of India has resulted in attracting doctors and nurses to rural postings [29]. The review suggests that the retention of health workers in rural areas can be ensured by a multiplicity of interventions across states of India which has to be fieldtested with a view to improve efficiency and effectiveness of the healthcare services [30].

Besides all the efforts, this sharply uneven distribution of human resources for healthcare across urban and rural areas has been a long-standing concern in India. The review suggested that none of the research has comprehensively studied and validated the reasons associated with the non-selection of rural posting after Bachelor of Medicine and Bachelor of Surgery (MBBS) in India. Most of the existing literature has either considered a very limited spectrum of potential deterrents to serve in rural areas or has deployed qualitative methods of enquiry such as semi-structured questionnaires [31]. Also, all of them have been developed for students studying in Western countries and are therefore difficult to apply in developing countries such as India because of differences in culture and health systems.

To plug the gap in current literature in India, a cross-sectional descriptive qualitative study was conducted as part of the current thesis. To the best of our knowledge, this was the first qualitative study from India, which explored the discouraging and encouraging factors from three large states of India i.e. Punjab, Haryana and Himachal Pradesh. From the thematic analysis of data, it was revealed that the primary discouraging factors among medical students, as perceived by them, were 'scientific and professional' (poor accommodation facilities and lack of necessary infrastructure; lack of drug and equipment supplies; inadequate human resource support, less travel and research opportunities) and 'societal' (less salary and incentives, social isolation, political interference and lack of security)similar to those observed in other studies globally[32,33-35] However, the encouraging factors identified were 'humanitarian' (desire to serve poor, underprivileged and home community), 'scientific and professional' (preferential admission in post-graduation after working more than 2-3 
years in rural areas) and 'societal' (achieving higher social status) factors determining their decision to serve rural areas. These findings are consistent with many other studies conducted across the world that have identified humanitarian factors as the dominant component [36,37-39]. Other studies have also quoted prestige and respect as the facilitators for working in rural areas [40-42]. The findings substantiate the central argument of the dissertation that human resource policy for medical doctors at national and state level is the need of hour. This should ensure rational staffing along with adequate remuneration and designing tailor made, field-tested and cost-effective measures for attracting and retaining workforce in rural areas.

\section{Comparing perspectives of medical students to select medical studies and work in rural areas}

The current dissertation found that the motivation factors for the selection of medical studies by the students were humanitarian and societal. On having a deep insight into the encouraging factors affecting medical students' interests in working in rural areas through qualitative study, the primary encouraging factors were again 'humanitarian' (desire to serve poor, underprivileged and home community), 'scientific and professional' (preferential admission in post-graduation after working more than 2-3 years in rural areas) and 'societal' (achieving higher social status). This strengthened our view that humanitarian and societal factors are common prime factors for selecting medical studies and working in rural and remote areas of India. ${ }^{24}$ This provides sufficient evidence regarding medical students' social awareness and sense of duties to serve the masses in need and to have a respectable status in the society. Despite being motivated and oriented towards their social responsibilities, there is a huge shortage of doctors especially in rural areas, affecting delivery of health care services in rural parts of the country.

The study also elicited that the primary discouraging factors for working in rural areas, as perceived by medical students, were grouped under 'scientific and professional' (poor accommodation facilities and lack of necessary infrastructure; lack of drug and equipment supplies; inadequate human resource support, lesser travel and research opportunities) and 'societal'(less salary and incentives, social isolation, political 
interference, lack of security). This elucidates the noteworthy fact that though the medical students were inspired and had recognized their social role while selecting medical studies as their professional career, lack of basic amenities and professional satisfaction were overweighing the motivation and encouraging factors, leading to unequal and a biased distribution of the healthcare workforce in India.

\section{Findings in perspective of different theories of motivation}

The research findings presented in this thesis shed new light on the reasons for choosing a medical career or work in rural and remote settings. As such, they should be seen in light of various motivation theories as have been described by Deci and Ryan [23], Brissette and Howe,[22] Maslow's hierarchy of needs [43] and Taylor, McClelland and Herzberg [44]. According to the Deci and Ryan's self-determination theory, the motivation factors have been dichotomised into intrinsic and extrinsic factors. Intrinsic motivation reflects the human propensity to learn from internal motives or 'self', while extrinsic motivation results from external motives like awards or 'outside the self' [23]. However, it has been a matter of theoretical debate that both types cannot be seen as dichotomous categories or an either-or problem. Further, one can be intrinsically motivated for certain issues and extrinsically motivated for other issues. In addition, both types are a developmental and translational phenomenon [22].

On the other hand, Maslow theory remains to be the most detailed and frequently used theory, which suggests five independent levels of basic human needs (motivators) that must be satisfied in strict sequence, starting with lowest level and eventually leading to self-actualization [43]. According to this theory, motivation directs behaviour. The findings of the systematic literature review as described in this thesis were in congruence with Maslow's theory (as against self-determination theory of dichotomising motivation into intrinsic and extrinsic). The primary motivators (scientific factors) to select medicine by students of high-income countries lie in the third and fourth segments of the Maslow's hierarchy of needs pyramid. In the upper-middle income countries the motivating factors (job security, social status, and parental wish) lie in the middle zone of Maslow's pyramid. In low-middle income countries, they (basic needs, safety, stability and protection) fall under the first two segments of the pyramid and in low-income countries, 
they (basic needs) hold the bottom position in the hierarchical pyramid reflecting the necessity to address their basic needs [43].

\section{Methodological reflection}

\section{Mixed Method Approach deployed for data collection}

Several lessons can be drawn from the methodologies employed in this dissertation. The mixed-method research methodology of collecting, analyzing and integrating quantitative (e.g. surveys) and qualitative (e.g. focus group discussion, in-depth interviews, Delphi technique) data along with literature reviews was applied to understand complex human behavior as a sequel to many inter-related factors behind their motivation to select medical studies and postings in rural and remote areas of India. In addition, two new measurement instruments were developed and validated for understanding the main motivation factors that influence students to opt for medical studies in India.This first mixed methods research from India on the issue combines qualitative and quantitative research approaches for the broad purpose of increasing the breadth and depth of understanding of the reasons behind the motivation to select medical studies and postings in rural and remote areas of the country [45]. The open-ended structures of qualitative research, in addition to quantitative research, made it possible to get even more refined information about perceptions and insight into medical student's attitudes, motivations, and perceptions that influence their decisions [45].

\section{Development and validation of the Motivations for Selection of Medical Study tool}

Despite the fact that there are arrays of questionnaires developed to identify the main reasons for selecting medical studies by students, very few are standardized or are focused on different goals and populations. For example, Agyei-Baffour [10] used a questionnaire on medical students of Ghana to assess the role of intrinsic and extrinsic motivation on their willingness to work in rural areas, rather than measuring motivation factors to join medical study. Some other tools such as the Academic Motivation Scale (AMS) by Valler and et al. [46,47] Maslach Burnout Inventory-Student Survey(MBI-SS) containing Exhaustion scale [48] and Strength of Motivation for Medical School(SMMS) 
questionnaire $[49,50]$ for the evaluation of strength of motivation of students for medical study exist in literature but all of them have been validated in culturally different contexts of western countries. Therefore, applying these instruments in countries, such as India, could lead to bias and unreliable findings.

Therefore, in order to understand the main motivation items that influence students to opt for medical studies in India, a Motivation for Selection of Medical Study (MSMS) tool was developed and validated as part of the dissertation. The questionnaire was developed using extensive literature review followed by Delphi technique, a practical approach to achieve a consensus among a group of experts during various rounds of discussion. The scale consisted of 12 items, 5 measuring intrinsic dimensions of motivations and 7 measuring extrinsic dimensions. Exploratory factor analysis (EFA), confirmatory factor analysis (CFA), validity, reliability and data quality checks were conducted on a sample of 636 medical students from six medical colleges of three North Indian states. The three dimensions of the scale (scientific, societal and humanitarian) cut across the traditional dichotomy between intrinsic and extrinsic motivation and highlight instead a novel distinction. These dimensions have never been consolidated into a single comprehensive tool in earlier studies. These three subscales with an 8-item scale is a valid and reliable tool and therefore could be used to study the intentions of medical students to join medicine in India and other similar settings. The study is limited by the fact that all the motivation items were equally weighted and some might have not been included in the questionnaire, despite best efforts of the researchers through extensive literature review and adopting group consensus methods.

Development and validation of the Medical Student's De-motivation to work in Rural India (MSDRI) tool

Similarly to the dearth of validated tools to study selection of medical studies by the students, most of the prevailing tools have either considered a very limited spectrum of perceived potential deterrents of medical students to serve in rural areas or have deployed qualitative methods of enquiry such as semi-structured questionnaires. Also, all the tools have been developed for students studying in Western countries and therefore difficult to apply in developing countries such as India because of differences in culture and health 
systems, underpinning India's sharply unequal distribution of health workforce between rural and urban areas.

Hence, a validated scale named Medical Student's De-motivation to work in Rural

India (MSDRI) was developed to identify barriers for medical students for accepting rural postings in Indian settings. This 33-item scale consisting of 5 subscales namely, lack of professional challenge, social segregation, socio-cultural gap, hostile professional environment, and lack of financial incentives, comprehensively described a complex connection of reasons that undermines the presence of medical professionals in rural areas. Thus, this scale comprehensively captures all the deterrents reported by the medical students under five items/subscales, which were not conscripted in previous studies, and have the potential to adjust and enlist the deterrents explored subsequently. During the process of development, thorough literature review was carried out which was eventually narrowed down to 20 relevant studies, which were used to develop a conceptual framework of the questionnaire. Delphi technique followed the literature review in which consensus on the items in the questionnaire among a group of experts was achieved. The psychometric properties of the questionnaire were assessed in terms of content validity, construct validity, data quality and reliability. Exploratory factor analysis (EFA) followed by Confirmatory factor analysis (CFA) was performed to identify the primary deterrents. Despite various strengths, there is a slightly increased risk of misguided conclusions from Structured Equation Modeling (SEM) used in the development of the scale. Acceptable fit statistics might be caused by the estimation of correlations among measurement errors and omitting relevant variables from the model. This may lead to deviation from the model applying to the true population and may also bias the parameter estimates. However, in absence of a well-defined theoretical framework, which guides variable selection, adoption of a data-driven empirical approach by correlating errors is a good alternative. This model may be tested by researchers in a range of settings.

\section{Validity of the findings}

Two novel instruments were developed and validated in the current dissertation, which were used to determine the motivation factors for selecting medical studies and work in 
rural and remote areas, respectively. The fitting of the items into their corresponding themes/sub-scales supported by their superior goodness of fit over competing models through confirmatory factor analysis and by the expected correlations among its subscales supported the instrument validity. Further, qualitative content validity (adequacy of content) using systematic literature review for identifying motivation and demotivation factors supplemented by qualitative propels content validity (relevance of questions and language used) using Delphi technique, decreases the possibility of uncontrolled explanatory variables, which increased the internal validity of the study. Thus, the inferences generated out of the study are presumed to be accurate or have a high internal validity. Since the study was confined to Northern region of India, a cautious approach should be adopted to generalize the findings to other parts of the country and low-income settings across the globe (external validity).

\section{Limitations and directions for future research}

Despite sincere and extensive efforts to identify all relevant studies in two reviews conducted as a part of this dissertation, few studies might have been inadvertently missed. Additionally, unpublished studies from low- and middle-income countries were not represented (publication bias). The exclusion of articles published before 2006 may have omitted literature that could have provided valuable information. However, our review supplement two existing reviews published earlier [8,9]. The conclusions should also be seen in light of a few design limitations as our sample consists of students from medical colleges of three states of the country of India, which may not necessarily represent the entire medical student population of the country (see under the previous section about the validity of the findings). Furthermore, the findings do not provide an in-depth understanding for low motivation of MBBS students. The qualitative study conducted explained the opinion of medical students, which may not be truly reflecting their perceptions at the time of posting in rural settings. Hence, it did not link motivation to their decision to work in rural settings and actual service delivery for establishing any possible causal link, which was beyond the scope of present research. Secondly, the FGD may have led to socially desirable responses in form of positive self-descriptions rather than an honest opinion of it. Moreover, since most of the students did not have much 
exposure and experience of rural areas, they were restricted in their ability to correctly put together the discouraging and encouraging factors. Also, improving curriculum design of medical schools based on rural needs and requirements was beyond the scope of the study. Despite the limitations, the findings of the present study encapsulate the important aspects that may be required to recruit and retain the future doctors in rural areas (see the next section about the implications for policy and practice).

The current dissertation provides several avenues for future research. It is recommended that further exploratory, mixed method studies, with FGDs or interviews, should be done to collect in-depth information for exploring the reasons of varying levels of motivation among medical students along with linking it with health system performance. We also propose to conduct research amongst high school students to extract the factors that motivate or de-motivate them to choose medical study. The changing priorities of medical students from their first till final year of medical study should also be assessed in terms of their motivation to work in rural and remote areas. In addition, it needs to be explored that out of those who completed their medical study, what proportion of them wish to stay in India and to work in rural areas. More comprehensive evaluation of different interventions conducted in different parts of the globe to attract and retain health care providers, especially in low income countries, should be done. We would also like to propose that further research should be done in different cross-cultural settings and also among different categories of healthcare professionals' (o.a. nurses) practicing in rural areas, to validate the findings of present study and document their views and perceptions about joining medical profession and subsequently working in rural areas.

\section{Implications for policy and practice}

The recruitment and retention of medical students in rural areas appear to remain a continuous challenge for the governments across the globe. The present study offers important clues to policy makers, implementers and medical educators in designing tailor made field-tested and cost-effective measures for attracting and retaining workforce in rural areas. Further, the findings substantiate the fact that human resource policy for medical doctors at national and state level is the need of hour. The current mixed method study emboldened our understanding that humanitarian and societal factors are key 
motivation factors for selecting medical studies and working in rural and remote areas of India. The study also highlighted the importance of providing basic infrastructure of health services in rural areas, community-based medical education, sufficiently raising the salary and other emoluments in consonance with other white-collar professions in order to attract and retain doctors in rural and remote areas. Lastly, the newly-developed and validated instruments in the study, MSMS and MSDRI, to measure the reasons that motivate and discourage medical students from selecting medical studies and working in rural areas shall also be helpful for policy makers in setting context-specific priorities to improve medical student's willingness to accept rural postings. 


\section{References}

1. Hazarika I. Health workforce in India: assessment of availability, production and distribution. WHO South East Asia Journal of Public Health. 2013; 2:106 \pm 112.

2. Rao M, Rao KD, Kumar AK, Chatterjee M, Sundararaman T. Human resources for health in India.

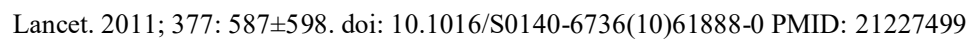

3. High Level Expert Group Report on Universal Health Coverage for India Planning Commission of India New Delhi, November, 2011. http://planningcommission.nic.in/reports/genrep/rep_uhc0812. pdf. Accessed 7th April 2015.

4. Kuriakose S, Revankar SKB, Viveka S, Shetty B, Rao CP. Why become a Doctor? Evaluation of Motivational factors for selecting medical profession as career. Journal of Evidence based Medicine and Healthcare.2015; 2: 206 \pm 211 .

5. Hurst SA. Eroding students' rural motivation: first do no harm? Swiss Med Wkly. 2014;144

6. Medical Council of India. http://www.mciindia.org. Accessed 7th April 2015.

7. Aggarwal S, Rai A, Bath KS, Singh H, Sharma V. Migratory Trends of Medical Graduates in India.Journal of Pioneering Medical Sciences.2014; 4:155 \pm 158 .

8. Katrak, H. (2008), Measuring the shortage of medical practitioners in rural and urban areas in developing countries: a simple framework and simulation exercises with data from India. Int. J. Health Plann. Mgmt., 23: 93-105. doi:10.1002/hpm.87

9. Garg S. Singh R, Grover M.India's health workforce: Current status and the way forward. National Med J of India. 2012;25 (2):111-113

10. Agyei-Baffour P, Kotha SR, Johnson JC, Gyakobo M, Asabir K, Kwansah J et al. Willingness to work in rural areas and the role of intrinsic versus extrinsic professional motivations- a survey of medical students in Ghana. BMC Medical Education.2011; 11:56 \pm 64 . doi: 10.1186/1472-6920-11-56 PMID:21827698.

11. Dutt R, Shivalli S, Bhat M, Padubidri J. Attitudes and perceptions toward rural health care service among medical students. Medical Journal of Dr. D.Y. Patil University. 2014;7(2):705-707.

12. Shahab F, Hussain H, Inayat A and Shahab A. Attitudes of medical students towards their career perspective from Khyber-Pukhtunkhwa. J. Pak. Med. Ass. 2011; 61: 832 \pm 836 .

13. Bank TW. The World bank. World bank country and lending groups [internet]. [cited 16Jan2017].Available from: https://datahelpdesk. Worldbank. org/ knowledgebase /articles/906519world-bank-country-andlending-groups.

14. Gąsiorowski J, Rudowicz E, Safranow K. Motivation towards medical career choice and future career plans of polish medical students. Adv Heal Sci Educ. 2015;20(3):709-25.

15. Győrffy Z, Birkás E, Sándor I. Career motivation and burnout among medical students in Hungary-could altruism be a protection factor? BMC Med Educ.2016;16(1):182.

16. Kim KJ, Hwang JY, Kwon BS. Differences in medical students' academic interest and performance across career choice motivations. Int J Med Educ. 2016;7:52.

17. Kavousipour S, Noorafshan A, Pourahmad S, Dehghani-Nazhvani A. Achievement motivation level in students of Shiraz University of Medical Sciences and its influential factors. J Adv Med Educ Prof. 2015;3(1):26.

18. Pagnin D, De Queiroz V, De Oliveira Filho MA, Gonzalez NVA, Salgado AET, Oliveira BCE, et al. Burnout and career choice motivation in medical students. Med Teach. 2013;35(5):388-94. 
19. Diwan V, Minj C, Chhari N, De Costa A. Indian medical students in public and private sector medical schools: are motivations and career aspirations different?-studies from Madhya Pradesh, India. BMC Med Educ. 2013; 13(1):127.

20. Seetharaman N, Logaraj M. Why become a doctor? Exploring the career aspirations and apprehensions among interns in South India. Natl J Res Community Med. 2012; 1(4):188-95.

21. Brissette A, Howes D. Motivation In Medical Education: A Systematic Review . WebmedCentral Medical Education 2010;1(12):WMC001261

22. World Health Organization. Increasing access to health workers in remote and rural areas through improved retention. Geneva: WHO; 2010. Available at www.searo.who.int/nepal/mediacentre/ 2010_increasing_access_to_health_workers_in_remote_and_rural_areas.pdf (accessed on $18 \mathrm{Sep}$ 2015).

23. Ryan, R. M., \&Deci, E. L. (2000). Self-determination theory and the facilitation of intrinsic motivation, social development, and well-being. American Psychologist, 55, 68-78.

24. Goel S, Angeli F, Dhirar N, Sangwan G, Thakur K, Ruwaard D. Factors affecting medical students' interests in working in rural areas in North India-A qualitative inquiry.PLoS One. 2019; 14(1):e0210251. doi: 10.1371

25. Matsumoto M, Inoue K, Kajii E. Characteristics of medical students with rural origin: Implications for selective admission policies. Health Policy 2008; 87:194-202.

26. Saini NK, Sharma R, Roy R, Verma R. What impedes working in rural areas? A study of aspiring doctors in the National Capital Region, India.Rural Remote Health. 2012; 12:1967.

27. Bruno Mascarenhas JM. Overcoming shortage of doctors in rural areas: Lessons from Tamil Nadu. Natl Med J India2012; 25:109-11.

28. Chomitz K, Setiadi G, Azwar A. What do doctors want? In developing strategies for doctors to serve in Indonesia's rural and remote areas. World Bank Policy ResearchWorking Paper no. 1888. Washington, DC:The World Bank Development Research Group; 1998.

29. Ramani S, Rao KD, Ryan M, Vujicic M, Berman P. For more than love or money:Attitudes of student and in-service health workers towards rural service in India.HumResour Health2013;11:58.

30. Goel S, Angeli F, Bhatnagar N, Singla N, Grover M, Maarse H. Retaining health workforce in rural and underserved areas of India: What works and what doesn't? A critical interpretative synthesis. TheNationalMedicalJournalofIndia. 2016; 29(4).

31. Goel S, Angeli F, Singla N, Ruwaard D. Measuring the reasons that discourage medical students from working in rural areas: Development and validation of a new instrument. Medicine. 2018; 97:2

32. Gadi AD, Higuchi M, Warnasuriya N, et al. Medical students' willingness to work in post-conflict areas: a qualitative study in Sri Lanka. Health 2012;4:824-31.

33. Rao KD, Bhatnagar A, Berman P, Saran I, Raha S. India's Health Workforce: Size, Composition and Distribution. HRH Technical Report \#1. Public Health Foundation of India and the World Bank, New Delhi, India; 2008. Accessed from: http://www.hrhindia.org/assets/images/Paper-I.pdf.

34. Dieleman $\mathrm{M}$ et al. Identifying factors for job motivation of rural health workers in North Viet Nam. $\mathrm{J}$ Hum Resour Health, 2003; 1(10): 1-10.

35. Couper I et al. Influences on the choice of health professionals to practice in rural areas. SAfr Med J2007;97:1082-1086. 
36. Saini NK, Sharma R, Roy R, Verma R. What impedes working in rural areas? A study of aspiring doctors in the National Capital Region, India. Rural Remote Health 2012;12 (1967):1-7.

37. Rao M, Rao KD, Kumar AKS et al. India: Towards Universal Health Coverage 5 Human resources for health in India. Lancet 2011; 377:587-98.

38. Kruk ME, Johnson JC,Gyakobo M et al. Rural practice preferences among medical students in Ghana: a discrete choice experiment.Bull World Health Organ. 2010;88:333-341

39. Mohamed AM.Willingness and professional motivations of medical students to work in rural areas: a study in Alexandria, Egypt. Healthcare in Low-resource Settings.2013;1:1

40. Playford D, Larson A, Wheatland B. Going country: rural student placement factors associated with future rural employment in nursing and allied health. Aust J Rural Health 2006; 14(1): 14-19.

41. Syed NA, Khimani F, Andrades M et al. Reasons for migration among medical students from Karachi. Med Educ 2008;42:61-8.

42. Dussault G, Franceschini MC: Not enough there, too many here: understanding geographical imbalances in the distribution of the health workforce. Hum Resour Health 2006; 4:12

43. Maslow AH. Maslow's hierarchy of needs. Psychol Rev. 1943; 50:370-96.

44. Puertas EB, Arósquipa C. Factors that influence a career choice in primary care among medical students from high-, middle-, and low-income countries: a systematic review. Rev PanamSaludPublica. 2013;34(5):351-8.

45. Kumari D, Surana A. Trends of Mixed Methods Researches of Education in Indian Context. IJRSI 2017;4(6):94-8

46. Vallerand RJ, Blais MR, Brie 're NM, Pelletier LG. Construction et validation de l'E0 chelle de Motivation en Education (EME). Revue canadienne des sciences du comportement. 1989; 21:323 \pm 349 .

47. Vallerand RJ, Pelletier LG, Blais MR, Briere NM, Senecal C, Vallieres EF. The Academic Motivation Scale: A measure of intrinsic, extrinsic and amotivation in education. Educational and Psychological Measurement. 1992; 52: 1003 \pm 1017 .

48. Schaufeli WB, Martinez IM, Pinto AM, Salanova M, Bakker AB. Burnout and engagement in university students: A cross-national study. Journal of Cross-Cultural Psychology. 2002; 33(5): 464 \pm 481 .

49. Nieuwhof MGH, Ten Cate TJ, Oosterveld P, Soethout MBM. Measuring strength of motivation for medical school. Medical Education Online. 2004; 9: 16.

50. Kusurkar R, Croiset G, Kruitwagen C, ten Cate O. Validity evidence for the measurement of the strength of motivation for medical school. Adv in Health Sci Educ. 2011; 16:183 \pm 195 . 


\section{Summary}

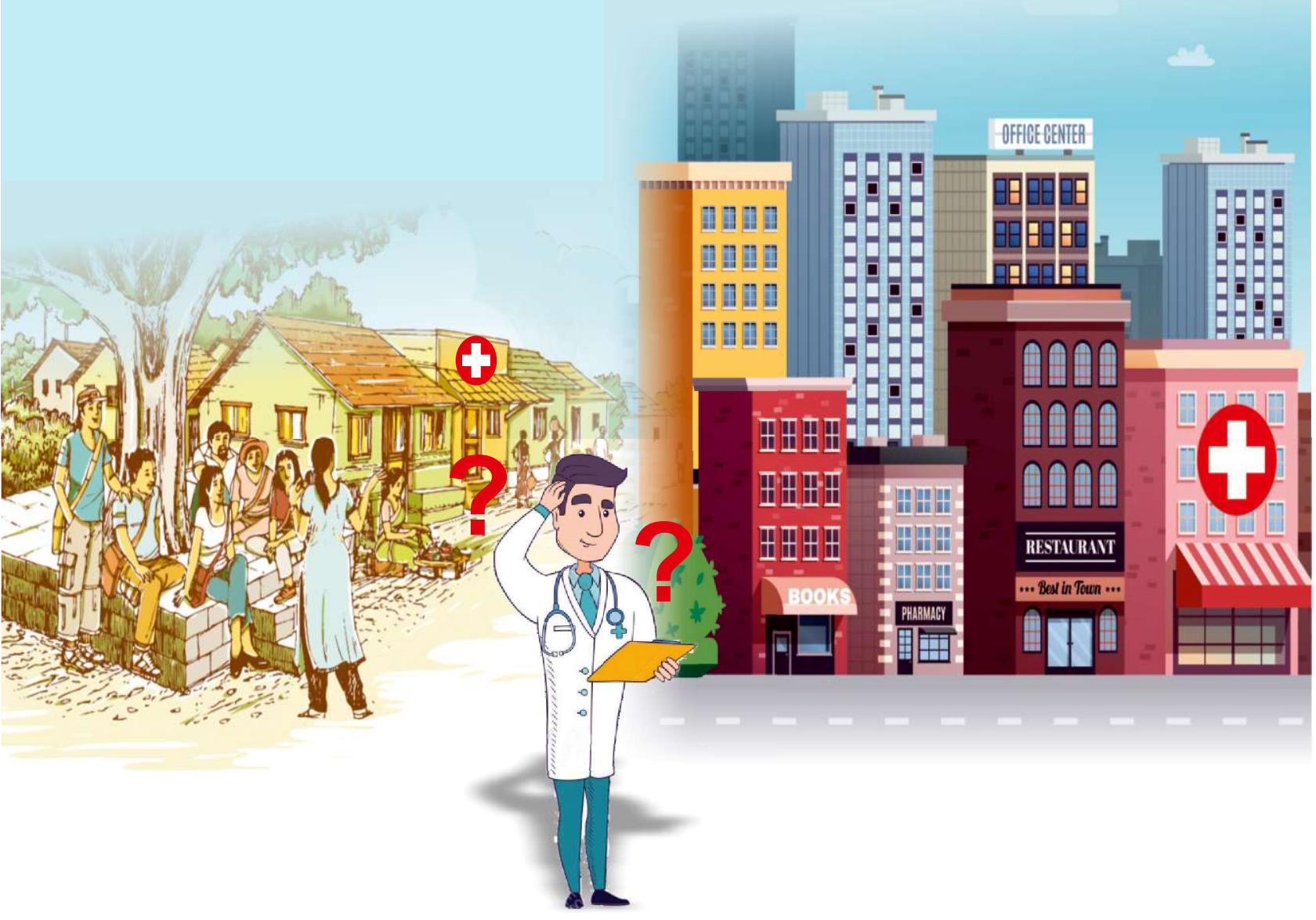




\section{Summary}

Human resource is one of the most important factors in the healthcare sector. It directly affects the quality of service delivery. Hence, human resources have been given priority in various health related goals and programs. Initiatives like Sustainable Development Goals focus on human resources for universal health coverage. Even after all these efforts the world is facing problems of dearth and inequitable distribution of health workers. These problems are more prevalent in middle and low income countries. The shortage and unequal distribution of health personnel leads to inequities in health services delivery and eventually to poor health outcomes.

The medical profession is one of the most reputed professions around the globe. Medical professionals are highly respected and are associated with high social status. Still, India has an acute shortage of medical professionals. The dearth of medical practitioners is even more in the rural parts of India. Several studies have been done worldwide to determine the factors influencing students' motivation to take up medical study. However, very few studies have been carried out in India. It is important to bridge this gap in literature to frame policies to counteract this acute shortage.

The objective of this $\mathrm{PhD}$ research was to thoroughly understand the motivational and demotivational factors of students to select medical studies and also their choice towards working in rural areas in India.

Chapter 1 contains the general introduction and description to the topic. It throws light on the current situation and the problems. Further in the chapter, the relevance and need of the study are discussed. The objectives of the research are also listed in the chapter.

Chapter 2 delineates the literature related to the motivation of medical students to pursue a career in the medical field. Studies investigating motivational factors that underpin students' selection of medical study were grouped and reviewed. Search of literature was executed with the purpose to identify the perceptions of medical students to enter medical studies. The search was carried out by two researchers independently in PubMed, Google 
Scholar, Wiley and IndMED databases for articles published from year 2006 till 2016. A total of 38 combinations of MeSH words were used for search. Studies related to medical students and interns were included. The application of inclusion and exclusion criteria and PRISMA guidelines for reporting systematic reviews led to the final selection of 24 articles. The majority of the studies included were from high-income countries. Thematic analysis of selected papers was done. Motivating factors that turned out from the study were scientific (interest in science/medicine, social interest and academia, flexible work hours and work independence), societal (prestige, job security, financial security) and humanitarian (serving the poor and under privileged) in high, upper-middle and lowermiddle income countries respectively. The findings were comparable to Maslow's hierarchy of needs theory of motivation. This study provides policy makers with the basic idea to understand the motivational factors and accordingly formulate policies.

Chapter 3 describes the development and validation of a reliable instrument for measuring the choice of medical students to study Bachelor of Medicine and Bachelor of Surgery (MBBS) in Indian settings using extensive literature review followed by Delphi technique. Two rounds of Delphi technique were conducted. The scale consisted of 12 items, 5 measuring intrinsic dimensions of motivations and 7 measuring extrinsic dimensions. The questionnaire was pilot tested on 20 students of a government college. Exploratory Factor Analysis (EFA) and Confirmatory Factor Analysis (CFA) validity, reliability and data quality checks were conducted on a sample of 636 medical students. The study was conducted in three northern states of Himachal Pradesh, Punjab and Haryana. Two government colleges from each state were included in the study. The study was ethically approved by the Institute's Ethical Committee, PGIMER, Chandigarh. Prior permission was sought from Principals of involved medical colleges. Informed written consent was obtained from the participants. The Motivation for Selection of Medical Study (MSMS) questionnaire consisted of 3 factors (subscales) and 8 items. The three main factors found after EFA were the scientific factor (e.g. research opportunities and the ability to use new cutting edge technologies), the societal factor (e.g. job security) and the humanitarian factor (e.g. desire to help others). The CFA conducted showed goodness of-fit indices supporting the 3-factor model. The study uncovers a novel threefaceted motivation construct based on scientific factors, societal expectations and 
humanitarian needs. The tool validated from the study can be further used in similar settings.

Chapter 4 represents the critical interpretative synthesis of the existing literature to capture various aspects that lead to human resource shortage in India and the strategies deployed globally which could be replicated and scaled up in developing countries such as India. The predefined selection criterion used to assess relevant manuscripts in this literature review was to identify 'the reasons for retaining health workforce in rural and underserved areas'. PubMed, Google Scholar and IndMED search engines were used to identify relevant articles. Articles published in English from 2005 to 2014 were included. A total of 56 articles were included after screening of full text of the article. The different strategies for retention of health workforce in rural areas were discussed on the basis of four major retention interventions, viz. education, regulation, financial incentives and personal and professional support. Healthcare in India is delivered by a diverse set of providers. The results revealed that the distribution of manpower is unequal across states, urban-rural areas, gender and category of health personnel. India lacks in health system development and financing. Workforce education and training is not given priority. Poor governance, insufficient salary and allowances, along with inability of employers to provide safe, satisfying and rewarding work conditions are causing health worker attrition in rural India. The review suggests that the retention of health workers in rural areas can be ensured by multiplicity of interventions such as medical schools in rural areas, rural orientation of medical education, introducing compulsory rural service in lieu of incentives providing better pay packages and special allowances, and providing better living and working conditions in rural areas. Hence, evidence based strategies are needed to ensure context-specific and field tested solution to existing problems.

Chapter 5 outlines the development and validation of a scale identifying barriers for medical students for accepting rural postings in Indian settings using extensive literature review followed by Delphi technique. EFA followed by CFA was performed to identify the primary deterrents. The findings of the quantitative and qualitative study were mixed at the interpretation level to enhance, validate and provide explanation of the quantitative findings by using a mixed method approach. The final instrument included 29 items whereas the EFA and CFA highlighted 5 main factors, namely lack of professional 
challenge, social segregation, socio cultural gap, hostile professional environment, and lack of financial incentives as underpinning students' demotivation towards working in rural areas. The developed Medical Student's De-motivation to work in Rural India (MSDRI) instrument is the first valid and reliable measure for identifying deterring factors for MBBS students to work in rural areas of India.

Chapter 6 depicts a cross-sectional, descriptive qualitative study in which Focused Group Discussions FGDs were used to display medical students' views about working in rural settings in India, in order to explore the discouraging and encouraging factors. A total of six focus group discussions each comprising 10-20 medical students were held in six medical colleges. The colleges were randomly selected, two from each state. The major factors highlighted were 'scientific and professional' (poor accommodation facilities and lack of necessary infrastructure; lack of drug and equipment supplies; inadequate human resource support, lesser travel and research opportunities) and 'societal'(less salary and incentives, social isolation, political interference, lack of security). The primary encouraging factors were 'humanitarian' (desire to serve poor, underprivileged and home community), 'scientific and professional' (preferential admission in post-graduation after working more than 2-3 years in rural areas) and 'societal' (achieving higher social status). These findings will help policy makers in formulating target specific policies.

Lastly, Chapter 7 presents the general discussion, addressing the theoretical and methodological reflection on the main findings as presented in the previous chapters. It also provides recommendations for policy and practice as well as directions for future research. The mixed-method research methodology of collecting, analyzing and integrating quantitative (e.g. surveys) and qualitative (e.g. focus group discussions, indepth interviews, Delphi technique) data along with literature reviews was applied to understand complex human behavior as a sequel to many inter-related factors behind their motivation to select medical studies and postings in rural and remote areas of India. In addition, two new measurement instruments were developed and validated for understanding the main motivation factors that influence students to opt for medical studies in India. This study encapsulates the important aspects that may be required to recruit and retain the future doctors in rural areas. 



\section{Valorization}

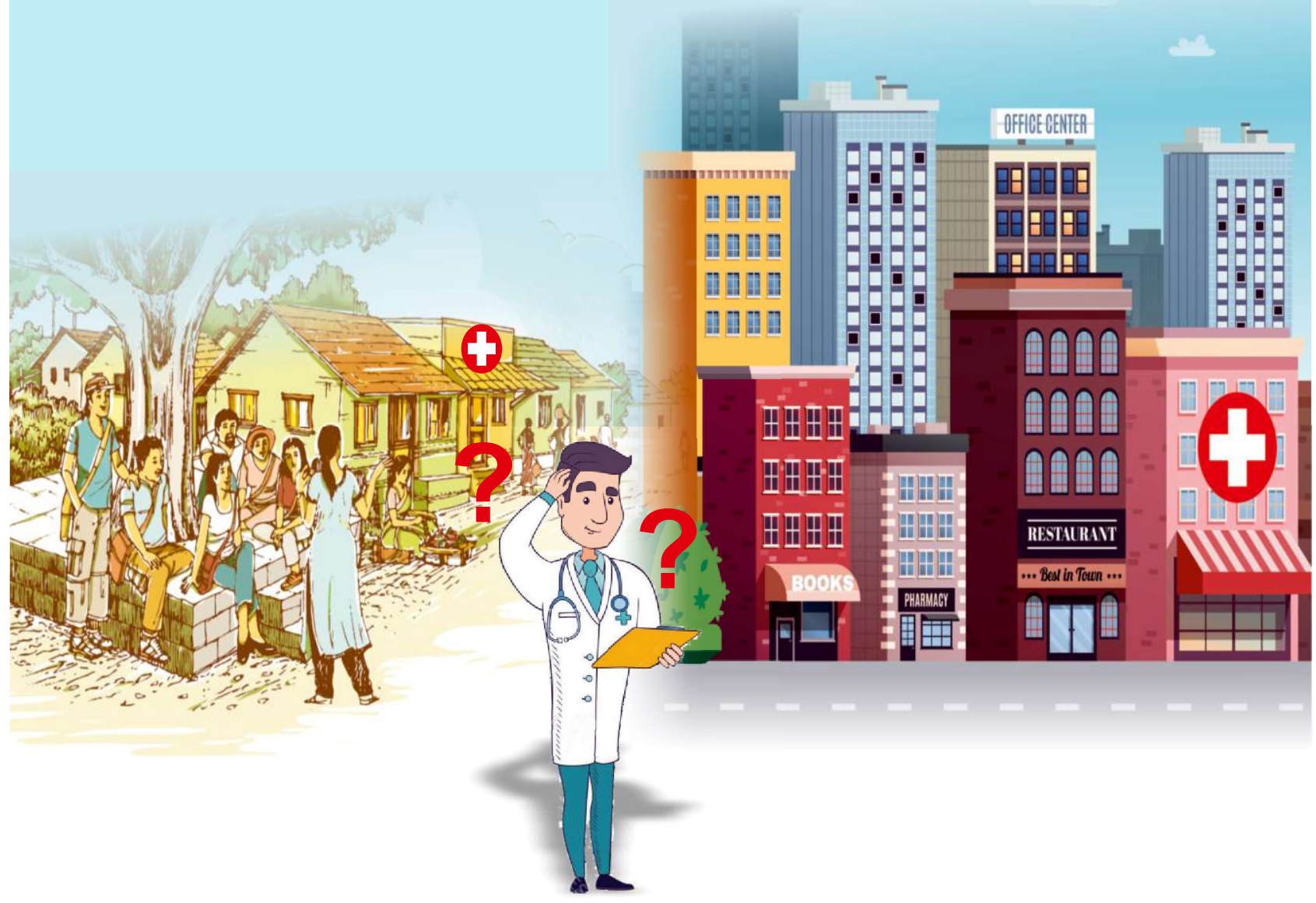




\section{Valorization}

The research conducted within the scope of this PhD-trajectory has contributed in identifying the major factors which have led to the acute shortage of medical professionals in India. It highlights the motivational factors which underpin medical students' selection of medical study and also the encouraging and discouraging factors affecting interest of medical students in working in rural areas. The research has not only offered new knowledge but also developed and validated two reliable instruments. The instruments developed measure the choice of medical students to study MBBS in Indian settings and factors deterring final year MBBS students from working in rural areas, respectively. These instruments can further be used for future research. In this chapter, the relevance of this study and recommendations for the educators, policy makers and implementers are presented.

\section{Relevance}

India is facing an acute shortage of medical practitioners in rural and regional areas, especially in North India [1,2]. The situation has become more critical over the last two decades. For $70 \%$ of the Indian rural population, the doctor to population ratio is extremely low [2]. Along with the overall shortage of medical practitioners, the number of doctors working in urban compared to rural areas is widening. This leads to poor service delivery and inequities in health. Therefore, understanding the perception of medical students about challenges in relation to rural areas was important. It could help in stimulating their choice to work or stay in rural areas. The research was carried out with the aim of comprehensively understanding the motivation factors stimulating students to select medical studies and to work in rural areas. The aim was pursued through two theoretical and three empirical studies.

\section{Target groups}

The results presented in the thesis are of relevance to various groups of the society. The three main groups who can take recommendations from this research are educators, 
policy makers and implementers. These groups can directly bring changes in the system and solve the crisis of shortage of medical practitioners in the country.

\section{Educators}

Educators are the ones who have the most influence on the students. They have a direct contact with students and hence are more aware about their perspectives and choices. The research revealed that the encouraging factors among medical students willing to serve in rural areas were majorly humanitarian (desire to serve poor, underprivileged and home community). The educators should keep these factors in mind while imparting education and try to instill them in all their students. This could lead to behavior change in students. The educators while making the curriculum and designing the course should keep in mind health needs of the whole country.

The curriculum can be revised looking at the present status of unequal distribution and shortage of medical practitioners. The research highlights the encouraging and discouraging factors that influence medical students' interest in working in rural areas. Using these factors as reference new courses can be designed laying emphasis on the priorities. New approaches like community-based medical education and a longer clinical apprenticeship in rural health facilities can be promoted. Early and long term clinical exposure in rural areas during medical education and training can also be increased.

\section{Policy makers}

Policy makers can bring the desired changes in the ongoing system to improve the current situation. Human resource policy for medical doctors at national and state level is the need of hour. They can take clues from the motivation factors for students to take up medical study which came across in the research. The major motivation factors that emerged out were scientific (work independence, interest in academia), societal (prestige, job and financial security) and humanitarian. Policies can be drafted to increase job security and financial security of doctors. This will lure students towards the profession. It can help in decreasing the overall dearth of doctors in India. An instrument 
has also been developed and validated to measure the choice of medical students to study MBBS. This instrument is the first of its kind in India. It is a tested and reliable tool and policy makers can formulate policies based on it to motivate students to take up medical study. This study throws light upon the medical students' interest to work in rural settings and highlights discouraging and encouraging factors that deter or attract them to work in rural areas. The discouraging factors overcame encouraging factors. The discouraging factors included lack of professional challenge, social segregation, socio-cultural gap, hostile professional environment, and lack of financial incentives. These factors need to be rectified to attract the medical practitioners to work in rural areas. Policy makers can make policies to tackle these challenges. Keeping these factors in mind policies can be made to improve work environment in rural areas and to increase privileges and financial incentives of doctors serving in these areas. The MSDRI instrument developed to explore demotivation factors of medical students for working in rural areas can also be used by the policy makers. It is a validated tool and can be used in other settings and policies can be made based on the results.

\section{Implementers}

Healthcare delivery is labour-intensive where quality, effectiveness and efficiency are dependent on successful planning of the health workforce. Various strategies for attraction and retention of the health workforce have been successfully and unsuccessfully implemented by the Indian government. Numerous efforts were made by the government to address issues of financial incentives, living conditions and future career prospects of doctors working in rural areas. These strategies were not successful in all parts of India. The diversity of India with each state having its own challenges makes it difficult to implement new policies which are not pre-tested. This study provides implementers with tested and valid instruments. The strategies designed based on the results of these instruments can be easily implemented. This way the success rate of the strategies implemented would increase. The study also highlights the discouraging factors that deter medical practitioners to work in rural areas. Some of the factors were

poor accommodation facilities, lack of necessary infrastructure, inadequate human 
support and lesser research opportunities. Implementers can focus on these factors and implement strategies to improve them.

Thus, the present study offers important clues to all stakeholders for designing tailormade, field-tested and cost-effective measures for attracting and retaining a workforce in rural areas.

\section{Future Directions}

The results of the research have important public health implications. Human resources are one the major factors which affects the quality of health service delivery. Poor quality services lead to poor health outcomes. Thus, human resource management is of utmost importance in the field of health and healthcare. The results of the study will help various stakeholders in taking better and more effective decisions for retention of medical professionals in rural areas. The outcomes of this research will assist in promoting and translating related policies into concrete and effective measures at local, regional and national level.

Based on the results of this study it is recommended that policy makers and implementers should prioritize the elimination of discouraging factors that deter students to take up medical study and also dissuade medical professionals from working in rural areas. All the stakeholders involved should work in coordination to come out with most suited strategies to overcome the problem. The instruments developed and validated in this study should further be used in various parts of India and also across different developing countries. There should be exchange of best practices among countries where similar strategies are being used. This gives a chance to policy makers and implementers to learn and formulate better strategies.

The current dissertation also provides direction for future research. Similar research should also be done among high school students to identify the factors that encourage or discourage them to choose the medical field. There is a need to explore that how many of those who complete their medical study wish to pursue their career in India. Similar research can be extended to various other health professionals like nurses. 


\section{Valorization}

Comprehensive evaluation of various interventions conducted in different parts of the world to attract and retain health care providers, especially in low income countries, should be done. Further research will help in exploring new perspectives and identifying more factors involved in opting for medical field. This will lead to formulation of more specific and effective strategies. 


\section{Valorization}

\section{References}

1. Hazarika I. Health workforce in India: assessment of availability, production and distribution. WHO South East Asia Journal of Public Health. 2013; 2:106 \pm 112.

2. Rao M, Rao KD, Kumar AK, Chatterjee M, Sundararaman T. Human resources for health in India. Lancet. 2011; 377: 587士598. doi: 10.1016/S0140-6736(10)61888-0PMID: 21227499

3. 



\section{Acknowledgement}

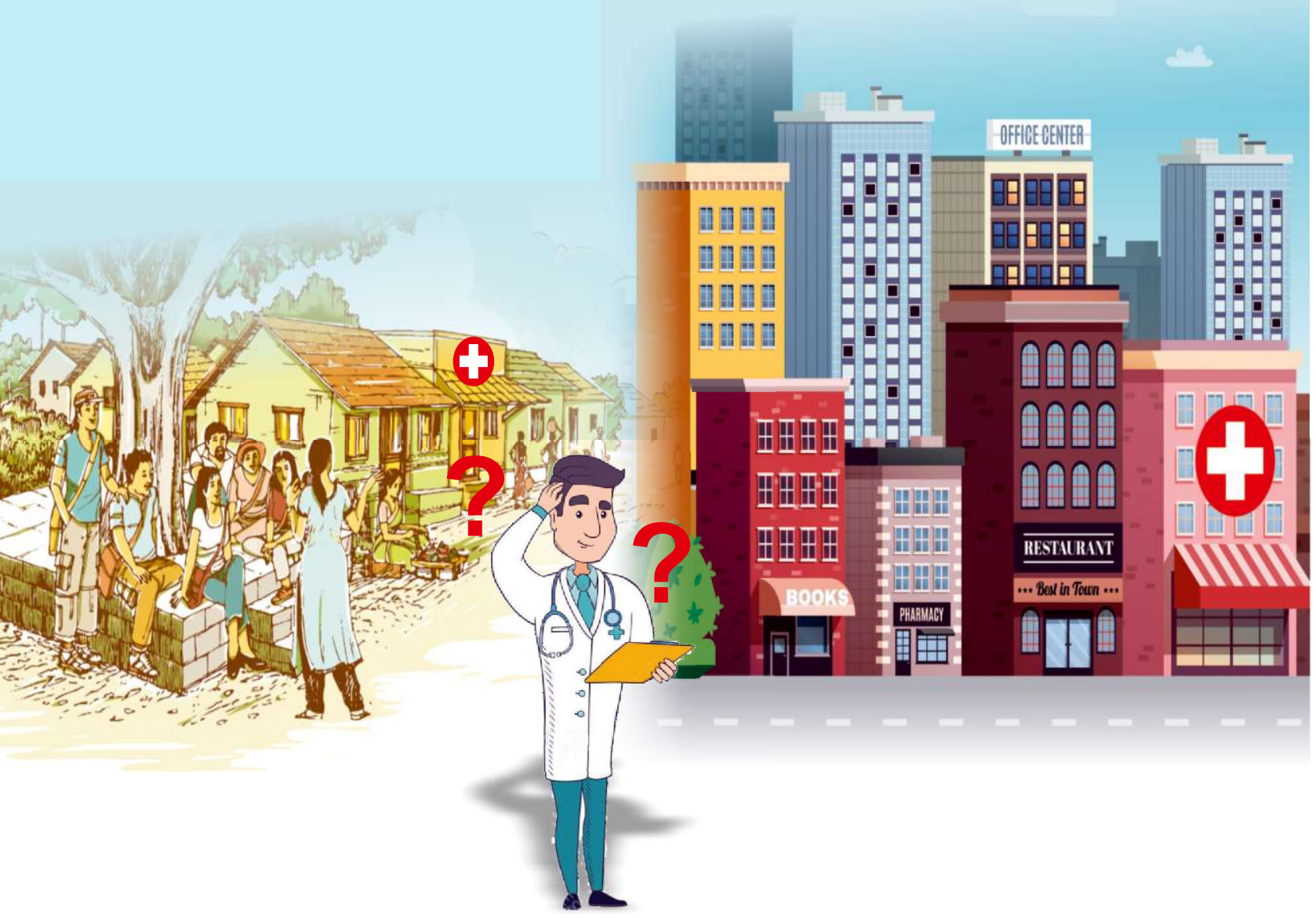


Acknowledgement

\section{Acknowledgement}

It is my great privilege to extend sincere thanks to all those who have contributed in numerous ways for the completion of my $\mathrm{PhD}$ and made it a beautiful experience for me. This thesis has been kept on track and been seen through to completion with the support and encouragement of numerous people including my supervisors, wellwishers, friends, colleagues and family members.

First, I am extremely grateful to Prof. Dr. Dirk Ruwaard for his expertise, assistance, guidance and faith throughout the process of writing this thesis. His constant words of encouragement had kept me motivated throughout this wonderful journey. His knowledge and ability of critically analyzing the work, has not only expanded my thinking process, but also taught me how to stay focused on my work. It was a great learning experience to work under his guidance.

I am also grateful to Prof. Dr. Federica Angeli for guiding and supervising my $\mathrm{PhD}$ work. Her knack of thoroughly reviewing the $\mathrm{PhD}$ work along with providing extra care and effort has improved the quality of my work to a great extent. Both of my supervisors worked extremely hard to get five papers published in good quality journals along with getting my thesis approved from the assessment committee. I could not have imagined having such wonderful supervisors and mentors for my $\mathrm{PhD}$ thesis.

My sincere thanks to Prof. Onno C.P. van Schayck who motivated me to pursue $\mathrm{PhD}$ from CAPHRI during his visit to my institute PGIMER, Chandigarh, India. He was so intrigued with my idea about medical students' motivation and preferences to select medical studies and work in rural areas, that my proposal got immediately accepted. My colleague Dr Madhu Gupta, who was also enrolled with CAPHRI in the same year, encouraged me to join the PhD. I also acknowledge the support received from Dr. Hannerieke van der Boom, CAPHRI PhD coordinator who showed faith in me and supported me throughout the thesis work. I also express my heartfelt gratitude to Prof. Dr. Hans Maarse who not only promoted and mentored me to conduct the PhD work on the selected topic but also took care of me when I visited Maastricht University in December 2011. I would also like to extend my heartfelt respect to Ms. Brigitte 
Caenen, Secretary and Office Management for her timely assistance during my entire journey of completion of my thesis work.

I express my sincere gratitude to the members of the assessment committee Prof. Dr. J.J.E. Rethans, Prof. Dr. J.S.M. Krumeich, Prof. Dr. S.V. Ramani, Prof. Dr. N.S. Klazinga and Dr. B. Kroon for their time to assess and approve my thesis.

I am indebted to Prof. Amarjeet Singh, Head of Department of Community Medicine and School of Public Health, PGIMER, Chandigarh, India for his constant support and practical suggestions during this long period, which helped me, improvise my thesis work.

I am also thankful to many of my friends, colleagues and teachers for their love and support in this endeavor of achieving this feat.

My special thanks to Dr. Nisha, Research Associate and Ms. Divya, Junior Research fellow at PGIMER for their constant support during the thesis work.

I also thank Indian Council of Medical Research for providing partial financial support for data collection during my thesis.

In the end, I would like to mention that this journey would not have been possible without the support of my family: my parents for taking care of me at every stage of my life, my beloved wife Sonika's constant moral support, patience and understanding, and my son Pushp's love which has kept me going to achieve this arduous task. 



\section{About the Author}

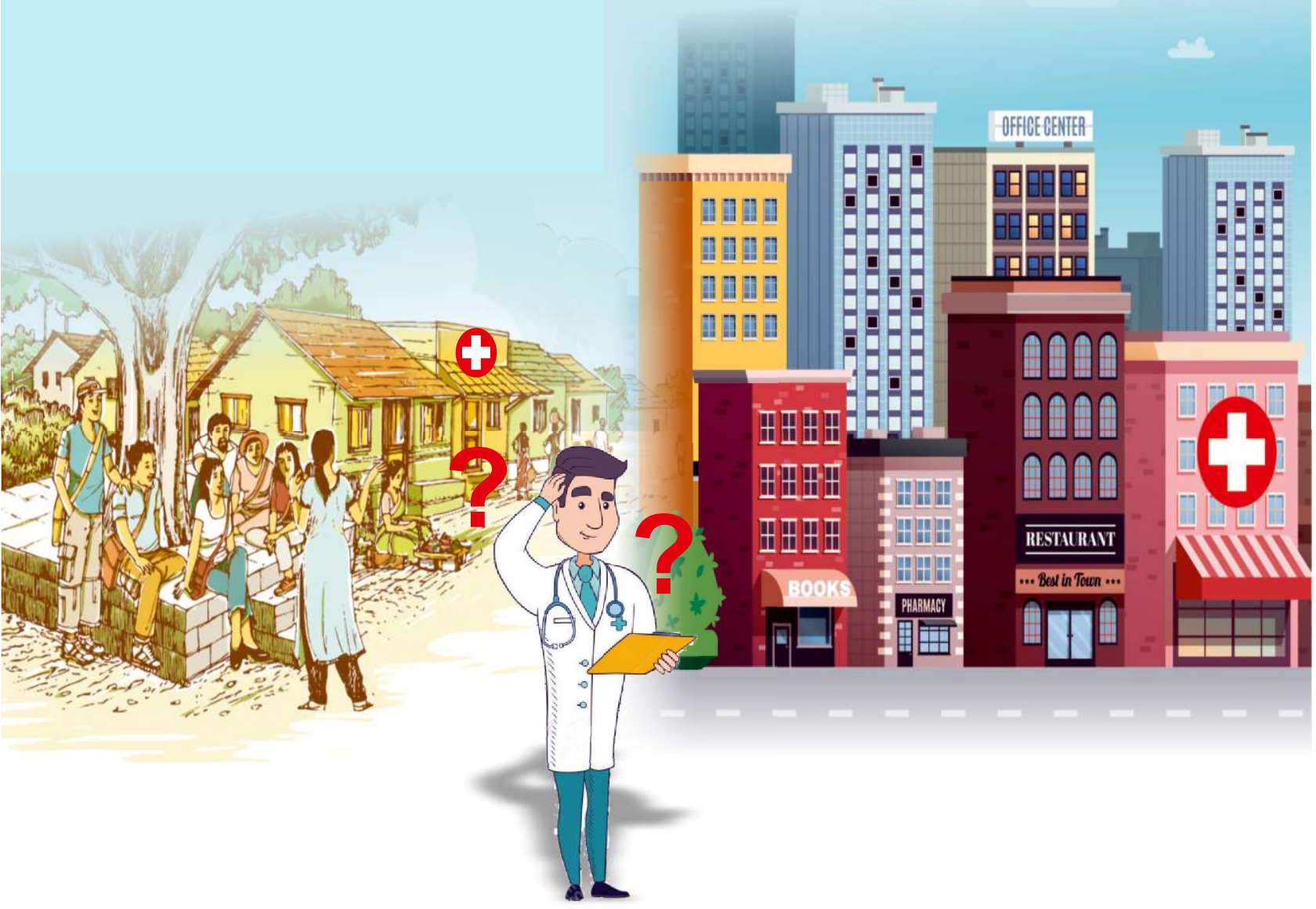




\section{About the author}

Sonu Goel was born on March $12^{\text {th }} 1975$ in Kanpur, Uttar Pradesh, India. In 1999 he graduated as a Bachelor of Medicine and Bachelor of Surgery (MBBS), and in 2003, post graduated as Doctor of Medicine (Community Medicine) from Indira Gandhi Medical College, Shimla, Himachal Pradesh, India. His MD thesis was on epidemiological aspects of chronic bronchitis in Shimla hills. He had joined the Department of Community Medicine, School of

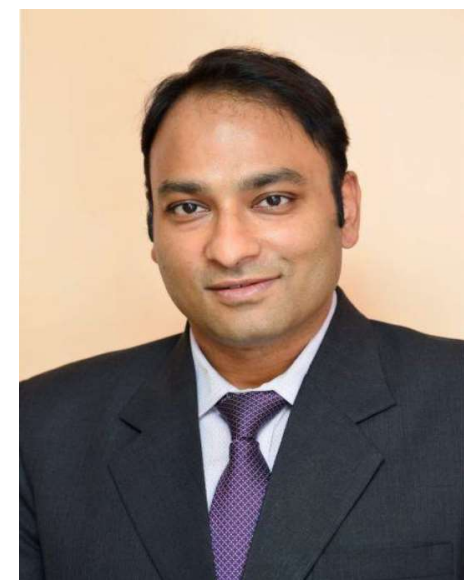
Public Health, Post Graduate Institute of Medical Education and Research (PGIMER), Chandigarh, India (an Institute of National Importance) as Senior Resident in 2006 as Senior Resident. During his residency he developed interest in human resource management in health and tobacco control.

In 2008, he joined as an Assistant Professor of Health Management in Department of Community Medicine and School of Public Health, Post Graduate Institute of Medical Education and Research (PGIMER), Chandigarh, India. His main areas of interest include health management, human resource management, operational research and tobacco control. He got promoted to Associate Professor in 2012, Additional Professor in 2015 and to Professor in 2019.

$\mathrm{He}$ is the youngest public health fraternity in India to have been bestowed fellowships from 3 prestigious public health organizations namely Indian Public Health Association, Indian Association of Preventive and Social Medicine and International Medical Science Academy and Dr. Harcharan Singh Oration.

Dr. Goel has over 100 publications, edited 2 books, produced 12 films on national health programs and wrote 35 chapters in various books on public health. He has independently completed over 50 projects with around 20 sub-national, national and international public health organizations. He had conceived two flagship programs of Ministry of External 
About the author

Affairs namely International Public Health Management Development Program and Public Health Policy and Management and Executive Leadership Program by Government of Odisha in which over 300 senior executives from over 50 countries have been trained in last 4 years. He has organised 28 programs/ workshops till date. Besides it, he has received visiting scholarships from Johns Hopkins (United States), International Union against TB and Lung Diseases, University Grants commission, Indian Council of Medical Research etc. He had won 'Public Health Excellence of India' award in 2016 and many other awards including best researcher award by PGIMER, Chandigarh. He is member of various state and national bodies and currently Vice-Chair of The Union's Tobacco control Section and Chair-MPOWER Global Working Group on Tobacco Control. He is widely travelled and had visited more than 40 countries to disseminate his research findings.

In 2011, he began his work as a PhD student at the School of Public Health and Primary Care (CAPHRI), Maastricht, The Netherlands. His PhD research focused on health system research and human resource management. The results of the thesis have been published in esteemed national and international journals.

Currently he's working as Professor of Health Management in Department of Community Medicine and School of Public Health, Post Graduate Institute of Medical Education and Research (PGIMER), Chandigarh, India. He continues to fulfill various teaching roles within the institution and is carrying out research activities mainly focused on tobacco control and health management. 
About the author

\section{List of Publications}

\section{International}

1. Goel S, Angeli F, Dhirar N, Sangwan G, Thakur K, Ruwaard D. Factors affecting medical students' interests in working in rural areas in North India—A qualitative inquiry. PloS one. 2019 Jan 10;14(1):e0210251.

2. Goel S, Verma M, Singh RJ, Bhardwaj AK. Integrating tobacco and tuberculosis control programs in India: A win-win situation. International Journal of Noncommunicable Diseases. 2018 Dec 1;3(5):9.

3. Goel S, Angeli F, Dhirar N, Singla N, Ruwaard D. What motivates medical students to select medical studies: a systematic literature review. BMC medical education. 2018 Dec;18(1):16.

4. Pandey R, Goel S, Koushal V. Assessment of motivation levels and associated factors among the nursing staff of tertiary-level government hospitals. The International journal of health planning and management. 2018Apr 15

5. Goel S, Angeli F, Singla N, Ruwaard D. Measuring the reasons that discourage medical students from working in rural areas: Development and validation of a new instrument. Medicine. 2018 Jan;97(2).

6. Kar SS, Goel S, Naik BN, Singh RJ, Subitha L, Premarajan KC, Lal P. Does capacity building on tobacco control change perception and knowledge among public health professionals? A case study from Puducherry, India. International Journal of Noncommunicable Diseases. 2018 Apr 1;3(2):60.

7. Goel S, Sharma D, Gupta R, Mahajan V. Compliance with smoke-free legislation and smoking behaviour: observational field study from Punjab, India. Tobacco control. 2018 Jul 1;27(4):407-13.

8. Bashar MA, Goel S. Are our subcenters equipped enough to provide primary health care to the community: A study to explore the gaps in workforce and infrastructure in the subcenters from North India. Journal of family medicine and primary care. 2017 Apr;6(2):208.

9. Dixit J, Goel S, Sharma V. A comparative study on the level of satisfaction among regular and contractual health-care workers in a Northern city of India. Journal of family medicine and primary care. 2017 Apr;6(2):416.

10. Goel S, Sharma D, Rani S. Factors influencing Janani Suraksha Yojana utilization in a northern city of India. International Journal of Reproduction, Contraception, Obstetrics and Gynecology. 2017 Jan 31;6(2):5759.

11. Goel S, Angeli F, Singla N, Ruwaard D. Development and validation of the motivations for selection of medical study (MSMS) questionnaire in India. PloS one. 2016. 20;11(12):e0164581.

12. Tripathy JP, Goel S, Kumar AM. Measuring and understanding motivation among community health workers in rural health facilities in India-a mixed method study. BMC health services research. 2016 ;16(1):366.

13. Gurung MS, Pelzom D, Dorji T, Drukpa W, Wangdi C, Chinnakali P, Goel S. Current tobacco use and its associated factors among adults in a country with comprehensive ban on tobacco: findings from the nationally representative STEPS survey, Bhutan, 2014. Population health metrics. 2016;14(1):28.

14. Khanal S, Baral S, Shrestha P, Puri M, Kandel S, Lamichanne B, Elsey H, Brouwer M, Goel S, Chinnakali P. Yield of intensified tuberculosis case-finding activities using Xpert® MTB/RIF among risk groups in Nepal. Public health action. 2016. 21;6(2):136-41. 
About the author

15. Raj S, Sharma VL, Singh AJ, Goel S: Evaluation of Quality and Readability of Health Information Websites Identified through India's Major Search Engines. Advances in Preventive Medicine2016, 2016:1-6.

16. Jeyashree K, Kathirvel S, Shewade HD, Kaur H, Goel S: Smoking cessation interventions for pulmonary tuberculosis treatment outcomes. The Cochrane Library2016, 5:1-10.

17. Goel S,Gupta R. India: Tobacco Products Sales By Unlicensed Vendors Banned In Punjab. BMJ 2016,25:8-8.

18. Padhy SK, Goel S, Das SS, Sarkar S, Sharma V, Panigrahi M. Perceptions of teachers about learning disorder in a northern city of India. Journal of Family Medicine and Primary Care 2015. 4 (3), 432-34

19. Agrawal D, Aggarwal AK, Goel S. Women exposed to second-hand smoke more at home than at workplace: An analysis of GATS Report, India, 2009-10. Journal of Family Medicine and Primary Care 2015. 4 (3), 293-97

20. Kanwar V, Gupta AK, Goel S, Gupta PK. Hospital Bed Utilization: Perceptions of Healthcare Practitioners from Northern India. International Journal of Hospital Research 2015. 4 (3)

21. Roy P, Goel S. Is female smoking rising or declining in India? South Asian Journal of Cancer 2015; 4 (2): 99-100

22. Raj S, Sharma VL, Singh A, Goel S. The health information seeking behaviour and needs of community health workers in Chandigarh in Northern India. Health Information \& Libraries Journal 2015; 32 (2): 143-149

23. Goel S, Gupta R. India: Punjab Bans Single Cigarette Sales. Tob Control 2015;24:213-16

24. Singh D, Singh SP, Kumaran M, Goel S. Epidemiology of road traffic accident deaths in children in Chandigarh zone of North West India. Egyptian Journal of Forensic Sciences 2015 (Available online 6 April 2015)

25. Lal P, Goel S, Sharma D. In harm's way: tobacco industry revenues from sales to underage tobacco users in India. Glob Health Promotion 2015: 1757975914567927.

26. Goel S, Kessar RR, Raj S, Ray P, Singh A. Relevance of Rapid Diagnostic Tests for Plague in the Field Settings: a Review. International Journal of Contemporary Microbiology 2015. 1(1): 161-69

27. Raj S, Goel S, Sharma VL, Goel NK. Screening for caries activity among preschool children of Anganwadi centers in a North Indian City. SRM Journal of Research in Dental Sciences 2015. 6 (1):1-4

28. Sharma S, Singh M, Lal P, Goel S. Predictors of Tobacco Use among Youth in India: GATS 2009-2010 Survey.Asian Pacific Journal of Cancer Prevention2014. 16 (17), 7535-40

29. Sardana M, Goel S, Gupta M, Sardana V, Singh B. Is Exposure to Tobacco Advertising, Promotion and Sponsorship Associated with Initiation of Tobacco Use among Current Tobacco Users in Youth in India?Asian Pacific Journal of Cancer Prevention 2014. 16 (15), 6299-302

30. Goel S, Kumar R, Lal P , Tripathi JP, Singh RJ , Rathinam A, Christian A. How Compliant are Tobacco Vendors to India's Tobacco Control Legislation on Ban of Advertisments at Point of Sale? A Three Jurisdictions Review. Asian Pacific Journal of Cancer Prevention 2014. 15 (24): 10637-42.

31. Pandey NU, Gupta AK, Jain AK, Kumar A, Goel S. Factors influencing the propensity of nurses to counsel patients for eye donation: a pilot study in a tertiary care hospital in north India. Public health 2014. 128 (12): $1128-1130$

32. Raj S, Sharma VL, Singh A, Goel S. Evaluating quantity and quality of outdoor advertising media for health information in a northern city of India. International Journal of Recent Scientific Research 2014. 5 (12)::2337-41. 
About the author

33. Goel S, JP Tripathy, RJ Singh, P Lal Smoking trends among women in India: Analysis of nationally representative surveys (1993-2009). South Asian Journal of Cancer2014. 3 (4), 200-202

34. Yadav A, Goel S, Sharma VL. Integration of Tobacco Control in Masters of Public Health Curricula of India. Asian Pacific Journal of Cancer Prevention 2014. 15 (14): 5611-5.

35. Lal P, Srinath S, Goel S, Singh RJ, Sharma D, Kumar R, Bera O. Unravelling India's tobacco epidemicpriorities and recommendations for the second round of Global Adult Tobacco Survey (GATS). Global health promotion 2014. 22 (2): 7-19

36. Tiwari Y, Goel S, Singh A. Arrival time pattern and waiting time distribution of patients in the emergency outpatient department of a tertiary level health care institution of North India. Journal of Emergencies, Trauma, and Shock 2014. 7 (3), 160

37. Kumar R, Goel S, Harries AD, Lal P, Singh RJ, Kumar AMV, Wilson NC. How good is compliance with smoke-free legislation in India? Results of 38 subnational surveys. International health 2014. 6(3): 189-95

38. Xia YY, Goel S, Harries AD, Zhang ZG, Gao TJ, Wang LX, Cheng SM. Prevalence of extended treatment in pulmonary tuberculosis patients receiving first-line therapy and its association with recurrent tuberculosis in Beijing, China. Transactions of The Royal Society of Tropical Medicine and Hygiene 2014 . 108(7):402-7

39. Goel S, Kaur H, Gupta AK, Chauhan U, Singh A. Socio-epidemiological determinants of 2002 plague outbreak in Himachal Pradesh, India: a qualitative study. BMC Public Health 2014; 14 (1), 325 (published online at www.biomedcentral.com/content/pdf/1471-2458-14-325.pdf(

40. Tharu MB, Harries AD, Goel S, Srivastava S, Kumar AMV, Adhikari M. Screening retreatment tuberculosis patients for drug resistance in mid-west Nepal: how well are we doing? Public Health Action2014. 4 (1): 6065

41. Goel S, Sharma D, Bahuguna P, Raj S, Singh A. Predictors of Patient Satisfaction in Three Tiers of Health Care Facilities of North India. J Community Med Health Educ2014. S 2, 002. doi:10.4172/2161-0711.S2002

42. Jeyashree K, Kathirvel S, Shewade HD, Kaur H, Goel S. Smoking cessation interventions for pulmonary tuberculosis treatment outcomes. The Cochrane Library 2014.

43. Goel S, Singh N, Lal V, Singh A. Evaluating the impact of comprehensive epilepsy education programme for school teachers in Chandigarh city, India.Seizure2014; 23(1): 41-6.

44. Goel S, Khaiwal R, Singh RJ, Sharma D. Effective smoke free policies in achieving high level of compliance with smoke free law: experiences from a district of North India. Tob Control 2014. 23 (4): 291-94

45. Goel S, Sharma D, Singh A. Development and validation of a patient satisfaction questionnaire for outpatients attending health centres in North Indian cities. J Health Serv Res Policy. 2014 ;19(2):85-93

46. Goel S, Gupta R. India: E-Cigarettes Banned In Punjab. Tobacco Control 2013; 23 (1): 6-6

47. Goel S, Kumar R, Lal P, Sharma D, Singh RJ. Refining compliance surveys to measure the smokefree status of jurisdictions using the Delphi method. Public Health Action 2013; 3 (4): 342-345

48. Goel S, Bhatnagar N, Sharma D, Singh A. Bridging the Human Resource Gap in Primary Health Care Delivery Systems of Developing Countries With mHealth: Narrative Literature Review.Journal of Medical Internet Research 2013; 1(2) e25. doi:10.2196/mhealth.2688 
About the author

49. Goel S, Gupta P, Aggarwal A.K, Patro B, Kaur J, Aggarwal N. Evaluation of Nischay scheme in improving antenatal care in a northern State of India. Archives of Gynecology and Obstetrics. Archives of Gynecology and Obstetrics 2013; 288 (4): 815-819

50. Raj S, Goel S, Sharma VL, Goel NK. Short-term impact of oral hygiene training package to Anganwadi workers on improving oral hygiene of preschool children in North Indian City. BMC oral health 2013 (1), 67. doi: 10.1186/1472-6831-13-67.

51. Puri P, Goel S, Gupta AK, Verma P. Management of Polytrauma patients in emergency department at a tertiary care institute of Northern India. World Journal of Emergency Medicine 2013. 4 (1): 15-19

52. Raj S, Goel S, Sharma VL, Goel NK. Prevalence of dental caries and its association with Snyder test among preschool children in anganwadis of a North Indian city. International Journal of Public Health Dentistry 2012:3(1):1-10

53. Goel S. India: Smokeless Tobacco Ban. Tob Control 2012;21 (5):456-459

54. Raj S, Goel S, Sharma M, Singh A.J.Ecological footprint score in university students of an Indian city. J Environ Occup Sci 2012; $1(1): 23-26$

55. Goel S, Goswami H, Rana J.S. India: Court rules that nicotine is poison. Tobacco Control 2012; 21 (4):387390

56. Goel S, Patro B, Goel SR. Ecological Footprint: A Tool for Measuring Sustainable Development International Journal of Environmental Sciences 2011. 2(1): 140-44

57. Chauhan A, Goel S, Singh AJ. Tackling Emerging Outbreaks of Infectious Diseases: Preparedness for H1N1 Influenza in Emergency Department of a Tertiary Care Institute of India. International Journal of Infection Control 2011. 7(4)

58. Goel S, Verma H. Scope of Dentists in Public Health. The Internet Journal of Public Health 2009. 9 (1):12

59. Goel S, Singh A.J. Comparative Impact of Two Training Packages on Awareness and Practices of First Aid for Injuries and Common Illnesses among High School Students in India. International Electronic Journal of Health Education 2008; 11: 69-80

60. Goel S, Singh A. Will Plague Continue to Haunt Hilly States of India?. The Internet Journal of Health 2008. $8(1): 1-4$

61. Goel S. From Bhore Committee to National Rural Health Mission: A Critical Review. The Internet Journal of Health 2008; 7 (1):1-6

62. Goel S, Gupta H, Mazta SR. Epidemiological profile of Bite Cases Admitted at a 50 bedded Community Health Centre of Himachal Pradesh, India. The Internet Journal of Health 2008;7 (1): 1-7

63. Goel S. An Introduction to Community Based Rehabilitation- Continuing Medical Education. The Internet Journal of Health 2007; 6 (2): 1-5

64. Goel S, Mazta SR. Challenges to access of primary health care in hilly terrains of Himachal Pradesh, India. The Internet Journal of Health Care Administration 2007; 5 (1): 1-3

65. Goel S, Sood R, Mazta SR., Bansal P, Gupta A: Bacteriological Quality of Water Samples of a Tertiary Care Medical Center Campus in North Western Himalayan Region of India: The Internet Journal of Third World Medicine 2007; 5(1): 1-11 
About the author

66. Goel S, Gupta A.K, Singh A, Lenka S.R.. Preparations and limitations for prevention of Severe Acute Respiratory Syndrome in a tertiary care center of India. Journal of Hospital Infection 2007; 66: 142-47

67. Goel S, Bali S, Singh AJ. Impact of a Short Term Intervention on Health Care Outreach to a Marginal Population in Rural North India. The Internet Journal of Health 2007:1-12

\section{National}

1. Goel S, Pandey R, Kumar M, Kankaria A, Khaneja R. Impact of introducing light-emitting diode fluorescence microscopy services for diagnosis of pulmonary tuberculosis under Revised National Tuberculosis Control Program India. Lung India. 2018. 1;35(4):307.

2. Bhatt G, Goel S, Mor S, Gupta R. Exposure to second hand smoke and its correlates in Northern State of India. Indian Journal of Public Health. 2018. 1;62(2):128.

3. Goel S, Kumar AM, Aggarwal AK, Singh RJ, Lal P, Kumar R, Gupta M, Dogra V, Gupta D. Capacity building through operational research training in tobacco control: Experiences and lesson learned. Indian journal of community medicine. $2018 ; 43(2): 77$.

4. Sharma D, Goel S, Lal P. Education differential in relation to tobacco use and its predictors across different regions of India. Indian Journal of Cancer. 2017. 1;54(3):584.

5. Negi S, Shroff A, Garg A, Aggarwal G, Meena J, Goel S. Implementation of epidemic disease act: An experience from a North Indian jurisdiction. Indian journal of public health. 2017. 1;61(2):148-

6. Passi R, Goel S, Ajay S. Assessment of village health sanitation and nutrition committees of Chandigarh, India. Indian journal of public health. 2017. 1;61(4):290.

7. Goel S, Kathiresan J, Singh P, Singh RJ. Effect of a brief smoking cessation intervention on adult tobacco smokers with pulmonary tuberculosis: A cluster randomized controlled trial from North India. Indian journal of public health. 2017. 1;61(5):47-

8. Dudeja P, Singh A, Sahni N, Kaur S, Goel S. Effectiveness of an intervention package on knowledge, attitude, and practices of food handlers in a tertiary care hospital of north India: A before and after comparison study. Medical journal armed forces India. 20171;73(1):49-53.

9. Goel S, Sardana M, Jain N, Bakshi D. Descriptive evaluation of cigarettes and other tobacco products act in a North Indian city. Indian journal of public health. 2016. 1;60(4):273.

10. Goel S, Angeli F, Bhatnagar N, Singla N, Grover M, Maarse H. Retaining health workforce in rural and underserved areas of India: What works and what doesn't? A critical interpretative synthesis. The National medical journal of India. 2016 1;29(4):212.

11. Bashar MA, Goel S. Knowledge, Attitude and Self-care practises of type 2 Diabetics towards Diabetes and its complications in a rural block of Haryana, North India. National Journal of Research in Community Medicine. 2016;5(2):91-7.

12. Nagarajan P, Tripathy JP, Goel S: Is mother and child tracking system (MCTS) on the right track? An experience from a northern state of India. Indian J Public Health2016, 60:34-39.

13. Padhy SK, Goel S, Das SS, Sarkar S, Sharma V, Panigrahi M. Prevalence and Patterns of Learning Disabilities in School Children. The Indian Journal of Pediatrics 2016. 83(4):300-6. 
About the author

14. Goel S, Singh RJ, Tripathy JP. Impact of modular training on tobacco control on the knowledge of health workers in two jurisdictions of northern India. Indian J Cancer 2015. 52 (4), 685-88

15. Kansal OP, Goel S. Results-based management-Developing one's key results areas (KRAs). Indian J Public Health 2016, 60:34-39.

16. S Goel, A Gauri, H Kaur, US Chauhan, A Singh. Linking lifestyle of marginalized Gujjar population in Himachal Pradesh with plague outbreaks: A qualitative enquiry. Indian J Public Health. 2014. 58(2):113-5.

17. Bansal P, Bhardwaj AK, Goel S, Kumar D. Rationale of Local Sexually Transmitted Infections (STIs) Surveillance at Rural Health Centre of Himachal Pradesh. Indian Journal of Public Health Research \& Development 2014. 5 (4): 71-4

18. Raj S, Shruti G, Goel S, Singh AJ. Assessment of Quality of Raw Milk Samples from a Jurisdiction of Northern India. Healthline, Journal of Indian Association of Preventive and Social Medicine 2014; 5(1): 44-48

19. Singh D, Moorthi K, Singh SP, Goel S. Profile of Road Traffic Fatalities in Adults A 40 Year Study in Chandigarh Zone of North West India. Journal of Indian Academy of Forensic Medicine 2014. 36 (1): 4751

20. Goel S, Rana J, Sharma D, et al. Public opinion poll about smoking and smoke free legislation in a district of North India. Indian Journal of Cancer 2014. 51 (3). 330-34

21. Sharma M, Goel S, Singh SK, Sharma R, Gupta PK. Determinants of Indian physicians' satisfaction \& dissatisfaction from their job. The Indian Journal Of Medical Research2014;139(3):409-17

22. Goel S, Singh N, Lal V, Singh A. Knowledge, attitude and practices of students about first aid epilepsy seizures management in a Northern Indian City. Annals of Indian Academy of Neurology 2013; 16 (4): 538-43

23. Tripathy JP, Goel S, Patro BK. Compliance monitoring of prohibition of smoking (under section-4 of COTPA) at a tertiary health-care institution in a smoke-free city of India. Lung India 2013; 30 (4): 312-15

24. Kaur H, Goel S, Sharma Y, Kessar RR, Singh A. Socioenvironmental Etiology of Plague Outbreak in Himachal Pradesh- a Reterospective Enquiry. J Post Grad Med Edu Res 2013; 47 (2): 112-16

25. Kaur H, Goel S, Sharma Y, Kessar RR, Singh A. Socio-environmental Etiology of Plague Outbreak in Himachal Pradesh- A Retrospective Enquiry. Journal of Postgraduate Medicine Education and Research 2013. 47 (2): $112-116$

26. Dikid T, Gupta M, Kaur M, Goel S, Aggarwal A.K, Carravota J, Kumar R. Maternal and perinatal death inquiry and response project implementation review in India. The Journal of Obstetrics and Gynecology of India 2013. 63(2):101-7.

27. Goel S. Book Review - Six Thinking Hats by Edward De Bono. Journal of Health Management 2012. 14 (1):76-77

28. Goel S. Book Review - Seven Habits of Highly Effective People by Stephen R Covey. Journal of Health Management 2012. 14 (2), 252-253

29. Goel S, Gupta AK, Bains P, Jain B.U, Ahuja P, Goel S, Singh A.J.. Health Promotion Hospital Initiative Begins in India: A Comparison of Health Promoting Orientation of Three Leading Tertiary Care Hospitals of India. National Medical Journal of India 2011. 24 (2):16-18 
About the author

30. Goel S, Dogra V, Gupta S, Lakshmi PVM, Varkey S, Pradhan N, Krishna G, Kumar R. Effectiveness of Muskaan Ek Abhiyan (The Smile Campaign) for Strengthening Routine Immunization in Bihar State of India. Indian Pediatrics 2011: 48; 1-6

31. Goel S, Singh A.J.Health Awareness of North Indian High School Students. Indian Jour of Community Medicine 2007: 32 (3); 192-4

32. Goel S, Kashyap S, Bhardwaj AK. Epidemiological aspects of Chronic bronchitis in Shimla Hills. Indian J Chest Dis and Allied Sci 2007; 49: 143-47

33. Sood RK, Goel S, Gupta AK.Public Health Foundation- Concern and Missing Areas. Indian Jour of Community Medicine 2007: 32 (2); 162

34. Goel S, Gupta BP. Low Anemia Prevalence among Adolescents of an Urban Hilly Community. Indian Jour of Community Medicine 2007;32(1):67-8

35. Goel S, Lenka SR, Shailainder, Singh A. Streamlining Working of a Hospital Immunization Clinic -A Pilot Study. Indian Jour of Community Medicine 2006;31(4):297-99

36. Goel S. Book Review - Essentials of Management fifth edition by Prof. Harold Koontz and Prof. Heinz Weihrich. Indian Journal of Community Medicine 2006; 31(3):105

37. Goel S, Thakur J.S., Singh A.J. Stop Unnecessary and forced HIV testing of Student. Indian Journal of Community Medicine 2006; 31(2):105. 


\section{Appendices}

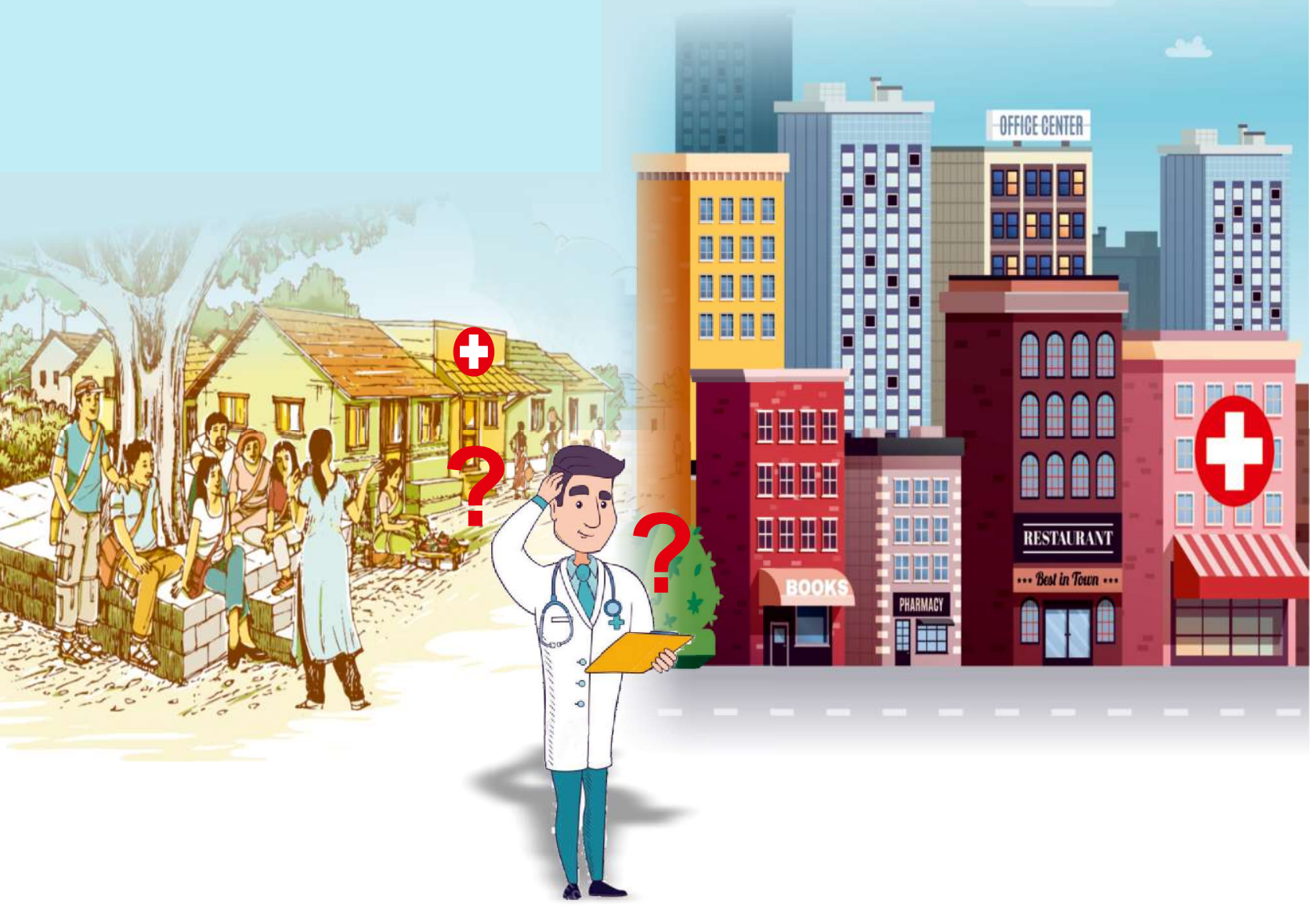


Appendix

$\underline{\text { Appendix } 1}$

\section{QUESTIONNAIRE FOR MEDICAL STUDENTS AND INTERNS}

“Understanding Medical Students' Motivation and Preferences to select Medical Studies and Work in Rural areas in North India"

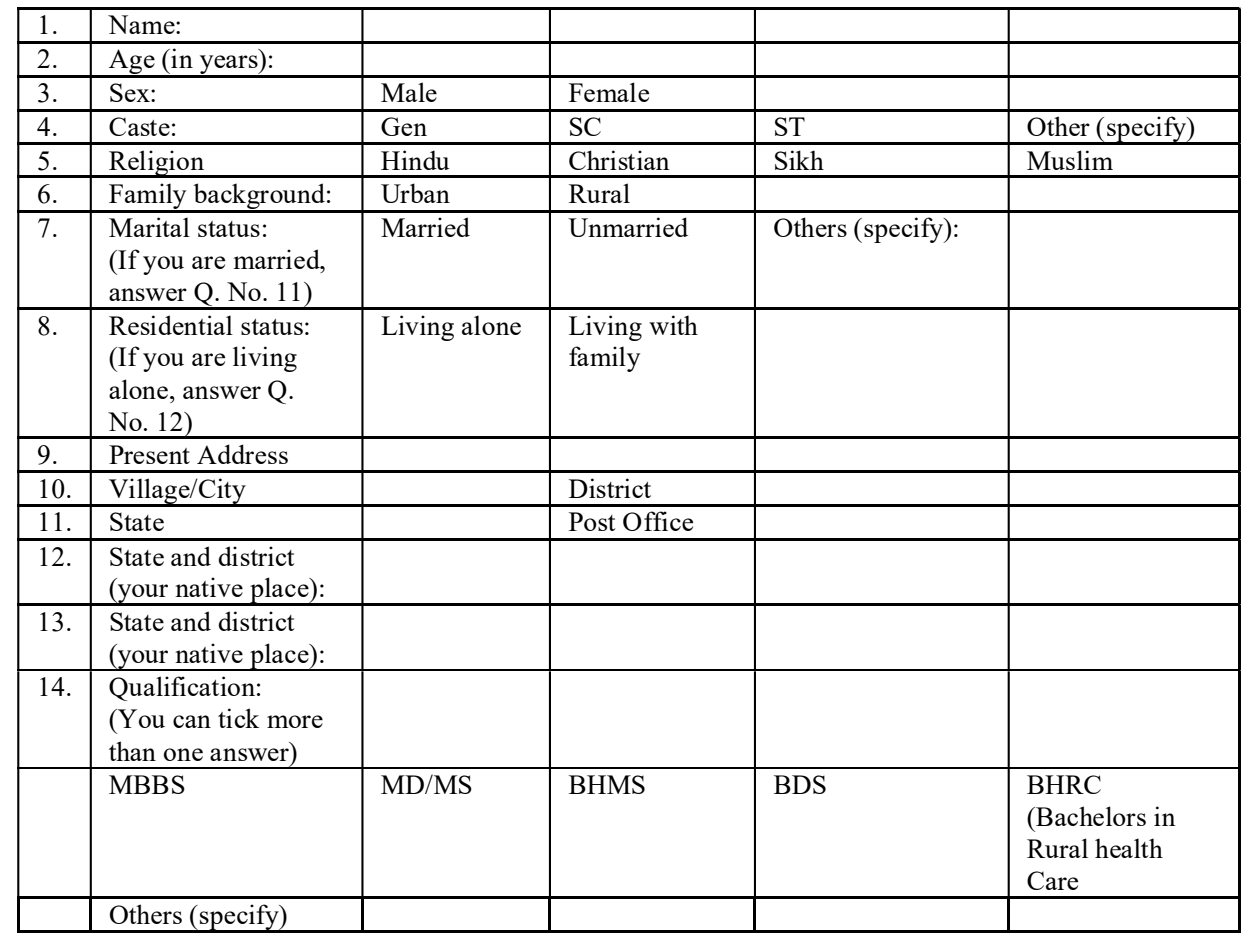

\section{Phone/ Mobile No.:}

2. According to you, what is the current status of rural health services?

\begin{tabular}{|c|c|c|c|c|c|}
\hline $\begin{array}{l}\text { Kindly rate } \\
\text { your opinion } \\
\text { from highly }\end{array}$ & $\begin{array}{c}\text { Highly } \\
\text { Unsatisfactory } \\
\text { (1) }\end{array}$ & $\begin{array}{c}\text { Slightly } \\
\text { Unsatisfactory } \\
\text { (2) }\end{array}$ & $\begin{array}{c}\text { Neutral } \\
\text { (3) }\end{array}$ & $\begin{array}{c}\text { Slightly } \\
\text { Satisfactory } \\
\text { (4) }\end{array}$ & $\begin{array}{c}\text { Highly } \\
\text { Satisfactory } \\
\text { (5) }\end{array}$ \\
\hline $\begin{array}{l}\text { to highly } \\
\text { unsatisfactory } \\
\text { (1). }\end{array}$ & & & & & \\
\hline
\end{tabular}


3. According to you, what are potential benefits of working in rural areas? Kindly rate your opinion from strongly agree (5) to strongly disagree (1).

\section{Personal gains}

\begin{tabular}{|l|l|l|l|l|l|}
\hline Statements & $\begin{array}{l}\text { Strongly } \\
\text { Disagree } \\
(1)\end{array}$ & $\begin{array}{l}\text { Slightly } \\
\text { Disagree } \\
(2)\end{array}$ & $\begin{array}{c}\text { Neutral } \\
(3)\end{array}$ & $\begin{array}{l}\text { Slightly } \\
\text { Agree } \\
(4)\end{array}$ & $\begin{array}{c}\text { Strongly } \\
\text { Agree (5) }\end{array}$ \\
\hline $\begin{array}{c}\text { A. Easy/ stress free personal } \\
\text { life }\end{array}$ & & & & & \\
\hline B. Workplace is near to home & & & & & \\
\hline $\begin{array}{c}\text { C. Less expenditure in day to } \\
\text { day living }\end{array}$ & & & & & \\
\hline $\begin{array}{c}\text { D. More time for himself and } \\
\text { for family }\end{array}$ & & & & & \\
\hline $\begin{array}{l}\text { E. Less family liabilities } \\
\text { F. Less professional } \\
\text { competition in public } \\
\text { service }\end{array}$ & & & & & \\
\hline
\end{tabular}

\section{Professional enrichment}

\begin{tabular}{|l|l|l|l|l|l|}
\hline \multicolumn{1}{|c|}{ Statements } & $\begin{array}{l}\text { Strongly } \\
\text { Disagree (1) }\end{array}$ & $\begin{array}{l}\text { Slightly } \\
\text { Disagree } \\
\text { (2) }\end{array}$ & $\begin{array}{c}\text { Neutral } \\
\text { (3) }\end{array}$ & $\begin{array}{l}\text { Slightly } \\
\text { Agree (4) }\end{array}$ & $\begin{array}{c}\text { Strongly } \\
\text { Agree (5) }\end{array}$ \\
\hline $\begin{array}{l}\text { A. Greater autonomy in } \\
\text { ability to utilize professional } \\
\text { skills }\end{array}$ & & & & & \\
\hline $\begin{array}{l}\text { B. More training } \\
\text { opportunities }\end{array}$ & & & & & \\
\hline $\begin{array}{l}\text { C. Better promotion } \\
\text { chances }\end{array}$ & & & & & \\
\hline $\begin{array}{l}\text { D. Better scope of getting } \\
\text { postgraduate seat } \\
\text { (reservation in PG seats) }\end{array}$ & & & & & \\
\hline $\begin{array}{l}\text { E. Gain experience about } \\
\text { managing rural diseases and } \\
\text { conditions }\end{array}$ & & & & & \\
\hline
\end{tabular}


Appendix

F. Easy/ stress free professional life

III. Financial incentives

\begin{tabular}{|l|l|l|l|l|l|}
\hline \multicolumn{1}{|c|}{ Statements } & $\begin{array}{l}\text { Strongly } \\
\text { Disagree (1) }\end{array}$ & $\begin{array}{l}\text { Slightly } \\
\text { Disagre } \\
(2)\end{array}$ & $\begin{array}{l}\text { Neutral } \\
(3)\end{array}$ & $\begin{array}{l}\text { Slightly } \\
\text { Agree (4) }\end{array}$ & $\begin{array}{c}\text { Strongly } \\
\text { Agree (5) }\end{array}$ \\
\hline A. Higher salaries & & & & & \\
\hline B. Extra allowances & & & & & \\
\hline C. Higher perks & & & & & \\
\hline D. Lower rates of loans & & & & & \\
\hline
\end{tabular}

\section{Social capital gains}

\begin{tabular}{|c|l|l|l|l|l|}
\hline Statements & $\begin{array}{l}\text { Strongly } \\
\text { Disagree (1) }\end{array}$ & $\begin{array}{l}\text { Slightly } \\
\text { Disagree } \\
(2)\end{array}$ & $\begin{array}{l}\text { Neutral } \\
(3)\end{array}$ & $\begin{array}{l}\text { Slightly } \\
\text { Agree (4) }\end{array}$ & $\begin{array}{l}\text { Strongly } \\
\text { Agree } \\
(5)\end{array}$ \\
\hline A. Opportunity to serve poor & & & & & \\
\hline B. Get more respect as \\
doctor
\end{tabular}

23. According to you, what are potential drawbacks of working in rural areas? Kindly rate your opinion from strongly agree (5) to strongly disagree (1). 
Appendix

\section{Lack of personal support}

\begin{tabular}{|c|c|c|c|c|c|}
\hline Statements & $\begin{array}{l}\text { Strongly } \\
\text { Disagree } \\
\text { (1) }\end{array}$ & $\begin{array}{c}\text { Slightly } \\
\text { Disagree(2) }\end{array}$ & $\begin{array}{l}\text { Neutral } \\
(3)\end{array}$ & $\begin{array}{l}\text { Slightly } \\
\text { Agree (4) }\end{array}$ & $\begin{array}{l}\text { Strongly } \\
\text { Agree (5) }\end{array}$ \\
\hline A. Poor living conditions: & & & & & \\
\hline Substandard housing & & & & & \\
\hline Poor electricity supply & & & & & \\
\hline $\begin{array}{ll}\text { iii. } & \begin{array}{l}\text { Inadequate water } \\
\text { supply }\end{array} \\
\end{array}$ & & & & & \\
\hline $\begin{array}{l}\text { iv. Lack of sanitation } \\
\text { facility }\end{array}$ & & & & & \\
\hline $\begin{array}{l}\text { v. Less means of } \\
\text { entertainment }\end{array}$ & & & & & \\
\hline $\begin{array}{ll}\text { vi. } & \text { Fewer opportunities } \\
& \text { for recreational } \\
\text { activities (gym, } \\
\text { library, indoor and } \\
\text { outdoor sports, etc.) } \\
\end{array}$ & & & & & \\
\hline $\begin{array}{l}\text { B. Feeling of social and } \\
\text { professional isolation }\end{array}$ & & & & & \\
\hline $\begin{array}{l}\text { C. Have to live away from } \\
\text { own family }\end{array}$ & & & & & \\
\hline $\begin{array}{l}\text { D. No opportunity for } \\
\text { spouse job near place of } \\
\text { posting }\end{array}$ & & & & & \\
\hline $\begin{array}{ll}\text { E. } & \text { Possible effects on own } \\
\text { health/ illnesses due to } \\
\text { work associated risks } \\
\text { (HIV/ AIDS) and lack of } \\
\text { health care }\end{array}$ & & & & & \\
\hline \multicolumn{6}{|c|}{ II. Lack of professional growth } \\
\hline Statements & $\begin{array}{l}\text { Strongly } \\
\text { Disagree } \\
\text { (1) }\end{array}$ & $\begin{array}{l}\text { Slightly } \\
\text { Disagree } \\
\text { (2) }\end{array}$ & $\begin{array}{l}\text { Neutral } \\
(3)\end{array}$ & $\begin{array}{l}\text { Slightly } \\
\text { Agree (4) }\end{array}$ & $\begin{array}{l}\text { Strongly } \\
\text { Agree (5) }\end{array}$ \\
\hline A. $\frac{\text { Poor working }}{\text { conditions: }}$ & & & & & \\
\hline $\begin{array}{l}\text { i. Poor infrastructure } \\
\text { (building, etc.) at } \\
\text { workplace }\end{array}$ & & & & & \\
\hline ii. Lack of equipment ace & & & & & \\
\hline
\end{tabular}


Appendix

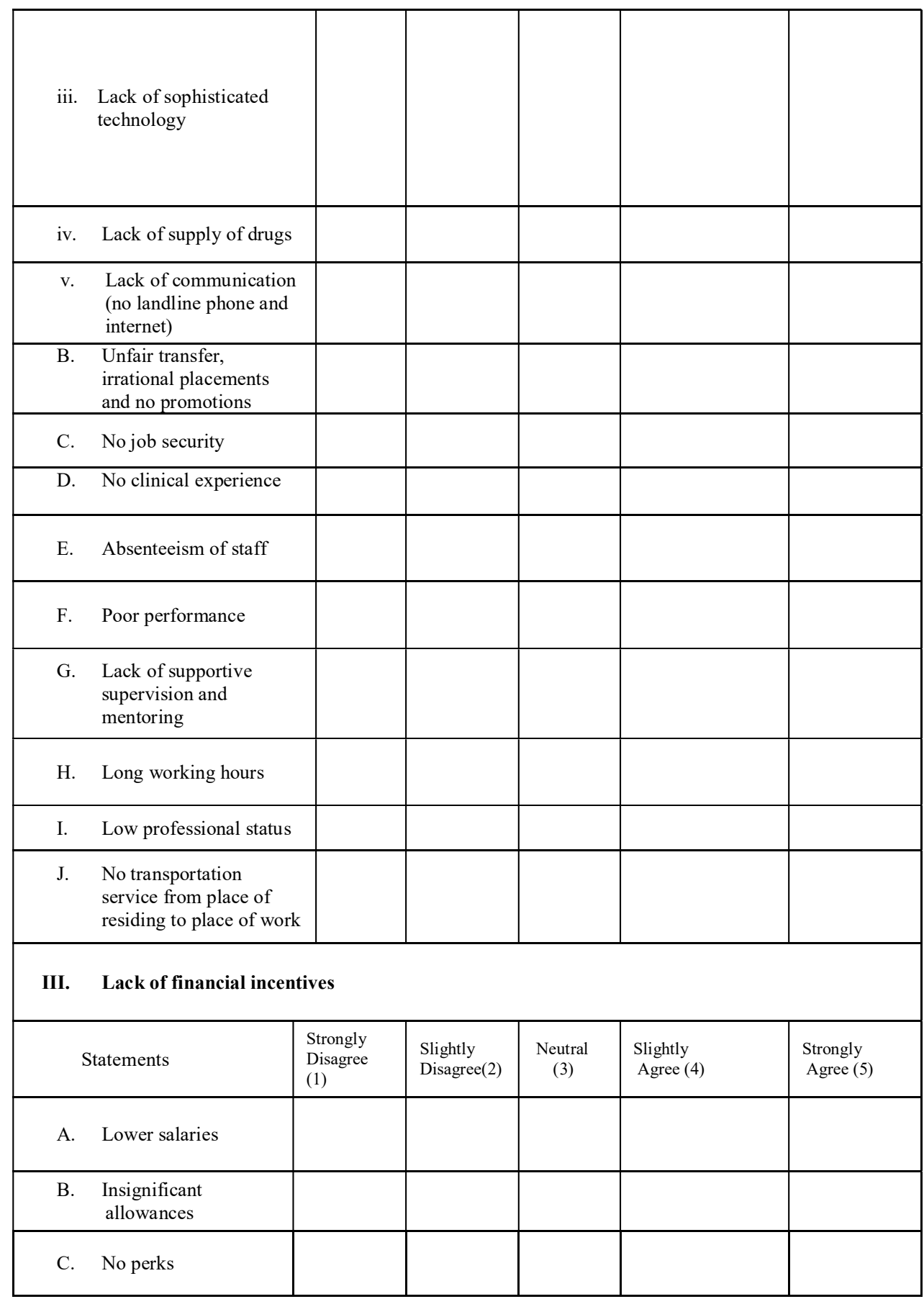


Appendix

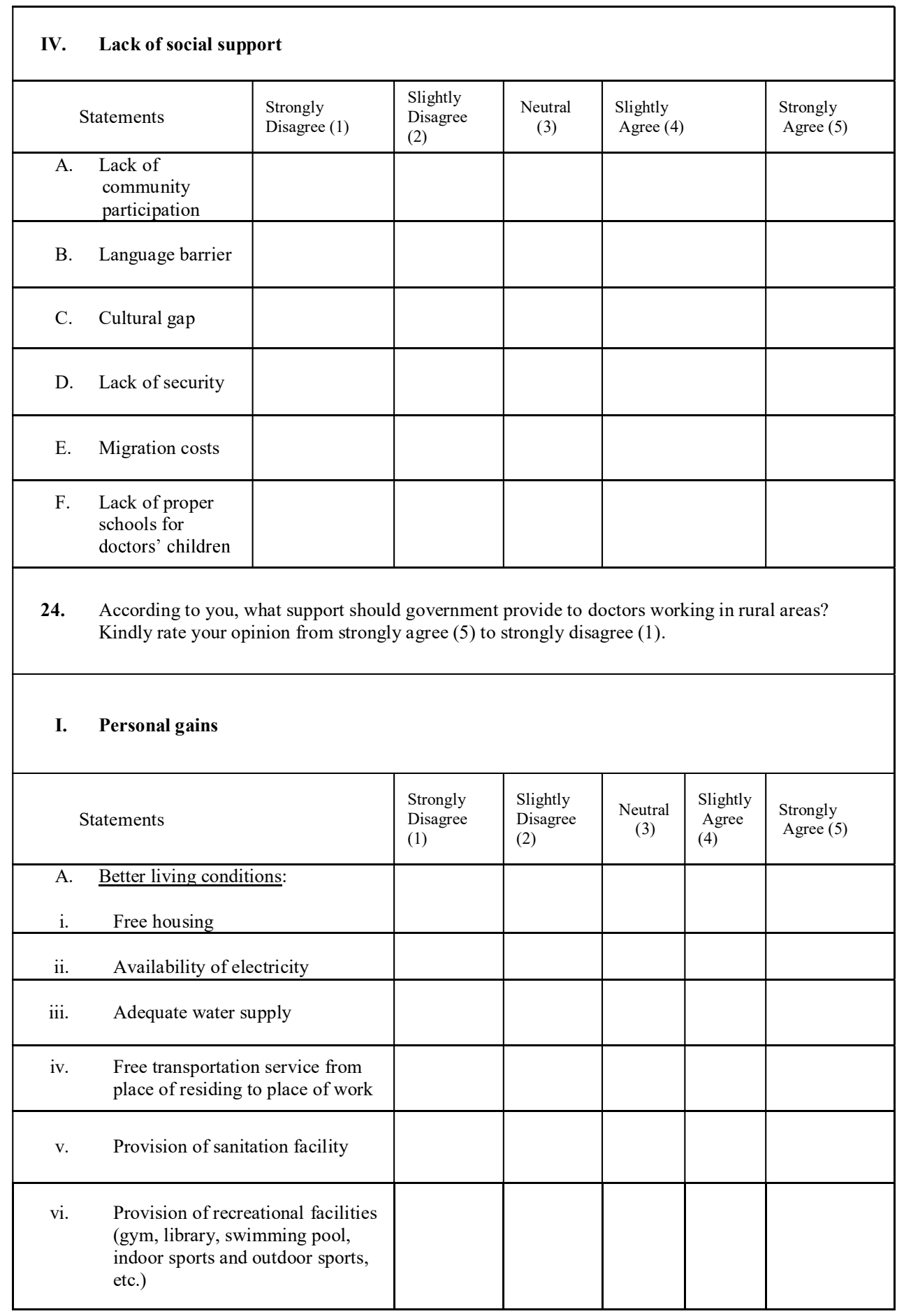


Appendix

\section{Professional enrichment}

\begin{tabular}{|c|c|c|c|c|c|}
\hline Statements & $\begin{array}{l}\text { Strongly } \\
\text { Disagree } \\
\text { (1) }\end{array}$ & $\begin{array}{l}\text { Slightly } \\
\text { Disagree } \\
\text { (2) }\end{array}$ & $\begin{array}{c}\text { Neutral } \\
(3)\end{array}$ & $\begin{array}{l}\text { Slightly } \\
\text { Agree (4) }\end{array}$ & $\begin{array}{l}\text { Strongly } \\
\text { Agree (5) }\end{array}$ \\
\hline A. Better working conditions: & & & & & \\
\hline $\begin{array}{l}\text { i. Better infrastructure at workplace } \\
\text { (building, roads, etc.) }\end{array}$ & & & & & \\
\hline ii. Better equipment at workplace & & & & & \\
\hline iii. More sophisticated technology & & & & & \\
\hline iv. Adequate supply of drugs & & & & & \\
\hline $\begin{array}{l}\text { v. Improved communication through } \\
\text { phones and internet facilities }\end{array}$ & & & & & \\
\hline $\begin{array}{l}\text { vi. Availability of manpower at } \\
\text { workplace }\end{array}$ & & & & & \\
\hline $\begin{array}{l}\text { B. Career enhancement by provision of } \\
\text { senior service posts }\end{array}$ & & & & & \\
\hline C. Regular service security & & & & & \\
\hline $\begin{array}{l}\text { D. Subsidized education during MBBS } \\
\text { for return of service in rural areas }\end{array}$ & & & & & \\
\hline $\begin{array}{l}\text { E. Internship training in rural areas for } \\
\text { MBBS graduates }\end{array}$ & & & & & \\
\hline
\end{tabular}

\section{Financial incentives}

\begin{tabular}{|l|l|l|l|l|l|} 
Statements & $\begin{array}{l}\text { Strongly } \\
\text { Disagree } \\
(1)\end{array}$ & $\begin{array}{l}\text { Slightly } \\
\text { Disagree (2) }\end{array}$ & $\begin{array}{l}\text { Neutral } \\
(3)\end{array}$ & $\begin{array}{l}\text { Slightly } \\
\text { Agree } \\
(4)\end{array}$ & $\begin{array}{l}\text { Strongly } \\
\text { Agree } \\
(5)\end{array}$ \\
\hline
\end{tabular}




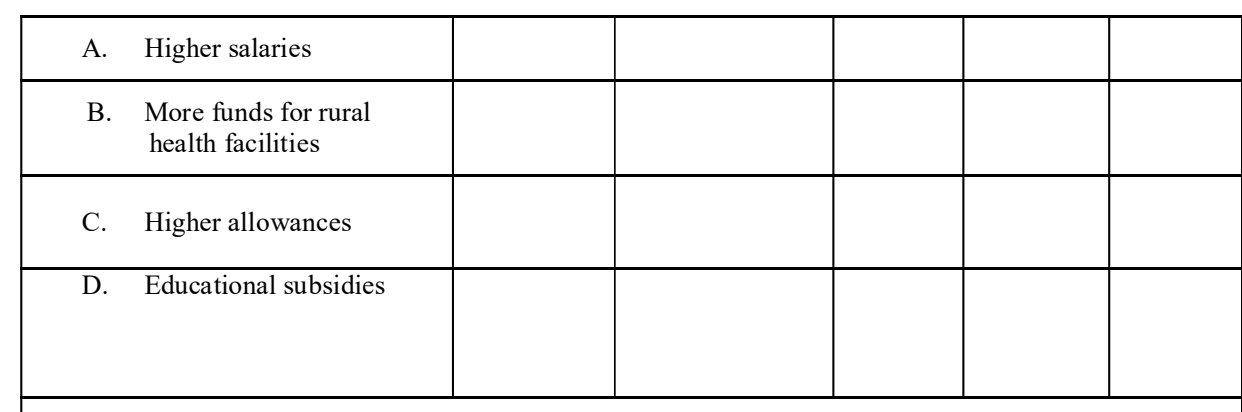

\section{Social support}

\begin{tabular}{|c|l|l|l|l|l|}
\hline Statements & $\begin{array}{l}\text { Strongly } \\
\text { Disagree } \\
(1)\end{array}$ & $\begin{array}{l}\text { Slightly } \\
\text { Disagree(2) }\end{array}$ & $\begin{array}{c}\text { Neutral } \\
(3)\end{array}$ & $\begin{array}{l}\text { Slightly } \\
\text { Agree } \\
(4)\end{array}$ & $\begin{array}{l}\text { Strongly } \\
\text { Agree } \\
(5)\end{array}$ \\
\hline A. $\begin{array}{l}\text { Set up proper secondary } \\
\text { schools for education of } \\
\text { doctors' children }\end{array}$ & & & & & \\
\hline B. $\begin{array}{l}\text { Establishment of more } \\
\text { medical and nursing } \\
\text { colleges in rural areas }\end{array}$ & & & & & \\
\hline
\end{tabular}

25. According to you, what do you think will help in improving the rural health care provided by doctors in rural areas? Kindly rate your opinion from strongly agree (5) to strongly disagree (1).

Categories Of Interventions -

I. Educational intervention

\begin{tabular}{|c|l|l|l|l|l|}
\hline Statements & $\begin{array}{l}\text { Strongly } \\
\text { Disagree } \\
(1)\end{array}$ & $\begin{array}{l}\text { Slightly } \\
\text { Disagree(2) }\end{array}$ & $\begin{array}{c}\text { Neutral } \\
\text { (3) }\end{array}$ & $\begin{array}{c}\text { Slightly } \\
\text { Agree (4) }\end{array}$ & $\begin{array}{c}\text { Strongly } \\
\text { Agree (5) }\end{array}$ \\
\hline A. $\quad \begin{array}{l}\text { Include rural health issues } \\
\text { in curricula of studies in } \\
\text { medical colleges }\end{array}$ & & & & & \\
\hline B. $\begin{array}{l}\text { Early and increased } \\
\text { exposure to rural practice } \\
\text { i.e. rural placement of } \\
\text { students during MBBS }\end{array}$ & & & & & \\
\hline C. $\begin{array}{l}\text { Targeted admission of } \\
\text { students from rural/ tribal } \\
\text { and economically weak } \\
\text { background in medical } \\
\text { colleges }\end{array}$ & & & & & \\
\hline D. $\begin{array}{l}\text { Internship training in } \\
\text { procedures relevant to } \\
\text { working in rural areas }\end{array}$ & & & & & \\
\hline E. $\begin{array}{l}\text { Educational outreach } \\
\text { programs / camps during } \\
\text { MBBS in rural areas }\end{array}$ & & & & & \\
\hline
\end{tabular}




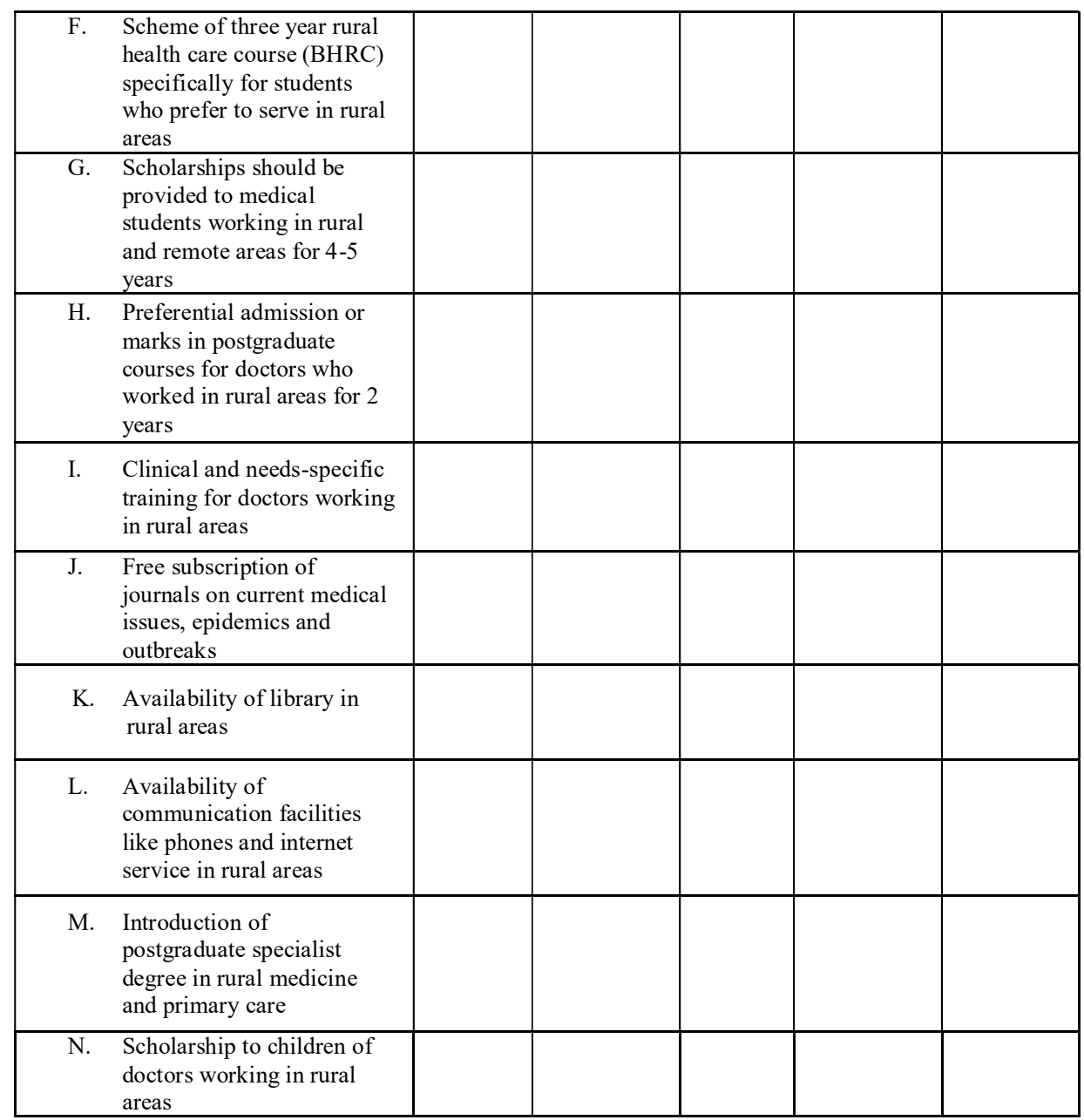

\section{Regulatory intervention}

\begin{tabular}{|c|l|l|l|l|l|}
\hline Statements & $\begin{array}{l}\text { Strongly } \\
\text { Disagree } \\
(1)\end{array}$ & $\begin{array}{l}\text { Slightly } \\
\text { Disagree } \\
(2)\end{array}$ & $\begin{array}{l}\text { Neutral } \\
(3)\end{array}$ & $\begin{array}{l}\text { Slightly } \\
\text { Agree } \\
(4)\end{array}$ & $\begin{array}{l}\text { Strongly } \\
\text { Agree (5) }\end{array}$ \\
\hline A. $\quad \begin{array}{l}\text { Compulsory rural service } \\
\text { requirements with incentives by } \\
\text { doctors }\end{array}$ & & & & & \\
\hline B. $\begin{array}{l}\text { Bonding schemes by state } \\
\text { government for doctors in rural } \\
\text { areas }\end{array}$ & & & & & \\
\hline
\end{tabular}


Appendix

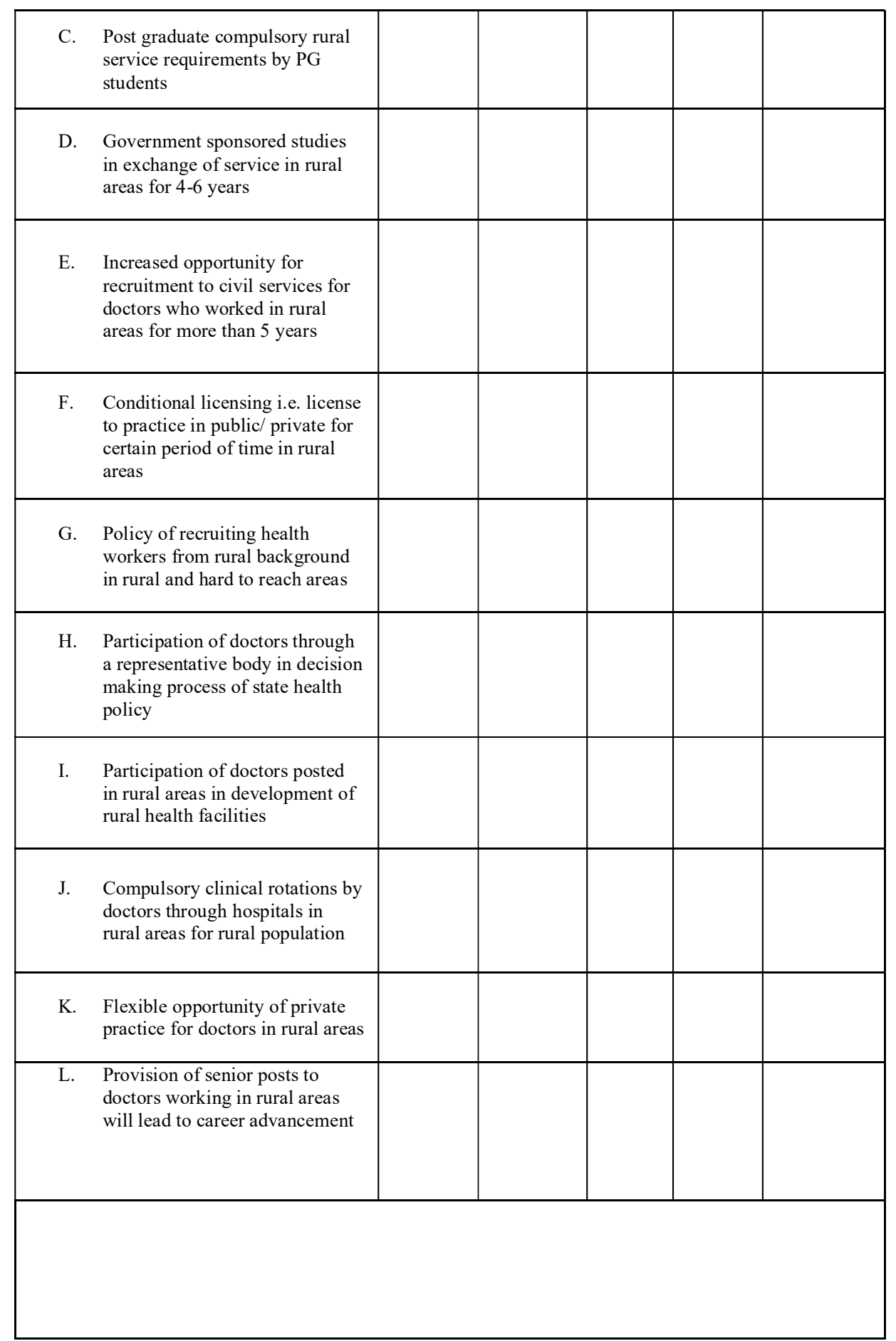




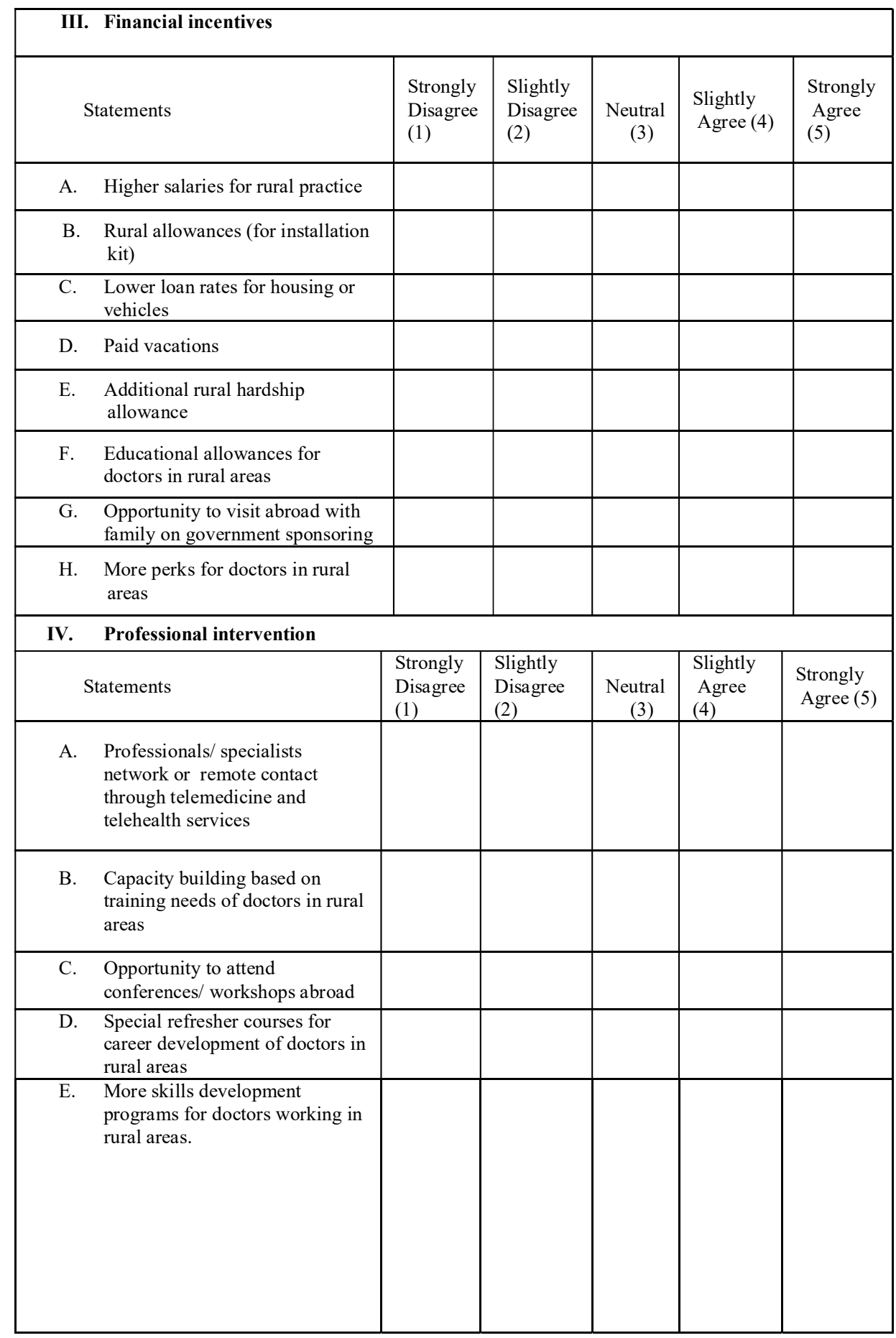


Appendix

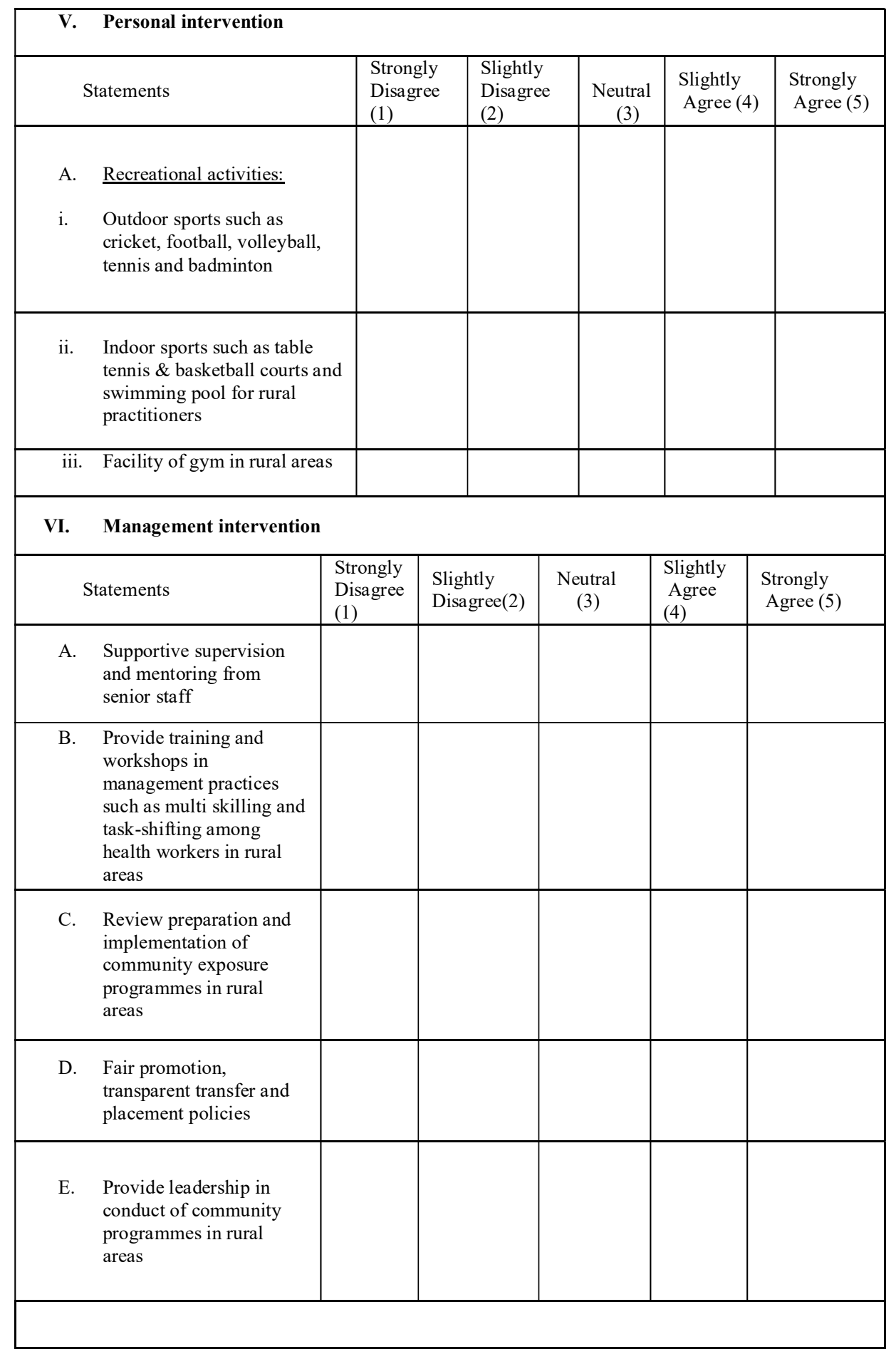


Appendix

\begin{tabular}{|c|c|c|c|c|c|}
\hline Statements & $\begin{array}{l}\text { Strongly } \\
\text { Disagree } \\
\text { (1) }\end{array}$ & $\begin{array}{l}\text { Slightly } \\
\text { Disagree } \\
\text { (2) }\end{array}$ & $\begin{array}{l}\text { Neutral } \\
(3)\end{array}$ & $\begin{array}{l}\text { Slightly } \\
\text { Agree } \\
\text { (4) }\end{array}$ & $\begin{array}{l}\text { Strongly } \\
\text { Agree (5) }\end{array}$ \\
\hline A. Better living conditions: & & & & & \\
\hline Adequate water supply & & & & & \\
\hline ii. Availability of electricity & & & & & \\
\hline $\begin{array}{l}\text { iii. Provide accommodation } \\
\text { as per the status of health } \\
\text { staff at place of posting }\end{array}$ & & & & & \\
\hline $\begin{array}{ll}\text { iv. } & \text { Free transportation } \\
& \text { service from place of } \\
\text { residing to place of work }\end{array}$ & & & & & \\
\hline $\begin{array}{l}\text { v. Provision of sanitation } \\
\text { facility }\end{array}$ & & & & & \\
\hline B. Better working conditions: & & & & & \\
\hline $\begin{array}{l}\text { i. Better infrastructure at } \\
\text { workplace (building, } \\
\text { roads, etc.) }\end{array}$ & & & & & \\
\hline $\begin{array}{l}\text { ii. Better equipment at } \\
\text { workplace }\end{array}$ & & & & & \\
\hline $\begin{array}{ll}\text { iii. } & \text { More sophisticated } \\
\text { technology available at } \\
\text { workplace }\end{array}$ & & & & & \\
\hline iv. Adequate supply of drugs & & & & & \\
\hline $\begin{array}{ll}\mathrm{v} . & \text { Improved } \\
& \text { communication by } \\
\text { phones and internet } & \text { facilities } \\
\end{array}$ & & & & & \\
\hline $\begin{array}{l}\text { vi. Manpower is available at } \\
\text { the workplace }\end{array}$ & & & & & \\
\hline $\begin{array}{l}\text { C. Increased social and } \\
\text { political stability in rural } \\
\text { areas }\end{array}$ & & & & & \\
\hline $\begin{array}{ll}\text { D. } & \text { Enabling working } \\
& \text { environment: }\end{array}$ & & & & & \\
\hline
\end{tabular}




\begin{tabular}{|c|l|l|l|l|l|}
\hline i. $\begin{array}{l}\text { By conducting more tour } \\
\text { programmes for health } \\
\text { staff in rural areas }\end{array}$ & & & & & \\
\hline ii. $\begin{array}{l}\text { Organized forums and } \\
\text { more occasions for } \\
\text { intermingling with social } \\
\text { and professional peers } \\
\text { and with local } \\
\text { communities }\end{array}$ & & & & & \\
\hline iii. $\begin{array}{l}\text { More scientific events in } \\
\text { rural areas }\end{array}$ & & & & & \\
\hline
\end{tabular}

26. What support or incentives government is providing to doctors working in rural areas? Kindly rate your opinion from don't know (3) to yes (1).

\begin{tabular}{|c|c|c|c|c|}
\hline I. & Personal support & & & \\
\hline & Statements & Yes (1) & No (2) & Don't know (3) \\
\hline \multicolumn{5}{|c|}{ A. Better living conditions: } \\
\hline i. & Free housing & & & \\
\hline \multicolumn{5}{|c|}{ ii. Proper sanitation facility } \\
\hline \multicolumn{5}{|c|}{$\begin{array}{l}\text { Provision of basic facilities such as } \\
\text { electricity and adequate water supply }\end{array}$} \\
\hline \multicolumn{5}{|c|}{$\begin{array}{l}\text { iv. Transportation service from place of } \\
\text { residing to workplace }\end{array}$} \\
\hline \multicolumn{5}{|c|}{$\begin{array}{l}\text { B. Boarding and lodging to doctors' } \\
\text { children }\end{array}$} \\
\hline \multicolumn{5}{|c|}{$\begin{array}{l}\text { C. Provided with spouse employment } \\
\text { near place of posting }\end{array}$} \\
\hline \multicolumn{5}{|c|}{$\begin{array}{l}\text { D. Provision of recreational facilities } \\
\text { such as library, gym, swimming pool } \\
\text { and indoor and outdoor sports, etc. }\end{array}$} \\
\hline \multicolumn{5}{|c|}{ II. Professional growth } \\
\hline & Statements & Yes (1) & No (2) & Don't know (3) \\
\hline
\end{tabular}


Appendix

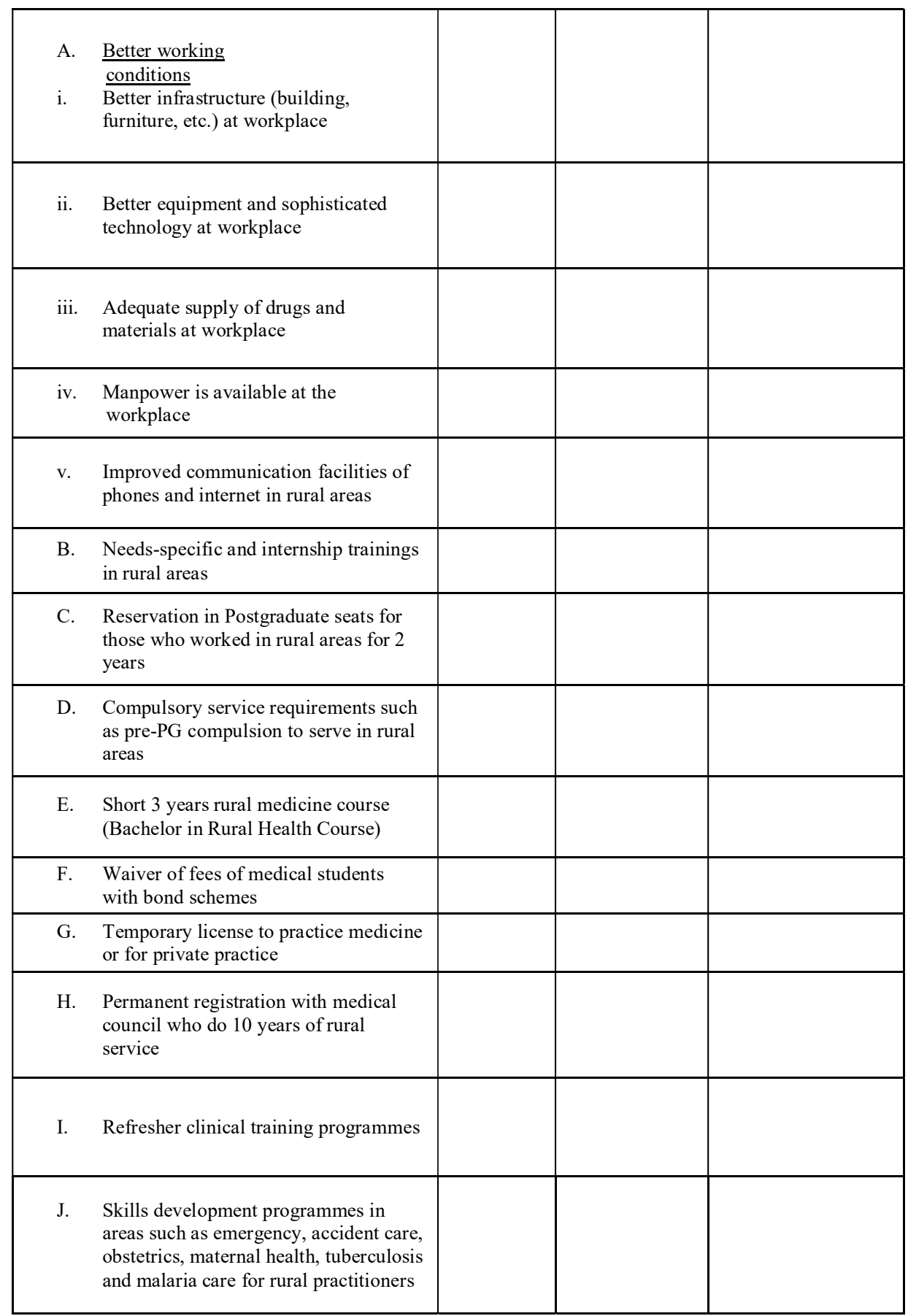


III. Financial incentives

\begin{tabular}{|c|c|c|c|}
\hline \multicolumn{1}{|c|}{ Statements } & Yes (1) & No (2) & Don't know (3) \\
\hline A. Higher salaries & & & \\
\hline B. Increased rural hardship allowance & & & \\
\hline C. $\quad \begin{array}{l}\text { Graded salary scale based on remoteness } \\
\text { and difficulty of terrain }\end{array}$ & & & \\
\hline D. $\quad \begin{array}{l}\text { Pensions should be given to rural } \\
\text { practitioners with 5 years or more } \\
\text { experience of rural practice }\end{array}$ & & & \\
\hline E. More perks for rural practitioners & & & \\
\hline
\end{tabular}

IV. Social support

\begin{tabular}{|c|c|c|c|}
\hline \multicolumn{1}{|c|}{ Statements } & Yes (1) & No (2) & Don't know (3) \\
\hline A. $\begin{array}{l}\text { Establish more private hospitals in } \\
\text { rural areas }\end{array}$ & & & \\
\hline B. $\begin{array}{l}\text { Establish proper secondary schools } \\
\text { in rural areas }\end{array}$ & & & \\
\hline C. $\begin{array}{l}\text { More community programmes in } \\
\text { collaboration with NGOs in rural } \\
\text { areas }\end{array}$ & & & \\
\hline
\end{tabular}

27. What are retention factors which influence the decision of doctors to stay in rural areas? Kindly rate your opinion from strongly agree (5) to strongly disagree (1).

\section{Personal support}

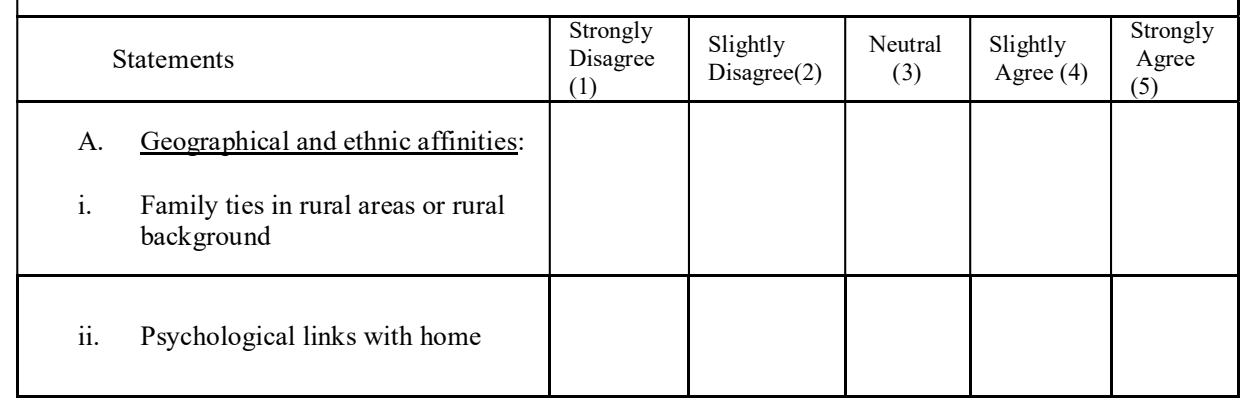




\begin{tabular}{|c|c|c|c|c|c|c|}
\hline \multicolumn{7}{|c|}{ iii. No language barrier } \\
\hline $\begin{array}{l}\text { B. } \\
\text { i. }\end{array}$ & $\begin{array}{l}\text { Better living Conditions: } \\
\text { Decent accommodation at place of } \\
\text { posting }\end{array}$ & & & & & \\
\hline ii. & $\begin{array}{l}\text { Availability of electricity, } \\
\text { adequate supply of water and } \\
\text { sanitation facility at workplace }\end{array}$ & & & & & \\
\hline iii. & $\begin{array}{l}\text { Transportation service from place } \\
\text { of residing to workplace }\end{array}$ & & & & & \\
\hline iv. & $\begin{array}{l}\text { Recreational facilities such as } \\
\text { gym, library, swimming pool, } \\
\text { indoor and outdoor sports }\end{array}$ & & & & & \\
\hline C. & $\begin{array}{l}\text { Positive opportunity to serve poor } \\
\text { i.e. contribution to broader social } \\
\text { good }\end{array}$ & & & & & \\
\hline D. & $\begin{array}{l}\text { Opportunity for both spouses to } \\
\text { work and live in same location }\end{array}$ & & & & & \\
\hline \multicolumn{7}{|c|}{$\begin{array}{ll}\text { E. } & \text { Financial Compulsions }\end{array}$} \\
\hline \multicolumn{7}{|c|}{ II. Professional growth } \\
\hline \multicolumn{2}{|c|}{ Statements } & $\begin{array}{l}\text { Strongly } \\
\text { Disagree } \\
\text { (1) }\end{array}$ & $\begin{array}{l}\text { Slightly } \\
\text { Disagree } \\
\text { (2) }\end{array}$ & $\begin{array}{l}\text { Neutral } \\
(3)\end{array}$ & $\begin{array}{l}\text { Slightly } \\
\text { Agree (4) }\end{array}$ & $\begin{array}{l}\text { Strongly } \\
\text { Agree } \\
(5)\end{array}$ \\
\hline \multicolumn{7}{|c|}{$\begin{array}{ll}\text { A. } & \text { Better working } \\
\text { i. } & \begin{array}{l}\text { Propditions } \\
\text { furniture, etc.) at workplace }\end{array} \\
\end{array}$} \\
\hline & $\begin{array}{l}\text { Improved communication by phones } \\
\text { and internet facility in rural areas }\end{array}$ & & & & & \\
\hline & $\begin{array}{l}\text { Better equipment and sophisticated } \\
\text { technology at workplace }\end{array}$ & & & & & \\
\hline \multicolumn{7}{|c|}{$\begin{array}{l}\text { iv. Adequate supply of drugs and } \\
\text { materials }\end{array}$} \\
\hline \multicolumn{2}{|c|}{$\begin{array}{l}\text { v. Manpower is available at the } \\
\text { workplace }\end{array}$} & & & & & \\
\hline \multicolumn{2}{|c|}{$\begin{array}{ll}\text { B. } & \text { Compulsory rural service } \\
\text { requirements for MBBS graduates } \\
\text { and Postgraduate doctors }\end{array}$} & & & & & \\
\hline & $\begin{array}{l}\text { Government service in rural areas } \\
\text { through bonding schemes }\end{array}$ & & & & & \\
\hline
\end{tabular}


Appendix

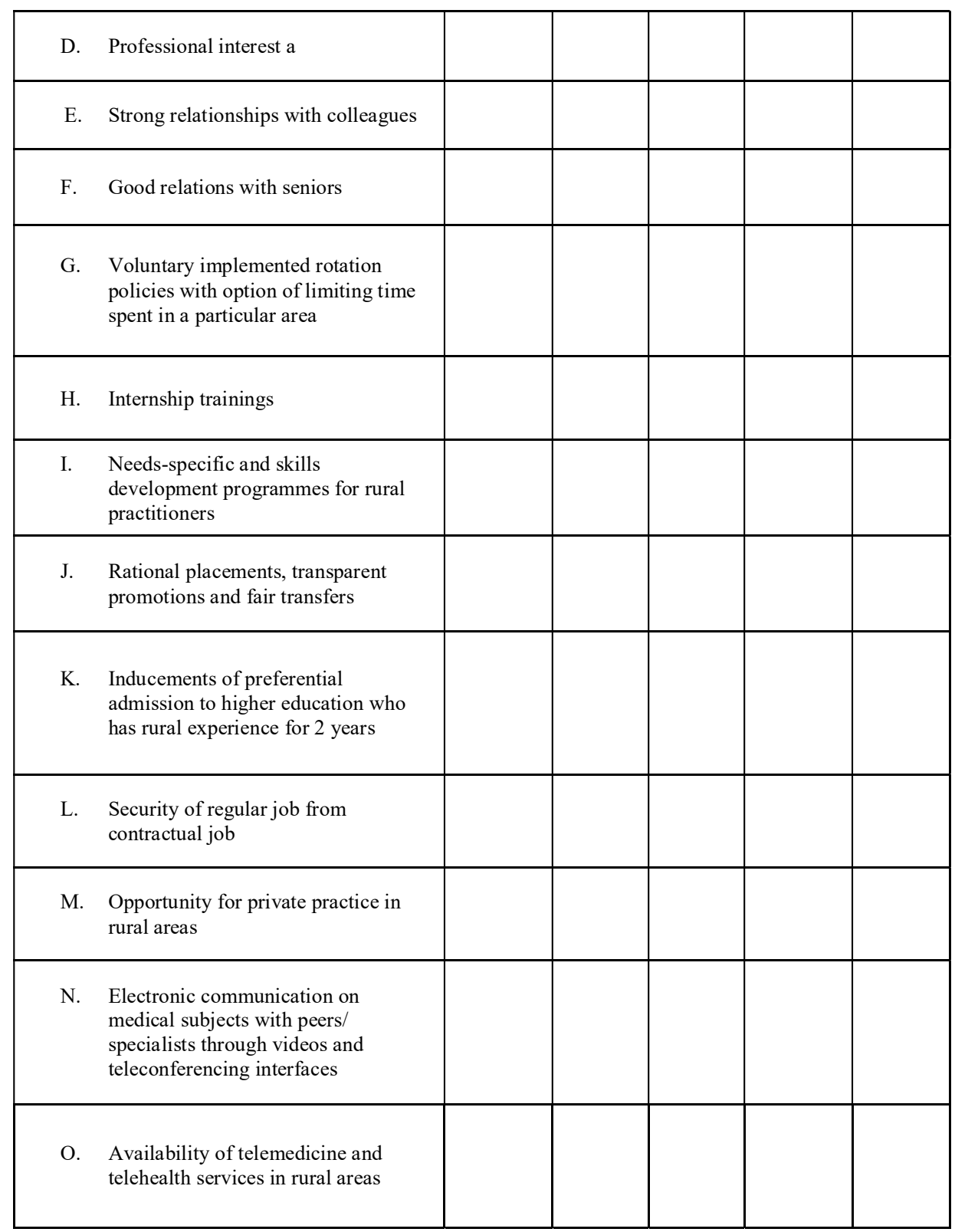




\section{Financial incentives}

\begin{tabular}{|c|c|c|c|c|c|}
\hline Statements & $\begin{array}{l}\text { Strongly } \\
\text { Disagree } \\
\text { (1) }\end{array}$ & $\begin{array}{l}\text { Slightly } \\
\text { Disagree(2) }\end{array}$ & $\begin{array}{l}\text { Neutral } \\
(3)\end{array}$ & $\begin{array}{l}\text { Slightly } \\
\text { Agree } \\
\text { (4) }\end{array}$ & $\begin{array}{l}\text { Strongly } \\
\text { Agree } \\
\text { (5) }\end{array}$ \\
\hline A. Higher salaries & & & & & \\
\hline B. Significant rural hardship allowanc & & & & & \\
\hline C. More funds for rural health service & & & & & \\
\hline D. More perks for rural practitioners & & & & & \\
\hline E. Extra allowances & & & & & \\
\hline $\begin{array}{l}\text { F. Educational allowances for rural } \\
\text { practitioners }\end{array}$ & & & & & \\
\hline $\begin{array}{l}\text { G. Lower rates of loans for rural } \\
\text { practitioners }\end{array}$ & & & & & \\
\hline
\end{tabular}

\section{Social support}

\begin{tabular}{|c|c|c|c|c|c|}
\hline Statements & $\begin{array}{l}\text { Strongly } \\
\text { Disagree } \\
\text { (1) }\end{array}$ & $\begin{array}{l}\text { Slightly } \\
\text { Disagree } \\
\text { (2) }\end{array}$ & $\begin{array}{l}\text { Neutral } \\
\text { (3) }\end{array}$ & $\begin{array}{l}\text { Slightly } \\
\text { Agree } \\
\text { (4) }\end{array}$ & $\begin{array}{l}\text { Strongly } \\
\text { Agree (5) }\end{array}$ \\
\hline A. Familiarity with village life & & & & & \\
\hline B. Good relations with local community & & & & & \\
\hline $\begin{array}{l}\text { C. Formal recognition and reward for } \\
\text { services under difficult conditions to } \\
\text { health workers with appropriate } \\
\text { credentials and histories of rural } \\
\text { service }\end{array}$ & & & & & \\
\hline
\end{tabular}




\begin{tabular}{|l|c|c|c|c|c|}
\hline 28. How interested will you be in working in rural areas, when you graduated? \\
\hline $\begin{array}{c}\text { Kindly rate } \\
\text { your opinion } \\
\text { from extremely } \\
\text { (5) to not at all } \\
(1)\end{array}$ & $\begin{array}{c}\text { Not at all } \\
(1)\end{array}$ & Slightly (2) & $\begin{array}{c}\text { Moderately } \\
(3)\end{array}$ & Very (4) & $\begin{array}{c}\text { Extremely } \\
(5)\end{array}$ \\
\cline { 2 - 6 } & & & & \\
\hline $29 . \quad$ Enlist five factors which attracted you to work in rural areas? & \\
\hline 1. \\
\hline 2. \\
\hline 3.
\end{tabular}

30. If given an opportunity, how much time in your career you wish to work in rural areas? (Tick right answer)

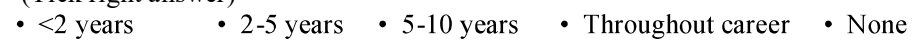

31. Are you willing to set up private practice in rural areas after your retirement?

$$
\text { - Yes } \quad \text { No } \text { - Can't say }
$$

\begin{tabular}{|c|c|c|c|c|c|}
\hline $\begin{array}{l}\text { Kindly rate } \\
\text { your opinion } \\
\text { from strongly }\end{array}$ & $\begin{array}{c}\text { Strongly } \\
\text { Disagree (1) }\end{array}$ & $\begin{array}{c}\text { Slightly } \\
\text { Disagree (2) }\end{array}$ & $\begin{array}{l}\text { Neutral } \\
\text { (3) }\end{array}$ & $\begin{array}{c}\text { Slightly } \\
\text { Agree (4) }\end{array}$ & $\begin{array}{l}\text { Strongly } \\
\text { Agree (5) }\end{array}$ \\
\hline $\begin{array}{l}\text { agree (5) to } \\
\text { strongly } \\
\text { disagree (1) }\end{array}$ & & & & & \\
\hline
\end{tabular}

32. Only trained staff should be sent to work in rural areas?

33. The appreciation by managers, colleagues and community is the most motivating factors for job in rural areas?

\begin{tabular}{|c|c|c|c|c|c|}
\hline Kindly rate & Strongly & Slightly & Neutral & Slightly & Strongly \\
your opinion & Disagree (1) & Disagree (2) & (3) & Agree (4) & Agree (5) \\
\cline { 2 - 6 } from strongly & & & & & \\
agree (5) to & & & & & \\
strongly & & & & & \\
disagree (1) & & & & \\
\hline
\end{tabular}

34. The alternative service delivery systems will help retain doctors in rural areas? Kindly rate your opinion from strongly agree (5) to strongly disagree (1).

\begin{tabular}{|c|l|l|c|l|l|}
\hline Statements & $\begin{array}{l}\text { Strongly } \\
\text { Disagree (1) }\end{array}$ & $\begin{array}{l}\text { Slightly } \\
\text { Disagree } \\
(2)\end{array}$ & $\begin{array}{c}\text { Neutral } \\
(3)\end{array}$ & $\begin{array}{l}\text { Slightly } \\
\text { Agree } \\
(4)\end{array}$ & $\begin{array}{l}\text { Strongly } \\
\text { Agree (5) }\end{array}$ \\
\hline
\end{tabular}


Appendix

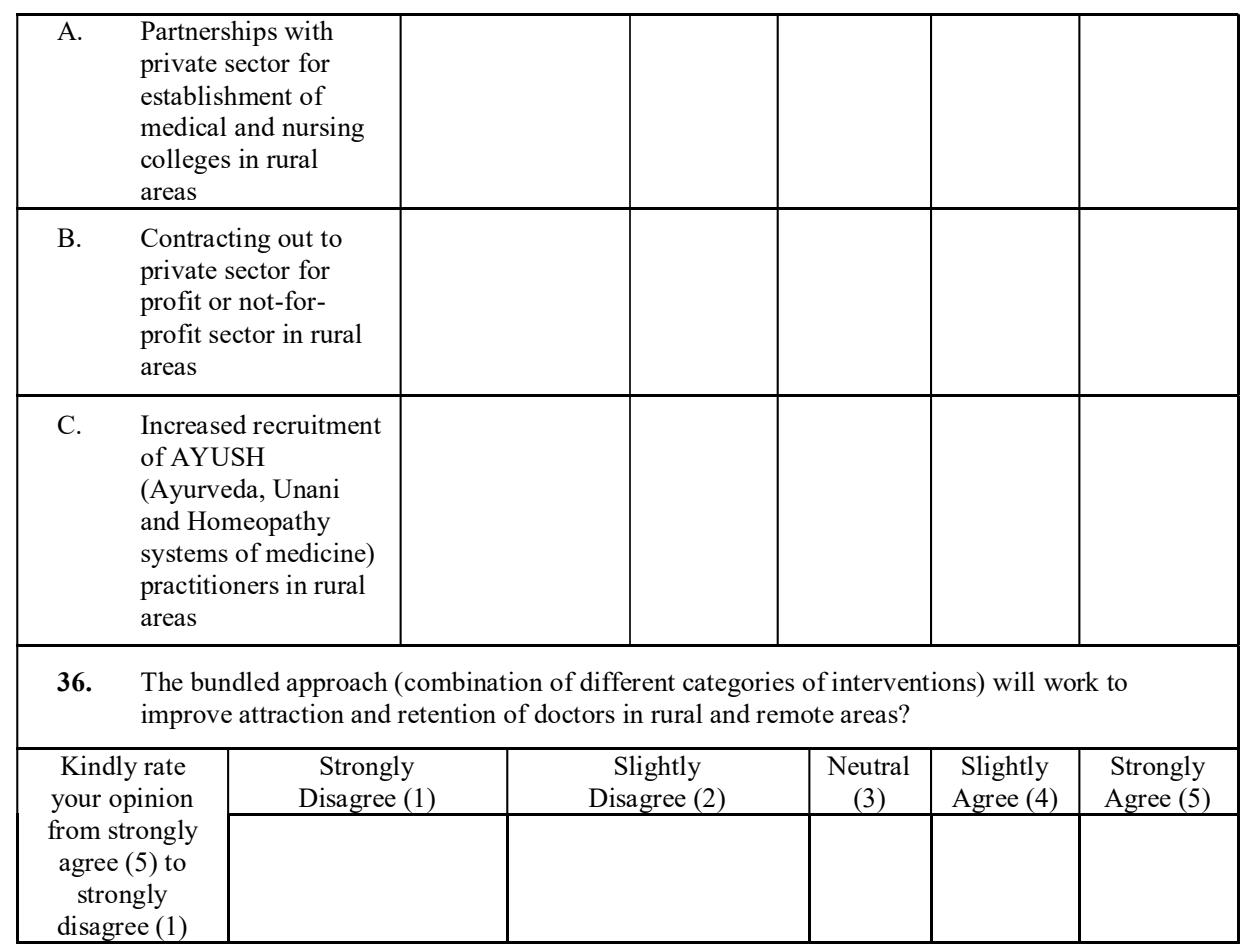


$\underline{\text { Appendix } 2}$

\section{QUESTIONNAIRE FOR ADMINISTRATORS}

“Understanding Medical Students' Motivation and Preferences to select Medical Studies and Work in Rural areas in North India"

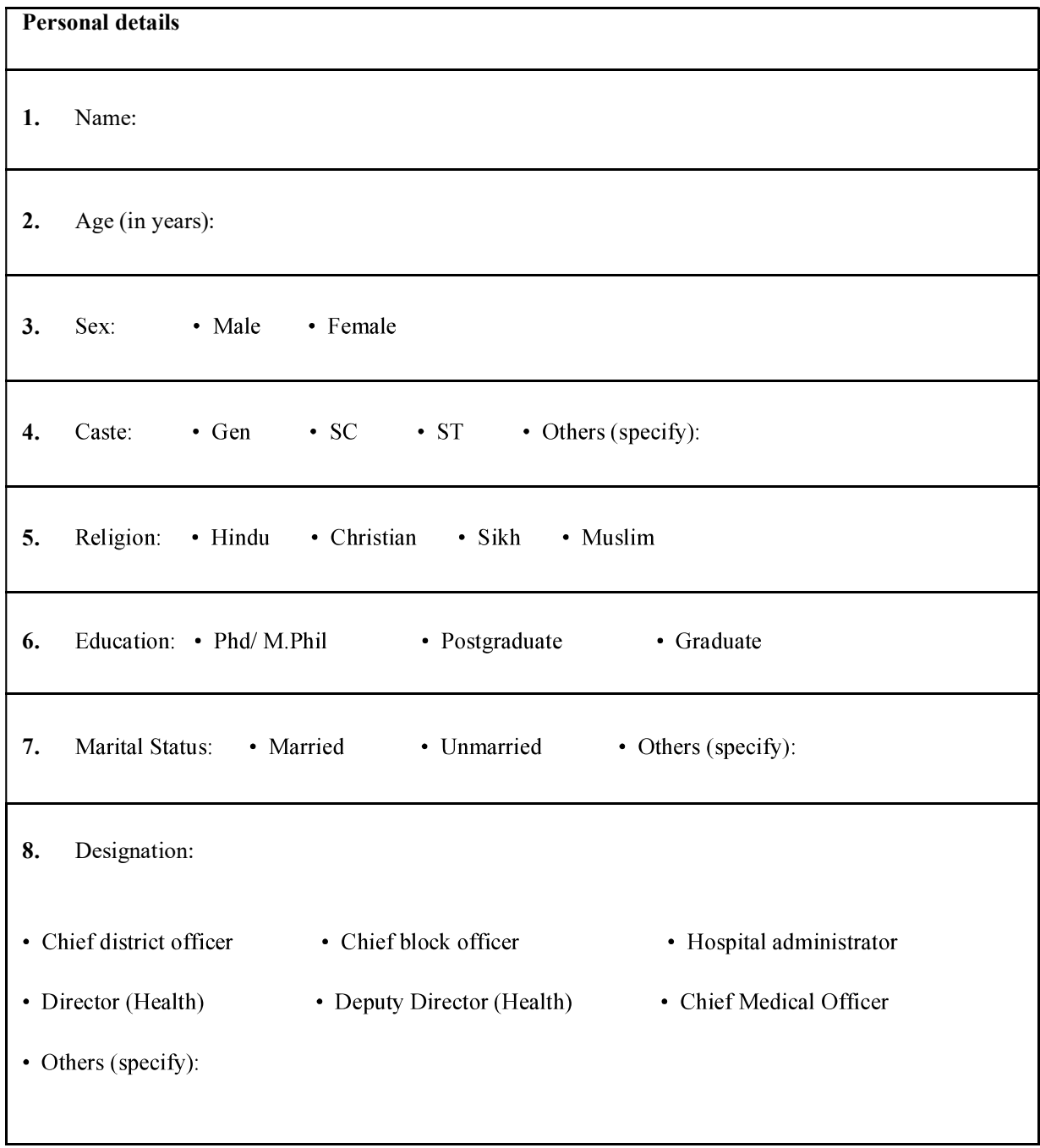


9. Present Address:

Village/ City: District:

State: $\quad$ Post Office:

10. State and district (your native place):

11. Since when you are in your current posting?

$\begin{array}{llll}\cdot<\text { year } & \cdot 1-3 \text { years } & \cdot 3.1-5 \text { years } & ->5 \text { years }\end{array}$

12. Do you find that the current status of rural health services is satisfactory?

\begin{tabular}{|c|c|c|c|c|c|}
\hline $\begin{array}{l}\text { Kindly rate } \\
\text { your opinion } \\
\text { from strongly } \\
\text { agree (5) to } \\
\text { strongly }\end{array}$ & $\begin{array}{c}\text { Strongly } \\
\text { Disagree (1) }\end{array}$ & $\begin{array}{c}\text { Slightly } \\
\text { Disagre } \\
\text { e (2) }\end{array}$ & $\begin{array}{c}\text { Neutral } \\
\text { (3) }\end{array}$ & $\begin{array}{l}\text { Slightly } \\
\text { Agree (4) }\end{array}$ & $\begin{array}{l}\text { Stro } \\
\text { ngly } \\
\text { Agr } \\
\text { ee } \\
(5)\end{array}$ \\
\hline & & & & & \\
\hline
\end{tabular}

13. The work force management policies (eg. transfer, promotion and residential facilities, etc.) are difficult to practice given its linkages to basic issues of governance?

\begin{tabular}{|c|c|c|c|c|c|}
\hline $\begin{array}{c}\text { Kindly rate } \\
\text { your opinion } \\
\text { from strongly } \\
\text { agree (5) to } \\
\text { strongly } \\
\text { disagree (1) }\end{array}$ & Disagree (1) & $\begin{array}{c}\text { Disagre } \\
\mathrm{e}(2)\end{array}$ & (3) & Agree (4) & $\begin{array}{c}\text { Agree } \\
(5)\end{array}$ \\
\cline { 2 - 7 } & & & & & \\
\hline
\end{tabular}

14. How frequently monitoring and evaluation of health policies should be done in rural areas?

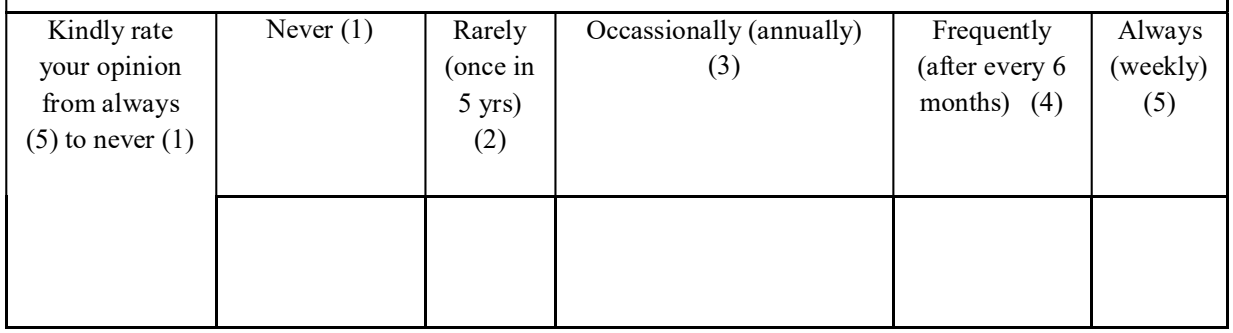


15. Is monitoring and evaluation of health policies being done in rural areas?
- Yes
- No
- Don't know

(If yes, answer Q. No. 16)

16. At what level, the benefits of current health policy are reaching?

\{Tick right answer\}
- At district level only
- Rural areas
- Hard to reach areas
- None

17. The attraction and retention of doctors in rural areas has been prioritized as a problem by the state government?

\begin{tabular}{|c|c|c|c|c|c|}
\hline $\begin{array}{l}\text { Kindly rate } \\
\text { your opinion } \\
\text { from strongly } \\
\text { agree (5) to } \\
\text { strongly }\end{array}$ & $\begin{array}{c}\text { Strongly } \\
\text { Disagree (1) }\end{array}$ & $\begin{array}{l}\text { Slightly } \\
\text { Disagree } \\
\text { (2) }\end{array}$ & Neutral (3) & $\begin{array}{c}\text { Slightly } \\
\text { Agree (4) }\end{array}$ & $\begin{array}{l}\text { Strongly } \\
\text { Agree (5) }\end{array}$ \\
\hline disagree (1) & & & & & \\
\hline
\end{tabular}

18. Improved investments for health workers in the form of pay, working conditions, living conditions, etc have been recognized by the state government?

\begin{tabular}{|c|c|c|c|c|c|}
\hline $\begin{array}{c}\text { Kindly rate your } \\
\text { opinion from } \\
\text { strongly agree (5) } \\
\begin{array}{c}\text { to strongly } \\
\text { disagree (1) }\end{array}\end{array}$ & $\begin{array}{c}\text { Strongly } \\
\text { Disagree }\end{array}$ & $\begin{array}{c}\text { Slightly } \\
\text { Disagree } \\
(1)\end{array}$ & Neutral (3) & Slightly & Strongly \\
\cline { 2 - 6 } & & & & Agree (4) & Agree (5) \\
& & & & & \\
\hline
\end{tabular}

19. Do you think that the financial resources for the problem of retention of doctors in rural areas to be solved are a limiting factor?

\{Tick right answer\}

- Yes $\quad$ - No $\quad$ Don't know

20. What drawbacks of current health policy do you find in rural areas?

\{You can tick more than one answer\}

- $\quad$ Lack of infrastructure (housing, roads, electricity, safe water and transport)

- Lack of equipment, supplies of drugs, etc.

- $\quad$ Lack of workforce management

- Lack of supervision 
- $\quad$ Absenteeism of health staff

- Low remuneration of health staff

- $\quad$ Lack of security

- Low educational opportunities for children of health staff

21. What improvement should be done in current health policy in rural areas?

\{You can tick more than one answer\}

- Higher salaries of health staff

- Subsidized education for return of service should be implemented

- Rotational postings of doctors

- In-service training such as multi-skilling and task-shifting among health workers

- Preferential selection of students from rural background for rural service

- Increased public-private partnerships by contracting-in, contracting-out, etc.

- Mobile clinics by hospitals for rural population

- Increased role of alternative service providers such as AYUSH and Homeopathy in rural health service

- Continuing medical education for doctors in rural areas

- Provision of study leave for interns to complete postgraduation

- Overtime pay included with salaries for health staff

- Improved working and living arrangements i.e. availability of transportation, electricity, roads, water supply, equipment, etc.

- $\quad$ Group housing for doctors

22. Do you think that lengthy recruitment procedure of health staff is causing shortage of doctors in rural areas?

\begin{tabular}{|l|c|c|c|c|c|}
\hline $\begin{array}{l}\text { Kindly rate your } \\
\text { opinion from strongly } \\
\text { agree (5) to strongly } \\
\text { disagree (1) }\end{array}$ & $\begin{array}{c}\text { Strongly } \\
\text { Disagree } \\
\text { (1) }\end{array}$ & $\begin{array}{c}\text { Slightl } \\
\mathrm{y} \\
\text { Disagr } \\
\text { ee (2) }\end{array}$ & Neutral (3) & Slightly & $\begin{array}{l}\text { Strongly } \\
\text { Agree (5) }\end{array}$ \\
\cline { 2 - 6 } & & & & & \\
\hline
\end{tabular}

23. What measures can be taken for recreational activities for doctors in rural areas? \{You can tick more than one answer\}

- Provision of library and gym

- Indoor sport facilities like swimming pool, tennis court, badminton court, etc.

- Outdoor sport facilities like cricket ground, football ground, volleyball, etc.

- Rural Club membership should be provided

- Internet, phone and computer facilities

- $\quad$ Others (specify)

24. Corruption or nepotism plays a role in allocation of postings of doctors in rural areas? 
Appendix

\begin{tabular}{|l|c|c|c|c|c|}
\hline $\begin{array}{l}\text { Kindly rate your } \\
\text { opinion from strongly } \\
\text { agree (5) to strongly } \\
\text { disagree (1) }\end{array}$ & $\begin{array}{c}\text { Strongly } \\
\text { Disagree } \\
(1)\end{array}$ & Disagree (2) & (3) & Agree (4) & Agree (5) \\
\cline { 2 - 6 } & & & & & \\
\hline
\end{tabular}

25. Adequate training support is being provided to medical students/ postgraduate students/ specialist doctors for working in rural areas?

\begin{tabular}{|l|c|c|c|c|c|}
\hline $\begin{array}{l}\text { Kindly rate your } \\
\text { opinion from } \\
\text { strongly agree (5) } \\
\text { to strongly } \\
\text { disagree (1) }\end{array}$ & Sisagree (1) & Disagree (2) & (3) & Agree (4) & Agree (5) \\
\cline { 2 - 6 } & & & & & \\
\hline
\end{tabular}

26. Current health policy of preferential admission in postgraduation to those who served in rural areas is retaining doctors in rural areas?

\begin{tabular}{|c|c|c|c|c|c|}
\hline $\begin{array}{c}\text { Kindly rate your } \\
\text { opinion from } \\
\text { strongly agree (5) } \\
\text { to strongly } \\
\text { disagree (1) }\end{array}$ & Disagree (1) & Disagree (2) & (3) & Agree (4) & Agree (5) \\
\cline { 2 - 6 } & & & & & \\
\hline
\end{tabular}

27. Measures such as multi-skilling and task-shifting among health staff have been taken to meet shortage of doctors in rural areas?

\begin{tabular}{|l|c|c|c|c|c|}
\hline $\begin{array}{l}\text { Kindly rate your } \\
\text { opinion from } \\
\text { strongly agree (5) } \\
\text { to strongly } \\
\text { disagree (1) }\end{array}$ & Disagree (1) & Disagree (2) & (3) & Agree (4) & Agree (5) \\
\cline { 2 - 6 } & & & & & \\
\hline
\end{tabular}

28. Absence of formal transparent transfer and promotion policy in the state is adding to the problem of retention of doctors in rural areas?

\begin{tabular}{|l|c|c|c|c|c|}
\hline $\begin{array}{l}\text { Kindly rate your } \\
\text { opinion from } \\
\text { strongly agree (5) }\end{array}$ & Strongly & Slightly & Neutral & Slightly & Strongly \\
\hline
\end{tabular}




\begin{tabular}{|l|c|c|c|c|c|}
\hline $\begin{array}{l}\text { to strongly } \\
\text { disagree (1) }\end{array}$ & & & & \\
\hline \begin{tabular}{l} 
29. $\begin{array}{l}\text { Lack of clearly defined job roles and responsibilities is leading to a mismatch between the } \\
\text { qualification/ skills and the job requirements? }\end{array}$ \\
\hline $\begin{array}{l}\text { Kindly rate your } \\
\text { opinion from } \\
\text { strongly agree (5) } \\
\text { to strongly } \\
\text { disagree (1) }\end{array}$
\end{tabular}$\quad$ Strongly & Slightly & Neutral & Slightly & Strongly \\
\cline { 2 - 6 } & & Disagree (2) & (3) & Agree (4) & Agree (5) \\
\hline
\end{tabular}

30. Initiatives such as well connected roads and transport services with the district hospital and district headquarter in the state will help to retain doctors in rural areas?

\begin{tabular}{|l|c|c|c|c|c|}
\hline $\begin{array}{l}\text { Kindly rate your } \\
\text { opinion from } \\
\text { strongly agree (5) } \\
\text { to strongly } \\
\text { disagree (1) }\end{array}$ & Disagree (1) & $\begin{array}{c}\text { Disagree } \\
(2)\end{array}$ & (3) & Agree (4) & Agree (5) \\
\cline { 2 - 6 } & & & & & \\
\hline
\end{tabular}

31. The flexible approach to post the candidate at the preferred location whenever feasible has been taken to retain doctors in rural areas?

\begin{tabular}{|l|c|c|c|c|c|}
\hline $\begin{array}{l}\text { Kindly rate your } \\
\text { opinion from } \\
\text { strongly agree (5) } \\
\text { to strongly } \\
\text { disagree (1) }\end{array}$ & Disagree (1) & Disagree (2) & (3) & Agree (4) & Agree (5) \\
\cline { 2 - 6 } & & & & & \\
\hline
\end{tabular}

32. By giving a greater role to specialists in decision making process related to health facility development (through procurement of drugs and equipments required to perform their duties) will retain doctors in remote areas?

\begin{tabular}{|l|c|c|c|c|c|}
\hline $\begin{array}{l}\text { Kindly rate your } \\
\text { opinion from } \\
\text { strongly agree (5) }\end{array}$ & Strongly & Slightly & $\begin{array}{c}\text { Neutra } \\
1\end{array}$ & Slightly & Strongly \\
& & Disagree (1) & Agree (4) & Agree (5) \\
\hline
\end{tabular}




\begin{tabular}{|l|l|l|l|l|l|}
\hline $\begin{array}{l}\text { to strongly } \\
\text { disagree (1) }\end{array}$ & & & & & \\
& & & & & \\
\hline
\end{tabular}

33. Measures such as good performances being rewarded with better promotion and transfer opportunities, awards and recognition have been taken for doctors in rural areas?

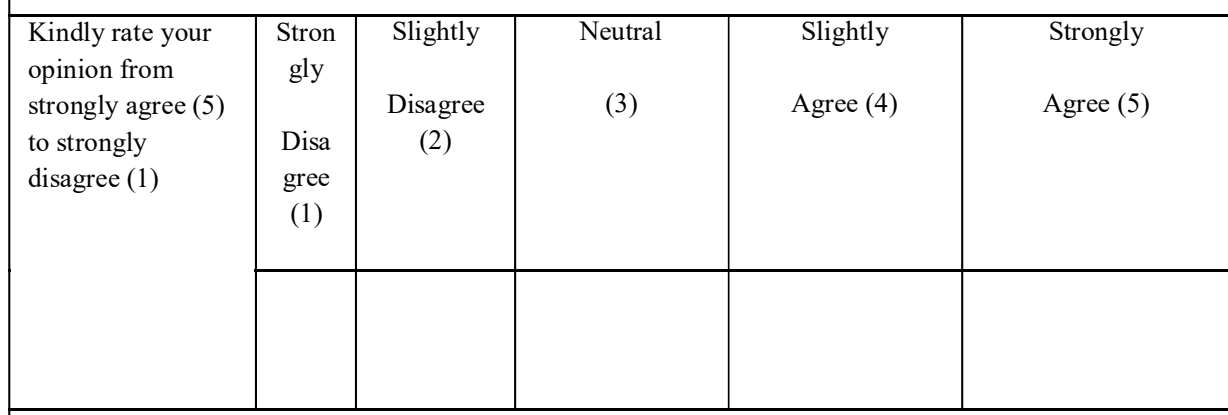

34. The shortage of health workers in rural areas can be addressed by training students with rural background through short 3 year rural service course?

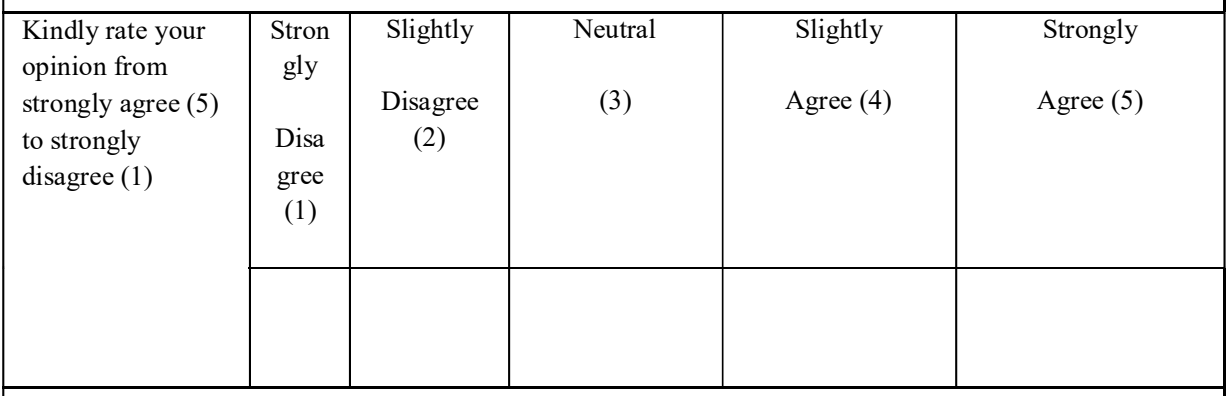

35. The post Postgraduate compulsion services in rural areas through bonds has helped in retaining doctors in rural and remote areas?

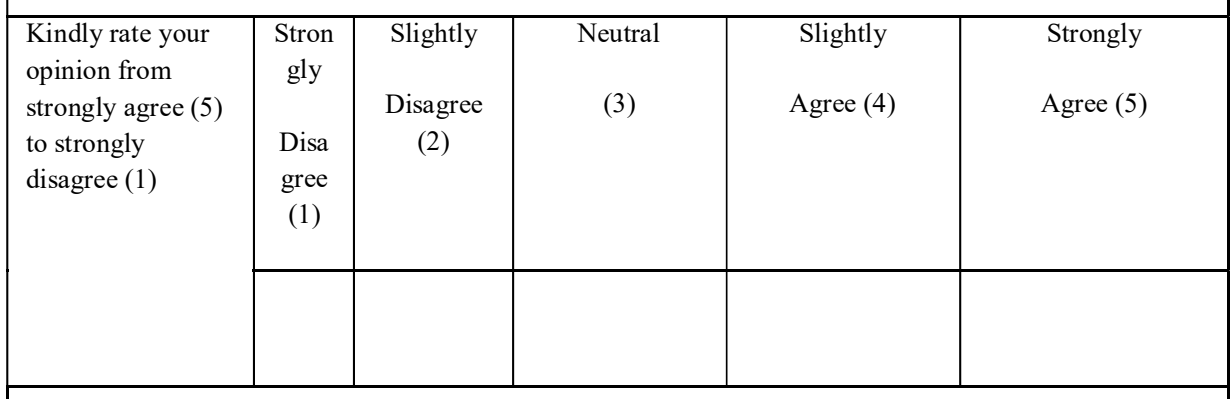

36. The current graduate medical curriculum includes rural health issues to attract doctors to rural areas? 
Appendix

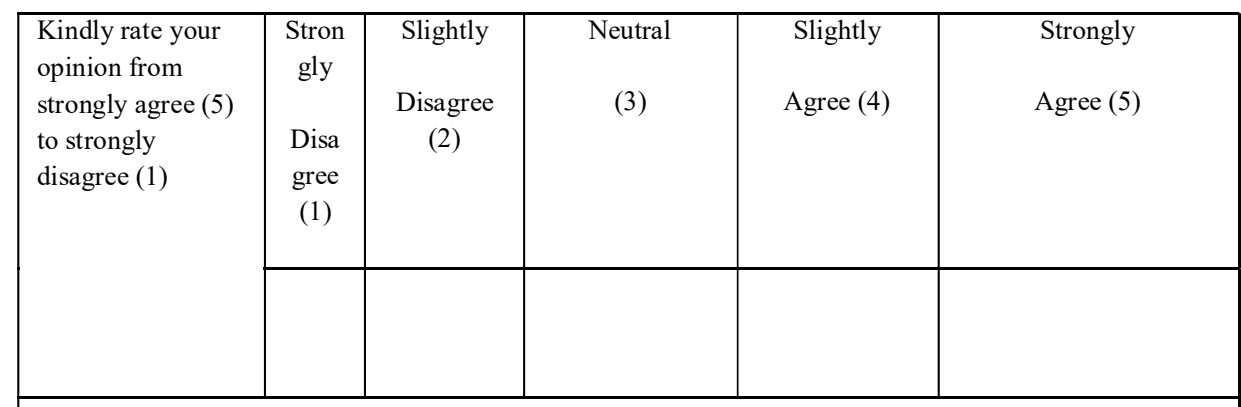

37. Increased investment in sophisticated technology and equipment will improve retention of doctors in rural areas?

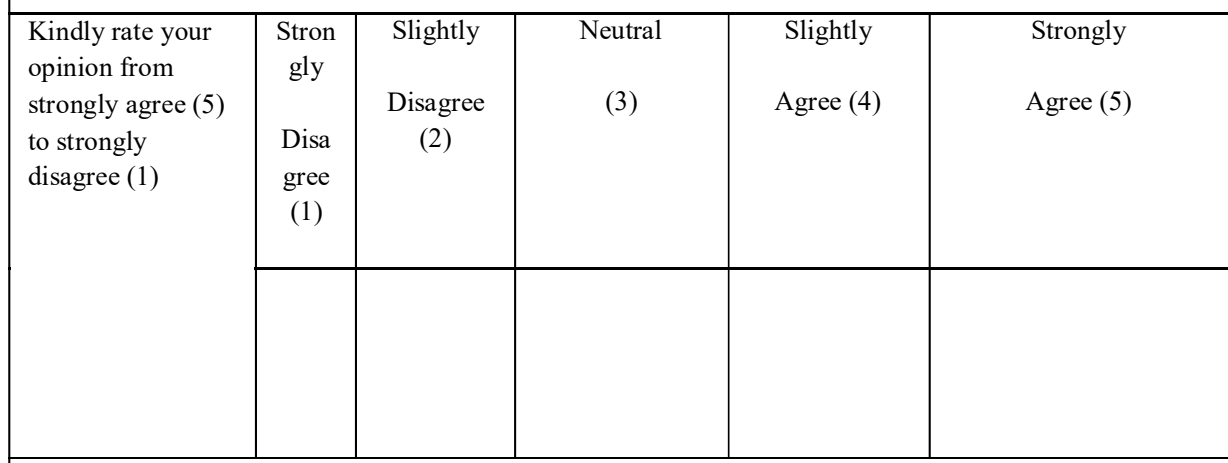

38. What problems/ difficulties are you facing in implementation of the health policy in rural and remote areas? Enlist them below.

1.

2 .

3.

4.

5.

6.

7.

8.

9.

10. 
Appendix

\begin{tabular}{|l|l|}
\hline $\begin{array}{l}\text { 39. What impact/ outcomes of current health policy do you see in your area of practice? Enlist them } \\
\text { below. }\end{array}$ \\
\hline 1. \\
\hline 2. \\
\hline 3. \\
\hline 4. \\
\hline 5. \\
\hline 6. \\
\hline 7. \\
\hline 8. \\
\hline 9. \\
\hline 10.
\end{tabular}


Appendix

\section{Appendix 3}

\section{In-depth Interview Check-list}

\section{"Assessment of approaches and factors in increasing attraction and improving retention of Physicians in rural and remote areas of Northern India"}

You are being interviewed for the purpose of research study exploring the factors and ass essment of approaches in increasing attraction and improving retention of physicians in rural and remote areas of northern India. This study is being conducted by ICMR, New Delhi.

We wish to talk with you for about 30-45 minutes. Your identity and information will remain confidential. If you have any questions now I will answer them, and if you have questions later you can contact us. At any time, you may terminate an interview or request that interview data be removed from the study. Take informed consent for interview and for recording the interview. Switch on the recorder. Commence the interview.

1. So, could you please tell me what would attract you to work in rural areas (if applicable)?

2. What do you think are benefits of working in rural areas?

3. What in your opinion should government do to improve motivation of doctors to stay in rural areas?

4. According to you, what are the main problems faced while working in rural areas?

5. Some people say that rural population doesn't have access to health care. What do you think?

\section{Probe Questions:}

6. Do you think that fair transfer, transparent placement and promotion policies are being practiced for doctors working in rural areas?

7. Can you share with us your experience of geographical distancing from family, if so?

8. Can you share with us your experiences of opportunities for personal development/ capacity building training programmes in rural areas if any? 
Appendix

\section{Appendix 4}

\section{Methodology of In-Depth Interview-}

Interview guide will be prepared. Participants will be recruited and a informed consent will be obtained from them. Approximate duration of an interview would be 45 minutes.

- $\quad$ The interview will be recorded in a recorder.

- Interviews will be transcribed verbatim. Data analysis will be done according to the framework approach.

- Two researchers will independently review the transcripts and clarify comments according to a predetermined framework.

In case of disagreement consensus will be achieved via a third researcher. Categories will be made according to personal and policy factors. Additional categories will be formulated that will not fit into the framework. 
Appendix

\section{Appendix 5}

\section{FOCUS GROUP DISCUSSION CHECK-LIST}

"Assessment of approaches and factors in increasing attraction and improving retention of Physicians in rural and remote areas of Northern India"

We are doing a focus group discussion and it will take 6-8 hours for thorough discussion on the research topic, "Assessment of approaches and factors in increasing attraction and improving retention of Physicians in rural and remote areas of Northern India".

The objectives of the study are, firstly, to examine existing knowledge, evidence, strategies and policies to attract and retain physicians in rural and remote areas of India; secondly, to analyze the relative impact of various factors in the policy on the attraction and retention of physicians and thirdly, to strengthen the capacity of health systems by providing up-to-date, practical guidance to policy-makers on how to design, implement and evaluate policy to attract and retain physicians in rural and remote areas of India.

Your participation in this study and all records about your participation will remain confidential. Please talk to us freely and frankly and let us know if there are any issues we bring up that you do not want to discuss.

1. What are potential benefits of working in rural areas?

A. Personal gains such as workplace are near to home, more time for himself and family.

B. Professional enrichment such as better scope of getting Postgraduate seat based on rural experience, more training opportunities and better promotion chances.

C. Financial incentives such as higher salaries, extra allowances and more perks.

D. Easy/ stress free life and get more respect as doctor.

E. Opportunity to serve poor

2. What are potential drawbacks of working in rural areas?

A. Lack of personal support such as poor living conditions, no opportunity for spouse employment near place of posting, have to live away from own family as well as no recreational facilities in rural areas.

B. Lack of professional support such as poor working conditions, absenteeism of staff at workplace, lack of job security and low professional status.

C. Lack of financial incentives such as lower salaries, insignificant allowances and no perks.

D. Lack of proper schools for education of doctors' children in rural areas.

E. Lack of social support such as cultural gap and language barrier.

3. What are retention factors that can influence the doctor's decision to stay in rural areas?

A. Personal factors such as geographical and ethnic affinities. 
B. Environmental factors such as better living and working conditions.

C. Financial compulsions and incentives such as higher salaries, significant allowances and more perks.

D. Professional support such as internship training and skills development programmes for doctors working in rural areas and security of regular job.

E. Preferential admission to Postgraduate seats based on rural experience and compulsory rural service by doctors with bonding schemes.

4. What measures are being taken by government to increase retention of doctors in rural areas?

A. Environmental measures such as better living and working conditions including boarding and lodging to doctors' children and recreational facilities for doctors in rural areas.

B. Educational measures such as reservation in postgraduate seats for doctors who have rural experience of 2 years and introduction of short 3 years rural medicine course (Bachelors in Rural Health Care) for those who want to work in rural areas.

C. Professional measures such as skills development programmes in various areas such as emergency, accident care, obstetrics, etc. for doctors working in rural areas as well as internship training in rural areas.

D. Financial incentives such as higher salaries, significant allowances and more perk for rural practitioners.

E. Policy of recruiting health workers from rural background in rural areas.

5. What improvements are needed in the current health policy for increasing retention of doctors in rural areas?

A. Educational intervention such as including rural health issues in curricula of medical colleges with increased exposure to rural practice during MBBS and targeted admission of students from rural background in medical colleges.

B. Professional intervention such as internship/ clinical and needs-specific trainings for doctors working in rural areas as well as supportive supervision and mentoring from senior staff.

C. Environmental intervention such as better living and working conditions with recreational facilities should be available for doctors working in rural areas.

D. Regulatory intervention such as participation of doctors in decision making process of health policy and development of rural health facilities.

E. Increased financial incentives such as higher salaries, significant allowances and more perks for rural practitioners. 
Appendix

\section{$\underline{\text { Appendix } 6}$}

\section{Methodology of Focus Group Discussion-}

Focus Group guide will be developed. During FGDs, note taker will be assisting the research worker and sociograms will be plotted.

FGDs will be first transcribed verbatim by research assistants and then into English by a bilingual person not associated with the study. Audio tapes will be preserved to check for any potential discrepancies in data.

Framework analytical approach will be used for data analysis. This will include following stages:

a. Familiarization with data

b. $\quad$ Identifying a thematic framework

c. Indexing or shifting through data and sorting quotes

d. Charting or selection of quotes and placing them under the appropriate thematic category

e. $\quad$ Mapping and interpretation of data

Each transcript will be coded inductively by '2' independent coders to enhance validity. Once FGDs will be coded, segments of common themes will be placed together and emergent themes will be identified. " $N$ Vivo" software will be used for data analysis. 